\title{
DESIGNING THE DESIGN EXPERIENCE: IDENTIFYING FACTORS OF STUDENT MOTIVATION IN PROJECT-BASED LEARNING AND PROJECT-BASED SERVICE-LEARNING
}

\author{
By Lauren Anne Cooper \\ B.S., Colorado School of Mines, 2006 \\ M.S., University of Colorado at Boulder, 2009 \\ A thesis submitted to the Faculty of the Graduate School \\ of the University of Colorado at Boulder in partial fulfillment \\ of the requirement for the degree of \\ Doctor of Philosophy \\ Department of Mechanical Engineering \\ 2014
}


This thesis entitled:

\section{DESIGNING THE DESIGN EXPERIENCE: IDENTIFYING FACTORS OF STUDENT MOTIVATION IN PROJECT-BASED LEARNING AND PROJECT-BASED SERVICE-LEARNING \\ Written by Lauren Anne Cooper \\ Has been approved for the Department of Mechanical Engineering}

Dr. Daria Kotys-Schwartz

Dr. Derek Reamon

Date

The final copy of this thesis has been examined by the signatories, and we Find that both the content and the form meet acceptable presentation standards Of scholarly work in the above mentioned discipline.

IRB protocol \# 
Cooper, Lauren A. (Ph.D., Mechanical Engineering)

Designing the Design Experience: Identifying Factors of Student Motivation in Project-based Learning and Project-Based Service-learning

Thesis directed by Dr. Daria Kotys-Schwartz

Grounded in motivation theory, this study evaluates how the contexts of project-based learning (PBL) and project-based service-learning (PBSL) affect student motivation in a required undergraduate mechanical engineering course - Component Design. This study aims to answer: 1) How does the context of service in project-based learning affect student motivation? and 2) What factors are most influential on student motivation to persist in project-based learning experiences? In spring 2011, the control group participated in a conventional PBL experience - to build an aesthetically pleasing vehicle that could be powered by a cordless electric drill. In spring 2012, the treatment group participated in a PBSL experience - fabricating tricycles for children in the community with physical disabilities. Pre-course and post-course surveys were administered to both cohorts to gather data about students' baseline levels and changes in interest and value for the course and the project, confidence in technical and non-technical skills, feelings of success, and indicators of engagement. Additionally, three 60-minute focus groups were held with each cohort following the project. Student motivation was sustained in both project contexts. Students in both cohorts began the course with relatively high levels of interest, value, and expectancy for success. Students in both cohorts ended the course with relatively high levels of interest, value, and feelings of success in the course and the project. Students from both cohorts also reported relatively high indicators of course and project engagement. For students in the PBL control group, the most significant predictor of motivation was confidence in their ability-related beliefs as well as their previous course- and project- related experiences. For students in the PBSL control group, the most significant predictor of motivation was the amount of initial value for the course and the project the students held. Initial course and project interest were also among the most important predictors of motivation in both project contexts. The results suggest that the actual context of a PBL experience may be less important than a thoughtfully designed PBL experience - one that is interesting and valuable to students, provides opportunities to develop skills, and allows students to utilize prior experience and knowledge. 


\section{Acknowledgements}

I would like to thank my family for their lifelong support of my education, especially over the past several years. My dearest brother Brad has always been a immense source of inspiration and motivation to me. Next I give great appreciation to my mentor and primary advisor, Dr. Daria Kotys-Schwartz, as well as the other members of my committee: Dr. Holly Matusovich, Dr. Derek Reamon, Dr. Michael Hannigan, and Dr. Rajagopalan Balaji. Dr. Jacquelyn Sullivan and Dr. Juan Lucena have also been quite influential as they have revealed to me, by example, the extraordinary difference one person can have on the people around them. I would also like to acknowledge the National Science Foundation for supporting this research. Lastly, I give my deepest gratitude for the students who made this research interesting, challenging, and fun, and for the students I teach on a daily basis who continue to inspire my passion for engineering education. 


\section{CONTENTS}

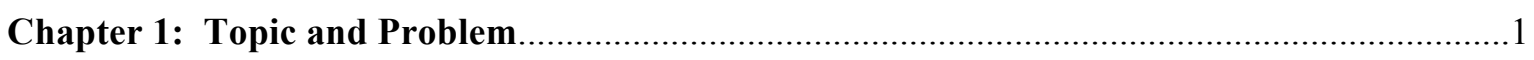

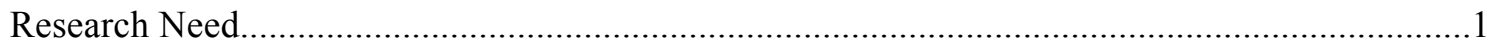

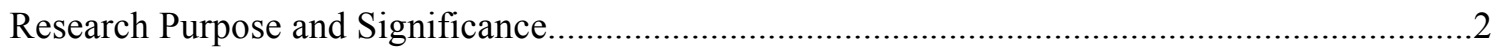

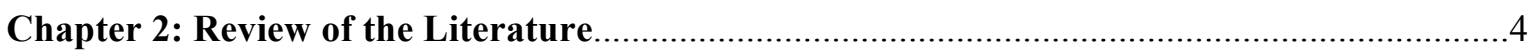

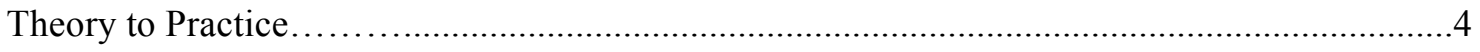

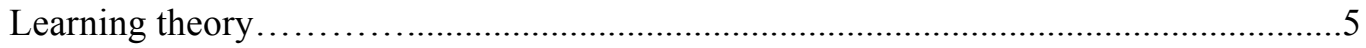

The role of constructivism in engineering education..................................................

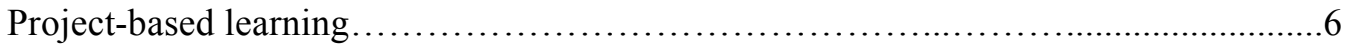

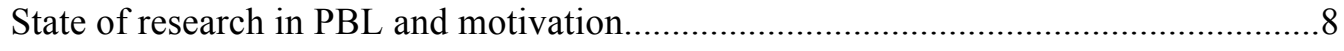

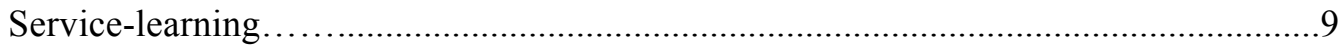

Project-based service-learning ....................................................................... 10

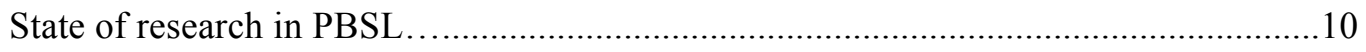

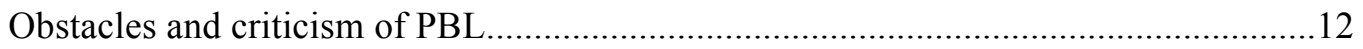

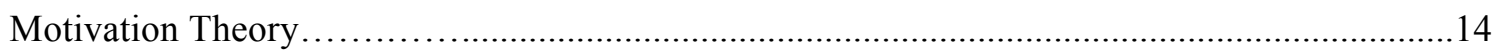

General statements about motivation.................................................................... 14

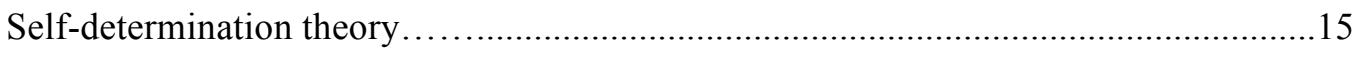

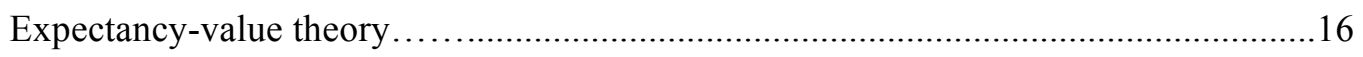

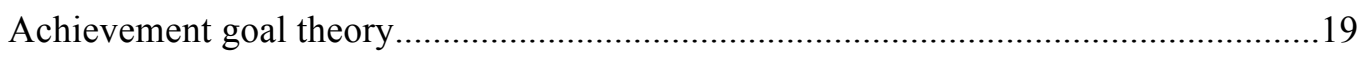

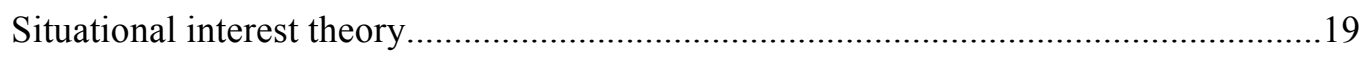

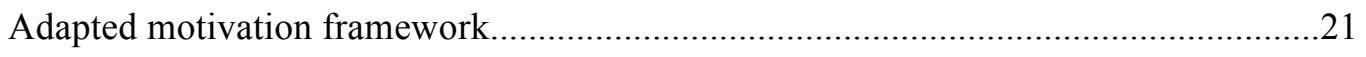

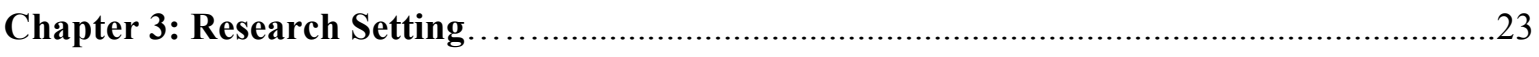

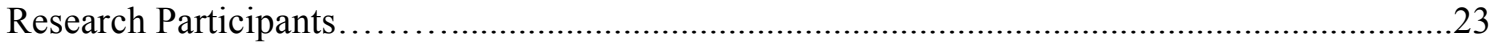

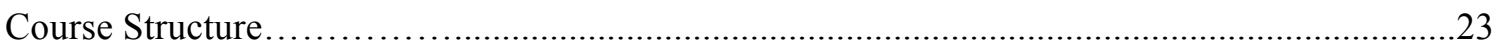

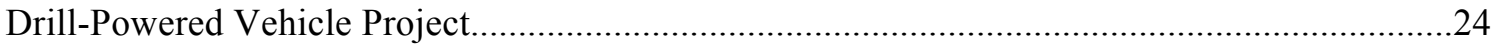




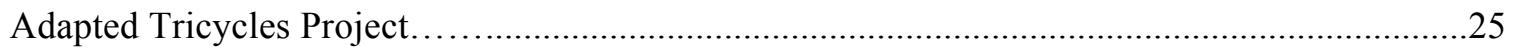

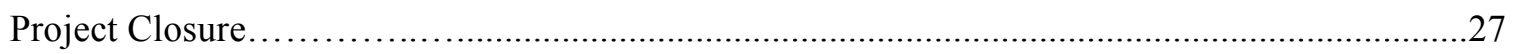

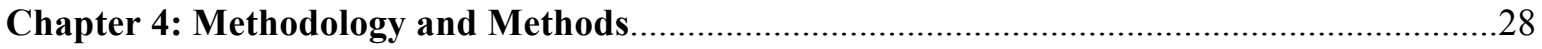

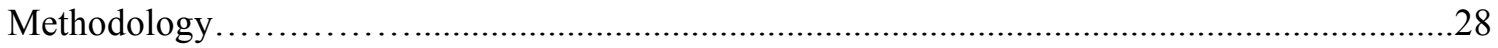

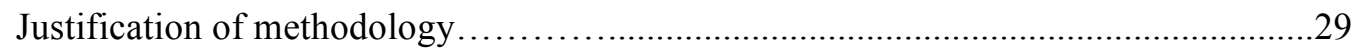

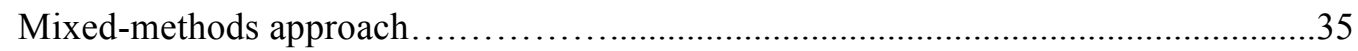

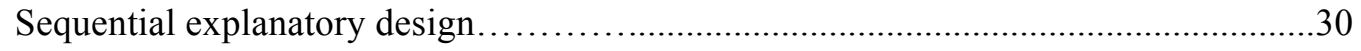

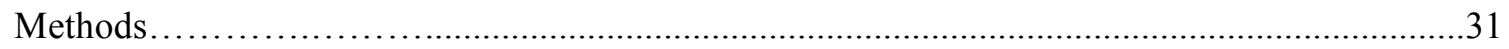

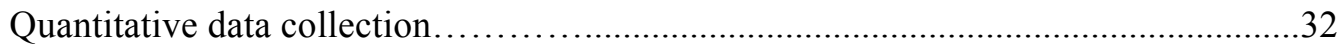

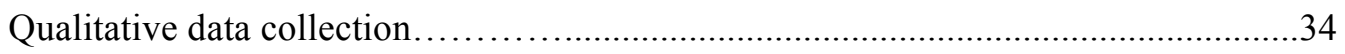

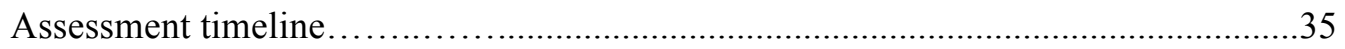

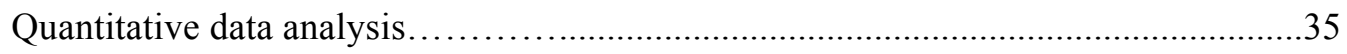

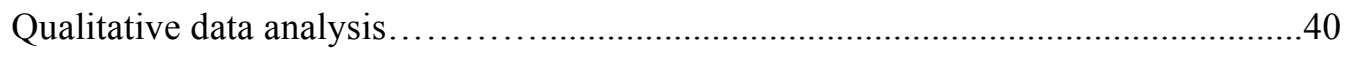

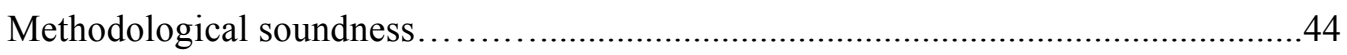

Connecting quantitative and qualitative strands..........................................45

Integration of quantitative and qualitative results..........................................45

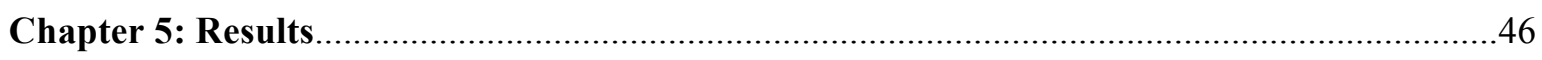

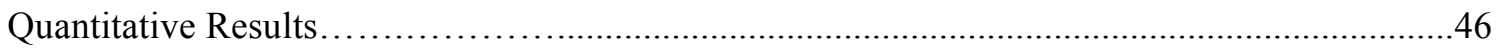

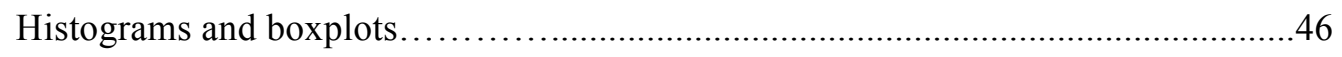

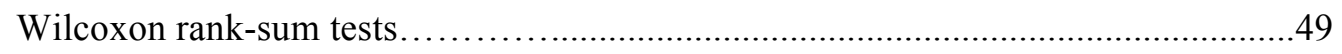

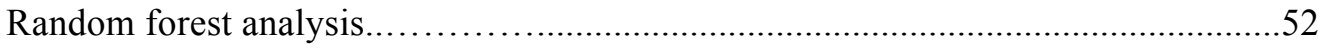

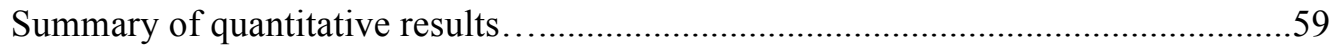

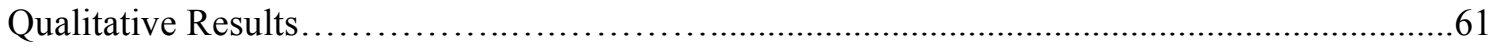

Summary of qualitative results......................................... 107

Connecting quantitative and qualitative phases..............................109 
Chapter 6: Discussion, Implications, and Future Research......................................................113

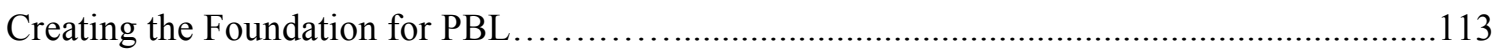

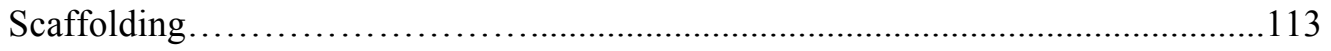

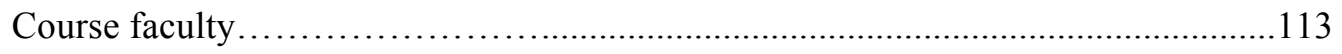

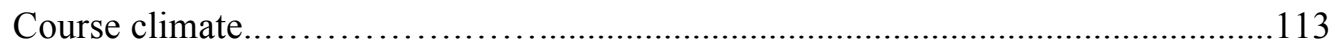

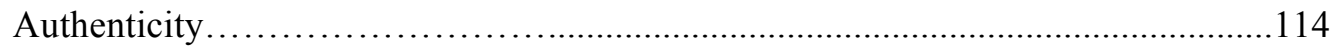

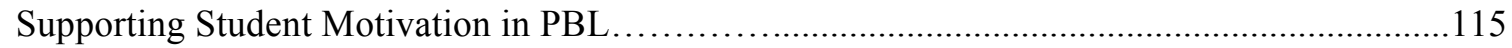

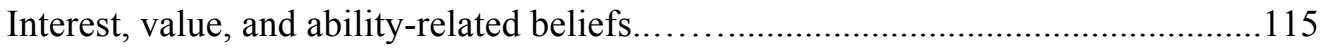

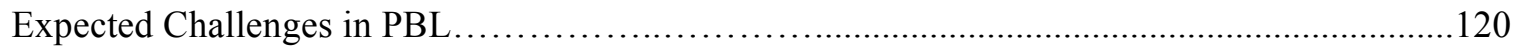

Team dynamics and solving ill-structured problems...........................................120

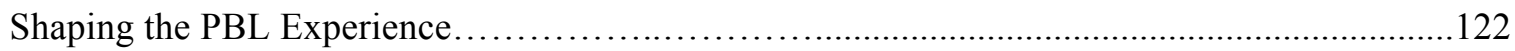

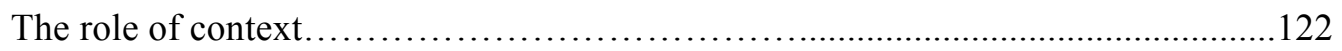

Designing the PBL Experience: Recommendations for Practitioners.........................................126

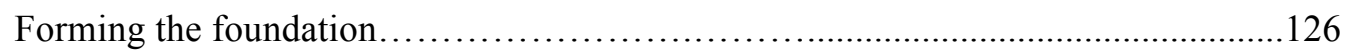

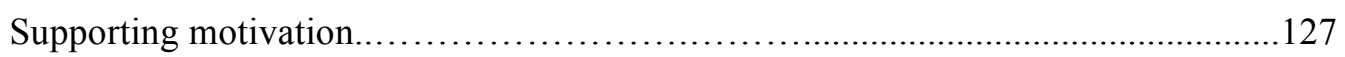

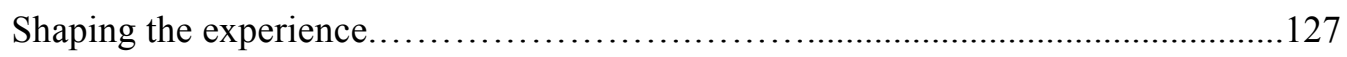

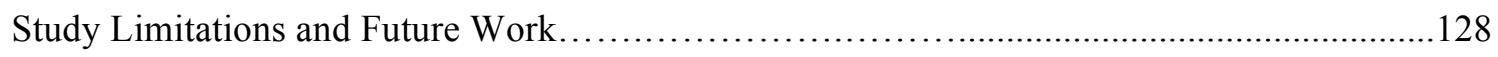

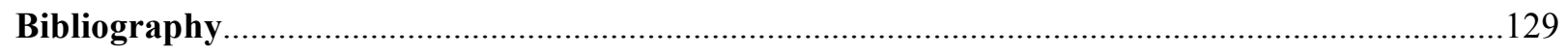

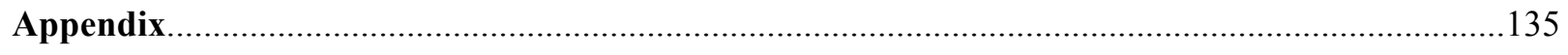

A. Assessment Instruments................................................... 135

B. Histograms and Boxplots................................................. 156

C. Summary of Focus Groups................................................. 182 


\section{TABLES}

Table

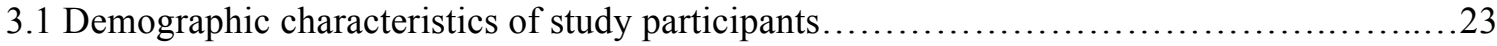

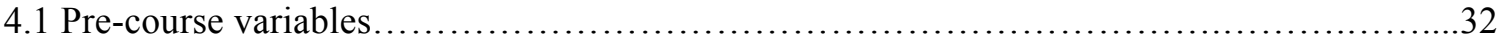

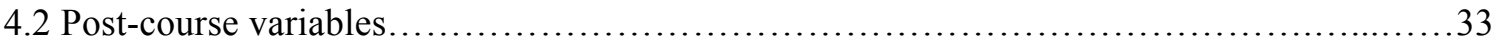

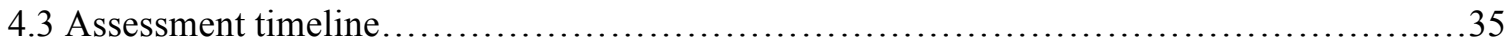

4.4 Random forest converting raw responses to appropriate variable type.....................39

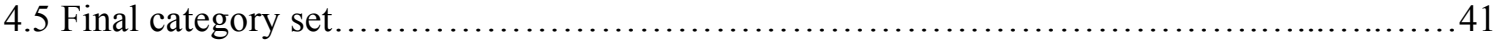

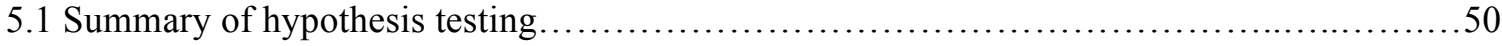

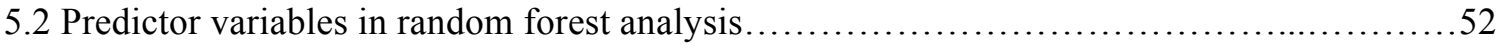

5.3 Response variables in random forest analysis..................................... 52

5.4 Summary of variable importance testing............................................. 54

5.5 Number of occurrences of each predictor variable..................................... 55

5.6 Overall important predictors of achievement motivation................................56

5.7 Qualitative themes inspired form quantitative results..................................59

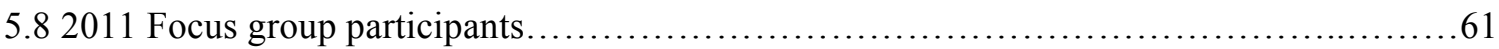

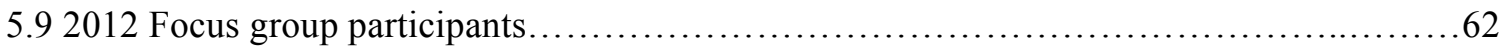




\section{FIGURES}

Figure

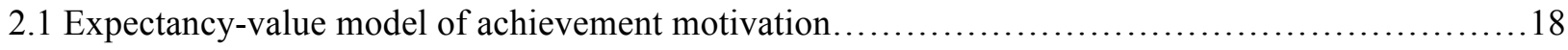

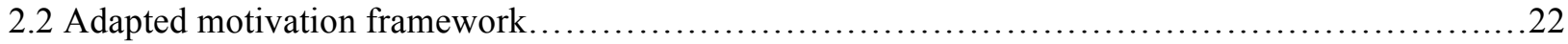

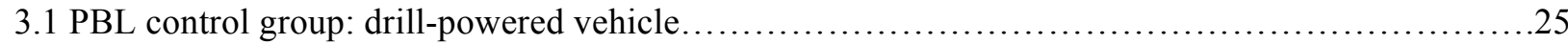

3.2 PBSL treatment group: adapted tricycles project..............................................

4.1 Summary of sequential explanatory design applied to this study .................................

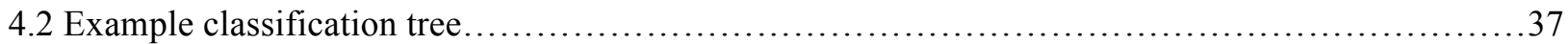

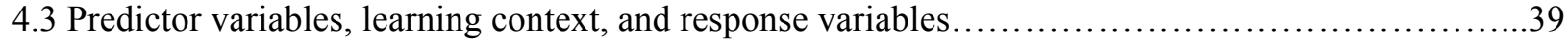

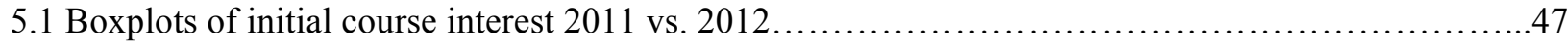

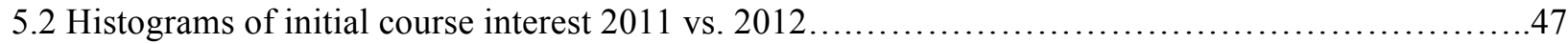

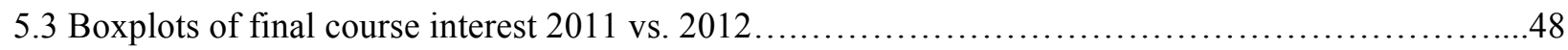

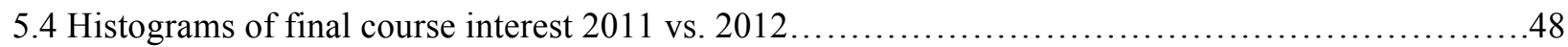

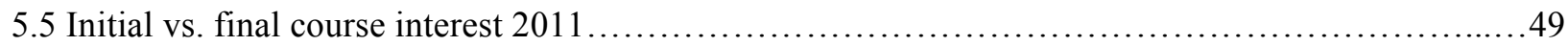

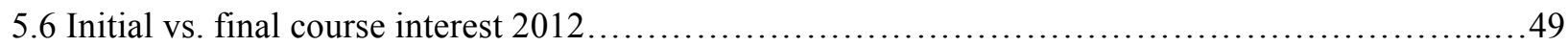

5.7 Example variable importance results from random forest analysis...............................53

5.8 Most important predictors of student achievement motivation in 2011 cohort.....................57

5.9 Most important predictors of student achievement motivation in 2012 cohort.....................58

5.10 Most important predictors of student achievement motivation in PBL experience..................58 


\section{Chapter 1 \\ Topic and Problem}

This research is part of the One Day's Pay (ODP) program at University of Colorado Boulder - an initiative that seeks to 1) involve students in engineering design work that benefits targeted local communities and 2) perform rigorous engineering education research to understand the impacts of altruistic design projects on student retention and recruitment, identity, attitudes, and motivation and engagement in engineering.

These initiatives are being achieved through two major studies completed by graduate student researchers under the direction and mentorship of faculty involved in the ODP program. One graduate student focused her research on altruistic design projects in local high school students and in a first-year introductory engineering design course at CU Boulder. The other graduate student (the author of this thesis) focused her research on project-based service-learning in a junior-level mechanical engineering course at CU Boulder.

Essentially, the ODP research team endeavors to provide evidence-based information about the effects of altruistic design on students, as well as to outline strategies for designing effective project-based service-learning experiences for students.

\section{Research Need}

Project-based learning (PBL) is a model that centers learning around projects that involve students in design, problem solving, decision making, and other investigative activities. Students engaged in PBL typically work autonomously over extended periods of time to create realistic products or presentations. There is a large body of evidence that suggests PBL 1) positively affects students' orientation toward learning and mastery; 2) enhances students' interest and perceived value of a given activity; 3 ) produces general gains in academic achievement; and 4) teaches students processes such as planning, communication, problem solving, and decision making. There is also research that indicates PBL can positively impact student motivation in a variety of learning situations. However, there is a limited amount of research on project-based learning (PBL) approached from a framework of motivation theory.

The rationale for using a motivation framework is this: motivation is a not a single construct. Rather, it is a synthesis of several constructs including a person's feelings of competence, autonomy, relatedness, interest, value, expectancy for success, and others. Investigating the phenomenon of motivation from a motivation framework allows us to apply research-based theory to help understand and explain how the 
different motivation constructs appear in a situation, how they relate to each other, and how they contribute to a person's motivational tendencies in a given social environment.

The need for research framed in motivation theory can also be applied to project-based servicelearning (PBSL). PBSL is a synthesis of project-based learning and service-learning, which is a model that integrates community service with learning objectives in such a way that the service activity impacts both the recipient and provider of the service. PBSL and PBL are similar in that the project serves as the vehicle for learning. The distinguishing feature of PBSL is the addition of the community as a full partner in the project. Past research indicates that PBSL can positively affect students' cognitive and affective development, strengthen their understanding of the broader context of engineering, and attract and retain female and minority students to engineering. However, little research has been completed to understand the connection between PBSL and student motivation.

\section{Research Purpose and Significance}

Grounded in motivation theory, the purpose of this research is to answer two overarching research questions:

1. How does the context of service in project-based learning affect student achievement motivation?

2. When designing project-based learning experiences, what factors are most influential on students' motivation to persist in those experiences?

This research is intended to fill several significant gaps in our understanding of PBL, PBSL, and student motivation. As discussed previously, the first unique element of this research is its approach to studying the phenomenon of student motivation in project-based learning contexts using a framework of motivation theory.

The second unique element of this research is its direct focus on the impacts of the service context in PBSL. As will be discussed in Chapter 2, there is a substantial body of research that suggests that servicelearning and project-based service-learning can positively affect students' cognitive and affective development, strengthen their understanding of the broader context of engineering, and attract and retain female and minority students in engineering. However, little research has been completed with true control and treatment groups in order to "isolate" the context of service.

For example, an extensive study by Astin, Vogelgesang, Ikeda, and Yee (2000) explored the comparative effects of service learning and community service on the cognitive and affective development of college undergraduates to understand how learning is enhanced by service. Their research showed that participation in service resulted in significant positive effects on all measured outcomes: 
academic, commitment to activism, promoting racial understanding, self-efficacy, leadership, choice of a service career, and plans to participate in further service after college. This study compared three groups of students: those who had participated in service-learning, those who had participated in general community service, and those who hadn't participated in either. However, the students were from a variety universities, had different baseline characteristics, backgrounds, competencies, goals, and so forth. Further, it is unclear how many of the students in this study had the option of self-selecting into a servicebased course or program and might be predisposed to the context of service in the academic setting.

This study and others with a similar research design are crucial for our foundational understanding of how service-learning affects students. However, moving forward, new research is needed that uses a true control and treatment group in an attempt to isolate (or at least account for) potentially confounding variables such as variations in student characteristics, institution, academic major and initial preferences for service.

Lastly, this research also contributes to an overall understanding of how to design effective projectbased learning experiences. By identifying the characteristics, or factors of PBL that positively affect student motivation, practitioners can design more thoughtful experiences for students. 


\section{Chapter 2}

\section{Review of the Literature}

"Learning and teaching are not symmetrical. They are not flip sides of the same coin...The working assumption is this: Solve teaching and you will get learning." Sugata Mitra

\section{Theory to Practice}

Learning theory. Although there exist a variety of definitions of what constitutes learning, most definitions incorporate the idea that learning is an enduring change in behavior, or the capacity to behave in a certain manner, which results from practice or other forms of experience (Schunk, 1991). Learning theories are explanations of how learning occurs, the role of memory in learning, and how transfer occurs. It is commonly agreed that there are three major learning theories: behaviorism, cognitivism, and constructivism:

The learning theory of behaviorism postulates that learning is a straightforward process of response to stimuli. The introduction of a reward or reinforcement is thought to strengthen the learner's response and result in behavioral changes. Behavioral changes are the primary indication that learning has occurred. The behaviorist perspective characterizes the learner as passive and reactionary because he or she simply learns to react appropriately to a given stimulus. Consideration is not given to the structure of a learner's knowledge or to understanding which mental processes a learner must use in a given situation. Teaching strategies rooted in behaviorism include presenting a target stimulus and providing repeated opportunities for the learner to practice making the proper response. For example, the use of vocabulary flashcards to memorize new terms and definitions. These strategies are most effective when the learning task requires lower-level skills such as memorization, recalling facts, and automatically performing a specified task (Ertmer and Newby, 1993).

The learning theory of cognitivism considers more than observable behavioral events and focuses on understanding learning processes such as how information is received, organized, stored, and retrieved. Cognitivism also considers the influence of people's thoughts, beliefs, attitudes, and values on their learning. The cognitivist approach requires that the teacher understand how learners bring various experiences to the learning scenario to determine the most effective way of organizing new information to help activate learners' previously acquired knowledge, abilities, and experience. It also includes providing the learner with feedback so that new information is assimilated into their cognitive structure. This may include the use of analogies, metaphors, framing, outlining, mnemonics, and concept mapping - all 
strategies to help organize information in a way that allows learners to connect new information with existing knowledge. Cognitivist approaches are better suited than behaviorist approaches for more complex forms of learning such as reasoning and problem solving (Ertmer and Newby, 1993).

The learning theory of constructivism places greater emphasis and responsibility on the learner. Whereas behaviorism and cognitivism share the perspective that learning is a process of mapping or imprinting external facts and knowledge onto the learners, constructivism is based on the premise that learners construct knowledge for themselves by creating new ideas and concepts based upon current and past knowledge or experiences. Learning is literally a process of constructing meaning; it is how people make sense of their experience. McHenry et al. (2005) cites four guiding principles of constructivism:

- Learning is a search for meaning. Therefore, learning must start with the issues around which students are actively trying to construct meaning.

- Meaning requires understanding wholes as well as parts. And parts must be understood in the context of wholes. Therefore, the learning process focuses on primary concepts, not isolated facts.

- In order to teach well, we must understand the mental models that students use to perceive the world and the assumptions they make to support these models.

- The purpose of learning is for an individual to construct his or her own meaning, not just memorize the "right" answers and regurgitate someone else's meaning.

Hence, from the perspective of constructivism, knowledge emerges in contexts within which it is relevant, and it is essential that learning occur in realistic settings that relate to the learner's lived experience. Teachers customize curricula to most effectively utilize students' prior knowledge by helping them make connections between prior knowledge and new concepts and facts. This is achieved through the use of open-ended questions, extensive dialogue among students to encourage students to analyze, interpret, and predict information. Hands-on problem solving is also strongly emphasized in the constructivist approach.

The role of constructivism in engineering education. When examining the role of constructivism in engineering education, it's important to consider what is required of today's engineering graduates. McHenry et al. (2005) states:

"As creative professionals, engineers purposefully conceptualize, design, and lead the systematic development of new innovative technology in the form of new and improved products, processes, systems, operations, and breakthrough developments that are responsive to real-world needs. In this process they use the integrative engineering method as a purposeful, deliberate, and systematic practice for innovation and entrepreneurship, driven by an engineering ethic and responsible professional leadership for improvement and betterment." 
McHenry et al. (2005), quoting the National Academy of Engineering, also offers a definition of technology for the $21^{\text {st }}$ century:

"In its broadest sense, technology is the process by which humans modify nature to meet their needs and wants. However, most people think of technology only in terms of its artifacts ...but technology is more than its tangible products. An equally important aspect of technology is the knowledge and processes necessary to create and operate those products, such as engineering know-how and design, manufacturing expertise, various technical skills, and so on."

What McHenry's definitions of engineering and technology suggest is the need for today's engineering graduates to cultivate a more versatile and dynamic skill set than what was required several decades ago when engineering education in the U.S. was research-based, geared toward preparing engineers for academic scientific research. During this time, technology was advancing relatively slowly, and the level of technical competence that engineers and developed on the job was sufficient for longer period of time. Hence, engineering curricula deemphasized technological abilities and focused on teaching students high-level cognitive abilities such as reasoning and problem solving.

Today's engineering graduates, however, are expected to apply creativity and innovation to design new "products, processes, systems, operations and breakthrough developments that are responsive to realworld needs." (McHenry et al., 2005). As leaders of technology and industry, engineers must also possess a strong engineering ethic and responsible professional leadership. These skills and competencies are exactly what the instructional strategy of constructivism aims to achieve. Hence the reason this approach to educating engineering students has been gaining popularity in recent years.

Project-based learning. Project-based learning (PBL) is derived from the constructivist approach to teaching and learning. PBL is a model that centers on learning around projects (Thomas, 2000). In other words project are central, not peripheral, to the curriculum. Thomas describes the projects in PBL as "complex tasks that involve students in design, problem solving, decision making, and other investigative activities. PBL gives students the opportunity to work relatively autonomously over extended periods of time, and the students' work generally culminates in realistic products or presentations." Thomas outlines five criteria for PBL projects as centrality, driving question, constructive investigations, autonomy, and realism.

- Centrality: In PBL projects themselves are the curriculum. By way of the project, students encounter and learn the underlying concepts of interest. Often, projects are used to enhance traditional instruction by providing tangible examples, extra practice, or practical applications. However, this is not PBL because the project itself is not serving as the primary vehicle for learning the underlying concepts. 
- Driving question: PBL poses a question or problem that "drives" students to encounter (and struggle) with the underlying concepts. The question or problem presented should not be constrained, and should allow students to develop their own approaches to the solution and to generate unique products or presentations.

- Constructive investigation: In PBL, the main activities of the project should cause students to construct new understandings and new skills as they investigate the question or problem. If students can complete the project activities by applying prior understandings and skills, the project is not PBL.

- Autonomy: PBL projects are designed to be student-driven vs. teacher-directed. Students are given less supervision, greater responsibility, and more freedom to determine a project's solution path and outcomes.

- Realism: Lastly, PBL is realistic and authentic to students. The project topic, tasks, student roles, outside project collaborators, and the final product should stem from real-life challenges (vs. academic challenges or scenario challenges).

As described by Blumenfeld (1991), PBL is as a framework for teaching and learning that engages students in investigation by pursuing solutions to nontrivial problems in realistic, contextualized problem solving environments. Students engage in authentic projects that require them to ask and refine questions, debate ideas, make predictions, design plans and experiments, collect and analyze data, draw conclusions, communicate ideas and findings, and create artifacts. Essentially, PBL serves to connect phenomena in the classroom with real-life experience.

Blumenfeld also claims that the framework for PBL must include the following elements in order to motivate students to engage in projects in a way that fosters understanding:

- Interest and value: Students must perceive both the project context and the project activities to be interesting and valuable. Student interest and perceived value are increased when project tasks are varied and include novel elements, the project is authentic, and the project is challenging.

- Creation of artifact: The artifacts that the students create must require the students to integrate new information and use complex thought. Similar to Thomas' (2000) claim, students should not be able to complete the project activities by applying prior understandings and skills. Also, having freedom to generate artifacts is critical because it is through this process that students construct their knowledge. The artifacts then serve as representations of the students' emergent knowledge and gives students something concrete to share and critique with others, which in turn allows them to reflect on and expand their knowledge. 
- Choice: Students must have choice and control in the selection of project questions, approaches, and artifacts so they gain a sense of ownership in the project. This is similar to Thomas' (2000) description of the role of autonomy in PBL.

- Classroom Environment: The classroom environment must promote inquiry and mastery orientation versus performance orientation, and the role of the teacher can have a significant impact on creating this positive classroom environment. Students must perceive making mistakes and errors as central to the success when working on projects.

State of research in PBL and motivation. As described by Thomas (2000), there is a large body of evidence suggesting that PBL positively affects students' orientation toward learning and mastery, interest and perceived value of a given activity, produces general gains in academic achievement, and can teach students processes such as planning, communication, problem solving, and decision making. There is also research indicating that $\mathrm{PBL}$ can positively impact student motivation in a variety of learning situations; however, there are few (if any) studies that are formally framed in motivation theory. Some of the existing research linking PBL and student motivation is described in the following paragraphs.

Research completed in conjunction with the Outward Bound program on the implementation of Expeditionary Learning (closely related to PBL but more focused on learning in a wilderness expedition context) at ten schools indicated that the Expeditionary Learning experience positively influenced school climate and student motivation (Expeditionary Learning Outward Bound, 1999).

Meyer, Turner, and Spencer (1997) studied fifth and sixth graders engaged in project-based geometry curriculum and showed that students who were identified as "challenge seekers" (characterized by having a high tolerance for failure and a learning goal orientation) vs. "challenge avoiders" were more likely to approach PBL with greater interest and mastery focus. Hence, students who are engaged in PBL will naturally apply various learning strategies and react differently to difficulty and failure, which has an effect on their persistence and flexibility toward PBL.

Bartscher (1995) studied third, sixth, and tenth grade students characterized as having low motivation. After these students were engaged in project work as well as field trips, student motivation increased among the third and sixth grade students (as measured by homework completion and class participation). However, motivation was not increased among the tenth graders. Bartscher's study did not address why motivation did not increase with these older students. Nor did it describe what students were more motivated toward.

Stolk, Savage, and Vanasupa (2007) compared a junior cohort of materials engineering majors engaged in PBL curriculum at California Polytechnic State University against a comparable junior cohort 
of other engineering majors exposed to more traditional curriculum. The results showed that students in the PBL cohort perceived themselves as more independent and self-reliant, and more able to direct their learning than those in the more traditional curriculum cohort.

Hence, there does exist a body of research that provides some evidence of the positive impacts of PBL on aspects of student motivation. However, what is lacking is research focused on the impacts of PBL on student motivation from a framework grounded in motivation theory. This is articulated in the following questions posed by Blumenfeld (1991):

1. What types of projects do students find interesting, challenging, and valuable enough to keep them engaged in the project over a sustained period of time?

2. How do individual differences in students influence the ways students engage in PBL?

3. How do students' self-perceptions of ability and their interest in a particular subject area influence their persistence in PBL?

4. Does it matter whether students engaged in PBL focus more on learning versus performance outcomes like grades?

This study aims to begin answering these questions.

Service-learning. As defined by the National Service Learning Clearinghouse (2005), servicelearning (SL) is a model of teaching and learning that integrates community service with learning objectives in such a way that the service activity impacts both the recipient and provider of the service. SL includes self-reflection, self-discovery, and the acquisition and comprehension of values, skills, and knowledge.

Eyler and Giles (1999) have researched the impacts of SL in various contexts. In one study with 1,500 students from 20 colleges and universities, SL was found to positively impact tolerance for diversity, personal development and interpersonal development, and community-to-college connections. Students reported working harder, being more curious, and connecting learning to personal experience.

An extensive study by Astin, et al. (2000) explored the comparative effects of SL and community service on the cognitive and affective development of college undergraduates to understand how learning is enhanced by service. The study used longitudinal data collected from roughly 22,000 college undergraduates attending colleges and universities nationally. $30 \%$ of students participated in SL during college, $46 \%$ in general community service, and $24 \%$ did not participate in any community service.

This study showed that participation in service resulted in significant positive effects on all measured outcomes: GPA; writing skills; critical thinking skills; value (commitment to activism and to promoting 
racial understanding); self-efficacy; leadership (leadership activities, self-related leadership ability interpersonal skills); choice of a service career; and plans to participate in further service after college. Concerning how service enhanced learning, the researchers' results indicated that SL is effective because it facilitates four types of outcomes: an increased sense of personal efficacy; an increased awareness of the world; an increased awareness of one's personal values; and increased engagement in the classroom experience. Interestingly, the single most important factor associated with a positive service-learning experience was the students' degree of interest in the subject matter. Subject matter interest was a significant determinant of how much the service experience enhanced understanding of the academic course material and the extent to which service was viewed by the students as a learning experience.

The second most important factor associated with a positive service-learning experience was whether the professor encouraged reflection (discussion among students, discussions among professors, and written reflection in the form of journals and papers). Structured reflection and discussion are crucial elements of SL because they help students connect learning to personal experience, which enhances both cognitive and affective development.

Project-based service-learning. Project-based service-learning (PBSL) is the synthesis of projectbased learning and service-learning and is also derived from the constructivist approach. In PBSL, students are engaged in authentic projects that involve complex, holistic social situations and issues in which students must combine their technological skills along with their critical thinking and interpersonal skills to understand the problems they must solve in the project (Brescia, Mullins, and Miller, 2009). PBSL is similar to PBL in that the project serves as the vehicle for learning. The distinguishing feature of PBSL is the addition of community members who should be equal partners in the process and feel a sense of ownership of the project (Swan, Paterson, and Bielefeldt, 2009).

State of research in PBSL. Much of the existing research in PBSL involves faculty and students involved in the SLICE program (Service-Learning Integrated throughout the College of Engineering) at the University of Massachusetts Lowell and in the EPICS program (Engineering Projects in Community Service) at Purdue University. The SLICE program integrates SL into a wide variety of its core and required undergraduate engineering courses (Duffy et al., 2008). Extensive research on students in the SLICE program has indicated that both faculty and students are more motivated, engaged, and able to master course material in a project-based service-learning context (Duffy, Barry, Barrington, and Heredia, 2009). 
Students in the EPICS program earn academic credit for participation in multi-semester, multidisciplinary design teams that solve technology-based problems for local non-profit organizations. Research conducted by Coyle, Jamieson, and Oakes (2005) on the EPICS program indicates that the service context provides a compelling framework for students to learn valuable lessons in citizenship, including the role of community service in society; the community-wide impact made possible by their engineering; and that assisting others contributes to their own growth as individuals, engineers and citizens.

This study also showed that a majority of EPICS students have reported the opportunity to gain practical, real-world experience in engineering design as well as to do community service as their primary reasons for participating in the program. Data collected on specific course and program objectives over 15 semesters indicated that students rank ability to work on a team, communication skills, and awareness of the customer in an engineering project among the top outcomes of the program. Also, $70 \%$ of students responded that their participation in the EPICS program positively impacted their decision to persist in engineering.

An additional study carried out by Brescia et al. (2009) involving five master's level instructional design students involved in PBSL curriculum. Their results indicated that all five students reported an overall positive service-learning experience, confidence in being more productive designers, ability to be more self-directed, and a greater awareness of community issues.

There is also evidence that PBSL can help attract retain women and minority students. SLICE faculty claim that when underrepresented groups have the option to pursue PBSL, they do so in overrepresented numbers. In one of their voluntary SL programs involving the design and installation of systems in remote regions of a developing country, 35\% of the engineering students have been female, three times the underlying population (Barrington and Duffy, 2007). Bielefeldt (2009) claims that this trend has also been observed in the EPICS program, where women students represent a higher percentage than those of their majors. As stated by researchers from the Sustainable Futures Institute at Michigan Technological University: "working toward solving environmental and societal problems resonates with women (e.g. high female enrollment in environmental and biomedical engineering programs); young women will be motivated to study science and engineering if they understand that careers in these fields will enable them to positively affect society." (Hokanson, Phillips, and Mihelcic, 2007).

Several researchers have offered explanations about why PBSL and SL in general are attractive to women and other underrepresented groups in engineering. Meadows and Jarema (2006) claim that "altruistic reasons for choosing a career in science or engineering are predominantly expressed by women 
or historically underrepresented minority students." Seymour and Hewitt (1997) claim that "making a long-term contribution to their families and communities" tends to be important for students of color.

Research completed by Bielefeldt (2009) compared the attitudes of female and male students in relation to how engineering benefits society. These traits were assessed using written surveys administered in first-year engineering courses in environmental engineering, civil engineering, and general engineering at CU Boulder from 2004 to 2008. The results showed that male students had a more favorable view of engineers' role in society than female students. Female students appeared more cognizant of cultural differences in appropriate engineering solutions to community problems and their importance to the success of engineering projects. Qualitative analysis of a selection of student essays suggested that females are more aware of the potential beneficial impacts of engineering on society and more interested in those aspects of engineering that help the developing world or impoverished communities.

This theme of females desiring to help others has emerged in other research. In a survey administered by the SLICE program to over 500 students who participated in PBSL, the most frequently reported reason by females and non-Caucasians for wanting to pursue engineering (out of 12 possible reasons) was "challenge" followed by "helping others." "Helping others" was not among the top four reasons reported by male Caucasians, who instead reported "challenge," "income," "creativity," and "security" as their top four reasons for pursuing engineering (Barrington and Duffy, 2007).

Clearly, there is a breadth of evidence that strongly suggests SL and PBSL can positively affect students' cognitive and affective development, strengthen their understanding of the broader context of engineering, and attract and retain female and minority students in engineering. What is still needed is research conducted with students who are 1) at the point in their engineering careers where retention is less of a concern than in the first or second year; 2) seeking engineering degrees that have less of an emphasis on the civic, service, biomedical, or humanitarian context of engineering; and 3) do not have the option of self-selecting into a service-based course or program. Research that controls for some of these confounding factors will reveal a more precise understanding of the context of service in PBSL.

Obstacles and criticism of PBL. Despite increasing student and faculty interest in PBL and PBSL, there are significant barriers to implementation, as well as criticism of these instructional strategies. The SLICE program has surveyed faculty involved with their PBSL program to reveal challenges including time constraints, reward and recognition, and the skills faculty needed to facilitate PBSL. Faculty also reported an increase in day-to-day workload associated with their PBSL activities (Duffy et al., 2009). 
The D80 (Development for the Other 80\%) Center at Michigan Technology University was created to provide engineering students with opportunities to engage in projects to serve people who have not historically been well-served by engineering. In March 2007, a survey of engineering undergraduate students investigated current participation and interest in D80 programs. The results of the survey showed that the interest level in D80 programs is highest during students' first couple of years but then diminishes (a senior who has not participated in a D80 activity is not likely to do so). The top three reasons for not participating are lack of money, lack of time, and a concern to do well in "major studies" (Paterson and Fuchs, 2008).

One solution to financial and time limitations is to integrate PBSL into existing courses, similar to the SLICE model; however, a disadvantage of this model has been the discontinuity of student involvement. Unlike extracurricular PBSL opportunities, where students can choose to participate in a project for several semesters, student participation in a PBSL experience is generally limited to the duration of that course (Duffy et al., 2008).

There are also different opinions about whether these instructional strategies are effective in engineering. One concern is that most engineering curriculum has a hierarchal structure. Properly learning the engineering foundations is essential for mastery of more complex topics, and novice learners should not be left to discover these essential concepts for themselves (Mills and Treagust, 2003). Another argument for the ineffectiveness of PBSL has to do with our cognitive architecture, or the manner in which our cognitive structures are organized (Kirschner, Sweller, and Clark, 2006). Research suggests that long-term memory is the central, dominant structure of human cognition. For example, expert problem solvers can draw from extensive experience stored in their long-term memory to quickly select and apply the best strategies for solving problems.

Kirschner et al. (2006) argue that although PBL challenges learners to search for and discover information, it does not provide them with specific guidance about how to cognitively manipulate information in order to store it in long-term memory. As previously discussed, PBL has its roots in the learning theory of constructivism, and, although the constructivist description of learning is accepted, the pedagogical techniques that have stemmed from this theory are contended. It may not be the case that the correct pedagogy for learning or teaching a discipline is identical to the functional knowledge (methods and processes) of that discipline. In other words, because engineering requires an ability to solve complex problems, ill-structured pedagogy may not be the most effective approach to teaching engineering.

Jonassen (1999) argues that teaching strategies rooted in behaviorism and cognitivism are more effective at teaching basic facts and knowledge. However, as the learner gains more knowledge, constructivist teaching strategies are necessary to help the learner deal with complex and ill-structured 
problems. Hence, it can be argued that behaviorist, cognitivist, and constructivist are all appropriate approaches to educating engineers, depending on the stage of the learner (novice to expert) and what the desired learning outcomes entail.

Blumenfeld (1991) outlines additional challenges with PBL. One, too little attention has focused on the role of the teacher. PBL requires significant changes in teachers' approaches toward classroom structures, activities, and tasks. Teachers also need professional development opportunities to learn how to engage students in PBL, and they need time and organizational support to implement PBL. Two, previous research often fails to consider questions about PBL from the point of view of the students. What kinds of projects and activities do students find interesting, valuable, and engaging? Three, projects are often developed without sufficient consideration of the complex nature of student motivation and the effort required to engage in high-level cognitive work. It is often assumed students that will be motivated by PBL and will therefore respond with increased use of learning strategies. However, students are often resistant to high-level cognitive tasks and instead try to simplify the demands of the situation through negotiation.

These criticisms of and obstacles to implementing PBL and PBSL provide an even more compelling need to perform more rigorous research on these pedagogical approaches to teaching and learning, especially with regard to the best design of PBL experiences for students.

\section{Motivation Theory}

"The fullest representations of humanity show people to be curious, vital, and self-motivated. At their best, they are agentic and inspired, striving to learn; extend themselves; master new skills; and apply their talents responsibly. That most people show considerable effort, agency, and commitment in their lives appears, in fact, to be more normative than exceptional, suggesting some very positive and persistent features of human nature. Yet, it is also clear that the human spirit can be diminished or crushed and that individuals sometimes reject growth and responsibility. Regardless of social strata or cultural origin, examples of both children and adults who are apathetic, alienated, and irresponsible are abundant. Such non-optimal human functioning can be observed not only in our psychological clinics but also among the millions who, for hours a day, sit passively before their televisions, stare blankly from the back of their classrooms, or wait listlessly for the weekend as they go about their jobs." Richard Ryan and Edward Deci

General statements about motivation. Ryan and Deci (2000) state: "motivation concerns energy, direction, persistence and equifinality - all aspects of activation and intention. In the real world, motivation is highly valued because of its consequences: motivation produces." Eccles and Wigfield (2002) state: "The Latin root of the word 'motivation' means 'to move'; hence, in this basic sense the study of motivation is the study of action. Modern theories of motivation focus more specifically on the relation of beliefs, values, and goals with action." 
There are a variety of motivation theories that help to explain the mechanisms involved in a person's incentive toward a desired goal or outcome and the subsequent behaviors involved in their pursuit. Each of these theories offers a framework by which we can structure our approach to studying and understanding human motivation. The theories that are most relevant to this study are self-determination theory, expectancy-value theory, situational interest theory, and achievement goal theory.

Self-determination theory. Self-determination theory (SDT) is a motivation theory that concerns the innate psychological needs as well as the external conditions that form the foundation for people's self-motivation and personality integration. Research in SDT has identified competence, relatedness, and autonomy as the three essential needs for people's growth and integration, healthy social development, and personal well-being (Deci and Ryan, 1985; Deci and Ryan, 1987; Ryan and Deci, 2000). In SDT, competence is defined as "feeling effective in one's interactions with the social environment and experiencing opportunities to exercise and express one's capacities." Relatedness is defined as "caring for and being cared for by others, having a sense of belongingness, both with other individuals, and one's own community." Autonomy is characterized by "choice, acknowledgement of feelings, and opportunities for self-direction. A sense that one's actions are self-determined, or self-authored." (Deci and Ryan, 2002).

According to SDT, the more a person's needs for competence, relatedness, and autonomy are satisfied, the more intrinsically motivated that person will be in a given situation. In SDT, "intrinsic motivation" is a unique type of motivation characterized by an inherent propensity for assimilation, mastery, spontaneous interest, and exploration. It is peoples' natural tendency to seek out novelty, challenge, opportunities to use and expand their capacities, to explore, and to learn.

The spectrum of motivation is an important concept in SDT. Intrinsic motivation is on one end of the spectrum; on the other end sits extrinsic motivation. Extrinsic motivation is characterized by the performance of an activity in order to attain some defined outcome. In SDT, extrinsic motivation varies greatly in its relative autonomy. The example that Ryan and Deci (2000) provide is students who are extrinsically motivated to complete homework because they see the value for their chosen career compared with students who are extrinsically motivated to complete their homework because they are conforming to their parents' desires. These two students vary in their degree of relative autonomy, with the former student experiencing a greater degree of personal choice and the latter student experiencing compliance and external regulation. The former student's feelings of extrinsic motivation would lie closer to the intrinsic motivation end of the motivation spectrum. 
Rarely are people purely intrinsically or extrinsically motivated in a given situation; in most circumstances people experience a motivation that falls in between these two extremes. The key point is that the more intrinsically motivated people feel, the greater their interest, excitement, and confidence, which results in enhanced persistence, performance, vitality, self-esteem, and general well-being. These positive characteristics are more prominent in intrinsically motivated people as compared to extrinsically motivated people, even when the two groups perceive their level of competence or self-efficacy to be the same in a given situation (Ryan and Deci, 2000).

Lastly, although intrinsic motivation seems to be a natural tendency, people's social environments can support or thwart their feelings of intrinsic motivation. Social environments that support intrinsic motivation are characterized by those that enhance feelings of competence by providing communication, optimal challenges, effectance-promoting feedback, and freedom from demeaning evaluations. Additionally, choice, acknowledgement of feelings, opportunities for self-direction, and the absence of tangible rewards made contingent on task performance enhance intrinsic motivation, because they result in a stronger feeling of autonomy. Research in SDT has shown that teachers who are autonomy supportive versus controlling inspire in their students stronger intrinsic motivation, curiosity, and desire for challenge (Ryan and Deci, 2000).

Intrinsic motivation is also supported by contexts characterized by a sense of security and relatedness. Research in SDT indicates that lower intrinsic motivation is observed in students who experience their teachers as cold and uncaring. Also, a sense of relatedness does not always require the physical presence of others; in fact, many intrinsically motivated behaviors can be performed alone. However, a person must have a sense security and relatedness to feel intrinsically motivated (Ryan and Deci, 2000).

In this study, SDT was useful in understanding how the course climate contributed to students' motivation in PBL.

Expectancy-value theory. Another type of motivation that has important consequences in academic settings is achievement motivation (Elliot and Dweck, 2005), characterized by people's choice of tasks, persistence in tasks, vigor in carrying them out, and performance on tasks (Eccles, 1994; Wigfield and Eccles, 2000; Eccles and Wigfield, 2002; Eccles, 2009). One predominant theory developed by Eccles and Wigfield used to understand achievement motivation is expectancy-value theory (EVT), which posits that people's choice, persistence, and performance can be explained by their expectancy for success in the activity and the extent to which they value the activity.

In EVT, expectancy for success is defined as a person's beliefs about how well he or she will do on upcoming tasks, either in the immediate or longer-term future. There is a conceptual difference between a 
person's ability beliefs and his or her expectancy for success: ability beliefs is focused on a person's present competence whereas an expectancy for success is focused on a person's anticipated future competency. Empirically, however, these constructs are highly related (Eccles and Wigfield, 2002; Matusovich, H., Streveler, R., and Miller, R., 2010).

According to EVT, the construct of value is described as "subjective task value" and is characterized by four components: attainment value, intrinsic value, utility value, and cost.

- Attainment value is the personal importance of doing well on a given task.

- Intrinsic value is the enjoyment a person feels from performing a given a task or the interest the person has in the subject. This construct is similar to intrinsic motivation as defined in SDT.

- Utility value is characterized by how well a task relates to a person's current and future goals. It's important to note that a task can have positive value to a person because it facilitates important future goals, even if he or she is not interested in the task for its own sake. Again related to SDT, this component captures the more extrinsic reasons for engaging in a task but it also relates directly to personal short- and long-term goals.

- Cost is conceptualized in terms of the negative aspects of engaging in a task such as performance anxiety, fear of both failure and success, amount of effort needed to succeed and the lost opportunities that result from making one choice rather than another.

According to EVT, not only is a person's expectancy for success and subjective task value related to achievement choices, they are related to each other and to other factors as well. These relationships are represented in Figure 2.1, which shows the expectancy-value model of achievement motivation. Some of the key relationships to note in Figure 2.1 are noted below.

- Achievement-related choices (performance, persistence, and task choice) are directly influenced by a person's expectancy for success and subjective task values.

- Expectancy for success and subjective task value are influenced by task-specific beliefs such as perceptions of: competence, difficulty of different tasks, and individuals' goals and self-schema.

- A person's perceptions of competence, task difficulty, goals, and self-schema are themselves influenced by other factors including their own interpretation of their previous achievement outcomes and perceptions of other peoples' attitudes and expectations.

- A person's beliefs, perceptions, and interpretations of their past outcomes are influenced by gender role stereotypes and other cultural stereotypes. 


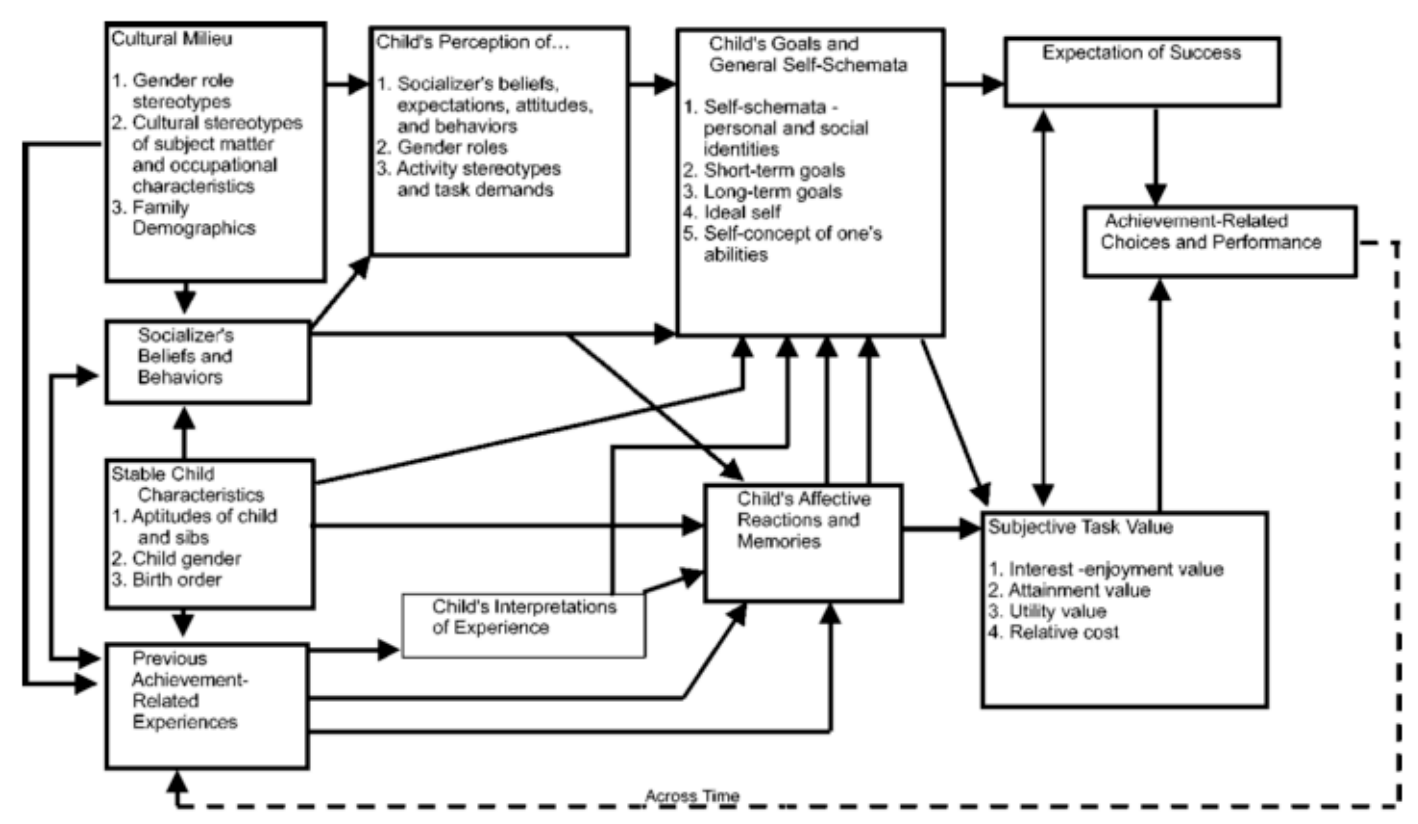

Figure 2.1: Expectancy-value model of achievement motivation (Eccles and Wigfield, 2002).

Clearly, the relationships between expectancy for success, subjective task value, and achievement motivation are not linear, nor can they be isolated from a person's background and social environment. For example, people's ability-related beliefs influence their subjective task values. MacIver, Stipek, and Daniels (1991) found that changes in high school students' competency beliefs over a semester predicted their change in effort and interest in an academic setting. Bandura (1997) found that interests emerge out of one's sense of self-efficacy and that children should be more interested in challenging than in easy tasks. Wigfield and Eccles (2000) proposed that children's competence and task-values beliefs are initially independent of each other but at some point become positively related. Over time, children may begin to attach more value to activities in which they do well, for two reasons: first, the positive effect a person feels when he or she does something well should become attached to the successful activities; second, lowering the value one attaches to difficult activities can be an effective way to maintain a positive global sense of efficacy and self-esteem.

Not only is there evidence that positively correlates ability-related beliefs and task values, Wigfield and Eccles (2000) state that younger children have more positive achievement-related beliefs than older children whose ability-related beliefs and values become more negative as they get older. The negative changes have been explained in two major ways. One explanation is that children become much better at understanding and interpreting the evaluative feedback they receive and engage in more social comparison with their peers. As a result, many children become more accurate or realistic in their self- 
assessments so that their beliefs become relatively more negative. A second explanation is that the school environment makes peer evaluation more salient and competitive, thus lowering some children's abilityrelated beliefs.

In this study, EVT was instrumental in understanding how students' ability-related beliefs shaped their perceptions of value for PBL.

Achievement goal theory. According to Harackiewicz, Barron, Carter, Lehto, and Elliot (1997), achievement goals are situation-specific orientations that represent a person's desire to develop, attain, or demonstrate competence in a particular context. Ames (1992) defines achievement goals as integrated patterns of beliefs, attributions, and affect that produce the intentions of achievement behavior.

Essentially, achievement goals are represented by the different ways a person approaches, engages in, and responds to achievement-related activities (Archer, 1994).

Harackiewicz et al. (1997) define three types of achievement goals that are important determinants of motivation and performance, influencing the way students approach and perform their coursework: mastery goals, performance goals, and work-avoidance goals. Essentially, mastery goals are associated with a desire to develop competence; performance goals are associated with a desire to demonstrate competence relative to other; and work-avoidance goals are associated with a desire to complete work with minimal effort.

Mastery goal orientation promotes a motivational pattern conducive to long-term and high-quality involvement in learning. People who adopt mastery goals are focused on mastering and understanding content and are eager to engage in the process of learning. Mastery goals are also associated with a person's preference for challenging work, ability and comfort in taking risks, intrinsic interest, developing new skills, positive attitude toward learning, time spent on learning tasks, and the quality of engagement in learning.

In contrast to mastery goal orientation, performance goal orientation promotes a failure-avoidance pattern of motivation. People who adopt performance goals are often focused on sense of self-worth and ability, where ability is associated with doing better than others, surpassing normative-based standards, and achieving success with minimal effort. Performance goals are also associated with a person's avoidance of challenging tasks, negative feelings following failure, positive feelings following success with minimal effort, and use of short-term learning strategies such as memorizing and rehearsing.

From a "multiple goals perspective" people might sequentially or simultaneously adopt mastery and performance goals to achieve a desired academic outcome. Although these two goal orientations are 
different, they both represent positive strides toward achievement. Work avoidance goals, however, have detrimental effects on motivation and performance.

Other researchers have studied how the classroom environment itself can make different goals salient. Ames (1992) has uncovered certain structures of the classroom that can lead to a mastery goal orientation as well as the way these structures affect how students engage in learning. These structures are the design of tasks and learning activities, the evaluation of practices and use of rewards, and the distribution of authority or responsibility.

Students are more likely to adopt a mastery goal orientation when engaged in tasks that involve variety and diversity, help them strengthen their skills, and emphasize personal relevance. Evaluation and recognition can also contribute to a mastery goal orientation when social comparison (i.e. announcements of highest and lowest scores, public charts of students' papers, scores and progress, and ability grouping) is minimized. Social comparison that is externally imposed and made public can cause students to avoid risk-taking, use less effective or superficial learning strategies, and develop a negative self-affect. Lastly, providing an autonomy-supportive environment that allows students to establish some of their own priorities in task completion, method, and pace of learning can also positively influence a mastery goal orientation.

Achievement goal theory was used to characterize the students in this study as mastery goal, performance goal, or work avoidance oriented. This was helpful in assessing whether PBL was likely to be effective with these students.

Situational interest theory. Interest theorists differentiate between two types of interest: individual interest and situational interest (Linnenbrink-Garcia et al., 2010). Individual interest is relatively stable across situations, characterized as a person's long-term, deepening personal connection to a domain. Individual interest deepens as a person acquires knowledge of a domain and comes to value that knowledge and believe in its significance, which in turn inspires curiosity and further exploration of the domain.

Whereas individual interest is related to the disposition of a person across different situations, situational interest (SI) emerges in response to events. SI consists of two forms - "triggered" SI and “maintained" SI. Triggered SI involves arousing or initiating a person's interest. Features that promote triggered SI can influence students' experiences so that they more actively engage in the material. For example, instructors might trigger SI by using colorful examples in lectures or flashy technology. Although these techniques can help students focus on the material while the material is present, triggered SI can be short-lived if the environment does not continue to support it. 
Maintained SI is a deeper form of SI in which a person forms meaningful connections with the content and realize its deeper significance. Learning contexts can promote maintained SI if they cause individuals to feel empowered by what they learn in a given situation. For example, certain classroom activities might encourage students to think about the importance of the course material, which can maintain and even increase their SI.

Although individual interest and situational interest are conceptually different, SI can grow into individual interest. Triggered SI can ignite students' attention, but individual interest won't necessarily be formed without the necessary link of maintained interest. Once students become immersed in the course material, those who perceive it to be enjoyable and meaningful are likely to value the material beyond the course and seek out new opportunities to expand their knowledge in that domain.

Adapted motivation framework. In the early stages of this study the researcher did not know which motivation theory would prove to be the best framework to contextualize the results. She also hypothesized that each theory could help explain a piece, but perhaps not all, of the story. Because each theory presents a different perspective of motivation, the theories cannot be used interchangeably; however, they can be synthesized to generate a more holistic understanding of the phenomenon of motivation.

Hence the "adapted motivation framework" used in this study was created by weaving together elements of motivation theory that seemed most relevant to understanding the link between PBL and student achievement motivation. For example, how does self-determination theory help us understand the role of autonomy in PBL? How does expectancy-value theory help us understand the influence of value and ability-related beliefs on students' persistence in PBL? How does situational interest theory help us understand interest shifts in students as they experience PBL? And how does achievement goal theory help us understand why some students may be better equipped to succeed in PBL?

Figure 2.2 presents this adapted motivation framework. The "factors of motivation" are the factors that can support or undermine a person's motivation in a given situation. The "indicators of motivation" are the characteristics of a person that can help indicate his or her level of motivation in a given situation. The adapted motivation framework will appear again in Chapter 4 as it informed the research methodology and research methods design. 
FACTORS OF MOTIVATION

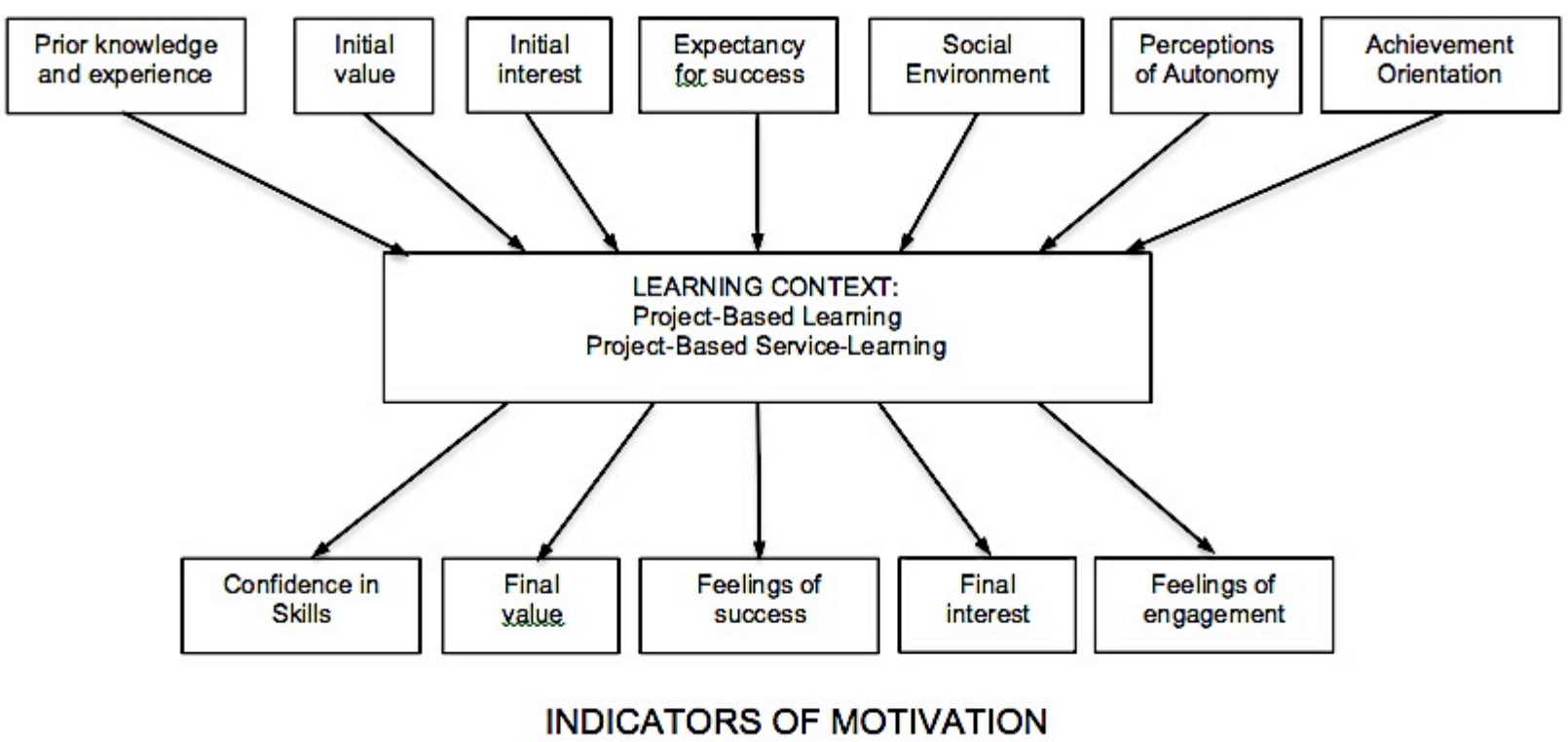

Figure 2.2: Adapted motivation framework 


\section{Chapter 3}

\section{Research Setting}

\section{Research Participants}

This study involved students at the University of Colorado at Boulder over a span of three years (including one pilot year of research in 2010). The students were junior-level Mechanical Engineering students in Component Design, a required course for their major that teaches fundamental design and analysis of mechanical components.

Table 3.1 shows the general demographic characteristics of the two cohorts. It should be noted that these characteristics were self-reported by the students and hence do not represent exact values. Students in the 2012 cohort were more reluctant to report demographic information. This is reflected in the smaller percentages of female, underrepresented minorities, and first-generation college bound students in the 2012 cohort. However, as will be discussed in Chapter 5, there were no statistically significant differences between the cohorts in terms of demographic characteristics.

Table 3.1: Demographic characteristics of study participants

\begin{tabular}{|l|l|}
\hline 2011 PBL Control Group & $\mathbf{2 0 1 2}$ PBSL Treatment Group \\
\hline 128 students & 127 students \\
\hline $79 \%$ male; $21 \%$ female & $89 \%$ male; $11 \%$ female \\
\hline $78 \%$ age $18-21$ & $80 \%$ age $18-21$ \\
\hline $58 \%$ reported "moderate" family income level & $57 \%$ reported "moderate" family income level \\
\hline $13 \%$ first-generation college bound & $7 \%$ first-generation college bound \\
\hline $10 \%$ underrepresented minority & $3 \%$ underrepresented minority \\
\hline
\end{tabular}

\section{Course Structure}

The course had a lecture component as well as a laboratory component. The lecture sessions were held twice a week for 75 minutes each and were designed to introduce new concepts, do interactive exercises, practice new material in a group session, and give students feedback on homework assignments and exams. Lectures were supplemented with laboratory sessions, which were held once a week for two hours. Laboratory sessions included hands-on activities, training seminars, machining and fabrication techniques, and project group meetings. Most of the laboratory sessions were dedicated to the semesterlong project.

Homework was assigned weekly and included originally developed real-world design problems such as designing a component to meet a specific need and selecting a real component using the Internet. 
Teaching assistants (TAs) were present at each lecture and were also available outside of lecture to help answer students' homework and group work questions.

The semester-long project was a major focus of the course and comprised $40 \%$ of students' final course grades (in lieu of a final exam). In spring 2011, the control group (128 participants) engaged in a conventional PBL experience by designing and fabricating aesthetically pleasing drill-powered vehicles. In spring 2012, the treatment group (127 participants) engaged in a PBSL experience by designing and fabricating adapted tricycles for children in the community with physical disabilities.

For both projects, every team was assigned a peer mentor - a senior Mechanical Engineering student who had taken Component Design the year prior - who helped each team run meetings, prepare meeting agendas, answer design questions, and grapple with various stages of the design process. Student teams also had access to a design lab with a dedicated staff member, Jerry, to assist with various machining and fabrication tasks.

At the start of the project, students were instructed to select their own project teams with no more than five students per team. Additionally, each student had to select a project role. The available project roles were Project Manager, Technical Director, and Communications Director. Each of the project roles and associated activities were described to the students in a training seminar. Additional training seminars covered project topics such as team dynamics, how to prepare meeting minutes and agendas, and technical writing.

The fundamental learning objectives of the project were the same for both cohorts:

- Learn professional skills essential for engineering including project management, working in a team, and technical design report writing

- Plan and implement the stages of the design loop

- Learn how to practically apply Component Design concepts

- Learn how to research information not explicitly given in a formal classroom setting

Additional learning objectives were specific to each project and described in the proceeding sections.

\section{Drill-Powered Vehicle Project}

The challenge presented to the students was to build an aesthetically-pleasing vehicle that could be powered by a standard cordless electric drill and driven by one of the team members. Other project requirements included:

- Height of the drill-powered vehicle and driver could be no more than 3'6"

- Driver had to complete a given obstacle course

- Select the chassis, the components, and the appropriate drill for the project within a $\$ 200$ budget 

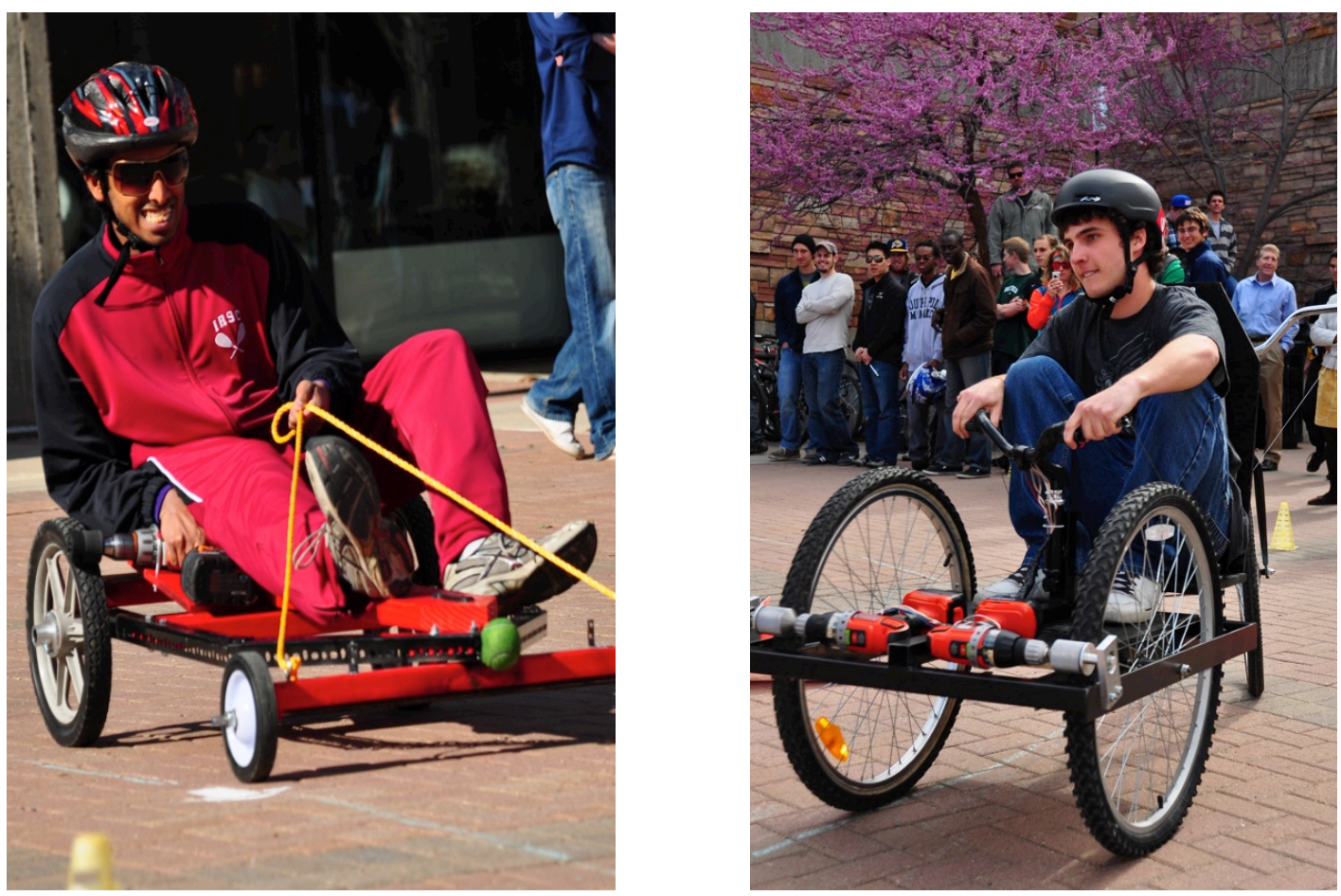

Figure 3.1: PBL control group: drill-powered vehicle project

Friendly competition was a major element of the project. The obstacle course or "run-off" served as the culminating event, where each team was evaluated on their vehicle's functionality, height requirement, vehicle performance (course completion time and power-to-weight ratio), and vehicle safety. The run-off, held in the main quad outside the Engineering Center, was lively and well-attended by approximately 75 additional students and faculty.

\section{Adapted Tricycles Project}

The challenge presented to the students was to design and fabricate adapted tricycles for children and one young adult in the community with physical disabilities. The idea for the project was inspired by a radio show that featured a local non-profit organization that provides durable medical equipment such as walkers and wheelchairs and other mobility devices to children whose families are underinsured or uninsured.

The instructor of Component Design and the researcher of this study contacted the director of this nonprofit and asked if he wanted to participate in the project by providing the names of several families who might be willing to serve as project clients. In return for meeting with each project team several times 
throughout the duration of the project as well as attending the design expo at the end of the semester, each project client would receive a custom-built adapted tricycle.

Five families were willing to participate. Because there were many more project teams than clients, each client was assigned to five teams who then competed against each other to produce the best design for their client. Student teams were not allowed to choose their client; however, special consideration was given to assigning Spanish-speaking students to the family who spoke little English.

To initiate the project, each student team conducted a needs assessment with their client's family and physical therapist to identify their client's specific needs, including the nature of the disability, range of motion and strength, movement patterns, and goals for mobility. Other project requirements included:

- Meet weight and size constraints

- Ensure safety and comfort

- Select the tricycle frame, gearing system, and all other components within a \$300 budget (higher budget allotted for this project to make safety a priority)

- Deliver a functional prototype to the client

Similar to the drill-powered vehicles project, the culminating event of the adapted tricycle project was a "design expo" where the teams presented their tricycles to their clients and to faculty design judges. After test riding each tricycle, the clients adopted their favorite. With the help of several local non-profit organizations in the community, the remaining tricycles have been placed with other families.
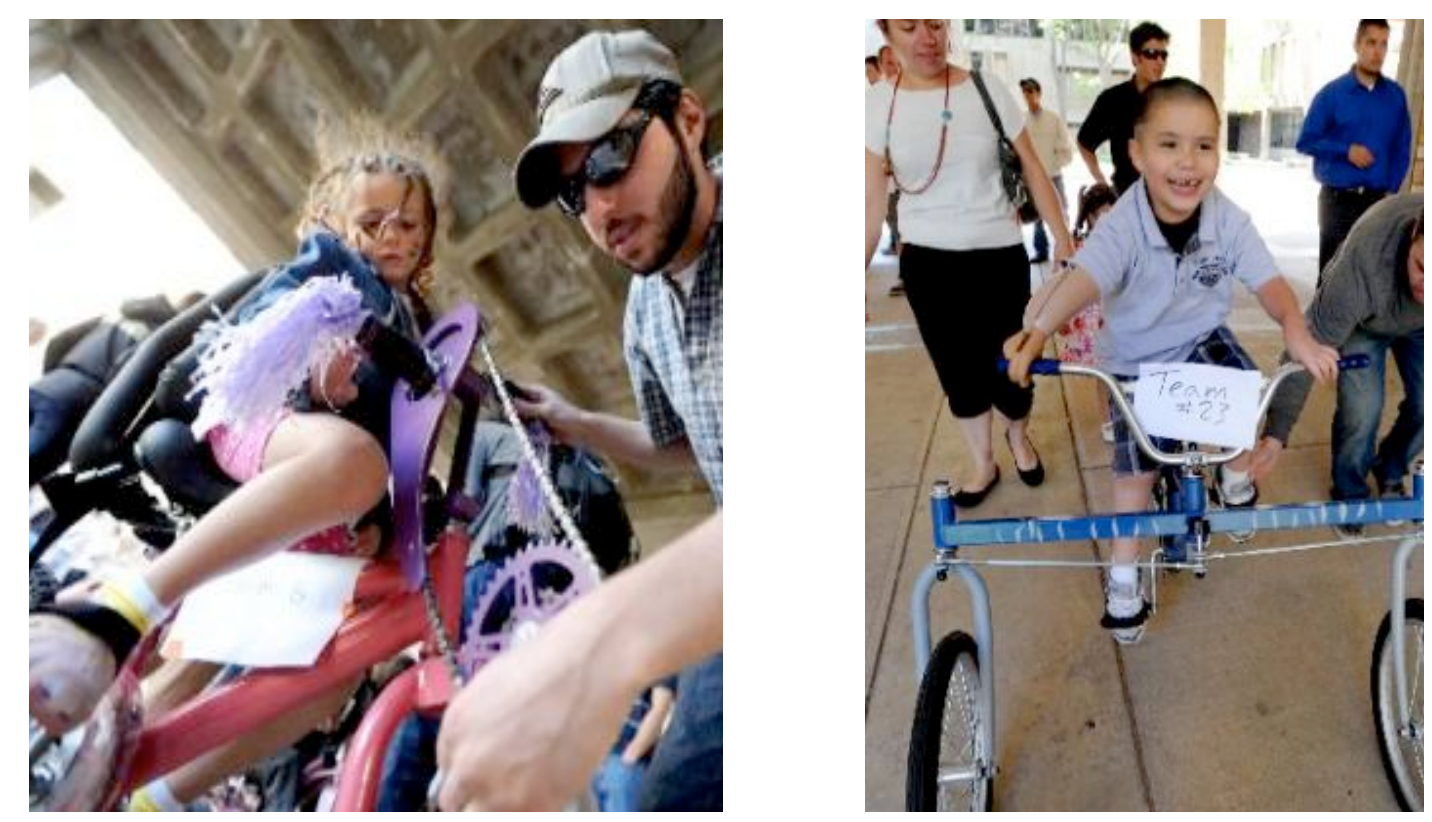

Figure 3.2: PBSL treatment group: adapted tricycles project 
Overall, the adapted tricycles project required significantly more time on part of the students and faculty than did the drill-powered vehicle project. Each client had a unique set of needs, resulting in customized design requirements, which in turn raised a myriad of questions from the students. Safety was a top concern; hence the budget for the project had to be increased in the middle of the project to discourage teams from cutting corners by fabricating with lower-quality components and materials. There was also great deal of logistics involved with the students meeting the families. Many teams wanted to meet with their clients more than their clients could accommodate given their busy schedules. Also, in the case of the Spanish-speaking family, not all students were able to speak directly with the client and had to rely on their team's translator.

\section{Project Closure}

Following both projects' culminating events, the instructor held a lecture dedicated to closing out the project with the students and teaching assistants. Awards were presented to the winning teams, and students engaged in a reflective discussion about their project experiences. 


\section{Chapter 4}

\section{Methodology and Methods}

Crudely, methods are best understood as the tools and procedures we use for our inquiries and methodology is about the framework within which they sit. Glynis Cousin

\section{Methodology}

Justification of methodology. A methodology is the reasoning behind the choice and use of certain research methods and how the methods link to an overriding theoretical perspective (Case and Light, 2011). During the preliminary stages of this study it was not planned to investigate student motivation but rather to assess the impact of PBL vs. PBSL on students' knowledge gain and skill development. However, after administering pre-course and post-course pilot surveys to the 2010 cohort of Component Design students as well as performing weekly observations of student teams engaged in a conventional PBL experience, some interesting patterns emerged that changed the course of this research.

First, even within a single project team, there appeared to be a great deal of variety in the way students approached learning situations and performed tasks. Some students tackled the project with vigor while others demonstrated apathy. Second, it appeared that the more eager and engaged students possessed great course and project interest, value, and confidence in their abilities. These two general observations suggested that the PBL experience was affecting more than just students' knowledge and skills gain and was also impacting engagement and persistence decisions. As a result, the research was refocused to more directly study student achievement motivation in the course and the project using an adapted motivation framework.

Considering the overall aim of this study - to understand students' subjective experiences in a given context - a "situational perspective" was adopted as the theoretical perspective of this study. According to Crotty (1998), a theoretical perspective is the "philosophical stance informing the methodology and thus providing a context for the process and grounding of its logic and criteria." A review of the theoretical perspectives used in engineering education research is beyond the scope of this study; however, a distinction will be noted between situational perspectives and the theoretical perspectives of positivism/post-positivism.

According to Koro-Ljungberg and Douglas (2008), the positivist/post-positivist perspective assumes one single falsifiable reality, and the purpose is generally to find cause-and-effect relationships among variables. The methods are predetermined, and the desired outcome is a context-free generalization. The situational perspective, on the other hand, assumes multiple subjective realities, and the purpose is to 
describe a situation, experience, or phenomenon. The research methods and approaches are inductive, emerge during the research, and can be adjusted during the study. The overall outcome is a situated description of the phenomenon of interest. As the major goal of this study was to produce a contextualized description of student motivation in a project-based experience, a situational theoretical perspective was most appropriate.

\section{Mixed-method approach.}

"In considering approaches to motivation enhancement, it is important to note that motivation is too often equated with quantitative changes in behavior (i.e. higher achievement, more time on task) rather than qualitative changes in the way students view themselves in relation to the task, engage in the process of learning, and then respond to the learning activities and situation. A qualitative approach to student motivation is concerned with how students think about themselves in relation to learning activities and the process of learning itself." Carol Ames

Creswell and Plano Clark (2010) describe qualitative approaches as "enabling inquiry into understanding of a social or human condition, experience or problem, based on building a complex, holistic picture, formed textually and analyzed inductively." During the 2010 pilot study, it became apparent that quantitative evidence alone would be insufficient to understand student motivation, as it is a complex and subjective phenomenon. Hence, understanding student motivation required the addition of a qualitative approach to gain an in-depth narrative of students' perceptions of interest, value, feelings of success, competence, and other experiences in the course and the project.

With the aim of generating this holistic picture of student achievement motivation by drawing on the strengths of both quantitative and qualitative approaches, the research design for this study evolved into a sequential explanatory mixed-methods study, which is a procedure for collecting, analyzing, and "mixing" or integrating both quantitative and qualitative data at some stage of the research for the purpose of gaining a better understanding of the research problem. Mixed methods are appropriate for research problems in which: 1) one data source proves insufficient and a secondary method is needed to enhance the primary methods; 2) results needs to be explained in more depth; 3) exploratory findings need to be generalized; 4) a theoretical stance needs to be employed; 5) the overall research objective can best be addressed with multiple phases (Ivankova, Creswell, and Stick, 2006).

Creswell and Plano Clark (2010) outline the core characteristics of mixed-methods research: 1) collecting and analyzing both quantitative and qualitative data based on the given research questions; 2 ) mixing the two forms of data by combining them concurrently, sequentially, or embedding one within the other; 3) explicitly giving priority to one or both forms of data; 4) using these procedures in a single study or in multiple phases of a program of study; 5) framing these procedures within philosophical worldviews 
and theoretical lenses; and 6) combining the procedures into specific research designs that direct the plan for conducting the study.

In this study, the quantitative strand included hypothesis testing and factor analysis. The decision to use hypothesis testing was based on the researcher's assumption that statistically significant differences and gains in students' interest, value, ability-related beliefs, and other factors would be observed and serve as a means to evaluate the extent to which each cohort was motivated by the project-based experience. The decision to use factor analysis was based on the researcher's assumption that there were certain characteristics of the students, elements of the project, and a confluence of the two that had the greatest influence on students' achievement motivation. Through factor analysis, these factors of motivation could be identified and could then serve as a set of best practices to inform the design of future project-based experiences.

The qualitative strand included a modified grounded theory approach. According to Strauss and Corbin (1994), grounded theory is a general methodology for "developing theory that is grounded in data and systematically gathered and analyzed." In other words, theory is generated from the data at hand rather than applying a pre-existing theory to the research. Case and Light (2011) state that "pure" grounded theory has limited use in education research where it is often advantageous to use existing theoretical constructs in the analysis. However, they argue that it is a very powerful approach to challenging preconceived ideas to allow for alternative ideas to emerge. In this study, too, traditional grounded theory methodology was modified to allow pre-existing motivation theory to drive the research design and also to contextualize the research findings.

Sequential explanatory design. In addition to selecting the quantitative and qualitative approaches, another important consideration of a mixed-methods study is the type of design. Creswell and Plano Clark (2010) define the six major typology-based designs: convergent parallel; explanatory sequential; exploratory sequential; embedded; transformative; and multiphase. The key decisions involved in choosing the design type are the level of interaction between the strands, the relative priority of the strands, the timing of the strands, and procedures for mixing the strands

For this study it was determined that an explanatory sequential design was most appropriate due to the timing of the data collection and the relative priority of the quantitative strand. An explanatory sequential design occurs in two distinct phases. The first phase includes the collection and analysis of quantitative data, which is given relative emphasis in answering the research questions. The second phase is the collection and analysis of qualitative data and is designed to help explain the quantitative results obtained in the first phase by exploring research participants' view in more depth. Typically, the strands are 
interactive, the quantitative strand is given relative emphasis, the timing of the strands is sequential (quantitative first), and the primary point of interface for mixing is during data collection (Creswell and Plano Clark, 2010).

\section{Methods}

Figure 4.1 is a graphical representation of the sequential explanatory design procedures applied to this study and portrays the sequence of research activities, indicates the priority of the quantitative phase, specifies all data collection and analysis procedures, and lists the products and outcomes from each stage.

\begin{tabular}{|c|c|c|}
\hline PHASE & PROCEDURE & PRODUCT \\
\hline $\begin{array}{l}\text { QUANTITATIVE } \\
\text { Data Collection }\end{array}$ & Administer web-based surveys & Numeric data \\
\hline $\begin{array}{c}\text { Qualitative } \\
\text { Data Collection }\end{array}$ & Run focus groups & $\begin{array}{l}\text { Text data - focus group } \\
\text { transcripts }\end{array}$ \\
\hline $\begin{array}{l}\text { QUANTITATIVE } \\
\text { Data Analysis }\end{array}$ & $\begin{array}{c}\text { Data screening } \\
\text { Frequencies and distributions } \\
\text { Tests of significance } \\
\text { Factor analysis }\end{array}$ & $\begin{array}{l}\text { Removal of missing data, } \\
\text { creation of matched pairs } \\
\text { Assessment of normality, } \\
\text { identification of outliers } \\
\text { Descriptive statistics } \\
\text { Variable importance scores }\end{array}$ \\
\hline $\begin{array}{l}\text { Qualitative } \\
\text { Data Analysis }\end{array}$ & $\begin{array}{c}\text { Code the data } \\
\text { Group codes into categories and } \\
\text { themes }\end{array}$ & $\begin{array}{c}\text { Codebook } \\
\text { Categories and themes }\end{array}$ \\
\hline & $\begin{array}{c}\text { Form smaller sets of categories } \\
\text { and themes }\end{array}$ & $\begin{array}{l}\text { Broad themes representing } \\
\text { major perspectives of students }\end{array}$ \\
\hline $\begin{array}{c}\text { Connecting } \\
\text { Quantitative } \\
\text { and Qualitative } \\
\text { Phases }\end{array}$ & Apply a theoretical framework & $\begin{array}{l}\text { Situated description of student } \\
\text { motivation }\end{array}$ \\
\hline $\begin{array}{l}\text { Integration of } \\
\text { Quantitative } \\
\text { and Qualitative } \\
\text { Results }\end{array}$ & $\begin{array}{l}\text { Evaluate how qualitative data } \\
\text { enhanced the interpretation of } \\
\text { the quantitative data }\end{array}$ & $\begin{array}{l}\text { Meta-inferences } \\
\text { Discussion } \\
\text { Implications } \\
\text { Future research }\end{array}$ \\
\hline
\end{tabular}

Figure 4.1: Summary of sequential explanatory design applied to this study 
Quantitative data collection. Identical web-based pre-course and post-course surveys were administered to both the PBL control and PBSL treatment groups. Surveys were homegrown but informed by survey questions used in the Classroom Survey of Student Engagement, a classroom-level adaptation of the National Survey of Student Engagement (National Survey of Student Engagement, 2014) and also informed by previous research studies in expectancy-value theory (Wigfield and Eccles 2000), achievement goal theory (Harackiewicz, Barron, Carter, Lehto, and Elliot, 1997), and situational interest theory (Linnenbrink-Garcia et al., 2010).

The pre-course survey consisted of 26 questions and gathered data about student demographics and student characteristics, students' initial interest and value for both the course and the project, initial confidence in non-technical skills, initial confidence in technical skills specific to Component Design, initial attitude toward service-learning, and expectancy of success in the course and project. Excluding some of the "yes/no" items pertaining to student demographics, all survey questions were formed using four-point or five-point Likert-type scales. The pre-course survey questions were combined to form a set of 17 variables, as shown in Table 4.1.

Table 4.1: Pre-course variables

\begin{tabular}{|c|c|}
\hline Variable & Description \\
\hline Age & Age of student \\
\hline Family income & Family income bracket \\
\hline First-generation college bound & Student the first in his or her immediate family to attend college \\
\hline Gender & Gender of student \\
\hline Underrepresented minority & $\begin{array}{l}\text { Student identifies as African American, Hispanic, or Native } \\
\text { American }\end{array}$ \\
\hline Achievement orientation & $\begin{array}{l}\text { The motive behind a student's desire to excel; conceptualized as } \\
\text { a relatively stable personality trait }\end{array}$ \\
\hline \multicolumn{2}{|c|}{ INITIAL MOTIVATION, SKILLS, AND ATTITUDES } \\
\hline Variable & Description \\
\hline $\begin{array}{l}\text { Attitude toward service- } \\
\text { learning }\end{array}$ & $\begin{array}{l}\text { Level of agreement that community service and academic } \\
\text { coursework should be combined }\end{array}$ \\
\hline $\begin{array}{l}\text { Expectancy for success in } \\
\text { course }\end{array}$ & Confidence in successfully learning the course material \\
\hline $\begin{array}{l}\text { Expectancy for success in } \\
\text { project }\end{array}$ & Confidence in succeeding in the course project \\
\hline
\end{tabular}




\begin{tabular}{|l|l|}
\hline Initial course experience & Previous experience with machine design topics \\
\hline Initial project experience & $\begin{array}{l}\text { Previous experience with mechanical engineering design } \\
\text { projects }\end{array}$ \\
\hline Initial course interest & Incoming interest for machine design topics \\
\hline Initial project interest & Incoming interest for mechanical engineering design projects \\
\hline Initial course value & Perceived value of machine design course topics \\
\hline Initial project value & Perceived value of course project \\
\hline Initial non-technical skills & $\begin{array}{l}\text { Self-rated confidence level of non-technical skills: technical } \\
\text { writing, oral presentation skills, ability to present ideas to a } \\
\text { non-technical audience, ability to identify the needs of a client, } \\
\text { ability to work on a team, and ability to work with non- } \\
\text { engineers }\end{array}$ \\
\hline Initial technical skills & $\begin{array}{l}\text { Self-rated confidence level of technical skills specific to } \\
\text { machine design }\end{array}$ \\
\hline
\end{tabular}

The post-course survey consisted of 17 questions and gathered data about students' final interest and value for both the course and project, final confidence in non-technical skills, final confidence in technical skills specific to Component Design, final attitude toward service-learning, and feelings of success in the course and the project. Similar to the pre-course survey, all survey questions were formed using four-point or five-point Likert-type scales. The post-course survey questions were combined to form a set of 10 variables, as shown in Table 4.2.

Table 4.2: Post-course variables

\begin{tabular}{|c|c|}
\hline Variable & Description \\
\hline $\begin{array}{l}\text { Attitude toward service- } \\
\text { learning }\end{array}$ & $\begin{array}{l}\text { Level of agreement that community service and academic } \\
\text { coursework should be combined }\end{array}$ \\
\hline Engagement & $\begin{array}{l}\text { Students' perceptions of how often they participated in class } \\
\text { discussions, interacted with the professor, helped a peer } \\
\text { understand course material, and worked harder than expected }\end{array}$ \\
\hline Feelings success in course & Feelings of successfully learning the course material \\
\hline Feelings of success in project & Feelings of succeeding in the project \\
\hline Final course interest & Final interest for machine design topics \\
\hline Final project interest & Final interest for mechanical engineering design projects \\
\hline
\end{tabular}




\begin{tabular}{|l|l|}
\hline Final course value & Perceived value of machine design course topics \\
\hline Final project value & Perceived value of project \\
\hline Final non-technical skills & $\begin{array}{l}\text { Self-rated level of non-technical skills such as technical writing, } \\
\text { ability to identify needs of a client, and ability to work with } \\
\text { non-engineers }\end{array}$ \\
\hline Final technical skills & Self-rated level of technical skills specific to machine design \\
\hline
\end{tabular}

Although all of the students were required to complete the surveys online for a portion of their homework grade, some students did not complete both surveys or did not complete a portion of one or both surveys. These students were removed from the two samples to achieve matched pairs. See Appendix A for copies of the pre-course and post-course surveys administered to the students.

Qualitative data collection. Three 60-minute focus groups were held with students from both the PBL control group and the PBSL treatment group one week after the culmination of the project. Krueger (1994) describes focus groups as purposefully-planned discussion groups that aim to gather perceptions on a specific topic from a predetermined and limited number of people. Because people are naturally influenced by the comments and opinions of others, focus groups can capture people's socially constructed thoughts, attitudes, and beliefs. Inhibitions soften in a group setting, so focus groups can encourage candor as well as allow the researcher to explore unanticipated discussion issues. One of the disadvantages of focus groups is that the researcher has less control as compared to an individual interview in terms of the course of the discussion and the raising of irrelevant issues. Also, the data can be more difficult to analyze. As focus groups create a social environment, comments must be interpreted within the group context.

In this study, the main purpose of the focus group interviews was to create a socially-constructed group perspective regarding the affect of PBL on students' achievement motivation to help explain some of the trends present in the quantitative data. During the focus groups, the questions were posed to the participating students in an open-ended manner and focused on aspects of both the course and the project that were most and least valuable to the students, how students' interest in Component Design changed over the course of the semester, the technical and non-technical skills that were gained from the project, how the project impacted students' excitement, and the types of challenges students encountered while working on a team. Participation in the focus groups was voluntary, and each focus group was audio recorded while another faculty member (external to this research) took notes to facilitate the transcription process. See Appendix A for the focus group questions used as well as the consent form given to each student. 
Assessment timeline. Table 4.3 outlines the timeline for the administration of the pre-course surveys, post-course surveys, and focus groups.

Table 4.3 Assessment timeline

\begin{tabular}{|l|l|l|}
\hline INSTRUMENT & TIME ADMINISTERED & DATA COLLECTED \\
\hline Pre-course survey & $\begin{array}{l}\text { January 2011 } \\
\text { (PBL control group) } \\
\text { January 2012 } \\
\text { (PBSL treatment group) }\end{array}$ & $\begin{array}{l}\text { Student demographics, prior knowledge and } \\
\text { experience, initial value and interest, attitude } \\
\text { toward service-learning, expectancy for success, } \\
\text { achievement orientation, and self-rated technical } \\
\text { and non-technical skills }\end{array}$ \\
\hline Post-course survey & $\begin{array}{l}\text { May 2011 } \\
\text { (PBL control group) } \\
\text { May 2012 } \\
\text { (PBSL treatment group) }\end{array}$ & $\begin{array}{l}\text { Indicators of motivation including maintained } \\
\text { interest and value, feelings of success, attitude } \\
\text { toward service-learning, feelings of engagement, } \\
\text { and self-rated gains in technical and non-technical } \\
\text { skills }\end{array}$ \\
\hline Focus groups & $\begin{array}{l}\text { May 2011 } \\
\text { (PBL control group) } \\
\text { May 2012 } \\
\text { (PBSL treatment group) }\end{array}$ & $\begin{array}{l}\text { Students' perceptions of course and project value, } \\
\text { elements of course and project that sustained } \\
\text { interest and enhanced engagement, technical and } \\
\text { non-technical skills gained, and challenges } \\
\text { encountered }\end{array}$ \\
\hline
\end{tabular}

Quantitative data analysis. The quantitative data were prepared for analysis by converting the raw data obtained from the online surveys into a more usable format by assigning numeric values to the students' responses and organizing this information in a spreadsheet format. Data entry errors were removed from the database, matched pairs were created, and the variables outlined in Tables 4.1 and 4.2 were formed. The data was then explored by creating histograms and boxplots to visually assess broad trends in the data and to determine the shape of the distribution for each variable. Understanding the shape of the distributions is crucial to selecting the appropriate statistical tests to apply.

The process of analyzing the data included Wilcoxon rank-sum tests for hypothesis testing and random forest analysis for identifying variable importance. The Wilcoxon rank-sum test is a non-parametric statistical hypothesis test for assessing whether one of two samples of independent observations tends to have larger values than the other (Navidi, 2010). This test was appropriate due to the fact that the data was predominantly non-normally distributed (see Appendix B for a presentation of the distributions for each variable). Wilcoxon rank-sum tests were used to determine statistically significant differences 
between the PBL control group and the PBSL treatment group in terms of student demographics and characteristics, and initial motivation, skills, and attitudes.

Random forest analysis was used to estimate the importance of each variable in predicting student motivation. Random forest analysis was developed by Leo Breiman and Adele Culter (2012) and is an analysis technique that falls under the broader category of "ensemble learning" - methods that generate many classifiers and aggregate their results (Hastie, Tibshirani, and Friedman, 2011). Essentially, random forests can be used to measure the prediction strength of a set of variables by looking at how much the prediction error increases when a subset of the data is permuted while the rest is left unchanged (Liaw and Weiner, 2002).

For example, an initial hypothesis might be that students' prior interest in service-learning is an important predictor of students' engagement in PBSL. Each student can be partially characterized by this pair of variables. The random forest algorithm "scrambles" these variables in such a way so that one student's level of initial interest in service-learning is used to predict another student's level of engagement in PBSL. If this process causes the predictor error to increase, it is an indication that students' prior interest in service-learning is, in fact, an important predictor of student engagement in PBSL.

Fundamental to understanding random forests is the understanding of decision trees, which form the basic "unit" of a random forest. A single decision tree is used to create a model that predicts the value of a target variable based on several input variables. Decision trees are of two main types: classification trees and regression trees (Prasad, Iverson, and Liaw, 2006). Classification trees are used when the predicted outcome is a class to which the data belongs. Regression trees are used when the predicted outcome is a real, continuous number. In this study the desired predicted outcome was a set of classes; hence, what follows is a more detailed explanation and example of the use of a classification tree.

Classification trees predict categorical responses by partitioning the data into different regions in which the predicted outcome, or classification, is the same in each region. There is no limit to the amount of input (predictor) variables that can be used to grow a tree due to the fact that the tree growing algorithm automatically selects the best input variables and split points for those variables in order to minimize the misclassification rate (Mendez, Buskirk, Lohr, and Hagg, 2008). For example, Figure 4.2 shows a classification tree from a research study completed by Mendez, et al. (2008) that used classification trees to understand how certain variables (i.e. student demographics, GPA, SAT scores, economic status, etc.) impacted students' persistence in earning a STEM (science, technology, engineering, or mathematics) degree at Arizona State University. 
In the classification tree in Figure 4.2, terminal nodes 1 through 7 are labeled with a " $Y$ " and "N" which indicates whether students did or did not persist in their STEM degree. The 1 or 2 digit integer to the left of the parenthesis indicates the actual number of students who were classified at that node, and the percent within the parenthesis indicates the percentage of students who were correctly classified. Figure 2 also shows how the tree-growing algorithm chose students' high school GPA (HSGPA), ethnicity (ETHNIC), and quantitative SAT score (SATQ) as the best variables to split the data at each node. The algorithm also chose the best split points, or values, to minimize misclassification. For example, at terminal node 1, 181 students were classified as "non-persisters" based on a split point value of high school GPA less than 3.595. The percent of correct classification at this node is $87 \%$.

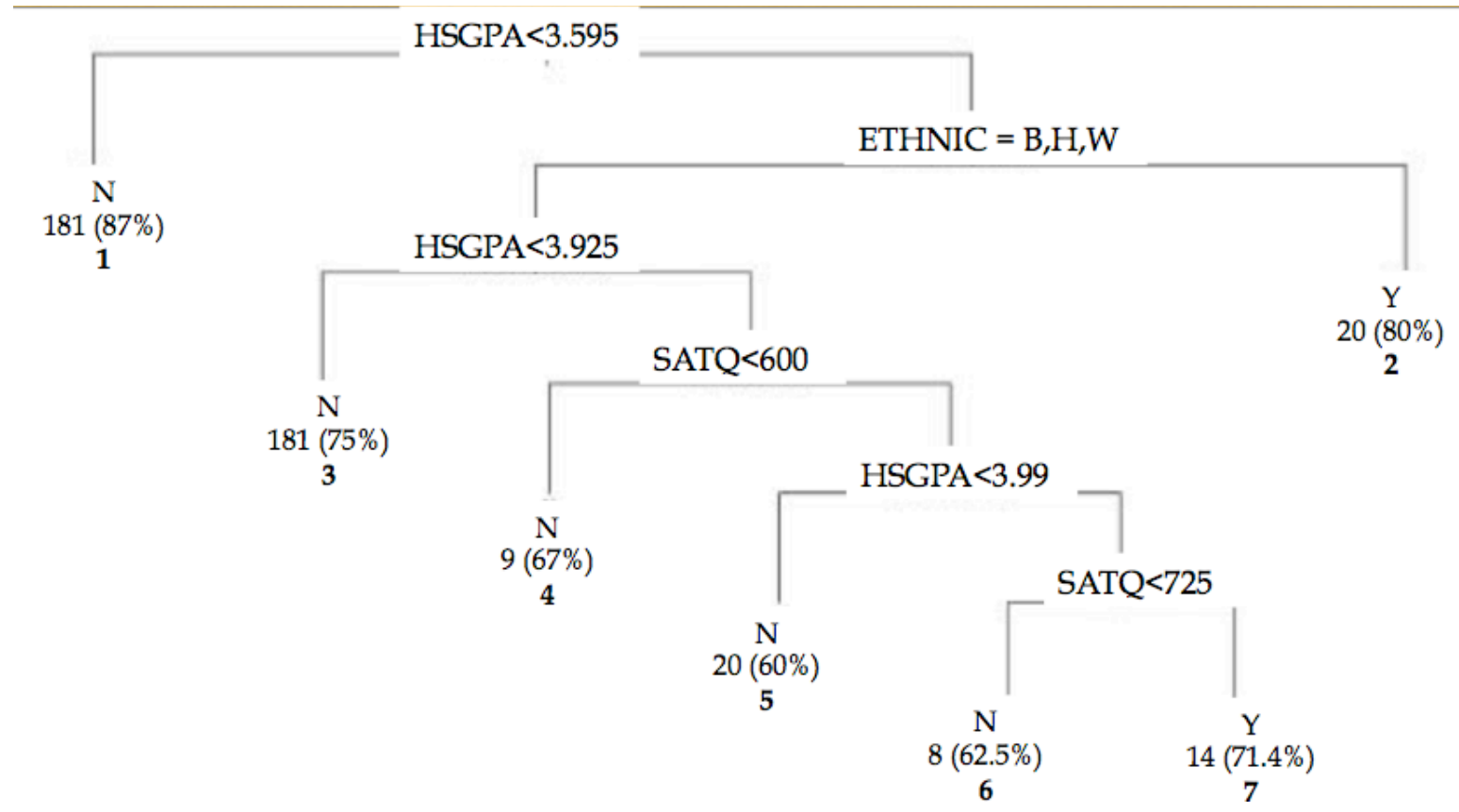

Figure 4.2: Example classification tree from Mendez, et al. (2008)

One issue with classification trees is the consequence of misclassifying observations by growing the tree so large so they "overfit" the data by making predictions that are too specific to fit the actual data structure (Prasad, et al, 2006). On the other hand, growing a tree that is too small can fail to capture the important structure of the data. Using the example of STEM persistence, the consequences of misclassification by overfitting could result in predicting that a student will persist in her degree when she actually won't. This scenario might be worse than the converse - predicting that a student won't persist in her degree when she actually will. The former scenario may represent greater consequences, especially if there was some faculty intervention that could have occurred had the student been correctly classified as a 
"non-persister". Another issue with trees is their high variance. Often a small change in the data can result in a very different series of splits, making interpretation difficult. Due to the hierarchical structure of the tree where an error in the top split is propagated down to all the splits below (Prasad, et al, 2006)..

One technique that can be used to reduce variance and classification error is "bagging." (Hastie, Tibshirani, and Friedman, 2011). Bagging is a method characterized as "ensemble learning," which is a group of methods that generate many classifiers and aggregate their results. In bagging, many trees (typically 30-50) are used to make predictions about the data, and each tree is independently grown using a bootstrapped sample of the data. The data not used in the training set, termed "out of bag" data can be used to provide better estimates of errors. In the end, a simple majority vote from all trees is taken for prediction. In other words, the bagging procedure grows many single classification trees, where each tree predicts a set of categorical responses from the data. The final predictions are simply a majority vote among all the trees.

Very similar to bagging is random forests, which adds an additional layer or randomness to the bagging procedure (Hastie, Tibshirani, and Friedman, 2011). In addition to constructing each tree using a different bootstrapped sample of the data, random forests change how decision trees are grown. For a tree grown in a "non-random" forest (i.e. bagging), each node is split using the best split among all variables. For a tree grown in a random forest each node is split using the best split among a subset of predictors randomly chosen at that node. Next, similar to bagging, the results aggregated by averaging the classification votes among all the trees. Due to this extra mechanism of randomization, random forests can handle variables that are highly correlated and hence serve as an alternative to more traditional methods such as logistic regression, where important predictors of motivation may not be deemed significant because of their high correlation with other predictors (Liaw and Weiner, 2002).

One of the caveats to the random forest algorithm is that the predictor variables must be formatted as ordered categorical or continuous, and the response variables must be formatted as binary or continuous. Because of the manner in which the survey questions were designed with students responding to questions on a Likert-type scale (i.e. 1="strongly disagree", 2="disagree", 3="neutral", 4="agree", $5=$ "strongly agree") the predictor variables were already formatted as ordered categorical. However, the response variables were not formatted as binary, which presented a bit of a roadblock. The strategy I chose to employ was to convert the response variables to a binary format by assigning a " 2 " to students' responses that fell in the "agree" or "strongly agree" category and by assigning a " 1 " to students" responses that feel in the "neutral", "disagree", or "strongly disagree" category. Table 4.4 illustrates this procedure. 
Table 4.4: Random forest converting raw responses to appropriate variable type

\begin{tabular}{|c|c|c|}
\hline $\begin{array}{c}\text { Raw response } \\
\text { (from survey) }\end{array}$ & $\begin{array}{c}\text { Response as ordered } \\
\text { categorical variable }\end{array}$ & $\begin{array}{c}\text { Response as binary } \\
\text { variable }\end{array}$ \\
\hline Strongly agree & 5 & 2 \\
\hline Agree & 4 & 2 \\
\hline Neutral & 3 & 1 \\
\hline Disagree & 2 & 1 \\
\hline Strongly disagree & 1 & 1 \\
\hline
\end{tabular}

In this study the random forest method allowed the researcher to explore the relationships among the "predictor variables" (student demographics and characteristics, initial course and project value, initial course and project interest, initial experience, ability-related beliefs, expectancy for success, and attitude toward service learning), the "learning context" (PBL and PBSL), and the "response variables" (final course and project value, final course and project interest, feelings of success, and feelings of engagement). Figure 4.3 shows the set of predictor variables that were used to estimate the importance of each response variable. This figure is nearly identical to the adapted motivation framework presented in Chapter 2, which described the various factors and indicators of motivation.

Predictor variables used in random forest analysis

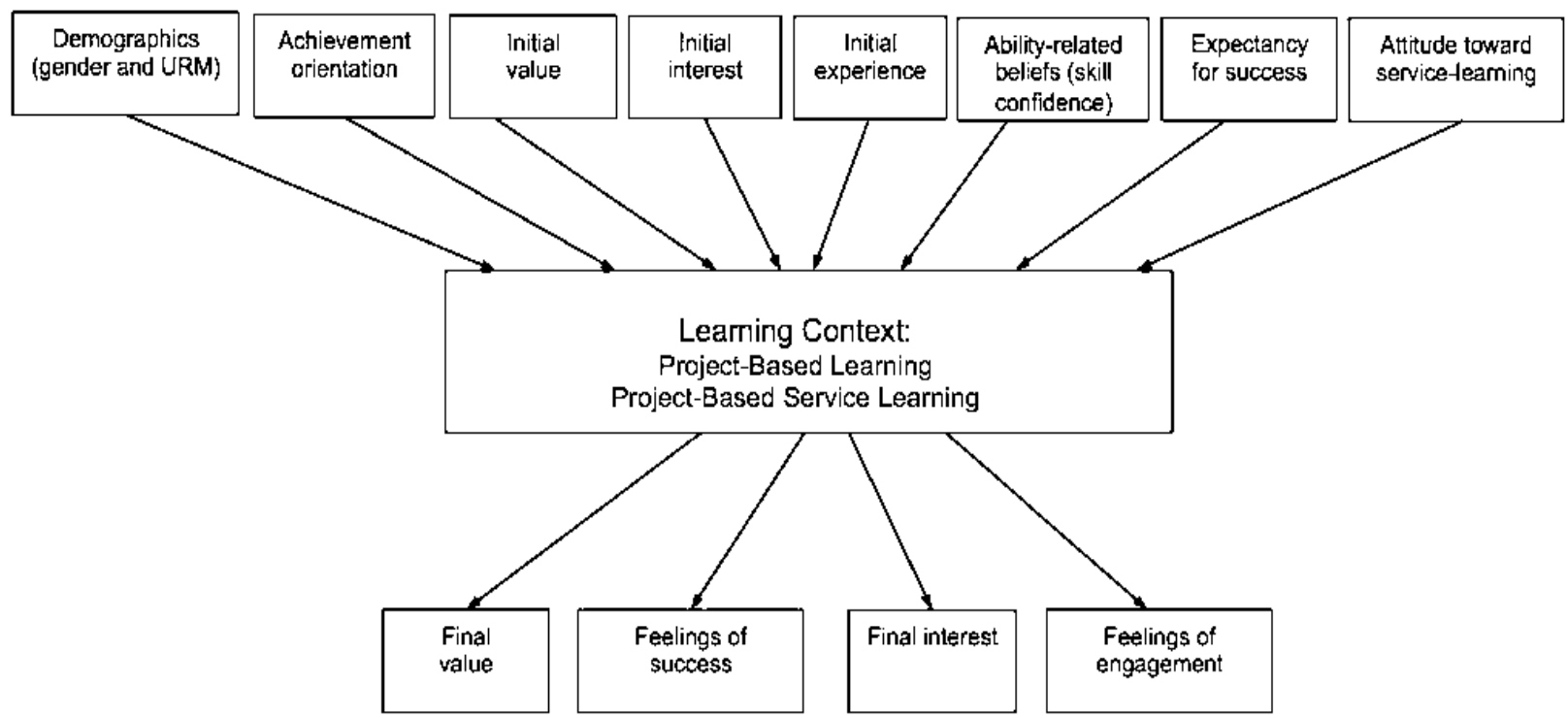

Response variables: indicators of achievernent motivation

Figure 4.3: Predictor variables, learning context, and response variables 
Qualitative data analysis. Following the focus groups held with each cohort, the qualitative data were prepared for analysis. Preparing the data involved transcribing text from the audio files into a word processing file. Pseudonyms were assigned to each student, and the transcriptions were checked for accuracy before each transcription was entered into MAXQDA, a qualitative data analysis software program. The original audio files for the focus groups were then destroyed to protect the anonymity of the students.

The constant comparison method, which is a central data collection method in grounded theory methodology, was then used to analyze the data. This method combines inductive category coding with a simultaneous cross-comparison of all data observed (Goetz and LeCompte, 1981). In other words, the initial category definitions used to analyze the focus group data were conceived from the transcriptions themselves and were further defined as more data was considered.

The first step in using the constant comparison method in this study was to explore the qualitative data, which involved reading through the focus group transcripts and recording initial thoughts in the form of short phrases and ideas to gain a general understanding of the database. These short phrases and ideas were expanded to create summaries of each focus group (see Appendix C) that highlighted the dominant themes present in each focus group.

These summaries helped create the initial categories that were then used to begin to code the focus group data. The categorization and coding procedure outlined by qualitative researcher Ian Dey (1993) was heavily referenced. Essentially, the process of coding involved identifying snippets of text from the focus group transcriptions that served as a unit of meaning or "databit" that could be identified or distinguished from the rest of the data. Each of these databits was assigned to one of the categories.

As databits were recorded and classified, they were also compared across categories. Hence, the process of generating the final category set began with the analysis of these initial databits. This process was iterative; as more and more databits were classified, the category set became more refined to better reflect the concepts and themes that emerged. At the same time, this category set was informed by the underlying framework of motivation theory and by the results of the quantitative analysis. 
Table 4.5 shows the final category set that was used to code the qualitative data.

Table 4.5 Final category set

\begin{tabular}{|c|c|}
\hline DESIGN & $\begin{array}{l}\text { Students' descriptions of lessons learned and points of struggle } \\
\text { involved in conceptualizing and engaging in design activities }\end{array}$ \\
\hline Design loop & How students learned and applied an iterative process for design \\
\hline Paper to product & $\begin{array}{l}\text { How students learned that there are a variety of steps involved in } \\
\text { making a product and that it can be a time-consuming process }\end{array}$ \\
\hline Designing for simplicity & $\begin{array}{l}\text { How students learned the advantages of eliminating complexity } \\
\text { from their designs }\end{array}$ \\
\hline Role of analysis & $\begin{array}{l}\text { How students understood the role of analysis in design and the } \\
\text { ways they found analysis versus trial-and-error to be useful }\end{array}$ \\
\hline Missing pieces & $\begin{array}{l}\text { Additional design considerations that students felt should have been } \\
\text { addressed in the course }\end{array}$ \\
\hline Feedback on design & $\begin{array}{l}\text { The quality of feedback students felt they received from course } \\
\text { faculty when experiencing the design process }\end{array}$ \\
\hline SKILLS AND CONFIDENCE & $\begin{array}{l}\text { Students' perceptions of their own skill levels and confidence } \\
\text { development and the skill levels and confidence development of } \\
\text { their peers.। }\end{array}$ \\
\hline $\begin{array}{l}\text { Prior machining and fabrication } \\
\text { experience }\end{array}$ & $\begin{array}{l}\text { Students' prior machining and fabrication experience and the } \\
\text { additional instruction they felt was needed }\end{array}$ \\
\hline $\begin{array}{l}\text { Machining and fabrication skills } \\
\text { gained }\end{array}$ & Specific machining and fabrication skills students gained \\
\hline Resources available & $\begin{array}{l}\text { Perceptions of how adequate the available machining and } \\
\text { fabrication facilities were and descriptions of the outside resources }\end{array}$ \\
\hline Computer-aided engineering & Computer-aided engineering skills students gained \\
\hline Writing skills gained & $\begin{array}{l}\text { Development of new technical writing skills and the role of } \\
\text { feedback from the instructor }\end{array}$ \\
\hline Prior writing experience & Prior experience in technical writing and writing in general \\
\hline Meeting minutes/agendas & $\begin{array}{l}\text { Perceptions of how useful students found the mandatory meeting } \\
\text { minutes and meeting agendas }\end{array}$ \\
\hline Time management & $\begin{array}{l}\text { Lessons learned and challenges encountered when scheduling } \\
\text { project tasks, coordinating schedules among team members, and } \\
\text { meeting deadlines }\end{array}$ \\
\hline
\end{tabular}




\begin{tabular}{|c|c|}
\hline Technical communication & $\begin{array}{l}\text { Lessons learned and challenges encountered when communicating } \\
\text { technical ideas and design concepts to each other }\end{array}$ \\
\hline Team dynamics & $\begin{array}{l}\text { Lessons learned, insights gained, and points of struggle associated } \\
\text { with working on a project team }\end{array}$ \\
\hline Role rigidity & $\begin{array}{l}\text { Challenges associated with adhering to project role descriptions in a } \\
\text { manner that hindered team collaboration or the development of new } \\
\text { skills }\end{array}$ \\
\hline Role practice & $\begin{array}{l}\text { How allocating roles to each team member provided a sense of } \\
\text { direction, accountability, and simulated a real-world environment }\end{array}$ \\
\hline Role feedback & $\begin{array}{l}\text { Challenges associated with students understanding how to best } \\
\text { choose a project role and also understanding the tasks expected in } \\
\text { each project role }\end{array}$ \\
\hline Skill assessment & $\begin{array}{l}\text { Suggestions to help more evenly distribute skills among teams by } \\
\text { implementing a skills survey }\end{array}$ \\
\hline Team selection & $\begin{array}{l}\text { Challenges associated with selecting team members to more evenly } \\
\text { distribute skills among teams }\end{array}$ \\
\hline Confidence as engineer & $\begin{array}{l}\text { Course and project elements that influenced students' confidence in } \\
\text { being an engineer }\end{array}$ \\
\hline Engineer disconnect & $\begin{array}{l}\text { Concerns about the gap or disconnect between engineers (those } \\
\text { who design things) and manufacturers (those who fabricate things) }\end{array}$ \\
\hline Senior Design & Perceptions of how this course prepared students for Senior Design \\
\hline SHIFTS & $\begin{array}{l}\text { Significant and meaningful changes in students' interest and } \\
\text { value for the course, the project, and engineering in general }\end{array}$ \\
\hline Interest/value shift & $\begin{array}{l}\text { Events that caused students' interest or value in the course or } \\
\text { project to change }\end{array}$ \\
\hline Memorable & $\begin{array}{l}\text { Aspects of the course and the project that students feel will be most } \\
\text { memorable }\end{array}$ \\
\hline PROJECT ELEMENTS & $\begin{array}{l}\text { Most salient elements of the project affecting achievement } \\
\text { motivation }\end{array}$ \\
\hline Fun and exciting & Aspects of the project that students perceived to be fun and exciting \\
\hline No client & How the absence of a client impacted student motivation \\
\hline Run-off & $\begin{array}{l}\text { How students in the } 2011 \text { cohort experienced the end-of-semester } \\
\text { drill-powered vehicle run-off }\end{array}$ \\
\hline
\end{tabular}




\begin{tabular}{|c|c|}
\hline Competition & How the element of competition influenced student motivation \\
\hline Service opportunities & How the project provided new service opportunities for students \\
\hline Altruism & How the integration of service/altruism influenced motivation \\
\hline Client & How the inclusion of a client influenced motivation \\
\hline Expo & $\begin{array}{l}\text { How students in the } 2012 \text { cohort experienced the end-of-semester } \\
\text { adapted tricycle design expo }\end{array}$ \\
\hline Previous year's project & $\begin{array}{l}\text { Perceptions of the previous years' projects and how these } \\
\text { perceptions impacted students' interest and value for their project }\end{array}$ \\
\hline Course/project integration & $\begin{array}{l}\text { The extent to which students perceived the project to be an integral } \\
\text { versus separate aspect of the course }\end{array}$ \\
\hline Practical/real-world & $\begin{array}{l}\text { Elements of the project that student perceived as real, practical, and } \\
\text { authentic }\end{array}$ \\
\hline Open-endedness & $\begin{array}{l}\text { Reactions to what students perceived to be a partially undefined } \\
\text { solution path or outcome }\end{array}$ \\
\hline Creativity & $\begin{array}{l}\text { The elements of the project that engendered feelings of creativity } \\
\text { and students' perceptions of the role of creativity in engineering }\end{array}$ \\
\hline Camaraderie & $\begin{array}{l}\text { Elements of the course and project that contributed to a sense of } \\
\text { camaraderie and relatedness among students }\end{array}$ \\
\hline Pride & How the project inspired a sense of pride in the students \\
\hline COURSE ELEMENTS & $\begin{array}{l}\text { Most salient elements of the course affecting achievement } \\
\text { motivation }\end{array}$ \\
\hline Theory to practice & $\begin{array}{l}\text { How students feel they were able or will be able to apply } \\
\text { Component Design formulas and theory to real world practice }\end{array}$ \\
\hline Videos/props/demos & $\begin{array}{l}\text { How the in-class videos, props, and demonstrations aided students' } \\
\text { learning of Component Design concepts }\end{array}$ \\
\hline Design HW & $\begin{array}{l}\text { How the homework assignments requiring students to select a } \\
\text { component to meet a given specification aided students' learning of } \\
\text { Component Design concepts }\end{array}$ \\
\hline Workshops & $\begin{array}{l}\text { How the in-class, team-based workshops aided students' learning of } \\
\text { Component Design concepts }\end{array}$ \\
\hline Lecture time & How efficiently lecture time was spent on various items \\
\hline Oral exams & How the oral exams helped students prepare for the in-class exam \\
\hline
\end{tabular}




\begin{tabular}{|l|l|}
\hline Instructor & $\begin{array}{l}\text { Perceptions of the instructor's role in facilitating student learning } \\
\text { and how the instructor contributed to the students' overall course } \\
\text { and project experience }\end{array}$ \\
\hline TAs (Teaching Assistants) & $\begin{array}{l}\text { Perceptions of the TAs roles in facilitating student learning and } \\
\text { how they contributed to the students' overall course and project } \\
\text { experience }\end{array}$ \\
\hline
\end{tabular}

\section{Methodological Soundness}

Questions of methodological soundness include whether appropriate methods were used consistently, how the researcher may have influenced the results, and whether the findings can be applied to other settings (Chism, Douglas, and Hilson, 2010). This includes consideration of internal validity (capturing what is actually occurring in a research setting), reliability (consistency of the methods and findings), objectivity (concerns with research bias), and generalizability (whether the results of the study can inform other cases in addition to the one described).

Several steps were taken to assure methodological soundness in this study. First, the researcher was engaged in the study for a prolonged period of time and examined enough data to feel confident in her interpretations of what was occurring with regard to student achievement motivation. Triangulation (comparing results of) was also used to compare and contrast the results of the quantitative and qualitative data to identify overarching patterns that were supported by both types of data. Divergent cases were also carefully considered and used to modify original explanations. Then, the results were contextualized within a theoretical framework to help understand these patterns.

Peer debriefing with three individuals not involved in this study was an important process for the researcher to understand her own biases and subjectivities and how they were influencing the results. By engaging with others in the interpretation of the data and by keeping a detailed reflexive journal and audit trail, the researcher was able to more fully acknowledge her biases and subjectivities and recognize that her own life experiences, judgments, and interpretations actually served to strengthen the study by infusing the results with meaning.

Lastly, the researcher provided vivid details of the study context, compelling quotations from the study participants, and a thorough explanation of how the results were interpreted within the adapted motivation framework. The goal of this thick description is to give the readers as much information as possible so they can determine whether the results of this study apply to their own cases of interest. 
Connecting quantitative and qualitative strands. Connecting or "mixing" the two strands to develop a situated description of student achievement motivation occurred during data interpretation. The mixing strategy was to apply the adapted motivation framework to bind together the two data sets. For example, the quantitative data analysis indicated that a vast majority of students in both the PBL and PBSL contexts perceived the project to be a valuable experience. However, there were differences between the cohorts in the quality of the value they experienced. Whereas the PBL cohort valued having a fun and exciting project, the PBSL cohort valued the sense of altruism they experienced from working with a real-world client. These differences in the quality of value experienced by the students can be interpreted through the framework of motivation theory.

Integration of quantitative and qualitative results. Lastly, by softening the focus on the direct results of the quantitative and qualitative strands and considering the larger meaning in terms of existing research, theoretical models, and personal experience, the researcher was able to weave together the whole story of student achievement motivation to provide a deeper understanding of the effect of service in PBL on student motivation as well as the factors of PBL experiences that are most influential on student motivation. As will be discussed in Chapter 6, these findings have important implications for the best design of PBL experiences for students and suggest direction for future research. 


\section{Chapter Five}

\section{Results}

"Computers are useless. They can only give you answers." $\sim$ Pablo Picasso

This chapter presents both the quantitative and qualitative results of this study. The quantitative results include histograms and boxplots for each variable assessed in the pre-course and post-course surveys, the results from the Wilcoxon Rank-Sum hypothesis tests, and the results of the random forest analysis. The presentation of the quantitative results ends with a series of investigative questions inspired by the quantitative results. These questions were then used to explore the focus groups and help guide the qualitative analysis. The presentation of the qualitative results includes the six major themes uncovered from the qualitative analysis along with student testimonials from the focus groups to support each theme.

\section{Quantitative Results}

Histograms and boxplots. Histograms and boxplots were created for each pre-course and postcourse variable to visually assess broad trends in the data and to determine the shape of the distribution for each variable. As presented in Table 4.1, the pre-course variables were: student demographics and student characteristics; students' initial interest and value for both the course and the project; initial confidence in non-technical skills; initial confidence in technical skills specific to Component Design; initial attitude toward service-learning; and expectancy of success in the course and project. As presented in Table 4.2, the post-course variables were: students' final interest and value for both the course and project; final confidence in non-technical skills; final confidence in technical skills specific to Component Design; final attitude toward service-learning; and feelings of success in the course and the project.

The full set of histograms and boxplots is presented in Appendix B for each pre-course and postcourse variable. Histograms of pre-course variables are shown in light blue. Histograms of post-course variables are shown in light green. As an example, the histograms and boxplots corresponding to initial (pre-course) and final (post-course) course and project interest are presented in Figures 5.1 - 5.6. 
The boxplots in Figure 5.1 show how students' initial course interest was very similar between the 2011 and 2012 cohorts. The median, falling between "moderate" and "high" indicates that the students in both cohorts began the course with a fair amount of prior interest in machine design concepts. The histograms in Figure 5.2 show that the two distributions are similar in shape and are both non-normal distributions.

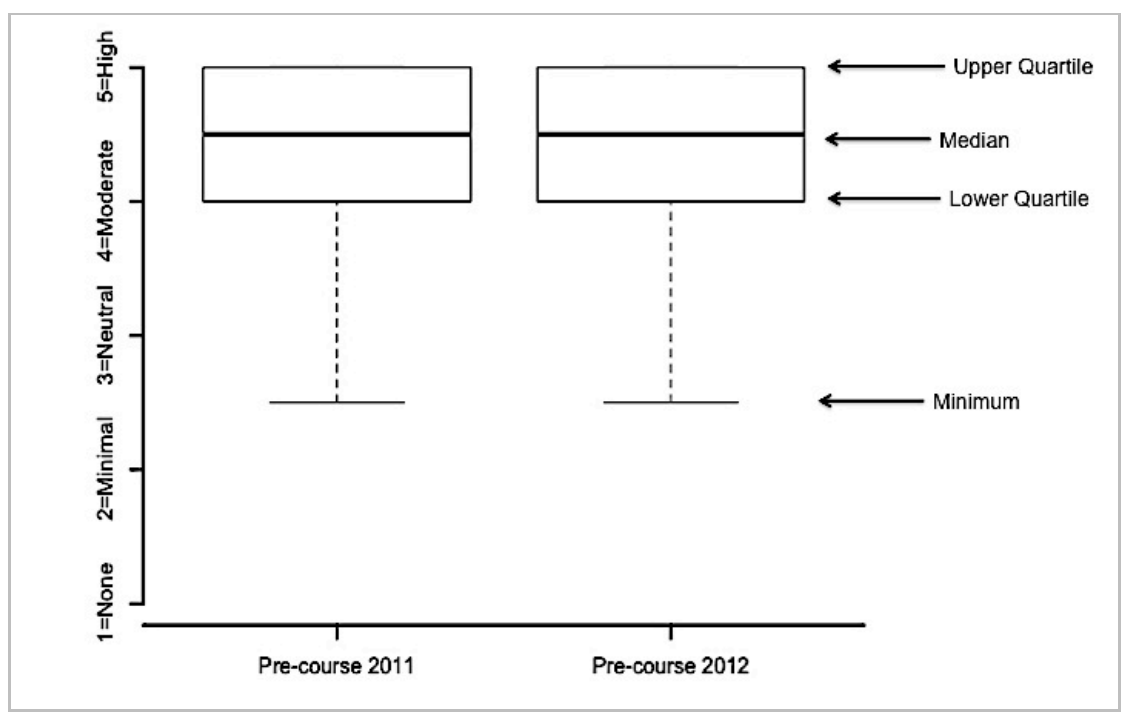

Figure 5.1: Boxplots of initial course interest 2011 vs. 2012

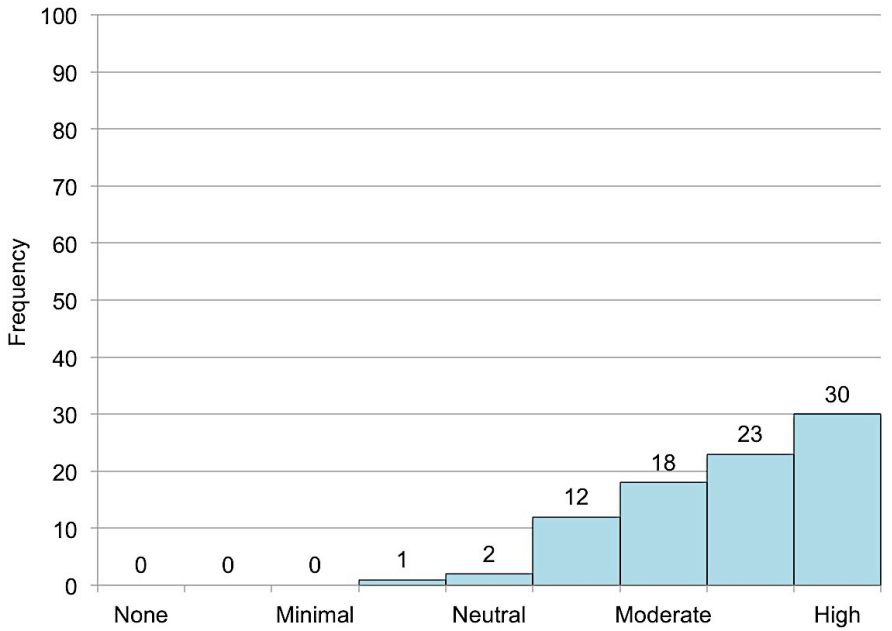

Pre-course $2011(\mathrm{n}=92)$

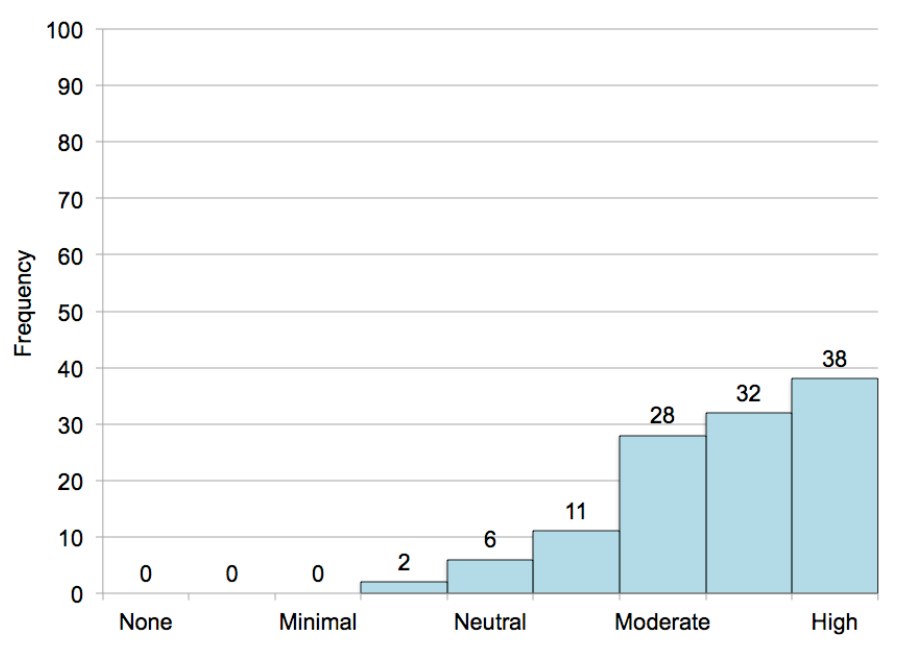

Pre-course $2012(n=117)$

Figure 5.2: Histograms of initial course interest 2011 vs. 2012 
The boxplots in Figure 5.3 show that students' final course interest was also quite similar between the 2011 and 2012 cohorts and that the median of students in both cohorts ended the course with "high" interest in machine design course concepts. The two outliers in Figure 5.3 represent students who reported their final course interest levels as "minimal" and "none". Similar to Figure 5.2, the histograms in Figure 5.4 show that the two distributions are similar in shape and are both non-normal.

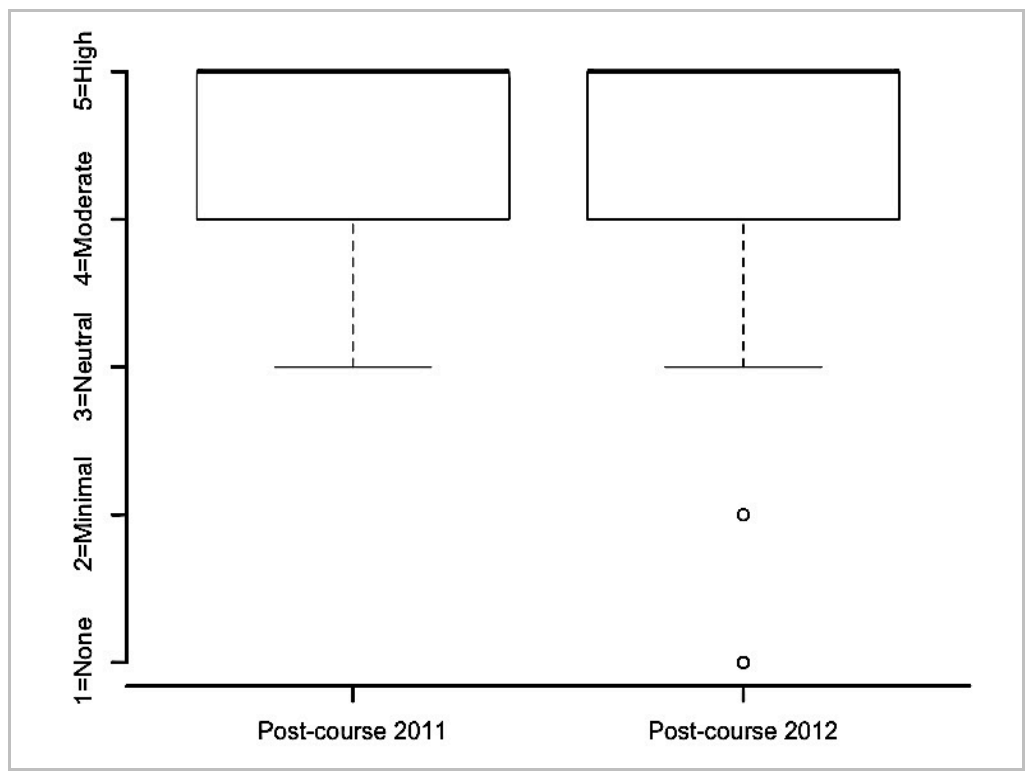

Figure 5.3: Boxplots of final course interest 2011 vs. 2012

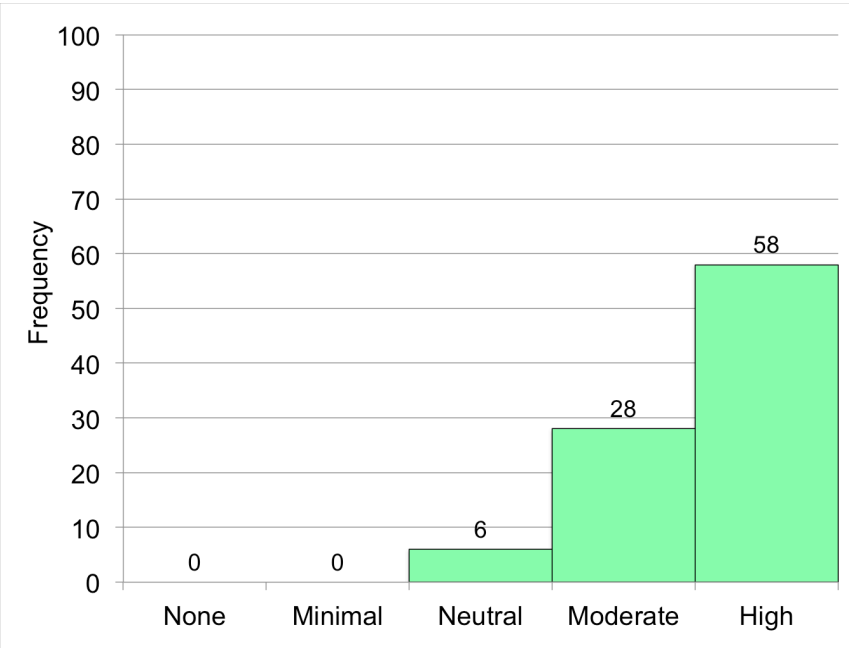

Pre-course $2011(\mathrm{n}=92)$

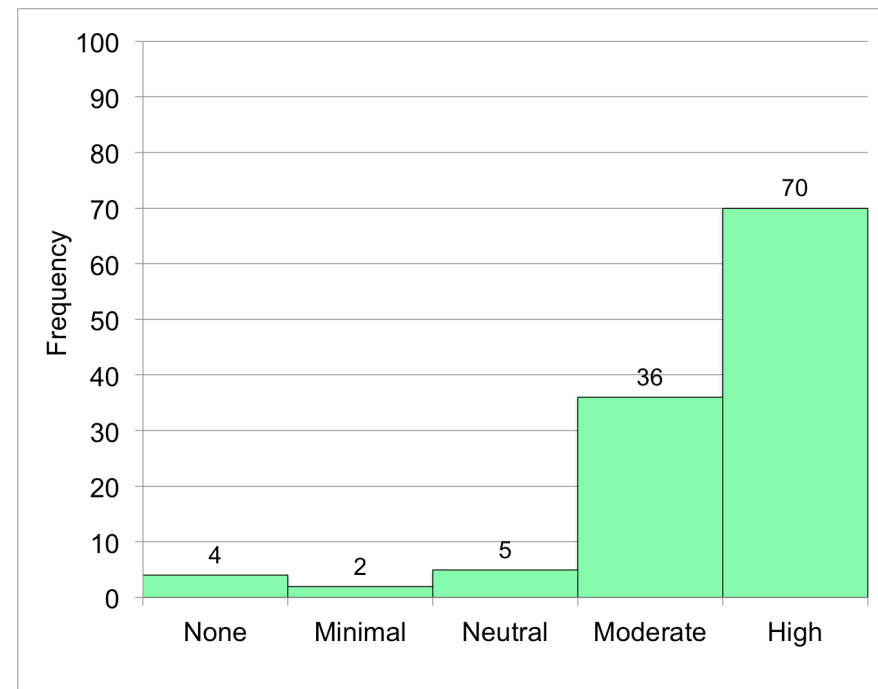

Post-course $2012(\mathrm{n}=117)$

Figure 5.4: Histograms of final course interest 2011 vs. 2012 
Figure 5.5 compares two boxplots side-by-side and indicates that the median initial course interest to final course interest in Component Design course concepts increased in 2011. Similarly, Figure 5.6 shows how median initial course interest to final course interest in Component Design course concepts also increased in 2012.

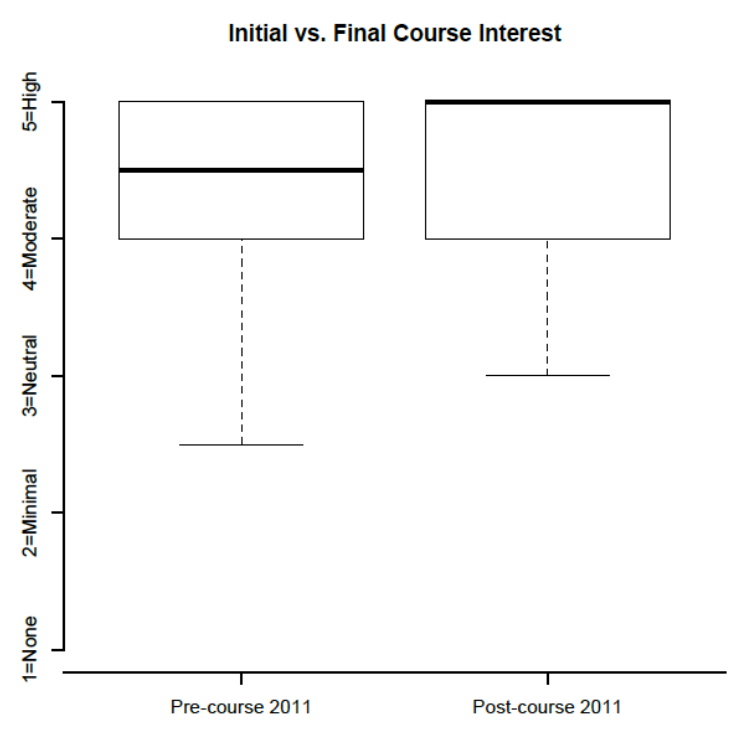

Figure 5.5: Initial vs. final course interest 2011

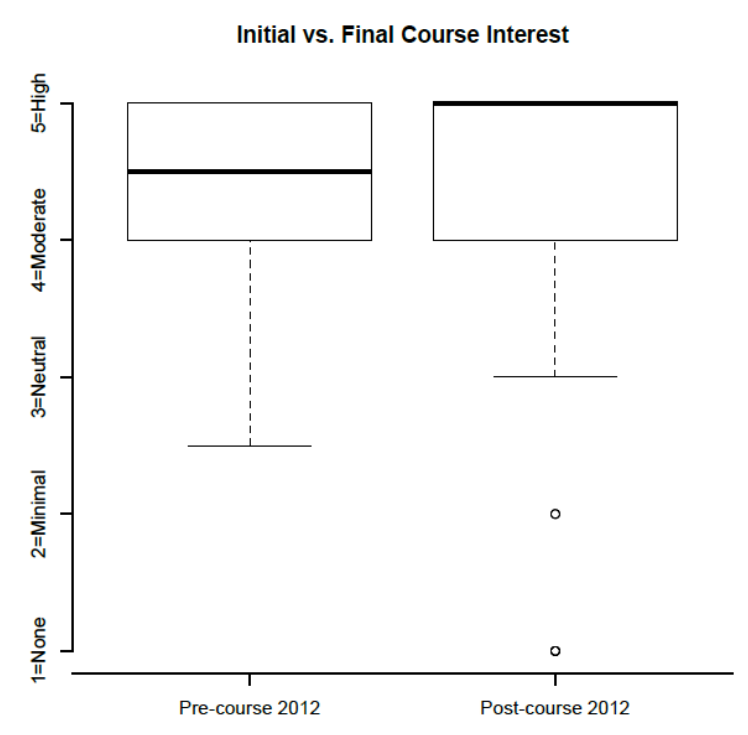

Figure 5.6: Initial vs. final course interest 2012

Overall, the vast majority of the histograms shown in Appendix C exhibit a non-normal trend. Also, the histograms and boxplots display a high degree of similarity between cohorts for each pre-course and post-course variable. Although boxplots display general differences between populations, they do not provide information regarding the underlying statistical distributions; hence Wilcoxon rank-sum hypothesis testing was used.

Wilcoxon rank-sum tests. As discussed in Chapter 4, Wilcoxon rank-sum hypothesis testing was used to determine statistically significant differences between the PBL control group and the PBSL treatment group in terms of student demographics and characteristics, and initial motivation, skills, and attitudes. This test was also used to compare initial versus final motivation, skills, and attitudes to assess whether any statistically significant gains occurred. Lastly, the Wilcoxon rank-sum test was also used to compare students' final motivation, skills and attitudes between the two cohorts. 
Table 5.1 shows the mean and standard deviation for each of the pre-course and post-course variables and the results of the hypothesis tests.

Table 5.1: Summary of hypothesis testing

\begin{tabular}{|c|c|c|c|c|c|}
\hline & $\begin{array}{l}2011 \\
\text { Pre-course } \\
\text { statistics } \\
\text { N=92 }\end{array}$ & $\begin{array}{l}2011 \\
\text { Post-course } \\
\text { statistics } \\
\mathrm{N}=92\end{array}$ & $\begin{array}{l}2012 \\
\text { Pre-course } \\
\text { statistics } \\
\text { N=117 }\end{array}$ & \begin{tabular}{|l}
2012 \\
Post-course \\
statistics \\
N=117
\end{tabular} & $\begin{array}{l}\text { Results of hypothesis tests } \\
\text { *Denotes statistical significance } \\
\text { at the } 0.05 \text { level } \\
\text { **Denotes statistical significance } \\
\text { at the } 0.10 \text { level }\end{array}$ \\
\hline $\begin{array}{l}\text { Interest: course } \\
(1=\text { none, } 5=\text { high })\end{array}$ & $\begin{array}{l}\mathrm{M}=4.39 \\
\mathrm{SD}=0.634\end{array}$ & $\begin{array}{l}\mathrm{M}=4.55 \\
\mathrm{SD}=0.634\end{array}$ & $\begin{array}{l}\mathrm{M}=4.34 \\
\mathrm{SD}=0.629\end{array}$ & $\begin{array}{l}\mathrm{M}=4.42 \\
\mathrm{SD}=0.921\end{array}$ & $\begin{array}{l}2011 \text { pre-post: } p=0.028^{*} \\
2012 \text { pre-post: } p=0.011^{*} \\
2011 / 2012 \text { pre-pre: } p=0.470 \\
2011 / 2012 \text { post-post: } p=0.621\end{array}$ \\
\hline $\begin{array}{l}\text { Interest: project } \\
(1=\text { none, } 5=\text { high })\end{array}$ & $\begin{array}{l}\mathrm{M}=4.60 \\
\mathrm{SD}=0.678\end{array}$ & $\begin{array}{l}\mathrm{M}=4.59 \\
\mathrm{SD}=0.647\end{array}$ & $\begin{array}{l}\mathrm{M}=4.52 \\
\mathrm{SD}=0.643\end{array}$ & $\begin{array}{l}\mathrm{M}=4.56 \\
\mathrm{SD}=0.904\end{array}$ & $\begin{array}{l}2011 \text { pre-post: } \mathrm{p}=0.901 \\
2012 \text { pre-post: } \mathrm{p}=0.010^{*} \\
2011 / 2012 \text { pre-pre: } \mathrm{p}=0.073^{* *} \\
2011 / 2012 \text { post-post: } \mathrm{p}=0.504\end{array}$ \\
\hline $\begin{array}{l}\text { Value: course } \\
(1=\text { none, } 5=\text { high })\end{array}$ & $\begin{array}{l}\mathrm{M}=4.86 \\
\mathrm{SD}=0.406\end{array}$ & $\begin{array}{l}\mathrm{M}=4.72 \\
\mathrm{SD}=0.432\end{array}$ & $\begin{array}{l}\mathrm{M}=4.78 \\
\mathrm{SD}=0.475\end{array}$ & $\begin{array}{l}\mathrm{M}=4.40 \\
\mathrm{SD}=0.859\end{array}$ & $\begin{array}{l}2011 \text { pre-post: } \mathrm{p}=0.000^{*} \\
2012 \text { pre-post: } 0.000^{*} \\
2011 / 2012 \text { pre-pre: } \mathrm{p}=0.134 \\
2011 / 2012 \text { post-post: } \mathrm{p}=0.007^{*}\end{array}$ \\
\hline $\begin{array}{l}\text { Value: project } \\
(1=\text { none, } 5=\text { high })\end{array}$ & $\begin{array}{l}\mathrm{M}=4.79 \\
\mathrm{SD}=0.481\end{array}$ & $\begin{array}{l}M=4.68 \\
S D=0.487\end{array}$ & $\begin{array}{l}\mathrm{M}=4.70 \\
\mathrm{SD}=0.606\end{array}$ & $\begin{array}{l}\mathrm{M}=4.57 \\
\mathrm{SD}=0.912\end{array}$ & $\begin{array}{l}2011 \text { pre-post: } \mathrm{p}=0.006^{*} \\
2012 \text { pre-post: } \mathrm{p}=0.267 \\
\text { 2011/2012 pre-pre: } \mathrm{p}=0.252 \\
2011 / 2012 \text { post-post: } \mathrm{p}=0.501\end{array}$ \\
\hline \begin{tabular}{|l|} 
Confidence in \\
technical skills \\
$(1=$ none, $5=$ high $)$
\end{tabular} & $\begin{array}{l}\mathrm{M}=2.82 \\
\mathrm{SD}=0.752\end{array}$ & $\begin{array}{l}\mathrm{M}=4.23 \\
\mathrm{SD}=0.454\end{array}$ & $\begin{array}{l}\mathrm{M}=2.79 \\
\mathrm{SD}=0.651\end{array}$ & $\begin{array}{l}\mathrm{M}=4.15 \\
\mathrm{SD}=0.546\end{array}$ & $\begin{array}{l}2011 \text { pre-post: } \mathrm{p}=0.000^{*} \\
2012 \text { pre-post: } \mathrm{p}=0.000^{*} \\
\text { 2011/2012 pre-pre: } \mathrm{p}=0.725 \\
2011 / 2012 \text { post-post: } \mathrm{p}=0.444\end{array}$ \\
\hline $\begin{array}{l}\text { Confidence in non- } \\
\text { technical skills } \\
(1=\text { none, } 5=\text { high })\end{array}$ & $\begin{array}{l}\mathrm{M}=3.84 \\
\mathrm{SD}=0.532\end{array}$ & $\begin{array}{l}\mathrm{M}=4.10 \\
\mathrm{SD}=0.545\end{array}$ & $\begin{array}{l}\mathrm{M}=3.80 \\
\mathrm{SD}=0.505\end{array}$ & $\begin{array}{l}\mathrm{M}=4.01 \\
\mathrm{SD}=0.514\end{array}$ & $\begin{array}{l}2011 \text { pre-post: } \mathrm{p}=0.002^{*} \\
2012 \text { pre-post: } \mathrm{p}=0.002^{*} \\
\text { 2011/2012 pre-pre: } \mathrm{p}=0.691 \\
2011 / 2012 \text { post-post: } \mathrm{p}=0.232\end{array}$ \\
\hline $\begin{array}{l}\text { Expectancy for success: } \\
\text { course } \\
(1=\text { none, } 5=\text { high })\end{array}$ & $\begin{array}{l}\mathrm{M}=4.37 \\
\mathrm{SD}=0.704\end{array}$ & & $\begin{array}{l}\mathrm{M}=4.43 \\
\mathrm{SD}=0.606\end{array}$ & & 2011/2012 pre-pre: $p=0.700$ \\
\hline $\begin{array}{l}\text { Expectancy for success: } \\
\text { project } \\
(1=\text { none, } 5=\text { high })\end{array}$ & $\begin{array}{l}\mathrm{M}=4.53 \\
\mathrm{SD}=0.565\end{array}$ & & $\begin{array}{l}\mathrm{M}=4.44 \\
\mathrm{SD}=0.607\end{array}$ & & $2011 / 2012$ pre-pre: $p=0.298$ \\
\hline $\begin{array}{l}\text { Indicators of engagement } \\
(1=\text { least, } 4=\text { greatest })\end{array}$ & & $\begin{array}{l}\mathrm{M}=2.85 \\
\mathrm{SD}=0.563\end{array}$ & & $\begin{array}{l}\mathrm{M}=2.83 \\
\mathrm{SD}=0.577\end{array}$ & 2011/2012 post-post: $\mathrm{p}=0.861$ \\
\hline $\begin{array}{l}\text { Feelings of success: course } \\
(1=\text { none, } 5=\text { high })\end{array}$ & & $\begin{array}{l}\mathrm{M}=4.43 \\
\mathrm{SD}=0.663\end{array}$ & & $\begin{array}{l}\mathrm{M}=4.25 \\
\mathrm{SD}=0.709\end{array}$ & 2011/2012 post-post: $\mathrm{p}=0.077^{* *}$ \\
\hline $\begin{array}{l}\text { Feelings of success: project } \\
(1=\text { none, } 5=\text { high })\end{array}$ & & $\begin{array}{l}\mathrm{M}=4.47 \\
\mathrm{SD}=0.982\end{array}$ & & $\begin{array}{l}\mathrm{M}=4.67 \\
\mathrm{SD}=0.509\end{array}$ & $2011 / 2012$ post-post: $\mathrm{p}=0.390$ \\
\hline $\begin{array}{l}\text { Attitude toward service- } \\
\text { learning } \\
(1=\text { none, } 5=\text { high })\end{array}$ & $\begin{array}{l}\mathrm{M}=3.85 \\
\mathrm{SD}=0.954\end{array}$ & $\begin{array}{l}\mathrm{M}=3.96 \\
\mathrm{SD}=0.903\end{array}$ & $\begin{array}{l}\mathrm{M}=3.93 \\
\mathrm{SD}=0.831\end{array}$ & $\begin{array}{l}\mathrm{M}=4.37 \\
\mathrm{SD}=0.822\end{array}$ & $\begin{array}{l}2011 \text { pre-post: } \mathrm{p}=0.461 \\
2012 \text { pre-post: } \mathrm{p}=0.000^{*} \\
\text { 2011/2012 pre-pre: } \mathrm{p}=0.680 \\
2011 / 2012 \text { post-post: } \mathrm{p}=0.000^{*}\end{array}$ \\
\hline
\end{tabular}


Table 5.1 illustrates the following trends:

- COUSRE INTEREST: a significant increase in pre-course to post-course interest in both 2011 $(\mathrm{p}=0.028)$ and $2012(\mathrm{p}=0.011)$. No significant differences between the cohorts in pre-course or post-course levels of interest.

- PROJECT INTEREST: a significant difference in pre-course interest between the cohorts ( $p=0.073$, with students in 2012 reporting lower interest). There was a pre-course to post-course interest gain in 2012 but not in 2011. No significant differences between the cohorts in postcourse levels of interest.

- COURSE VALUE: a significant decrease in pre-course to post-course value in both cohorts $(\mathrm{p}=0.000,2011$ and $\mathrm{p}=0.000,2012)$ as well as a significant difference between post-course value ( $\mathrm{p}=0.007$, with students in 2012 reporting lower value).

- PROJECT VALUE: a significant pre-course to post-course decrease in value of the project in $2011(\mathrm{p}=0.006)$ but not in $2012(\mathrm{p}=0.267)$. No significant difference between the years for precourse or post-course value.

- TECHNICAL SKILL CONFIDENCE: a significant increase in technical ( $p=0.000,2011$ and $p=0.000,2012$ ) skill confidence for both cohorts. No significant differences between the cohorts in terms of pre-course or post-course technical skill confidence.

- NON-TECHNICAL SKILLS CONFIDENCE: a significant increase in non-technical $(\mathrm{p}=0.002$, 2011 and $p=0.002,2012$ ) skill confidence for both years. No significant differences between the cohorts in terms of pre-course or post-course non-technical skill confidence.

- EXPECTANCIES FOR SUCCESS IN COURSE: no significant differences between the two cohorts.

- EXPECTANCIES FOR SUCCESS IN PROJECT: no significant differences between the two cohorts.

- FEELINGS OF SUCCESS IN COURSE: a significant difference in students' post-course feelings of success in the course between the two cohorts ( $p=0.077$, students in 2012 reporting lower feelings of success).

- FEELINGS OF SUCCESS IN PROJECT: no significant difference between the cohorts in students' feelings of success.

- ENGAGEMENT: no significant difference between the two cohorts in terms of indicators of engagement.

- ATTITUDE TOWARD SERVICE-LEARNING: no significant difference in pre-course attitude toward service-learning between the two cohorts. A significant increase $(\mathrm{p}=0.000)$ in the precourse to post-course attitude toward (support of) service-learning in 2012. 
Random forest analysis. As discussed in Chapter 4, random forest analysis was used to estimate variable importance. To reiterate, random forest is an analysis technique that can be used to measure the prediction strength of a set of variables. In this study the random forest technique was used to estimate the importance of the predictor variables in predicting the response variables that served as indicators of student achievement motivation.

Tables 5.2 and 5.3 show the predictor and response variables used in the random forest analysis along with their abbreviations. These are some of the same pre-course and post-course variables described in Tables 4.1 and 4.2; however, the full variable set was not used for two reasons. One, the initial random forest analysis showed a number of pre-course variables to have a much higher predictive strength than others; hence only these variables were retained as predictor variables in the random forest analysis. Two, only the response variables that correspond to variables considered to be indicators of student achievement motivation were used in the random forest analysis.

Table 5.2: Predictor variables in random forest analysis

\begin{tabular}{|c|c|}
\hline $\begin{array}{c}\text { Achievement orientation } \\
\text { (AchOrient) }\end{array}$ & $\begin{array}{c}\text { Initial course interest } \\
\text { (IIntCour) }\end{array}$ \\
\hline $\begin{array}{c}\text { Attitude toward service-learning } \\
\text { (AttSL1) }\end{array}$ & $\begin{array}{c}\text { Initial project interest } \\
\text { (IIntProj) }\end{array}$ \\
\hline $\begin{array}{c}\text { Expectancy for success in course } \\
\text { (ExpSucCour) }\end{array}$ & $\begin{array}{c}\text { Initial course value } \\
\text { (IValCour) }\end{array}$ \\
\hline $\begin{array}{c}\text { Expectancy for success in project } \\
\text { (ExpSucProj) }\end{array}$ & $\begin{array}{c}\text { Initial project value } \\
\text { (IValProj) }\end{array}$ \\
\hline $\begin{array}{c}\text { Gender } \\
\text { (Gender) }\end{array}$ & $\begin{array}{c}\text { Initial non-technical skills } \\
\text { (NonTechSk1) }\end{array}$ \\
\hline $\begin{array}{c}\text { Initial course experience } \\
\text { (IExpCour) }\end{array}$ & $\begin{array}{c}\text { Initial technical skills } \\
\text { (TechSk1) }\end{array}$ \\
\hline $\begin{array}{c}\text { Initial project experience } \\
\text { (IExpProj) }\end{array}$ & Underrepresented minority \\
(URM)
\end{tabular}

Table 5.3: Response variables in random forest analysis

\begin{tabular}{|c|c|}
\hline $\begin{array}{c}\text { Feelings of success in course } \\
\text { (FeelSucCour) }\end{array}$ & $\begin{array}{c}\text { Final value of course } \\
\text { (FValCour) }\end{array}$ \\
\hline $\begin{array}{c}\text { Feelings of success in Project } \\
\text { (FeelSucProj) }\end{array}$ & $\begin{array}{c}\text { Final value of project } \\
\text { (FValProj) }\end{array}$ \\
\hline $\begin{array}{c}\text { Final interest in course } \\
\text { (FIntCour) }\end{array}$ & $\begin{array}{c}\text { Engagement } \\
\text { (Engage) }\end{array}$ \\
\hline $\begin{array}{c}\text { Final interest in project } \\
\text { (FIntProj) }\end{array}$ & \\
\hline
\end{tabular}


As an example, Figure 5.7 shows the random forest results for the 2011 cohort's final course and project interest. The magnitude of the "mean decrease in accuracy" for each predictor variable (shown on the horizontal axis) corresponds to the relative importance of that variable in predicting the response variable (listed at the top of the graph). Figure 5.7 indicates that initial non-technical skills, initial project value, and initial course experience were the three most important variables in predicting final interest in the course. In terms of final interest in the project, initial course experience, initial project interest, and non-technical skills were the three most important predictors.

Final Course Interest (FIntCour)

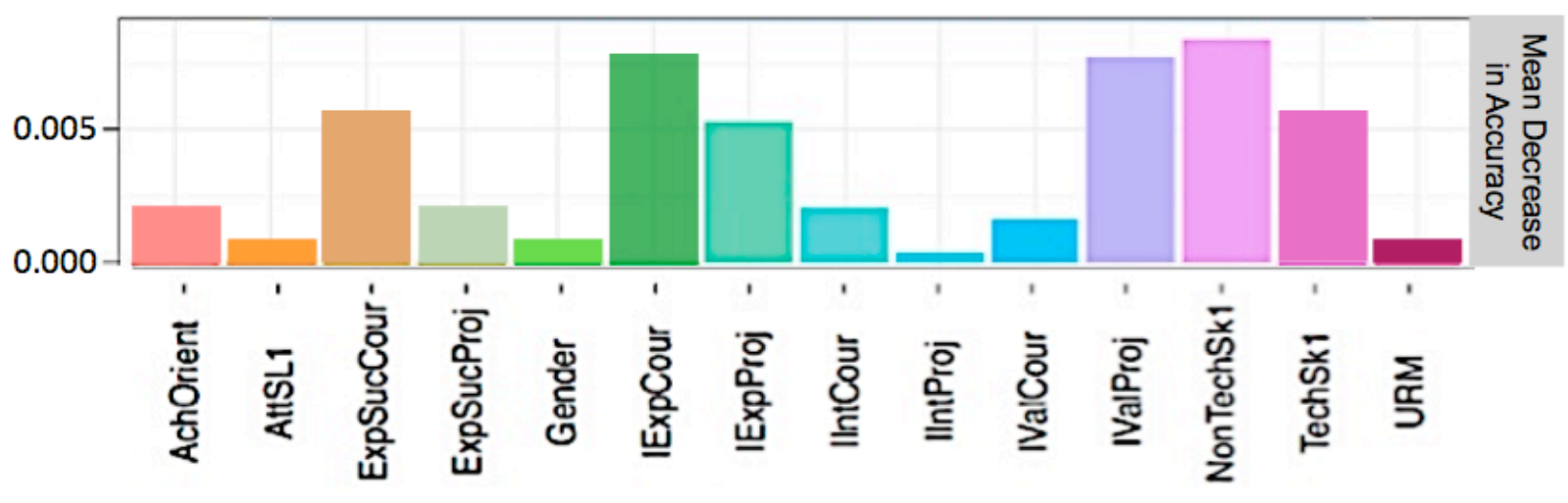

Final Project Interest (FIntProj)

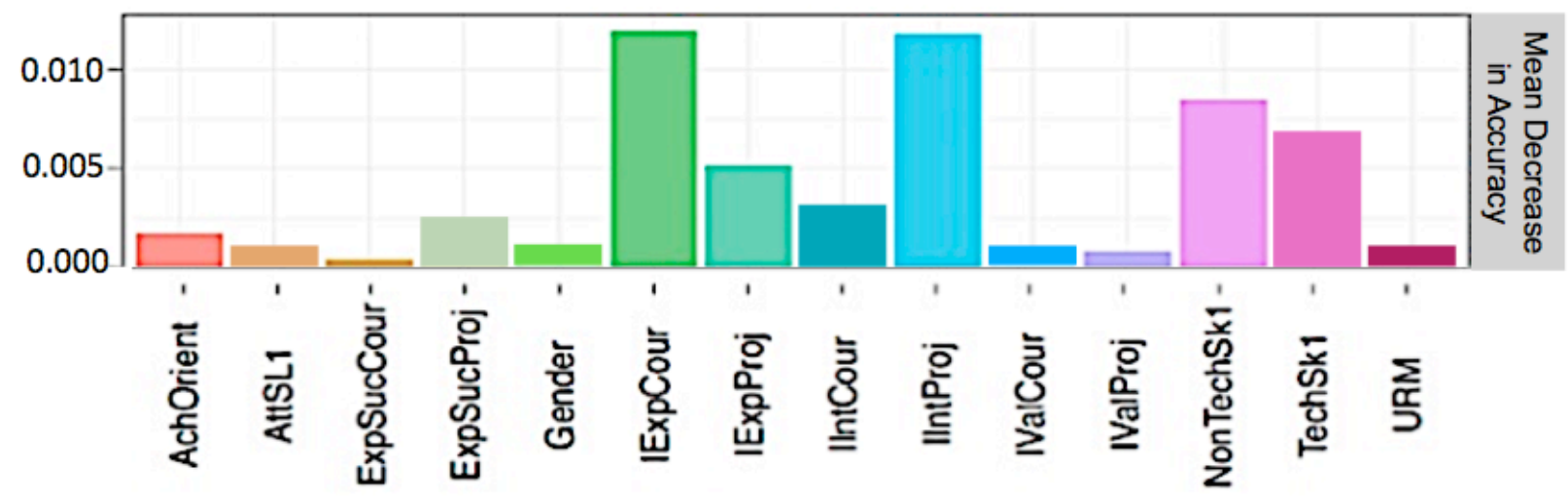

Figure 5.7: Example variable importance results from random forest analysis 
This analysis does not indicate whether the results are statistically significant; however, the results do indicate the relative importance of students' pre-course characteristics on predicting their achievement motivation in the course and project.

Table 5.4 provides a summary of the variable importance results from the entire random forest analysis. One of the most striking results is the similarity between the cohorts in terms of variable importance. For example, initial project value appeared as an important predictor of engagement for both cohorts, non-technical skills appeared as an important predictor of feelings of success in the course, and so on.

Table 5.4: Summary of variable importance testing

\begin{tabular}{|l|l|l|}
\hline $\begin{array}{l}\text { Response variables } \\
\text { indicators of achievement } \\
\text { motivation) }\end{array}$ & $\begin{array}{l}\text { 2011 Top three predictors } \\
\text { for each response variable } 2011\end{array}$ & $\begin{array}{l}\text { 2012 Top three predictors } \\
\text { for each response variable }\end{array}$ \\
\hline Engagement & $\begin{array}{l}\text { 1. Initial project value } \\
\text { 2. Initial course interest } \\
\text { 3. Achievement orientation }\end{array}$ & $\begin{array}{l}\text { 1. Non-technical skill confidence } \\
\text { 2. Initial project value } \\
\text { 3. Initial course value }\end{array}$ \\
\hline Feelings of success in course & $\begin{array}{l}\text { 1. Initial project experience } \\
\text { 2. Non-technical skill confidence } \\
\text { 3. Technical skill confidence }\end{array}$ & $\begin{array}{l}\text { 1. Non-technical skill confidence } \\
\text { 3. Initial course experience }\end{array}$ \\
\hline Feelings of success in project & $\begin{array}{l}\text { 1. Technical skill confidence } \\
\text { 2. Non-technical skill confidence } \\
\text { 3. Initial project experience }\end{array}$ & $\begin{array}{l}\text { 1. Underrepresented minority } \\
\text { 2. Technical skill confidence } \\
\text { 3. Initial project experience }\end{array}$ \\
\hline Final interest in course & $\begin{array}{l}\text { 1. Non-technical skill confidence } \\
\text { 2. Initial project value } \\
\text { 3. Initial course experience }\end{array}$ & $\begin{array}{l}\text { 1. Initial course value } \\
\text { 2. Initial course interest } \\
\text { 3. Achievement orientation }\end{array}$ \\
\hline Final interest in project & $\begin{array}{l}\text { 1. Initial course experience } \\
\text { 2. Initial project interest } \\
\text { 3. Non-technical skill confidence }\end{array}$ & $\begin{array}{l}\text { 1. Initial project interest } \\
\text { 2. Initial course value } \\
\text { 3. Initial project value }\end{array}$ \\
\hline Final value of course & $\begin{array}{l}\text { 1. Initial project value } \\
\text { 2. Initial project experience } \\
\text { 3. Non-technical skill confidence }\end{array}$ & $\begin{array}{l}\text { 1. Initial course value } \\
\text { 2. Initial project value } \\
\text { 3. Initial project interest }\end{array}$ \\
$\begin{array}{l}\text { 1. Initial interest project } \\
\text { 3. Initial course experience } \\
\text { 3. Initial course interest }\end{array}$ & $\begin{array}{l}\text { 1. Initial project value } \\
\text { 3. Technical skill confidence } \\
\text { 3. Achievement orientation }\end{array}$ \\
\hline
\end{tabular}


Another way to evaluate the results is to count the number of occurrences in which each predictor variable was one of the top three most important predictors for any of the seven achievement motivation response variables. As seen in Table 5.5 initial project value and non-technical skills had the highest number of occurrences as important predictors

Table 5.5: Number of occurrences of each predictor variable

\begin{tabular}{|l|c|c|c|}
\hline \multicolumn{1}{|c|}{ Predictor variable } & Occurrences in 2011 & Occurrences in 2012 & $\begin{array}{l}\text { Total } \\
\text { occurrences }\end{array}$ \\
\hline Initial course interest & 2 & 2 & $\mathbf{4}$ \\
\hline Initial project interest & 2 & 4 & $\mathbf{3}$ \\
\hline Initial course value & 0 & 4 & $\mathbf{4}$ \\
\hline Initial project value & 3 & 2 & $\mathbf{4}$ \\
\hline Technical skill confidence & 2 & 2 & $\mathbf{6}$ \\
\hline Non-technical skill & 4 & 1 & $\mathbf{4}$ \\
\hline confidence & 3 & 1 & $\mathbf{4}$ \\
\hline Initial course experience & 3 & 2 & $\mathbf{3}$ \\
\hline Initial project experience & 1 & 1 & $\mathbf{1}$ \\
\hline Achievement motivation & 0 & 4 & \\
\hline URM & & & \\
\hline
\end{tabular}

Table 5.5 was distilled even further by combining the variables initial course interest and initial project interest into an overall initial interest variable. This same procedure was used to form the variables overall initial value, overall initial ability-related beliefs, and overall initial experience.
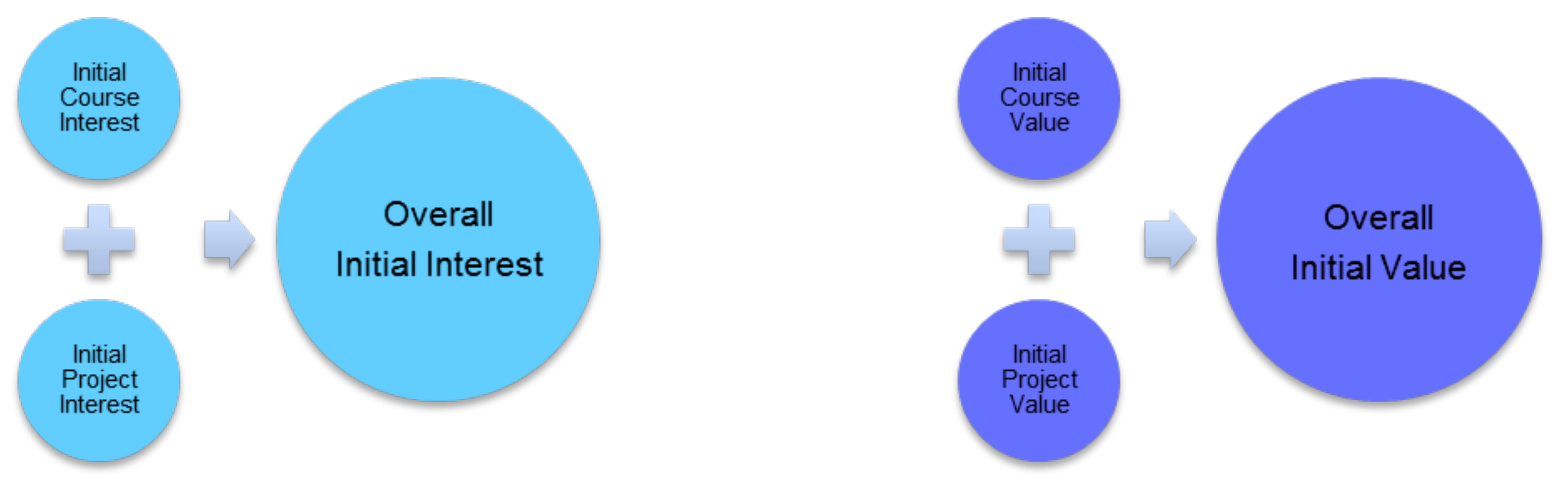

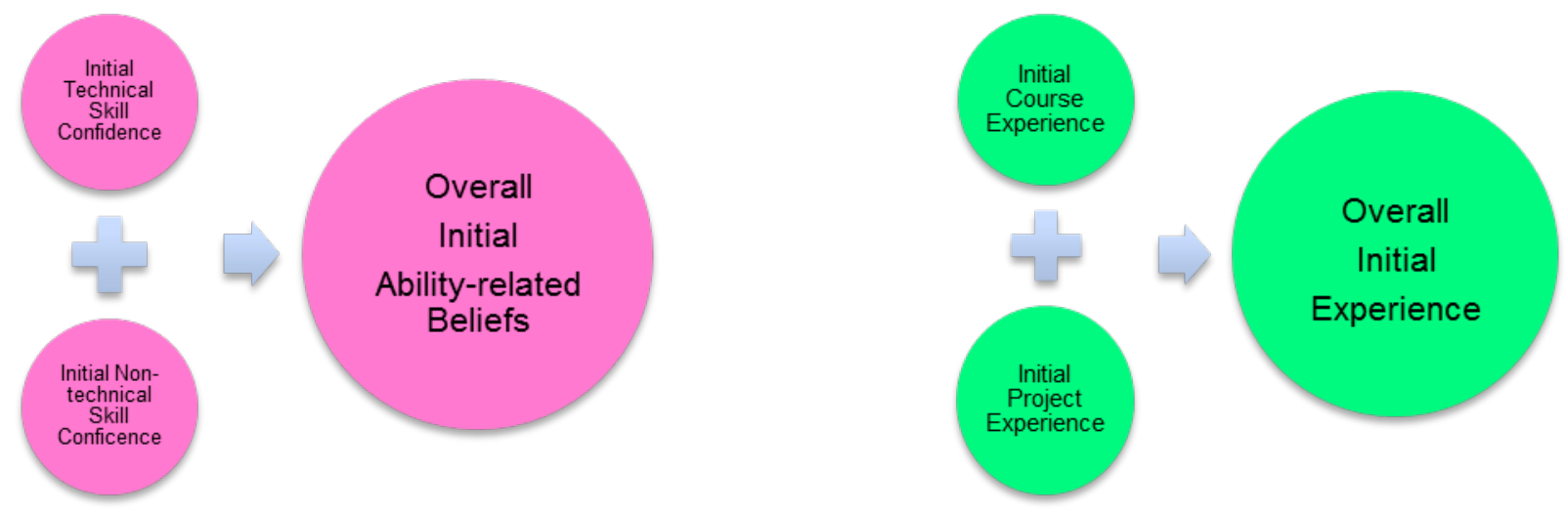

The rationale for combining these variables is as follows: while the quantitative aspect of this study distinguishes between course variables and project variables, evidence from the qualitative data indicates that students made much less of a conceptual distinction between course and project elements. Also, while students' initial confidence in technical skills is different than students' initial confidence in nontechnical skills, these variables both relate to students' beliefs about their abilities and hence were combined to form an overall initial ability-related beliefs variable.

Table 5.6 shows the number of occurrences in which each of these "overall" predictor variables was one of the top three predictors for any of the seven achievement motivation response variables.

Table 5.6: Overall important predictors of achievement motivation

\begin{tabular}{|l|c|c|c|}
\hline Predictor variable & Occurrences in 2011 & Occurrences in 2012 & Total occurrences \\
\hline Overall initial interest & 4 & 3 & 7 \\
\hline Overall initial value & 3 & 8 & 11 \\
\hline Overall initial ability-related beliefs & 6 & 2 & 8 \\
\hline Overall initial experience & 6 & 2 & 3 \\
\hline Achievement motivation & 1 & 1 & 1 \\
\hline URM & 0 & & 8 \\
\hline
\end{tabular}


Three very important results can be drawn from Table 5.6:

- For the 2011 PBL cohort, the most important variables for predicting student achievement motivation was a tie between overall initial ability-related beliefs and overall initial experience.

- For the 2012 PBSL cohort, the most important variable for predicting student achievement motivation was overall initial value.

- When both cohorts are considered together, the most important predictors for student achievement motivation were overall initial value and overall initial ability-related beliefs.

Figures 5.8 -5.10 represent these results in a visual manner and relate these results back to the adapted motivation framework that was presented in Chapter 2.

Predictor variables used in random forest analysis

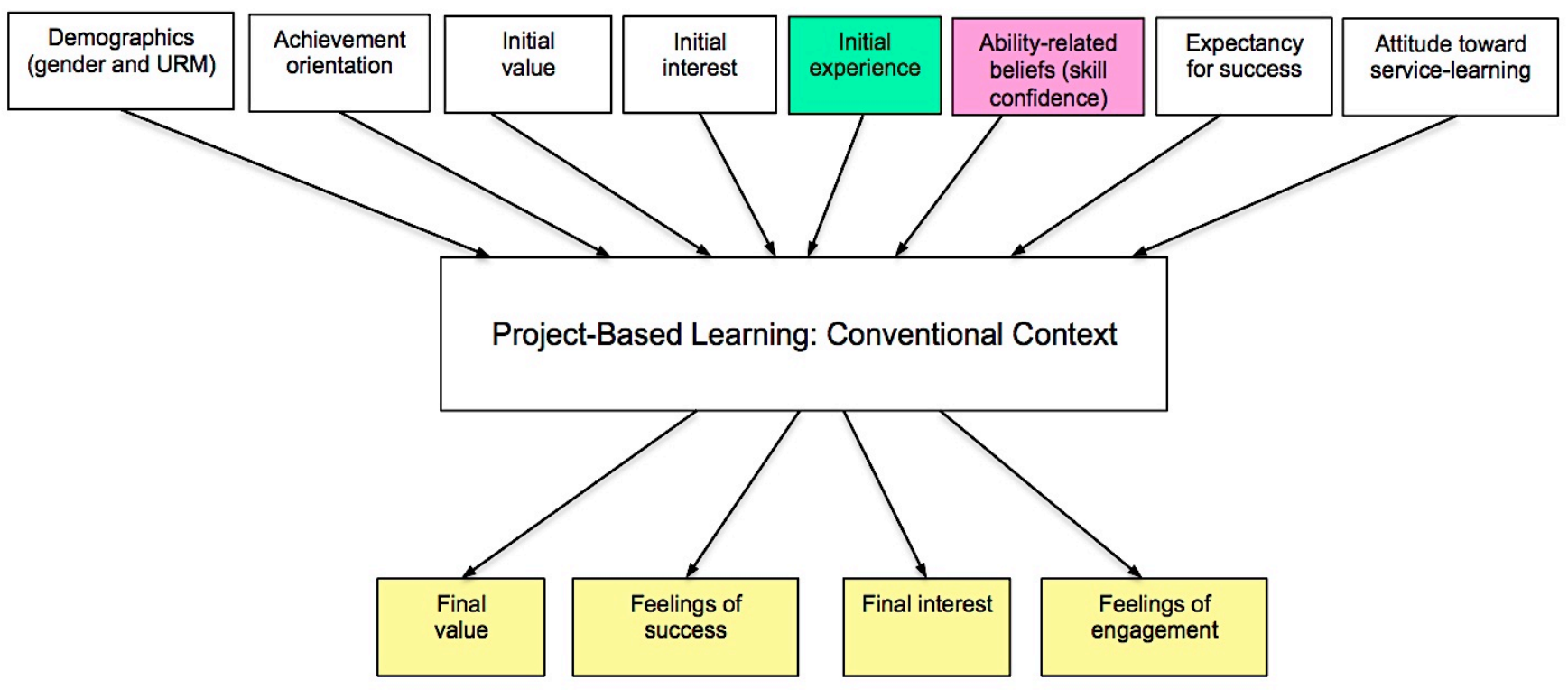

Response variables: indicators of achievement motivation

Figure 5.8: Most important predictors of student achievement motivation in 2011 cohort 
Predictor variables used in random forest analysis

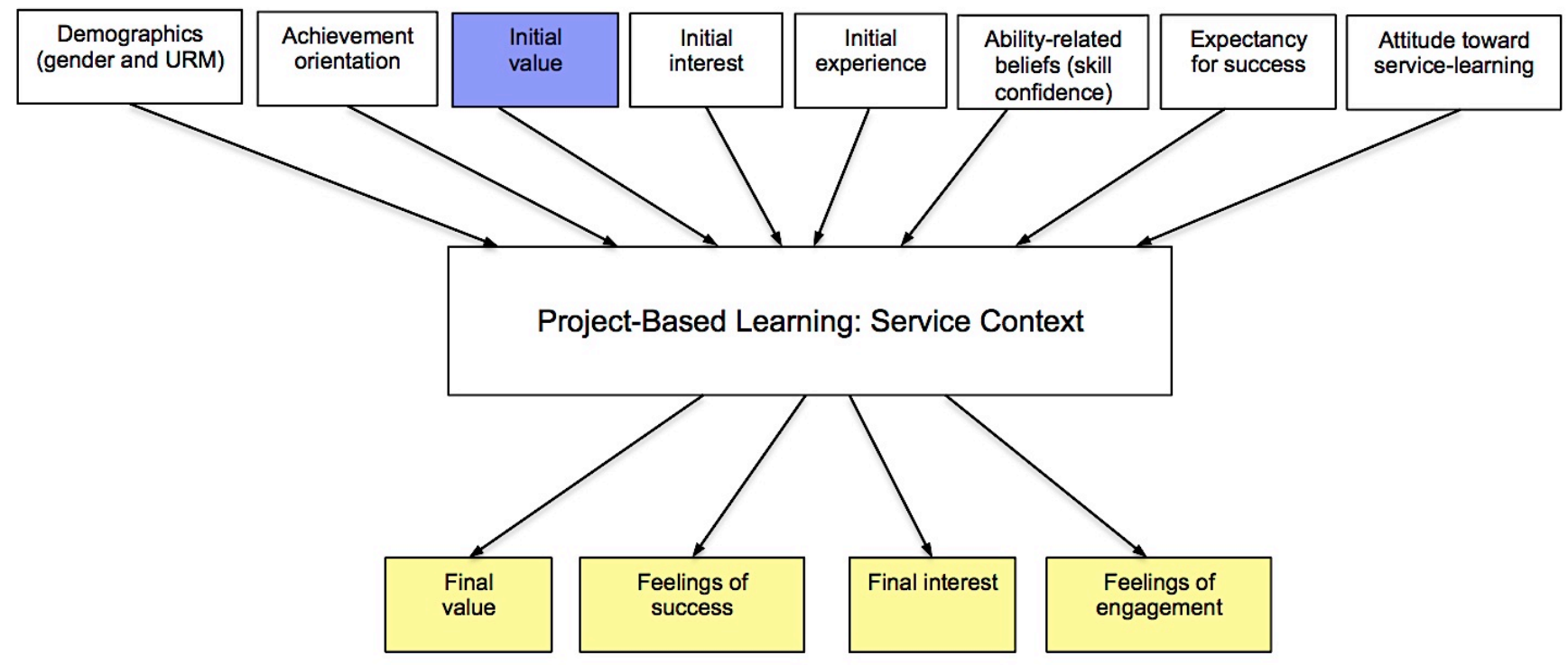

Response variables: indicators of achievement motivation

Figure 5.9: Most important predictors of student achievement motivation in 2012 cohort

Predictor variables used in random forest analysis

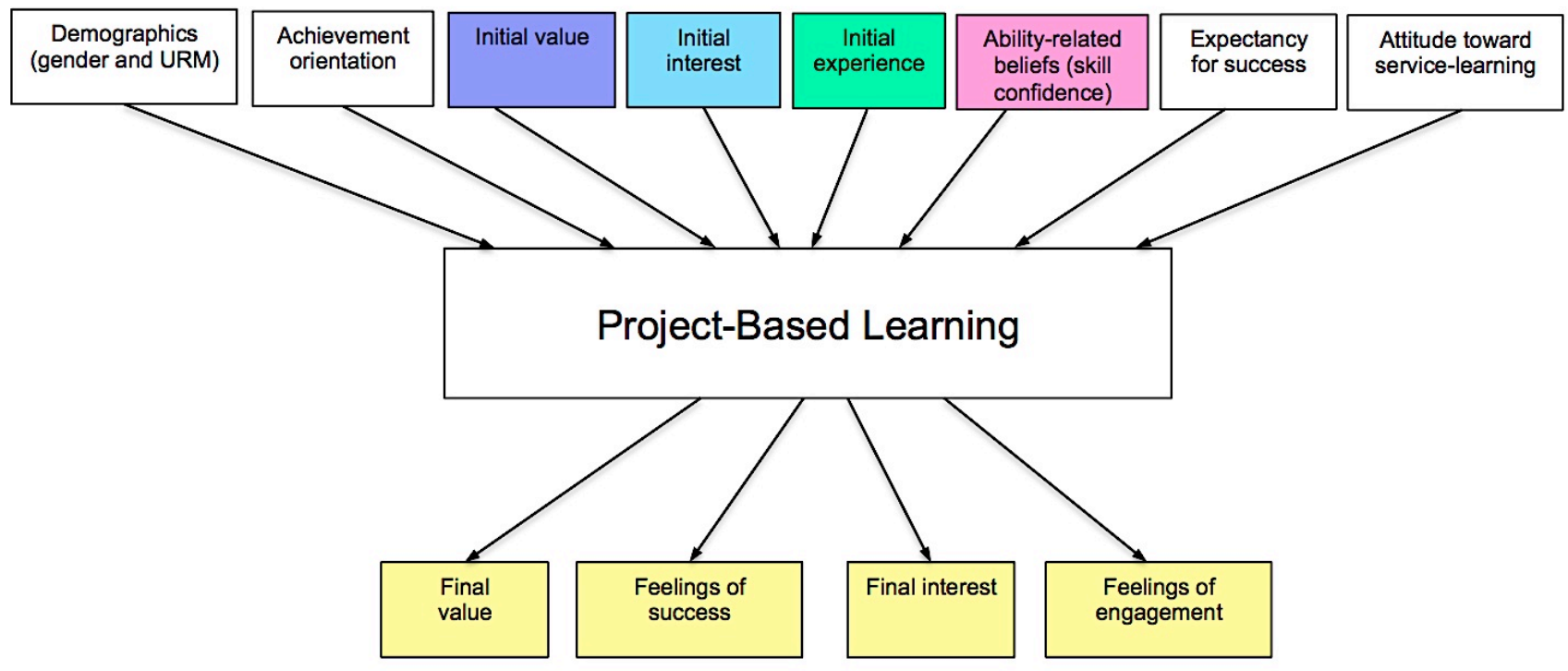

Response variables: indicators of achievement motivation

Figure 5.10: Most important predictors of student achievement motivation in PBL experience (both conventional and service contexts) 
Summary of quantitative results. Many interesting patterns emerged from the quantitative analysis which begin to answer the underlying research questions of this study. To remind the reader, these two questions are:

1. How does the context of service in project-based learning affect student motivation?

2. When designing project-based learning experiences, what factors are most influential on students' motivation to persist in those experiences?

The quantitative results provide significant insight into the gains, changes, and differences in student achievement motivation between the two cohorts. They also provide a more refined understanding about the specific elements of both PBL experiences that were most influential on student achievement motivation

The limitation of the quantitative results, however, is that they cannot explain the whole story; hence the advantage of a mixed-methods research design. As explained in Chapter 4, a sequential explanatory mixed methods study applies the results of the quantitative analysis to guide the qualitative analysis. In this study the quantitative results were instrumental in helping find a focus for the qualitative analysis. In other words, the quantitative results were used to identify the general themes that should be explored in the qualitative data to help explain the rest of the story. Table 5.7 summarizes the major themes that were inspired from the quantitative results and then were used as questions to "ask the data" in the qualitative analysis.

Table 5.7: Qualitative themes inspired from quantitative results

Results from Quantitative Analysis

Student achievement motivation was sustained in both cohorts as evidenced by students' post-course levels of value, interest, engagement, and ability-related beliefs.

Not only was student achievement motivation sustained in both cohorts, postcourse levels of achievement motivation were similar between the cohorts. In fact, there was no statistically significant difference in postcourse levels of project value, interest, engagement or ability-related beliefs.

Furthermore, the most important variables for predicting student motivation - engagement, interest, value, ability-related beliefs, and initial experience - were similar between the cohorts.
Themes to Explore in Qualitative Analysis

Which elements of the course and project did students perceive to be valuable, interesting, and engaging? Which elements strengthened students' ability-related beliefs?

Do the focus groups help explain this similarity in student achievement motivation, despite the different project contexts (service vs. non-service)? Was there a quality present in both contexts that impacted student achievement motivation more than the project context itself? 


\begin{tabular}{|c|c|}
\hline $\begin{array}{l}\text { In both cohorts, there was a statistically } \\
\text { significant increase in students' pre-course to } \\
\text { post-course technical and non-technical skill } \\
\text { confidence levels. Also, students had } \\
\text { significantly higher confidence in their technical } \\
\text { skills than their non-technical skills at the } \\
\text { beginning of the semester, but at the end of the } \\
\text { semester their confidence levels were more } \\
\text { similar to each other. }\end{array}$ & $\begin{array}{l}\text { Which elements of the course and project } \\
\text { contributed to students' confidence gains in their } \\
\text { technical and non-technical skill development? } \\
\text { What specific skills do students feel they } \\
\text { strengthened? }\end{array}$ \\
\hline $\begin{array}{l}\text { For both cohorts, there was a statistically } \\
\text { significant increase in pre-course to post-course } \\
\text { project interest levels but a decrease in pre- } \\
\text { course to post-course project value levels } \\
\text { (although only statistically significant in the } \\
2011 \text { cohort). However, at the end of the } \\
\text { semester, interest and value levels were more } \\
\text { similar to each other. }\end{array}$ & $\begin{array}{l}\text { Do the focus groups helps explain why many } \\
\text { students anticipated the project to be a very } \\
\text { valuable experience even though they felt a } \\
\text { moderate amount of initial interest in the } \\
\text { project? And do the focus groups offer a reason } \\
\text { for why students' value of the project decreased } \\
\text { while their interest increased? }\end{array}$ \\
\hline $\begin{array}{l}\text { The only statistically significant difference } \\
\text { between the cohorts was the } 2012 \text { cohort } \\
\text { reporting lower levels of project interest than } \\
\text { the } 2011 \text { cohort. However, at the end of the } \\
\text { semester, there was no statically significant } \\
\text { difference in final project interest between the } \\
\text { cohorts. }\end{array}$ & $\begin{array}{l}\text { What influenced students in the } 2012 \text { cohort } \\
\text { to feel less interested in the project initially? } \\
\text { What factors caused their project interest to } \\
\text { increase over the semester? }\end{array}$ \\
\hline $\begin{array}{l}\text { Although there was a similarity between the } \\
\text { cohorts in terms of most important variables for } \\
\text { predicting student achievement motivation, } \\
\text { there was a difference in the top most important } \\
\text { predictor variables. For the } 2011 \text { cohort, the } \\
\text { most important variables was a tie between } \\
\text { overall initial ability-related beliefs and overall } \\
\text { initial experience. For the } 2012 \text { cohort, the most } \\
\text { important variable was overall initial value. }\end{array}$ & $\begin{array}{l}\text { Do the focus groups explain why the most } \\
\text { salient factors of achievement motivation were } \\
\text { different between the cohorts? Does this } \\
\text { difference suggest that the project context has } \\
\text { some influence on the intrinsic and extrinsic } \\
\text { reasons students chose to persist in the project? }\end{array}$ \\
\hline $\begin{array}{l}\text { For the } 2012 \text { cohort, there was a pre-course } \\
\text { to post-course gain in students' positive attitude } \\
\text { toward service-learning. }\end{array}$ & $\begin{array}{l}\text { Which elements of the service experience } \\
\text { supported a positive attitude toward service for } \\
\text { the students? }\end{array}$ \\
\hline
\end{tabular}




\section{Qualitative Results}

There is a difference between an open mind and an empty head. The issue is not whether to use existing knowledge, but how. Our problem is to find a focus, without committing ourselves prematurely to a particular perspective and so foreclosing options for our analysis. The danger lies not in having assumptions but in not being aware of them. Ian Dey, Qualitative Data Analysis

This next section is a presentation of the focus group results. Student testimonials have been woven together by the researcher to describe the students' experience in the course and the project. In telling the story the researcher remained as objective as possible while still keeping in mind the questions presented in Table 5.7 as well as the adapted motivation theory framework. The dialogue of the focus group facilitator (the researcher) has been omitted to retain the fluidity of the students' conversations. However, the voice of the researcher is present in these results to guide the reader through the various topics and themes discussed and to help the reader make meaning of the results.

Because focus group participants construct meaning of an experience through group discussion and reflection, the results are presented in a narrative style to preserve this conversational nature. The conversations are laid out in tables with the pseudonyms and year of the speaker on the left. Each row in a table represents a single statement made by a student or a single conversation among students. The snippets of conversation have been pieced together to provide evidence to support the themes observed by the researcher.

Before the narrative data is presented, Tables 5.8 and 5.9 can be referenced for the pseudonyms of the students and number of students who participated in each focus group.

Table 5.8: 2011 Focus group participants

\begin{tabular}{cllll}
2011 & \multicolumn{2}{c}{2011} & 2011 \\
Focus Group \#1 & Focus Group \#2 & \multicolumn{2}{c}{ Focus Group \#3 } \\
1. Jill & 1. Beth & 1. Andrew \\
2. Matt & 2. Bill & 2. Brad \\
3. Sara & 3. Jake & 3. Erin \\
& 4. Kate & 4. Jason \\
& 5. Mark & 5. John \\
& & & 6. Tyrone \\
& & & Total Participants $=14$
\end{tabular}

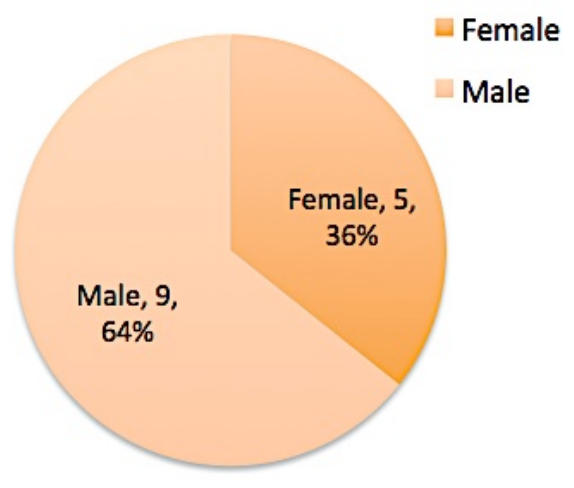


Table 5.9: 2012 Focus group participants

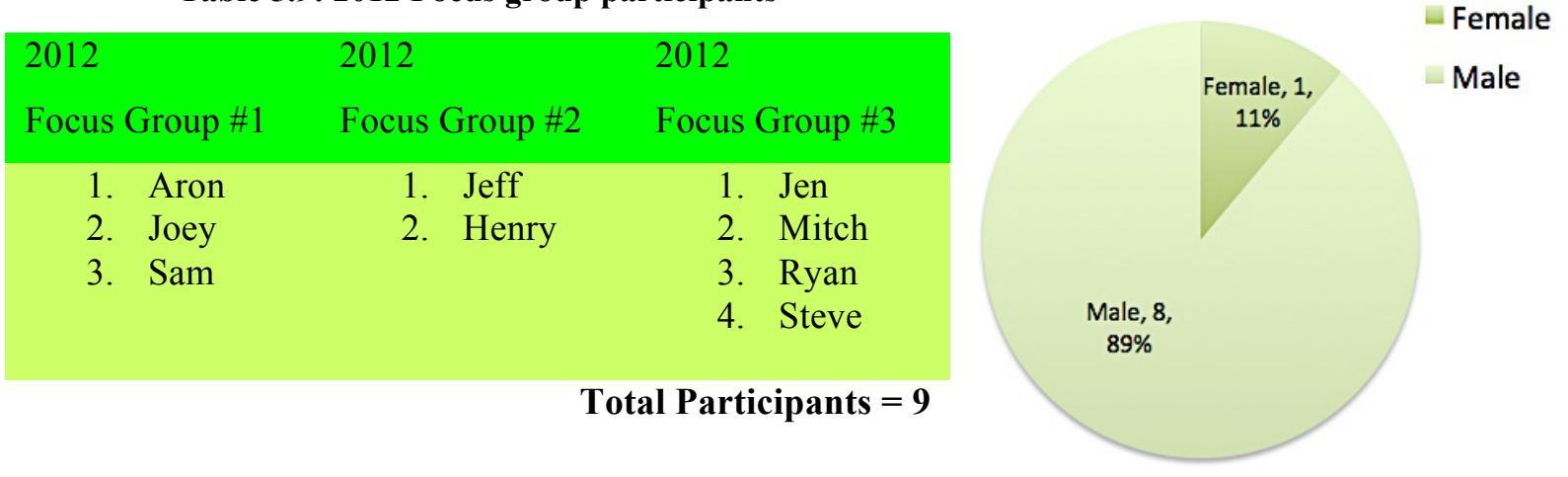

The remainder of this chapter contains the narrative of the focus group results, organized according to the dominant themes uncovered during the analysis. Prior to reading the narrative data, it may be helpful for the reader to review the focus group summaries in Appendix C.

\section{Theme \#1: Gaining real-world engineering design experience in an authentic context was the} most valuable and interesting aspect of the course experience.

The most valuable and interesting elements of the overall course experience were those that challenged students to relate machine design theory to real-world practice in a way that felt authentic. These elements served to increase students' engagement in the course and the project and also enhance their abilityrelated beliefs. Students identified the following specific elements that connected the course material to real-world experience: 1) focus of the course on linking theory to practice; 2) course faculty; 3) designbased homework assignments; 4) in-class use of videos, props, and demonstrations; 5) project-based learning.

\section{Course focus linking engineering theory to real world experience}

Students in both contexts valued how the underlying focus of the course was connecting course material to real-world experience. Especially with the project as an integral component, the course gave students an outlet to apply machine design theory in a tangible, hands-on manner.

\begin{tabular}{|l}
\hline Beth, 2011: $\begin{array}{l}\text { This was my favorite class. My absolute favorite class. We always learn all of } \\
\text { these crazy equations and we never know what to do with them, and now we } \\
\text { actually had a way to use them. }\end{array}$ \\
\hline Jason, 2011: \\
$\begin{array}{l}\text { I think I gained the most real-world experience out of this class, out of any class } \\
\text { I've had. From this class I feel like I can think through things better. The most fun }\end{array}$ \\
\hline
\end{tabular}




\begin{tabular}{|c|c|}
\hline & $\begin{array}{l}\text { was being able to do something with all the stuff we've been learning, like in } \\
\text { theory. Like in all of our classes like Thermodynamics and Heat Transfer it's like, } \\
\text { "great I can solve problems out of a textbook, but what does that mean?" }\end{array}$ \\
\hline Tyrone, 2011: & $\begin{array}{l}\text { I think for many classes, when I get done with it, I just really forget about } \\
\text { everything. But this class, as I'm done with it now I just see like random systems } \\
\text { or objects, and I kind of think about like bearings or gears. Like for other classes I } \\
\text { just drop everything. }\end{array}$ \\
\hline Erin, 2011: & I agree. \\
\hline Tyrone, 2011: & $\begin{array}{l}\text { Yeah, with this class, even if it's just a slight thing I remember, I can go back and } \\
\text { say, "oh yeah, she talked about this." And that's pretty cool. }\end{array}$ \\
\hline Sam, 2012: & $\begin{array}{l}\text { I enjoyed the fact that we were learning about stuff that is actually seen in the } \\
\text { field versus all the applied materials courses where you're learning formulas. It } \\
\text { was actually learning about fasteners, springs, all that stuff that is applied, and the } \\
\text { homework was applied to that. }\end{array}$ \\
\hline Henry, 2012: & $\begin{array}{l}\text { I liked how tangible all of the concepts were. It wasn't just theoretical, it was the } \\
\text { most tangible course I've had, where we can look at concepts like fatigue and } \\
\text { relate them to everyday experience. We actually worked with tables and charts } \\
\text { that we would use in industry, not differential equations that we won't be using in } \\
\text { industry. It's a lot different than just a textbook class. }\end{array}$ \\
\hline Jeff, 2012: & $\begin{array}{l}\text { Being hands on and taking the parts through all the steps gave me a sigh of relief } \\
\text { like, "oh finally, past the theoretical stuff with force bodies and ridiculous } \\
\text { dynamics equations. Can we please talk about building something and do it? And } \\
\text { actually use these equations?" }\end{array}$ \\
\hline Henry, 2012: & $\begin{array}{l}\text { It was interesting to see the formulas actually get applied. Seeing how they are } \\
\text { actually used was something that I wasn't expecting, so I came out with a very } \\
\text { positive experience learning about those things. I just didn't know how much } \\
\text { thought went into bearings, bushings, and fasteners. It's nice to appreciate those } \\
\text { things in everyday life now. This course gave me more than I expected. }\end{array}$ \\
\hline Jeff, 2012: & $\begin{array}{l}\text { Like, "yes this is how I use all these equations." Now I know what to look at } \\
\text { when designing. }\end{array}$ \\
\hline
\end{tabular}

\section{Supportive course faculty}

Students in both cohorts found the role of the instructor, Dana, to have a significant impact on their experience in both the course and the project. The students perceived her to be accessible, engaging, exciting, helpful, nurturing, knowledgeable, and prepared. They valued her guidance and the way she was able to relate course concepts to real-world engineering scenarios. Students also valued the way the teaching assistants (TAs) were involved in the course and available to answer students' questions. They 
also valued the feedback and guidance they received from Jerry, the design lab supervisor, regarding their project designs, especially the way he helped guide the students through the transition between design and fabrication.

\begin{tabular}{|c|c|}
\hline Matt, 2011: & Dana was definitely valuable. \\
\hline Jill, 2011: & $\begin{array}{l}\text { It was nice to have that joke around time where Dana's just sort of, you know, } \\
\text { being funny at the beginning of class. It sort of eases you into the subject and also } \\
\text { makes you want to be engaged. It's one of those classes where you can't just space } \\
\text { out because Dana might do something crazy, you don't know it, but you want to } \\
\text { get the inside joke. That was one thing that was positive about Professor Dana. She } \\
\text { was just entertaining. She was fun to watch and listen to. }\end{array}$ \\
\hline Sara, 2011: & Having the TAs, and Dana too, their input was very helpful. \\
\hline Tyrone, 2011: & $\begin{array}{l}\text { Going to Dana's office hours, she was super helpful. Like I could just drop in, and } \\
\text { if she wasn't doing anything, ask any question, and she was super interested in } \\
\text { helping. }\end{array}$ \\
\hline Erin, 2011: & $\begin{array}{l}\text { Dana literally had ten things to pass around in class every lecture and had all these } \\
\text { cool videos. She was just really prepared. }\end{array}$ \\
\hline Kate, 2011: & $\begin{array}{l}\text { I like how Dana had her own homework instead of just problems from the book. } \\
\text { She actually had to take the time to write the solutions instead so when we asked } \\
\text { her questions she knew what we were talking about instead of being like, "oh, hold } \\
\text { on. Let me pull up the solutions." So that was really nice that she had actually } \\
\text { gone through all the problems. }\end{array}$ \\
\hline Jake, 2011: & $\begin{array}{l}\text { I felt like Dana was spot on a lot of the time. A lot of times she said "a lot of you } \\
\text { probably haven't seen this before even though you are Mechanical Engineers." } \\
\text { And it was a true for a lot of people, a lot of people hadn't seen it. And so it was a } \\
\text { good introduction for me. }\end{array}$ \\
\hline Matt, 2011: & $\begin{array}{l}\text { It also helped also having six TAs that would go around during class, you could } \\
\text { ask questions, and they'd be able to clarify. }\end{array}$ \\
\hline Jill, 2011: & $\begin{array}{l}\text { And the TAs, there's a lot of them, and that takes a lot of organization between } \\
\text { them, and they were always all on the same page. And I know that's really } \\
\text { difficult, so I know they put in a lot of time to do meetings and to really work } \\
\text { together. So it was really nice to be able to go to one out of like eight people and } \\
\text { get the same answer. There was a lot of availability and information, and that was } \\
\text { great. They were all organized and on the same page. }\end{array}$ \\
\hline Matt, 2011: & Those were definitely the best TAs I've ever had in a class. \\
\hline Jill, 2011: & $\begin{array}{l}\text { Yeah, in some classes you have some TAs who are really awesome and some } \\
\text { people that you just agree that you don't go to, whereas in this class, everyone was } \\
\text { valuable and everyone was equally helpful. }\end{array}$ \\
\hline
\end{tabular}




\begin{tabular}{|c|c|}
\hline Sara, 2011: & Yeah, them all being on the same page was really noticeable, it was really helpful. \\
\hline Sara, 2011: & $\begin{array}{l}\text { The resources available to us were pretty helpful, like having Jerry and his design } \\
\text { lab open for us to use. We were able to ask him questions on our design or on } \\
\text { different parts that we needed to make, and how we should do it, and he was very } \\
\text { willing to help us, and he wanted to help us. }\end{array}$ \\
\hline Jill, 2011: & $\begin{array}{l}\text { I went down there and I talked to Jerry and was like, "I have a drawing, but I have } \\
\text { no idea." And he was like, "well, let's get you in there." And he set me up, and he } \\
\text { was just so nice, and so helpful, he was great. }\end{array}$ \\
\hline Mitch, 2012: & $\begin{array}{l}\text { Dana would still be a good enough teacher to teach the course without the project, } \\
\text { but the project definitely made it stand out among the other classes. }\end{array}$ \\
\hline Henry, 2012: & Dana does a good job in relating the concepts to real life. \\
\hline Jeff, 2012: & $\begin{array}{l}\text { She described potential problems in the workplace environment like "you need to } \\
\text { know this so you don't show up at a job and look like a newbie." At least after this } \\
\text { class you know where to find information in the book. }\end{array}$ \\
\hline Steve, 2012: & Dana made the course unique. \\
\hline Mitch, 2012: & Yup. \\
\hline Jen, 2012: & Yeah. \\
\hline Steve, 2012: & $\begin{array}{l}\text { I mean she just has a presence. And I think that, you know, most people don't have } \\
\text { presence. And when she walks into a room and gets going, she just owns the } \\
\text { classroom. And a lot of the professors, they just can't manage to do that. She's } \\
\text { excited about it, and it shows, and she's not just a professor just doing her own } \\
\text { research, which a lot of professors are just doing. She seems really involved with } \\
\text { the kids, and it's kind of like she's on your level instead of a professor who's doing } \\
\text { stuff that's millions of light years away in their research, and they have to teach } \\
\text { the course. }\end{array}$ \\
\hline Jen, 2012: & $\begin{array}{l}\text { It definitely felt like Dana and the TAs were committed as a team to helping us all } \\
\text { improve and broaden our understanding of Component Design, and I really } \\
\text { appreciated that. }\end{array}$ \\
\hline Sam, 2012: & $\begin{array}{l}\text { It helped with the volume of TAs that they had because it wasn't long to get a } \\
\text { question answered. }\end{array}$ \\
\hline Jen, 2012: & $\begin{array}{l}\text { I really liked the way that Dana used her TAs. I felt that she used them the best } \\
\text { way she could instead of just having them in the background grading. They were } \\
\text { always involved, and they were really helpful when I asked them questions. So I } \\
\text { feel like she used her TAs really well. In some classes you never see the TAs } \\
\text { because they're just grading. But in this class they actually helped teach, which } \\
\text { made the class a lot better. }\end{array}$ \\
\hline
\end{tabular}


Sam, 2012: We always just took our design to Jerry and were like, "Jerry, could we possibly build this in this amount of time?" And he would help us.

Jen, 2012: I felt like it helped our team a lot because we had our design checked by Jerry before we actually finalized it.

\section{Design-based homework assignments}

Students in the 2011 cohort found the design-based homework problems (i.e. designing a component to meet a specific need and using the Internet to select and specify an actual component) to be valuable and interesting. These types of problems challenged students to apply course knowledge in a more realistic context. Students in the 2012 cohort did not mention the design-based homework assignments.

\begin{tabular}{|c|c|}
\hline Jake, 2011: & $\begin{array}{l}\text { It was almost my first class where I felt like I was an engineer instead of just a } \\
\text { mathematician. It was definitely reinforced by the homework, which was design- } \\
\text { based. We would be actually designing something and going and selecting actual } \\
\text { products. Like the last two or three homework assignments you had to design } \\
\text { something from scratch, and that was really helpful. }\end{array}$ \\
\hline Mark, 2011: & $\begin{array}{l}\text { Yeah, it was definitely more difficult, actually having to like go on the websites } \\
\text { and be like, "well, okay, this graph that they gave us doesn't actually have units on } \\
\text { it." Having to deal with what it would actually be like to go through the process of } \\
\text { selecting standard parts and using them in your calculations. }\end{array}$ \\
\hline Bill, 2011: & It was eye opening. \\
\hline Jason, 2011: & $\begin{array}{l}\text { I think the problems where we actually had to give a spec, like the springs and } \\
\text { bearings and stuff, I thought those were the most interesting, because they actually } \\
\text { applied to building something. Where as like, with our drill-powered vehicle we } \\
\text { had bearings but we were like "yeah, these will be fine" but like we didn't really } \\
\text { think about it at all. But actually having a problem where you had to design to } \\
\text { meet a need, that was more interesting. }\end{array}$ \\
\hline Erin, 2011: & $\begin{array}{l}\text { She gave us two design problems for homework, and it wasn't just like, "calculate } \\
\text { the stresses on this." It was like, "on the Internet, find an actual bearing that you } \\
\text { could buy and spec it and make sure it's going to work in this application." It was } \\
\text { really cool. }\end{array}$ \\
\hline
\end{tabular}

\section{In-class use of videos, props, and demonstrations}

Students in both cohorts found the in-class use of videos, props, and demonstrations to be interesting, valuable, and exciting because they related the course material to real life in a tangible way. Students also reported an increase in their quality of learning. 


\begin{tabular}{|c|c|}
\hline Matt, 2011: & $\begin{array}{l}\text { I think switching it up between lecture, and the occasional video and the work } \\
\text { time, it definitely keeps the class going quick, especially an hour and fifteen } \\
\text { minute class. You can stay focused. I think mixing it up is definitely important. }\end{array}$ \\
\hline Bill, 2011: & $\begin{array}{l}\text { I thought the videos regarding how things were made were really helpful in } \\
\text { understanding a little bit more about what we were actually talking about. }\end{array}$ \\
\hline Jake, 2011: & $\begin{array}{l}\text { Yeah, like how springs were made. I think all the videos that she showed just } \\
\text { really helped concrete what she was talking about more than she could just do } \\
\text { verbally. }\end{array}$ \\
\hline Bill, 2011: & $\begin{array}{l}\text { My interest in Component Design definitely increased over the course of the } \\
\text { semester, and I think a big part of that was her handing out failures in class and } \\
\text { just being hands-on. I definitely just came to realize how important it was and felt } \\
\text { like I was learning something really valuable. Interesting and valuable for being an } \\
\text { engineer. }\end{array}$ \\
\hline Kate, 2011: & $\begin{array}{l}\text { Yeah, because when I started I was like, "oh we're going to learn how to analyze } \\
\text { like a spring or like a beam... yuck." But then she hands out realistic things and } \\
\text { you could see how they would fail, and how they could be bad, and how you could } \\
\text { relate it to your life. I felt my interest grew. }\end{array}$ \\
\hline Jake, 2011: & $\begin{array}{l}\text { It's really the only class where you actually get a real-life example. At least so far, } \\
\text { because everyone else, they teach it, and it's like weird things in the book that } \\
\text { aren't really relatable. Like just one beam sticking out of the side of a building. } \\
\text { When am I going to use that, you know? It's just helpful to have like a real, very } \\
\text { specific example, especially something you can hold in your hands. }\end{array}$ \\
\hline Mark, 2011: & $\begin{array}{l}\text { Almost every day she would have something, which was great. I don't think we } \\
\text { get that in almost any of our other classes. }\end{array}$ \\
\hline Erin, 2011: & $\begin{array}{l}\text { I thought it was awesome that Dana gave us a lot of real world examples to apply } \\
\text { the things that we were learning in class like bearings and the differential. She } \\
\text { showed us a video on how differentials work, and that made the gear application } \\
\text { pretty valuable. }\end{array}$ \\
\hline Tyrone, 2011: & $\begin{array}{l}\text { I think all those videos she showed in class were really helpful. I mean, just to } \\
\text { have an idea of how gears are made. It's something I would never had known, so } \\
\text { it's just good, because you see gears every day, so it's a good thing to know how } \\
\text { they're made. }\end{array}$ \\
\hline Jason, 2011: & $\begin{array}{l}\text { Yeah, I like how much stuff she brought in to show us how this breaks, why this } \\
\text { breaks, how to not let this break. I thought that was really helpful. }\end{array}$ \\
\hline Henry, 2012: & $\begin{array}{l}\text { We watched a lot of videos, and I watched others on my own, and it helped a lot. } \\
\text { For some of the other classes it would help to get a visual understanding of what's } \\
\text { going on for us to appreciate it, too. }\end{array}$ \\
\hline
\end{tabular}


Jeff, 2012: It definitely gets you way more excited like, "oh that's why I'm learning this!" So it's easier to stay engaged. It can revitalize a classroom by saying "this is why you're learning." It provides a rationalization.

Steve, 2012: I was pretty interested in the material to start, but I think I actually got more excited about it. I think, well, they weren't really demonstrations, but the realworld videos that allowed me to see like how I might apply things out of the classroom.

One student, however, didn't find the use of videos, props, and demonstrations to be effective in helping him comprehend the course material.

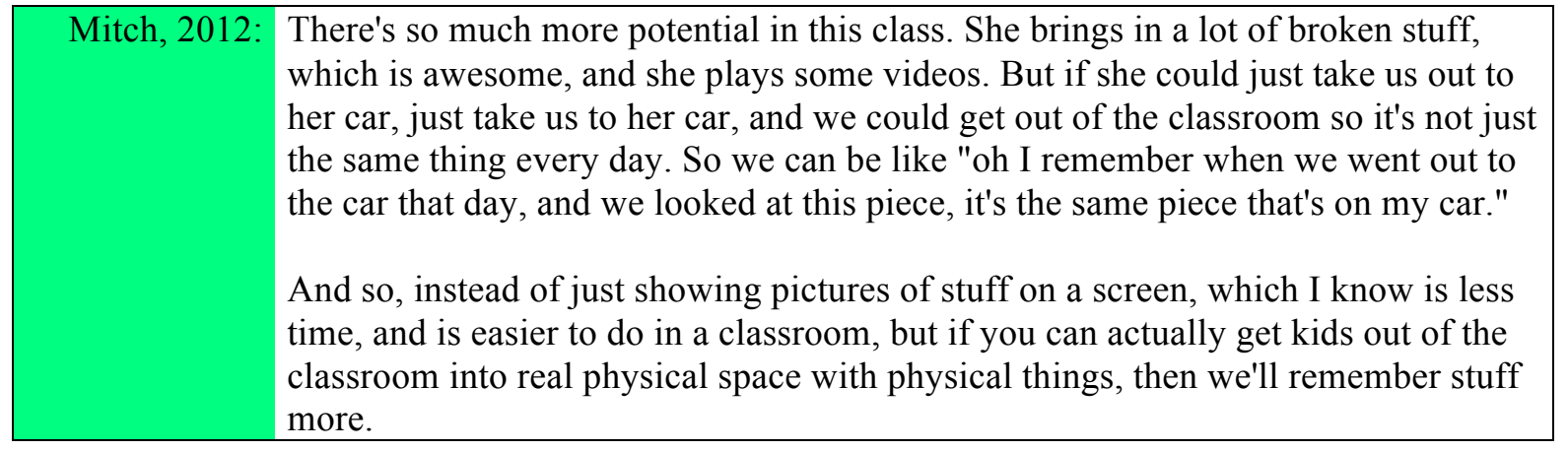

\section{Project-based learning}

Students in both cohorts found the project to be the overall most valuable element of the course. While each project represented a different design challenge and context, the essence of what students valued in the project was the same. Above all other qualities students valued the authenticity of the project, as it allowed them to experience real-world engineering design. The following testimonials highlight the elements of the project that made it feel authentic.

The project was a vehicle to apply course concepts to real life. Similar to how students perceived the underlying focus of the course, the project served as a link between machine design theory and the real world. Through the project, the students were able to experience how Component Design relates to everyday life.

Jill, 2011: I definitely see the transfer between this project and real life. Like welding - that's a skill that will transfer far beyond this semester.

Sara, 2011:

Building a car was pretty helpful. It just helps you to actually see how things are going to work together and fit together because you have an idea in your head and then you're like, "no, this is not going to work." 


\begin{tabular}{|c|c|}
\hline Jill, 2011: & $\begin{array}{l}\text { When I found out what our project was I was just really excited to do it. I was } \\
\text { really excited to do something large and tangible that you can ride on, you can feel } \\
\text { the effects of it. I thought that was the most exciting part of it, so that was kind of } \\
\text { a great start like "oh this awesome thing we were going to be doing!" }\end{array}$ \\
\hline Mitch, 2012: & $\begin{array}{l}\text { I really liked how we went over in class how to identify loading situations in the } \\
\text { real world, or fatigue loading, or tear out failure, that sort of thing and when they } \\
\text { might happen. And when as I was doing my project with my group I noticed that I } \\
\text { could actually see a few of these scenarios. }\end{array}$ \\
\hline Jen, 2012: & Without the project Component Design would be just another... \\
\hline Steve, 2012: & Boring class. \\
\hline Jen, 2012: & $\begin{array}{l}\text { Yeah where you just learn equations and you take a couple midterms and you take } \\
\text { a final, but the project really made it a lot more interesting and relevant. It was just } \\
\text { really great. }\end{array}$ \\
\hline Steve, 2012: & $\begin{array}{l}\text { The hands-on building definitely allowed us to practice the concepts that we } \\
\text { learned in class and learn how we might apply them, so I thought that was very } \\
\text { valuable. }\end{array}$ \\
\hline Aron, 2012: & $\begin{array}{l}\text { It was interesting to not just learn about fasteners and not just learn about drive } \\
\text { trains but to put all the pieces into one thing. it kind of forces you to look at the } \\
\text { bigger picture. The most interesting part for me was trying to put all the pieces into } \\
\text { one place. Not just fatigue and not just gear ratios but all of them together in a } \\
\text { single unified project. }\end{array}$ \\
\hline Jeff, 2012: & $\begin{array}{l}\text { This course did such a good job of integrating everything we learned up to this } \\
\text { point with what a finished product looks like. }\end{array}$ \\
\hline
\end{tabular}

The project was open-ended. Although there was a basic, unifying set of design goals for both projects, the students valued that there was enough flexibility to allow for multiple solution paths.

Bill, 2011: There was a base of design, and you can kind of branch out a little bit from that, or you can branch out really far. And there was enough variation that you could really try and go for torque, you could really try and go for speed, you could really try and go for economy.

Jill, 2011: We were given constraints, we were given an objective, and that was all we needed to sort of, tackle this project, and I thought having that sort of openendedness made it a lot more fun because we got so many different designs scooters, or bikes, or carts and stuff, so that was cool to see everybody's take on the project, so you get a lot more creativity, and I really enjoyed that.

Bill, 2011: Another thing that I liked about the project was that it was open-ended. 
Beth, 2011: Yeah.

Bill, 2011: I was actually surprised that we ended up having a lot of the same solutions, but it was definitely disappointing because it would have been cool to see some other solutions. But It was great that there was such flexibility to have the range of different solutions.

Aron, 2012: I liked the diversity of the project. It was more open-ended because everybody had a different client and a different spin on what the client needed. So that was most interesting to me because it allowed for more diversity in what you actually can incorporate into the project.

The project encouraged creativity. Along with the open-endedness of the project, students in both cohorts enjoyed applying creativity to engineering design. They perceived creativity to be an important engineering skill that must be developed through practice and cannot be learned from a book. Students in both cohorts were inspired by the diversity of designs at the end of the semester. Students in the 2012 cohort also described the lessons they gleaned from having to creatively problem solve, especially with the addition of a real-world client.

\begin{tabular}{|c|}
\hline John, 2011: \\
$\begin{array}{l}\text { I thought the run-off was really fun. It was really interesting to see a lot of } \\
\text { people's creativity. }\end{array}$ \\
\hline Erin, 2011: $\begin{array}{l}\text { I went into the run-off thinking that a lot of people would have the same design } \\
\text { because a drill-powered vehicle, a lot of people will just have a drill mounted to a } \\
\text { bike. But there were just so many different designs, and I was just really amazed } \\
\text { by how creative everyone was. It was really cool, I hadn't seen a lot of the designs. } \\
\text { I had seen some people testing it but it was just cool to see what everyone had } \\
\text { done. }\end{array}$ \\
\hline Henry, 2012: \\
$\begin{array}{l}\text { I was impressed at the expo, seeing all these trike designs. There were all these } \\
\text { designs that you thought of and didn't know how to implement and then you see } \\
\text { that someone else did it. Sometimes you have to see it from a different angle. }\end{array}$ \\
\hline Henry, 2012: $\begin{array}{l}\text { Another skill I gained was coming up with creative solutions for designing certain } \\
\text { things, like I didn't think I'd spend hours the last night sewing stuff. But by being } \\
\text { creative, using the resources at hand, going out to just find things that you never } \\
\text { thought of. Like calling around to get glitter spray! It was great to have these } \\
\text { things left up to us, to have to be creative and make things work. } \\
\text { Jeff, 2012: } \\
\text { Scrounging is definitely a good skill too, like approaching people in the } \\
\text { community. Can you ask someone for a rusted headset bearing, can you go up to a } \\
\text { bike shop and ask what they can throw your way? Creative problem solving. }\end{array}$ \\
\hline Mitch, 2012: $\begin{array}{l}\text { I also think in general just being able to give us time to be creative is the thing they } \\
\text { should be doing all the time. But there's no time to be creative. You have to do pen }\end{array}$ \\
\hline
\end{tabular}




\begin{tabular}{|c|c|}
\hline & $\begin{array}{l}\text { and paper equations. Allowing us to be creative will teach us way more about } \\
\text { designing cool things than writing stuff down. }\end{array}$ \\
\hline Ryan, 2012: & $\begin{array}{l}\text { I think it was just allowing us to be creative, finally, that was most valuable. All } \\
\text { this stuff we've been learning in school is basically to recognize where you can } \\
\text { apply equations and stuff. But in Component Design, again, this creativity thing is } \\
\text { unleashed. And it's so important! And the other thing is that computers are getting } \\
\text { ridiculously smart. But the one thing that computers can't do is be creative. So } \\
\text { really if we're competing with computers these days, which we are, then the only } \\
\text { edge we have on them is being creative. And if we're not allowing students to } \\
\text { practice those creative skills then we're training people for a job that won't exist in } \\
\text { a couple years. }\end{array}$ \\
\hline Ryan, 2012: & $\begin{array}{l}\text { You can't teach creativity, you can only allow for creativity. So giving us time to } \\
\text { work in groups to solve problems by taking in things that a computer would not } \\
\text { recognize like, "does our client have siblings?" which is something that would } \\
\text { totally change our project. }\end{array}$ \\
\hline Jen, 2012: & $\begin{array}{l}\text { Yeah, I really liked the creative aspect of the class and everything. Because our } \\
\text { whole curriculum is just about trying to write the right answer on a test and do the } \\
\text { right thing and think inside the box and do what the professor is telling us. But in } \\
\text { this class, like Ryan was saying, to think outside the box, to have to consider } \\
\text { different designs for the siblings. You have to take everything into account, and it's } \\
\text { not just straightforward. It's a really great learning experience. So I felt like the } \\
\text { project was a really, really great learning experience. }\end{array}$ \\
\hline
\end{tabular}

The project fostered the development of new skills. Students in both cohorts described in detail the various technical and non-technical skills they developed. Machining and fabrication were the most important technical skills gained. Technical writing, communication, working on a team, time management, and preparing meetings minutes and agendas were the most important non-technical skills gained.

\begin{tabular}{|c|c|}
\hline Brad, 2011: & I did a lot of milling for this one bearing mount we had. And a little bit of welding. \\
\hline Jill, 2011: & $\begin{array}{l}\text { It's little things like that that I learned like, "oh you can't weld to aluminum, or } \\
\text { welding to aluminum is hard?" It's stuff like that, those little details. }\end{array}$ \\
\hline Jill, 2011: & $\begin{array}{l}\text { I was sort of scared at first to come down to the design lab and manufacture stuff, } \\
\text { but my team needed something to be done and I was like, "well I guess I'm the } \\
\text { only free one. Power tools scare me." But now I am no longer afraid of power } \\
\text { tools! }\end{array}$ \\
\hline Matt, 2011: & $\begin{array}{l}\text { I've definitely done a fair amount of woodworking and stuff like that, but I've } \\
\text { never done too much metalworking, as far as lathes and mills. I guess I've done } \\
\text { some, but no lathes, so I guess I learned lathes. }\end{array}$ \\
\hline
\end{tabular}




\begin{tabular}{|l}
\hline Sam, 2012: $\begin{array}{l}\text { I definitely learned more on running a mill and running a lathe, and I just learned } \\
\text { basic tool use. I kind of already knew stuff, but I learned a lot of tools that I never } \\
\text { would have expected to use before, and how they're properly used so that was kind } \\
\text { of a big thing for me. And names of tools, like more unique tools, because that was } \\
\text { nice, you feel savvier talking to people in industry. }\end{array}$ \\
\hline Henry, 2012: \\
I got to weld for the first time too and now have a tangible understanding of it. \\
That was important for me. \\
\hline Joey, 2012: $\begin{array}{l}\text { I gained welding skills, definitely. I didn't have any before. And definitely } \\
\text { fabrication. When you don't actually build projects that you're designing or } \\
\text { thinking about, sometimes it is easy to forget how difficult fabrication actually is, } \\
\text { and how long everything takes. Everything takes five times as long as you plan on } \\
\text { it taking. }\end{array}$ \\
$\begin{array}{l}\text { Jen, 2012: } \\
\text { I definitely learned how to machine a lot better. What machines can and can't do. } \\
\text { You have to bring a drawing in and if it's not completely dimensioned out, then the } \\
\text { parts going to end up wrong or they're not going to do it, so you have to make sure } \\
\text { that everything is right before you give it to them. }\end{array}$ \\
$\begin{array}{l}\text { I'm also going to be taking notes on my fabrication process. I'm going to say the } \\
\text { general list with the date of when it happened, because it's hard and time } \\
\text { consuming to recall it all from memory. But if we keep a simple assembly and } \\
\text { manufacturing workbook then it organizes your thoughts. }\end{array}$ \\
\hline Jeff, 2012
\end{tabular}

Students in both cohorts described significant improvement in their technical writing, which will be valuable for their future careers.

\begin{tabular}{|l}
\hline Jill, 2011: $\begin{array}{l}\text { I thought the report iteration process was helpful. It wasn't like we turned in this } \\
\text { big thing at the end and then got nailed. So the staged report was awesome. } \\
\text { Because we could really learn from it as the semester went. }\end{array}$ \\
\hline Jake, 2011: $\begin{array}{l}\text { My technical writing skills improved. I think it really helped that Dana was so } \\
\text { strict about papers. We've never had anyone be like that. Every little detail, we got } \\
\text { graded down on it. It really makes you learn. What I learned is how easy it is to } \\
\text { make mistakes, and that's something that could really come back to haunt you } \\
\text { when you're in industry. You can't turn in something to your manager that has a } \\
\text { bunch of mistakes on it. }\end{array}$ \\
\hline Tyrone, 2011: $\begin{array}{l}\text { For the design reports, I like how we had two different checks before the final, } \\
\text { because writing the final thing would have been a real pain. }\end{array}$ \\
Erin, 2011: $\begin{array}{l}\text { Yeah, especially at the end of the semester. No one would have wanted to. } \\
\text { Matt, 2011: }\end{array} \begin{array}{l}\text { Having to do design reports was valuable, getting all the feedback on the design } \\
\text { reports, because they really went through them. That was really helpful. }\end{array}$ \\
\hline
\end{tabular}




\section{Tyrone, 2011: Writing technical reports has definitely helped me build some written skills. I mean I know it's just for a school project, but there are definitely things I have learned that I feel like I can apply someday in grad school, work, whatever. \\ Andrew, 2011: When you have to take five people's writings, some of which obviously isn't as polished and try to put it together into one coherent one voice paper, that really, really provides a lot of good training. \\ Henry, 2012: Technical writing was a paradigm shift for me. Everything I have written before was literal. I think the curriculum here is a little weak in the writing because you see a lot of students and it's surprising what level they are with their writing skills. It's something that you wouldn't think of Component Design teaching you, but its really versatile. That sticks out for me. \\ Jeff, 2012: I definitely saw the technical writing piece as almost a way to get ahead in your first job. The experience of having to write a paper like that, screwing it up, and then again the second time, then the next time.}

Students in the 2012 cohort also valued the communication skills they developed and described how they came to perceive it is a critical skill for engineering.

Joey, 2012: Another non-technical skill is communicating ideas to your teammates. We had a lot of trouble with that in the beginning because not everyone's as mechanically inclined.

Henry, 2012: Communication is a big part of the profession. Like communicating ideas in a tangible way on paper. Something we had to learn is being in front of a white board and trying to get your ideas across, and saying something without saying "um" every two seconds and getting lost and fidgeting. Thinking about what to say before actually bringing it up. That's one thing that is lifelong valuable from the course.

Jeff, 2012: Absolutely, there was a ton of growth. Jerry, for example, the first couple times getting a hole drilled or cut off, he demanded a drawing. He got up in a kid's face and says, "I told you to give me a drawing!" People now know what's expected of them and how to communicate. I think it will be a lot easier to work with people because of this class.

Henry, 2012: It was unique to have to have such regular communication between team members and be coordinated so well, and really understanding that communication is crucial. We're not taught that in engineering, but I took a project management course about communication, and we really learned this in this course.

Jeff, 2012: I noticed it's easier to talk to some students after this project because of having to take that interaction and be comfortable with speaking and listening. Like understanding that someone might have a great big vision. So it forced me to stop and listen to others. It's so easy to get sucked into your own computer. 
Students in both cohorts gained valuable experience working on a team where everybody has different expectations of the project and various levels of project interest and engagement.

\begin{tabular}{|l}
\hline Matt, 2011: $\begin{array}{l}\text { I guess just figuring out how to get everyone together was a skill I gained. I mean I } \\
\text { guess it's not really learning, more just experience gaining. Doing it and figuring } \\
\text { out what works best and what doesn't work. Like how you can motivate people. }\end{array}$ \\
\hline Jake, 2011: $\begin{array}{l}\text { The biggest skill I learned was really being able to understand how to influence } \\
\text { other people. Influence them to provide better work. I wasn't a project manager but } \\
\text { I ended up doing a lot of the project management responsibilities. I guess Dana } \\
\text { described that as leadership at the beginning of the semester. Being able to } \\
\text { influence our teammates by example. }\end{array}$ \\
\hline Kate, 2011: $\begin{array}{l}\text { I learned even more that working on a team it's really important for everybody to } \\
\text { lay their expectations out on the table because my team ended up working well } \\
\text { together, and I think part of that is because we said at the beginning, "I want this" } \\
\text { or, "I don't want to put in that much work in to the project." }\end{array}$ \\
\hline Mitch, 2012: $\begin{array}{l}\text { I definitely gained teamwork. Maybe not teamwork, but working with, dealing } \\
\text { with people. And you have to figure out how to keep the peace when you have } \\
\text { deadlines and stuff like that. }\end{array}$ \\
Steve, 2012: $\begin{array}{l}\text { Yeah. } \\
\text { Mitch, 2012: } \\
\text { And you put your personal issues beside because that only makes it worse. So that } \\
\text { was a personal skill gained, just dealing with people. }\end{array}$ \\
\hline Aron, 2012: $\begin{array}{l}\text { I had a lot of development of my managerial skills and my group management } \\
\text { skills. Because you really get to experience a huge variety of motivation issues. }\end{array}$ \\
\hline
\end{tabular}

Students in both cohorts also described time management as another important skill acquired.

Erin, 2011: Our bike didn't run the Saturday previous to the run-off and I was like, "that's never going to be me! No way!" And I took it home and my dad helped me out, but it was literally two days before the run-off, and I was like "we might fail this class." I had no idea that was going to happen to me during this course. And, we should have been testing it two weeks before that, but like, it wasn't even running. And I was like pretty confident in my time management skills up until this happened.

Jill, 2011: As people got busier toward the end of the semester we did run into a few hiccups with everybody being so busy, so maybe only one person could paint the vehicle, so work became a little lopsided. I think that more people who were really enthusiastic about the project really put out a lot of extra work. So that was difficult. 


\begin{tabular}{|l}
\hline Sam, 2012: $\begin{array}{l}\text { This class helped learn how to meet long deadlines. It's your first time of having a } \\
\text { deadline that is really far out, and like meeting small deadlines up to that. }\end{array}$ \\
Joey, 2012: $\begin{array}{l}\text { It's going to get even worse when we hit Senior Design, because we're going to get } \\
\text { a whole year. }\end{array}$ \\
\hline Steve, 2012: \\
$\begin{array}{l}\text { Scheduling was a huge soft skill that I gained. Especially around spring break. } \\
\text { Some of my team members weren't really available. And most of my group had } \\
\text { very different schedules, so especially toward the end we had to figure out who } \\
\text { could work and who couldn't work and what we could get done in the time that we } \\
\text { had. }\end{array}$ \\
\hline Mitch, 2012: \\
$\begin{array}{l}\text { I also kind of learned about scheduling and time management. Because all the } \\
\text { projects we've had before this it's been like, "oh well I guess I'll just go into the } \\
\text { computer lab on these days and just sit until it's done." But here there's too much to } \\
\text { get done in that short time, so we have to keep planning every week to get } \\
\text { everyone on the same schedule and getting everybody coordinated. }\end{array}$ \\
\hline
\end{tabular}

Although students valued developing time management skills, they had mixed feelings about the project requirement to prepare meeting minutes and agendas. While some students valued having a consistent time to meet with their team and a structured list of items to discuss, other students preferred to let the meetings happen more organically and perceived the meeting minutes and agendas as busywork.

Matt, 2011: At the beginning the meetings with the team were definitely helpful to get everyone on the same page, but as the semester progressed they kind of became worthless. Honestly, my team quit meeting halfway through the semester. So we'd make up the minutes. I felt unnecessary in this project to meet, so some people just didn't meet. I feel most people are pretty smart, our peers, and they could pick up on how to run a meeting, and how to take meeting minutes when they need to do it, so, I guess having a little bit of exposure is good. Maybe just having to meet at the beginning.

Jill, 2011: I disagree. I loved the meetings. I was the communications director and I was always writing in my little booklet, and I was always on top of it, so I sort of liked that aspect, having the meeting every week. I liked that we had that scheduled time in the beginning so we knew we could all meet Mondays. But I do agree though how at the end they kind of became less important, and our meetings became like fifteen minutes, even if it was just checking in. I thought that was helpful. I also enjoyed how you're all in other classes together, so if you didn't work on Component Design stuff during that time, you might be working on a lab for Thermo or homework for Heat Transfer or something like that. So it was great to have sort of this network of these people who you knew to sort of share our workload in this class and in other classes as well. 


\begin{tabular}{|l}
\hline Sara, 2011: $\begin{array}{l}\text { Getting used to doing the meeting minutes was a good skill, not just writing things } \\
\text { down. I was the communications leader as well, and I got more of that aspect of it. } \\
\text { So I learned what a good agenda should be and how to organize your time. }\end{array}$ \\
\hline Henry, 2012: \\
$\begin{array}{l}\text { Keeping track of things was really important. I'm not sure if it was emphasized } \\
\text { enough along the way. We were having a hard time keeping track of receipts, and I } \\
\text { knew I should have cared about this but it's also a good real world experience. I } \\
\text { understand that's the point of the meeting agendas so we're on task if we had to go } \\
\text { back and review, but it would have been nice to have that emphasized too. }\end{array}$ \\
\hline Ryan, 2012: $\begin{array}{l}\text { I kind of thought that the meeting minutes and the agenda, I don't know, I didn't } \\
\text { find those helpful really. It seemed like busy work. }\end{array}$ \\
\hline
\end{tabular}

The project culminated in a realistic product. Students in the 2011 cohort valued how, unlike other school project which are often discarded, the drill-powered vehicle will have practical and useful applications, even after the project is finished.

\begin{tabular}{|l}
\hline Beth, 2011: $\begin{array}{l}\text { The project was really cool because you had something to show when you were } \\
\text { done, and you could race it, and you could feel good about yourself. }\end{array}$ \\
\hline Andrew, 2011: \\
$\begin{array}{l}\text { I think one of the best parts of this project was that it still had practical } \\
\text { applications after you're done. I mounted headlights on it so we could drive it } \\
\text { around at night on the back roads. We'll take it down to 29th Street Mall when we } \\
\text { want food and stuff, and we'll park in the alternative fuel vehicle spot because } \\
\text { we're like "well, you know, this uses electric power." That was definitely one of } \\
\text { the best parts for us. }\end{array}$ \\
\hline Matt, 2011: \\
$\begin{array}{l}\text { I think the project was definitely cool. I think everyone enjoyed it. Everyone liked } \\
\text { having a little vehicle you could drive around, especially one that you built } \\
\text { yourself. Some of my roommates who saw the project at home were really excited } \\
\text { like "you built what in your class? That's cool!" Actually making something that } \\
\text { moves, making a practical device. }\end{array}$ \\
\hline Sara, 2011: $\begin{array}{l}\text { I think like the whole process of doing the project was definitely pretty exciting, } \\
\text { and like Matt said you can drive it around. It's more practical. }\end{array}$ \\
\hline
\end{tabular}


Theme \#2: Team dynamics and ill-structured problems presented the greatest challenges.

Prior evidence clearly suggests that students valued the overall course experience, especially the project. But what about the struggles they encountered along the way? The following testimonials illustrate the challenges the students faced, especially with regard to the open-endedness of the project, the students' different levels of technical and non-technical skills and abilities, access to project resources, team dynamics, and the integration of the project and the course. These challenges represent the types of "ill-structured" problems students are likely to encounter in workplace settings and future team-based design experience. It was many students' first experience with such complex, real-world problems.

\section{Struggle with open-endedness}

The open-endedness of the project was a double-edged sword. Although it was a highly valued element of the project, it was also problematic. Students grappled with not being able to control the project scope and not being explicitly told what they were "supposed" to be learning. Some were concerned that the quality of learning was not uniform across students. In other words, students were learning and doing different things. Another problem was that some students weren't branching out and learning new skills but staying too much in their comfort zone.

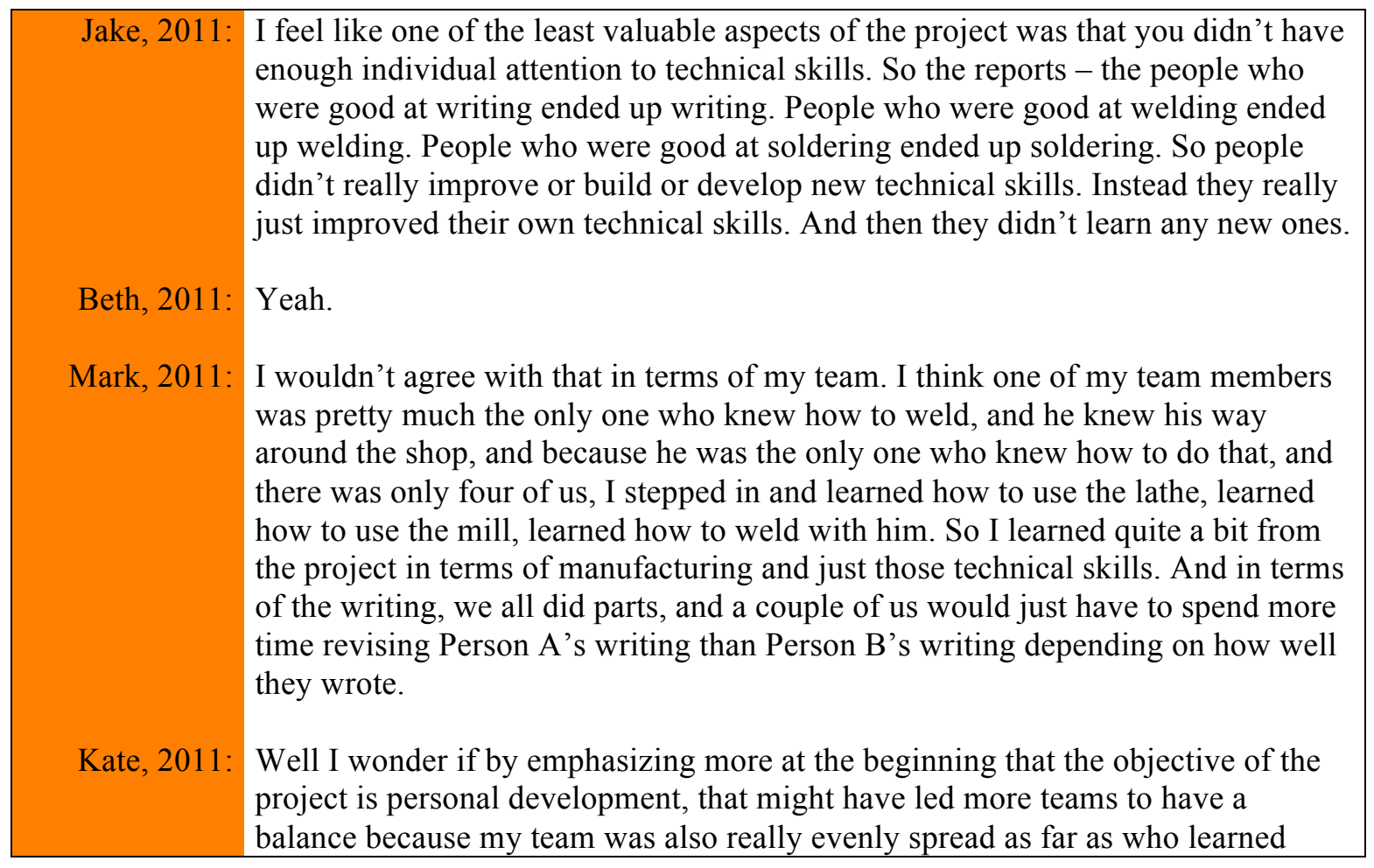




\begin{tabular}{|c|c|}
\hline Beth, 2011: & $\begin{array}{l}\text { what even for the writing parts. And I wonder if that is just because we } \\
\text { interpreted the objectives of the project differently. Because we thought that was } \\
\text { one of the things was to learn all of this stuff to do to make this project happen. } \\
\text { I think our group was more like "get it done, and get it done well!" And if you're } \\
\text { good at writing, you're going to be the writer. And if you can do the SolidWorks, } \\
\text { you're going to do the SolidWorks. We didn't care if you learned any new } \\
\text { technical skills because our goal was just to get the project done and get it done } \\
\text { well, so it didn't matter. }\end{array}$ \\
\hline Jake, 2011: & So an improvement might be to add a personal standard. Or personal goals. \\
\hline Beth, 2011: & Yeah. \\
\hline Bill, 2011: & $\begin{array}{l}\text { I think a reason for people just getting it done because we did that too was the } \\
\text { heavy course load. There was a lot more I wanted to do and learn about, and you } \\
\text { know, I'd go through the report as technical writer and I'd be like, "well I hope } \\
\text { these calculations are correct!" I don't get to learn this, I don't have time to sit } \\
\text { down with him and learn what he learned and you know share our learning, } \\
\text { learning together, that didn't happen as much as would have been great to } \\
\text { happen. }\end{array}$ \\
\hline Beth, 2011: & $\begin{array}{l}\text { Well, I think it would be really cool if there were like a list of things and you pick } \\
\text { a goal to learn a new skill. So, if someone doesn't know how to weld, their goal is } \\
\text { learning how to weld. Like pick a goal on something to improve on. }\end{array}$ \\
\hline Joey, 2012: & $\begin{array}{l}\text { I didn't really get to talk about controlling the scope of the project, like people } \\
\text { pitching ideas that aren't really doable in the time that you have. I'm definitely } \\
\text { one of those people. I was like, "we're definitely going to build a spaceship for } \\
\text { this little girl." And luckily some people on my team are a little more realistic } \\
\text { than I am. But if there were a team composed of people entirely like me than I } \\
\text { think there needs to be a little more guidance of what we should actually be } \\
\text { expecting to produce. And that elaborate, very complicated designs seem } \\
\text { realistic, at least to some of us in the beginning, but aren't so much at the end. }\end{array}$ \\
\hline Henry, 2012: & $\begin{array}{l}\text { I recommend that everyone have to do something. We left it up to ourselves. I } \\
\text { was fortunate to learn how to weld, but other students didn't have the opportunity. } \\
\text { I feel I had a lot of different experiences, so it would be nice to know what was } \\
\text { expected. We all have different experiences and specialties so some specialties } \\
\text { should be expected. I didn't do any SolidWorks, some people didn't weld, some } \\
\text { people didn't machine, some didn't write. This isn't good or bad but something to } \\
\text { be aware of. There will be different experiences, very different, so when someone } \\
\text { completes this course it's really hard to say what they were supposed to learn } \\
\text { from the project. }\end{array}$ \\
\hline
\end{tabular}




\section{Uneven distribution of skills and access to resources}

Another common struggle students encountered was leveraging each other's individual skills and abilities to function as a team. Students in both cohorts observed in themselves and their peers a significant lack of prior experience with machining, fabrication, and general tool use. They adamantly expressed a need for additional training and more equal access to machining and fabrication resources.

\begin{tabular}{|c|c|}
\hline Jill, 2011: & $\begin{array}{l}\text { I almost wish they did offer a welding workshop for a small fee for a few kids, } \\
\text { and I wish everyone had gotten to do that because that's a really valuable skill } \\
\text { that we'll probably need next year in Senior Design. I think it would be great if } \\
\text { we had a lab component where we learn to do things like welding and other sort } \\
\text { of assembly or hands-on things, small things like that. }\end{array}$ \\
\hline Matt, 2011: & $\begin{array}{l}\text { I definitely agree with that. I think hands-on, and being able to fabricate, it seems } \\
\text { like a lot of students don't have that background, never built anything. I } \\
\text { remember coming here freshman year and just looking around and thinking, } \\
\text { "these kids are going to be engineers?" Like these people are building stuff and } \\
\text { they have no idea how anything goes together. So I think actually forcing } \\
\text { students to have to build something, and teaching them how to weld would be } \\
\text { good. }\end{array}$ \\
\hline Sara, 2011: & $\begin{array}{l}\text { I feel like in Freshman Projects, or even in Intro to Engineering, with mechanical } \\
\text { we got to build like one little thing on the mill, but then from there to Component } \\
\text { Design, we don't really have anything. I feel like we were expected to know how } \\
\text { to do some of this stuff, and there was kind of a disconnect. }\end{array}$ \\
\hline Ryan, 2012: & $\begin{array}{l}\text { We have to understand how parts can be built in the machine shop, right? If kids } \\
\text { in the group don't have experience with the machines, then they're designing way } \\
\text { out of proportion. So you've spent all this time coming up with these really cool } \\
\text { designs but in actuality you can't build it. I mean you can make a lot of things in } \\
\text { the machine shop but you have to know what's possible to do in the machine shop } \\
\text { and then start designing from that. A lot of my group members have never been } \\
\text { in the machine shop so I was like, "you can't build that." Or, "we should do this } \\
\text { instead because you can build this really easily." }\end{array}$ \\
\hline Steve, 2012: & That would have been good. \\
\hline Jen, 2012: & Yeah. \\
\hline
\end{tabular}




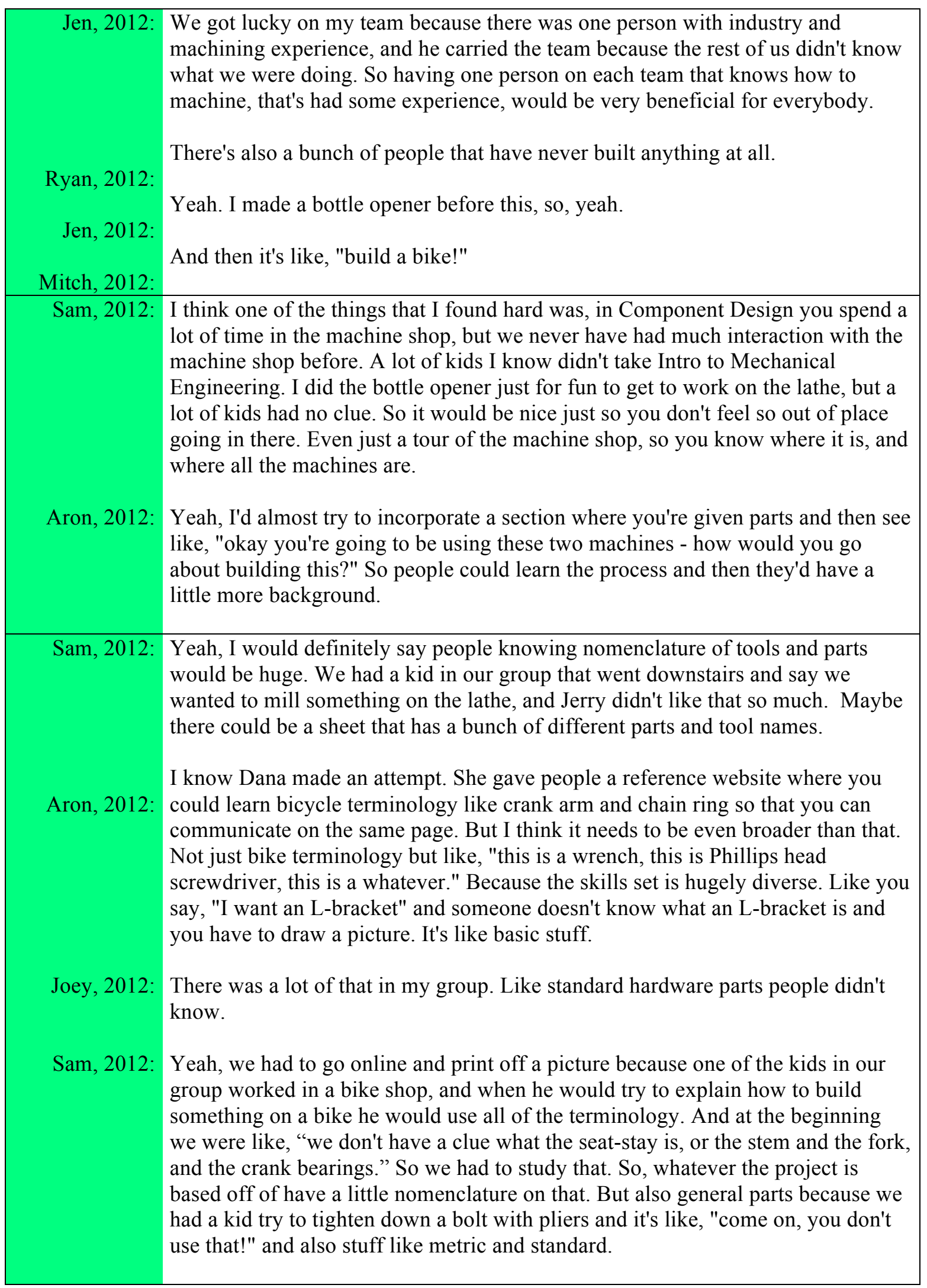


Henry, 2012: There could be improvement in the access to the tools we needed. We were fortunate that we had a contact with his own machine shop. A lot of groups did, but if those groups didn't it would have been hard to get everything done in just the design lab.

Jeff, 2012: Well there are a lot of other machine shops on campus.

Henry, 2012: If limited just to the design lab I doubt 27 bikes would have been completed. If we didn't have access to that other shop we would not have had the quality of work that we did.

Jeff, 2012: Our welding all got done at a parent's shop over spring break.

Henry, 2012: Multiple teams, I know a lot of teams had outside help.

Similar to how students described a lack of prior machining experience, they perceived their prior instruction in technical writing as inadequate.

\begin{tabular}{|c|c|}
\hline Sara, 2011: & $\begin{array}{l}\text { We're not really exposed to technical writing that much before. The Writing in } \\
\text { Science class I had to take was not technical at all. }\end{array}$ \\
\hline Jill, 2011: & No - it did not prepare you. \\
\hline Sara, 2011: & $\begin{array}{l}\text { It's just another literature class that the topic is science that you're writing about, } \\
\text { but it's not technical writing. }\end{array}$ \\
\hline Bill, 2011: & $\begin{array}{l}\text { I was slightly surprised by some of the writing ability and writing process } \\
\text { abilities. People would turn things in and I would be like "if you want to turn this } \\
\text { into me the day before it's due it should be a lot better than this." }\end{array}$ \\
\hline Mark, 2011: & I hate to say it, but it's almost like there should be more writing courses. \\
\hline Beth, 2011: & I agree, like a technical writing class. \\
\hline Mark, 2011: & $\begin{array}{l}\text { I took Writing in Science and I definitely did not learn as much about my writing } \\
\text { as I did in this class. And we didn't do anything technical. }\end{array}$ \\
\hline Kate, 2011: & $\begin{array}{l}\text { Yeah, because the writing is on things like science and society. It's not a technical } \\
\text { writing class, which is what you need. }\end{array}$ \\
\hline Beth, 2011: & $\begin{array}{l}\text { It's writing about the book, and your thoughts about the book and has nothing to } \\
\text { do with grammar. }\end{array}$ \\
\hline Mark, 2011: & Yeah, it's literary stuff. \\
\hline
\end{tabular}


Joey, 2012: On the topic of technical writing, I wish that were covered more before the final report was due. It's surprising actually, how bad some people are at it. I won't name names, but it's kind of astounding that some juniors in engineering are completely incapable of writing a formal, technical statement about something.

Aron, 2012: Or even just a cohesive statement about something.

Sam, 2012: Yeah, I definitely agree with that. I found that one of the problems with our group was when kids would try to write sections and have been taught for so long to add in the fluff and make it literary. That was frustrating because this is a technical paper and it doesn't need to be a novel that I'm going to sit down and read on a Saturday night. So I definitely say that technical writing should be kind of increased. Writing in Science is definitely different than technical writing, so the Writing in Science class we had didn't help me at all really. It taught me some stuff about writing in general but didn't teach me anything about writing in industry. So this class kind of helped me a lot more with that.

Recognizing the widely varying skills and background experiences as a problem, students discussed a possible solution. Both cohorts agreed that skill levels should be more evenly distributed to give teams a fair advantage to be successful. It was suggested that course faculty administer a skills survey similar to what is used in Senior Design.

\begin{tabular}{|c|c|}
\hline Mitch, 2011: & $\begin{array}{l}\text { Coming here with such a dissimilar technical background, and background in } \\
\text { general, just having to meet up, I mean it was a great learning experience. It } \\
\text { definitely helps to see people's strengths and weaknesses, to see how you have to } \\
\text { work with those, but definitely a challenge. }\end{array}$ \\
\hline Sam, 2012: & $\begin{array}{l}\text { I don't know how you'd really fix it if you want people to still be able to pick their } \\
\text { own groups, but it would almost be worth it to do the evaluation of people's } \\
\text { current skill set. Because I just know, coming from our group, I already knew how } \\
\text { to weld, and that completely changed the aspect of our group. My friend was in } \\
\text { another group that had a lot of welding that they needed to do, and that made it so } \\
\text { hard for them and put them behind, so if you could almost evaluate somehow the } \\
\text { skill sets, and maybe spread that out between groups. }\end{array}$ \\
\hline Aron, 2012: & $\begin{array}{l}\text { In Senior Design they actually do that, where you take surveys at the beginning of } \\
\text { the year and you're put in teams where at least one person in your group has this, } \\
\text { one person in your group has that, so you kind of balance it out. And that really } \\
\text { worked well for my Senior Design group. That was good that they did that because } \\
\text { otherwise it would have been way out of whack. }\end{array}$ \\
\hline Joey, 2012: & $\begin{array}{l}\text { I think if you improve the system so that everybody is picking better groups, then } \\
\text { where are those people who don't have strong skill sets going off to? Are they all } \\
\text { going to end up in one group? }\end{array}$ \\
\hline
\end{tabular}




\begin{tabular}{|c|c|}
\hline Aron, 2012: & $\begin{array}{l}\text { Well that 's why I think a skills survey like they do in Senior Design where } \\
\text { everyone takes the survey and then you get lumped into groups where at least } \\
\text { every group has at least one person who's got fabrication skills, every group has at } \\
\text { least one person with a decent technical background, so you get that evenly } \\
\text { divided up. }\end{array}$ \\
\hline Sam, 2012: & $\begin{array}{l}\text { Yeah, so not to pair them all on one team but to try to spread it out because, not } \\
\text { saying that people who don't have skill sets are any lower, it's just that some } \\
\text { people grew up in a different background. Because our high school, we had to take } \\
\text { two tech classes, and auto and welding were the big ones, so that helped a lot. So } \\
\text { just kind of spread it out because I know some kids in our group barely touched a } \\
\text { tool at the start of the project. }\end{array}$ \\
\hline Ryan, 2012: & $\begin{array}{l}\text { If everybody were to fill out a form just like Senior Design so everybody has } \\
\text { strengths, and we know what they can do, and you assign teams accordingly so } \\
\text { that it's evenly balanced. Like who's good at communicating, who's had machine } \\
\text { shop experience, what have people built, who's a good writer? You put them all } \\
\text { together so those people can hold their own in their categories. But now it's based } \\
\text { off of people just saying, "oh I want to be the project manager." And, "oh and I } \\
\text { want to be the team leader." But if you put people with the right skills together in a } \\
\text { group, one person can teach everybody about machining, and one person can teach } \\
\text { everybody about good writing, and everybody's kind of feeding off each other. }\end{array}$ \\
\hline
\end{tabular}

\section{More guidance on project roles}

Especially given the uneven skill distribution among teams, some students found it valuable to have a defined role in the project (project manager, technical coordinator, communications director, or financial manager) because it provided a mechanism of team organization and individual accountability for completion of tasks and also was similar to what is expected in the real world. However, some students didn't know exactly what tasks were expected of them in each project role and wanted more guidance. They also felt that more instruction was needed on how to assign the most appropriate project roles, and they perceived the project role selection process as being rushed.

Tyrone, 2011: I think allocating different roles to people was a good thing. How we had project manager and technical coordinator and stuff like that. It was just good because everyone knew they were head of something and what they were supposed to do. For Freshman Projects, it was just people on a team and you built something. I feel like when you go out to the real world and work on a team, definitely each person has a role, so it's good practice.

Mitch, 2012: There were a lot of different roles to fill. We've had group projects before but in this there was design, and fabrication, and analysis and management, and for once we got a project where basically you have to not only do the project but you also had to design all the guidelines for the project. 


\begin{tabular}{|c|c|}
\hline Sam, 2012: & $\begin{array}{l}\text { I would try to hold a workshop, like one of those lab workshops that cover what } \\
\text { your role is specific to the group. So if you're one of the technical advisors, go the } \\
\text { technical advisor workshop. If you're a project manager, go to the project manager } \\
\text { workshop. And just kind of talk about the roles and give examples and stuff. }\end{array}$ \\
\hline Aron, 2012: & They do that in Senior Design. \\
\hline Sam, 2012: & $\begin{array}{l}\text { Yeah, so then you know from the get-go what to expect. And have some examples } \\
\text { of what to expect. So for like the technical writers that may have a hard time } \\
\text { getting their ideas across they get some tools that can be used to do it. }\end{array}$ \\
\hline Joey, 2012: & $\begin{array}{l}\text { It would be great to take two days that divided each group member type like } \\
\text { technical directors, manager, and put them with past people. }\end{array}$ \\
\hline Jeff, 2012: & $\begin{array}{l}\text { I just wanted to learn how to do everything. I was a technical director and knew } \\
\text { my strengths would lie in communication and maybe in project management } \\
\text { because I already have a communications degree. So it was exciting to be technical } \\
\text { director and play with all toys in the design lab. But on one hand it's a bummer, } \\
\text { frustrating sometimes to not be able to do everything. It's good to tell yourself you } \\
\text { have to delegate your time. It's a great lesson to learn. With the scope of the } \\
\text { project, what a team can get done in } 16 \text { weeks, you definitely can't do more than } \\
\text { one job. }\end{array}$ \\
\hline Mitch, 2012: & $\begin{array}{l}\text { I feel like we need to have workshops for each role in the team because our project } \\
\text { manager didn't really know what to do for the first half of the semester. He didn't } \\
\text { know how to make the task lists and stuff. And I feel like maybe the different roles } \\
\text { could have had some sort of assignment to do, or a workshop or something so they } \\
\text { could get an idea of what they should be doing every week. }\end{array}$ \\
\hline Jen, 2012: & $\begin{array}{l}\text { Going off of what he said, more feedback on the roles was needed, because I was } \\
\text { the communications director, and I was doing agendas and meeting minutes. I } \\
\text { didn't get anything back until halfway through the semester, and we got a B on our } \\
\text { meeting minutes, but I didn't have any chance to improve on the rest of the ones I } \\
\text { had turned in because I hadn't seen them. I didn't see any of the beginning ones, so } \\
\text { maybe more feedback on that. Or more training in the workshops to know exactly } \\
\text { what I was supposed to do. Because all I had was the example online to copy. }\end{array}$ \\
\hline Jen, 2012: & And the same thing for choosing our roles. It was like, "choose your roles now!" \\
\hline Ryan, 2012: & Yeah. \\
\hline Steve, 2012: & Yeah! \\
\hline Ryan, 2012: & There was never really a thought-out process. It was kind of just thrown together. \\
\hline
\end{tabular}




\section{Power struggle with project manager}

One particularly significant issue students identified with the project roles was the dynamic that occurred with some teams' project managers, who were often perceived as inflexible, unreasonable, and poorly-suited for a leadership responsibility. From the perspective of some of the project managers, however, it was difficult to delegate tasks, enforce deadlines, give feedback, and engage the whole team.

\begin{tabular}{|c|c|}
\hline John, 2011: & $\begin{array}{l}\text { My project manager took it above and beyond what he thought, he totally took a } \\
\text { textbook out and was like, "I'm the boss and I do this!" And he ruined it. He killed } \\
\text { everything. He didn't quite grasp the whole concept of this project. }\end{array}$ \\
\hline Jason, 2011: & $\begin{array}{l}\text { I think I learned how to rely on people, and really you can't in large situations. We } \\
\text { were a group of four, and then our project manager never showed up. Or he } \\
\text { showed up to like one out of every six meetings. And he was just convinced that } \\
\text { we didn't need to start building until like the very last week because he was like, } \\
\text { "oh, we're not going to run into any problems. We just need to focus a lot on } \\
\text { design." But like he never did a thing with respect to design. }\end{array}$ \\
\hline Jason, 2011: & $\begin{array}{l}\text { We had it running, but as time went on, our project manager would just not show } \\
\text { up and we were like, "alright, you should be, if anyone's going to be here, you } \\
\text { should be." Our project manager insisted on becoming project manager, too. Two } \\
\text { other people in our group were actually in project management, and neither of us } \\
\text { were our team's project manager. And like, as little as we learned in the actual } \\
\text { project management class, there were so many things that we were like, "well, } \\
\text { yeah, if our project manager actually did that we might not hate him as much." }\end{array}$ \\
\hline Brad, 2011: & $\begin{array}{l}\text { Our project manager was like the opposite. He was very much like, "get it done, } \\
\text { get it done, get it done!" And he had very high expectations of the project that sort } \\
\text { of upset a few people. Like we had it working and he kept trying to add more and } \\
\text { more features. I mean, it was fine, but he wanted to keep adding trigger mount } \\
\text { links and rewiring certain aspects. He was trying to convince the team to take our } \\
\text { motor apart at the end! }\end{array}$ \\
\hline Aron, 2012: & $\begin{array}{l}\text { People kind of disperse, and you have to keep people together like, "we have to } \\
\text { meet to do this today." And, "no I need that by the end of the week!" And like } \\
\text { assigning deadlines and following through even though you really have no power } \\
\text { to follow through. That's the biggest thing about being a manager. You get all the } \\
\text { responsibility but none of the power. So it's like, "how do you manage people } \\
\text { without any power to manage people?" }\end{array}$ \\
\hline Sam, 2012: & $\begin{array}{l}\text { Yeah I kind of had the same problem. I was the project manager, and it wasn't so } \\
\text { much a struggle to get everybody motivated, but getting everyone to the weekly } \\
\text { meetings was hard. I would set out a guideline for the week like, "okay, this is } \\
\text { what I would like to see done by the end of the week." And it wasn't always easy } \\
\text { getting people to do it even when they said they would. I struggled with trying to } \\
\text { get people to do what they said, so I just learned management. }\end{array}$ \\
\hline
\end{tabular}




\begin{tabular}{|c|c|}
\hline Aron, 2012: & $\begin{array}{l}\text { I tried to lead by example as the project manager. Because if you show up and you } \\
\text { present quality work consistently from the beginning and you try to get your group } \\
\text { to come work with you when you're working, they can see that quality of work that } \\
\text { you expect. Then when you ask for help with something, they kind of have a } \\
\text { benchmark for what is expected, and they don't want to let you down. They don't } \\
\text { want to come up with something that's like,"wow he wouldn't do that." }\end{array}$ \\
\hline Henry, 2012: & $\begin{array}{l}\text { It could be frustrating depending on the team. You have to accept that you have to } \\
\text { trust others to get their jobs done and not micromanage. As a project manager you } \\
\text { want to check on them to make sure it's going well. It's a good experience to have } \\
\text { to trust others and let them know. It can be a positive or negative experience, and } \\
\text { in our case we had it not go so well. }\end{array}$ \\
\hline Aron, 2012: & $\begin{array}{l}\text { For me one of the most challenging and rewarding aspects was being a project } \\
\text { leader where you have to assess what everybody's technical abilities are. Not in } \\
\text { just the abilities to solve engineering problems but their ability to actually apply it } \\
\text { and build stuff and actually come up with viable designs that are actually going to } \\
\text { work and make sense. Being the most skilled member of my group, I struggled } \\
\text { with how to let people help and let them feel like they can be on all the things they } \\
\text { don't know how to do. But they have to want to be involved. I can't push and push } \\
\text { and push. But to give them enough work so they feel like they're contributing. } \\
\text { Because the other side of that is that you completely pull back. You want to do } \\
\text { everything, and then you get burnt out because you do everything. And then you } \\
\text { need help but you don't know how to ask for help. }\end{array}$ \\
\hline Aron, 2012: & $\begin{array}{l}\text { I mean, how do you tell someone to do something in a way that's not demeaning to } \\
\text { them? Because if you ask them and you give them a good shot to do it, and you get } \\
\text { it back and a it's really garbage or not what you expect or want or need. I mean, } \\
\text { you can't critique them, you can't say "this is trash." It's really hard. }\end{array}$ \\
\hline Sam, 2012: & To "nurture" as Dana put it. \\
\hline Aron, 2012: & $\begin{array}{l}\text { Yeah, to nurture, exactly. You have to almost hold their hand but not make it feel } \\
\text { like you're holding their hand. And then resist the urge to take the reigns. }\end{array}$ \\
\hline
\end{tabular}

\section{Challenging team dynamics}

Major team dynamics issues were not limited to those that students experienced working with their project manager or being project manager. Students also faced significant issues with their teammates' attitudes, behavior, and performance. One of the more difficult realizations students had was that on project teams not everyone has the same standard of good work, people have varying levels of motivation to engage in work, and people have different concepts of the "right way" to approach and perform tasks. 


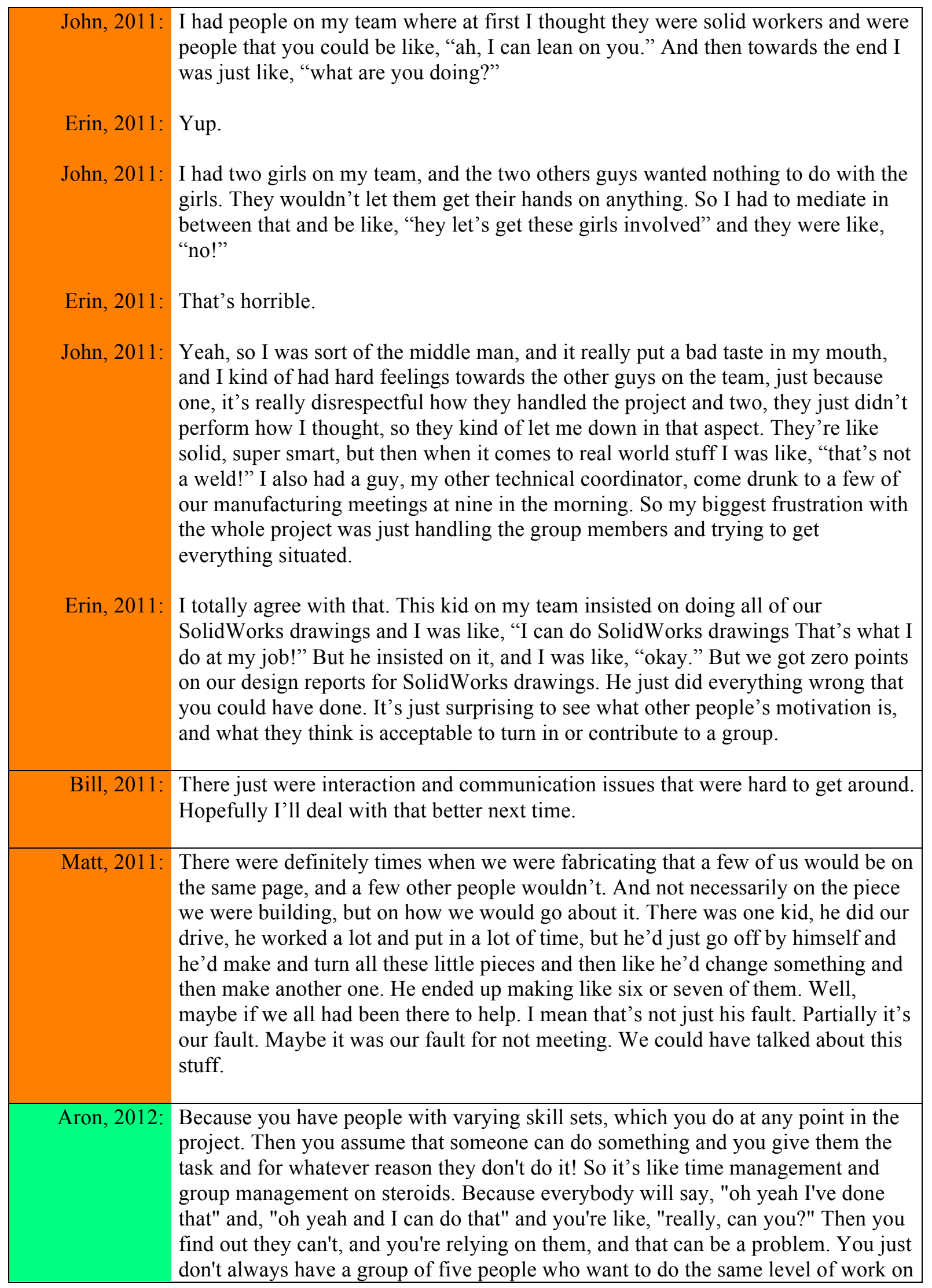




\begin{tabular}{|l}
\hline $\begin{array}{l}\text { the same project. You might have one person who's gunning for the best of the } \\
\text { best, and they have to drag the weight of everyone else along with them. The point } \\
\text { of working on a team is that everybody wants to be there because if you don't want } \\
\text { to be there then you shouldn't be there. What you're going to contribute to the } \\
\text { project is going to be counterproductive. }\end{array}$ \\
\hline Jeff, 2012:
\end{tabular}

\section{Autonomy in team selection}

Despite general agreement on the issues of uneven distribution of skills and the various team dynamics that negatively impacted students, they still showed mixed opinions on whether course faculty should continue to allow students to select their own teams. Alternatives presented included giving students better guidelines on how to strategically choose their teams or outright selecting the students' teams.

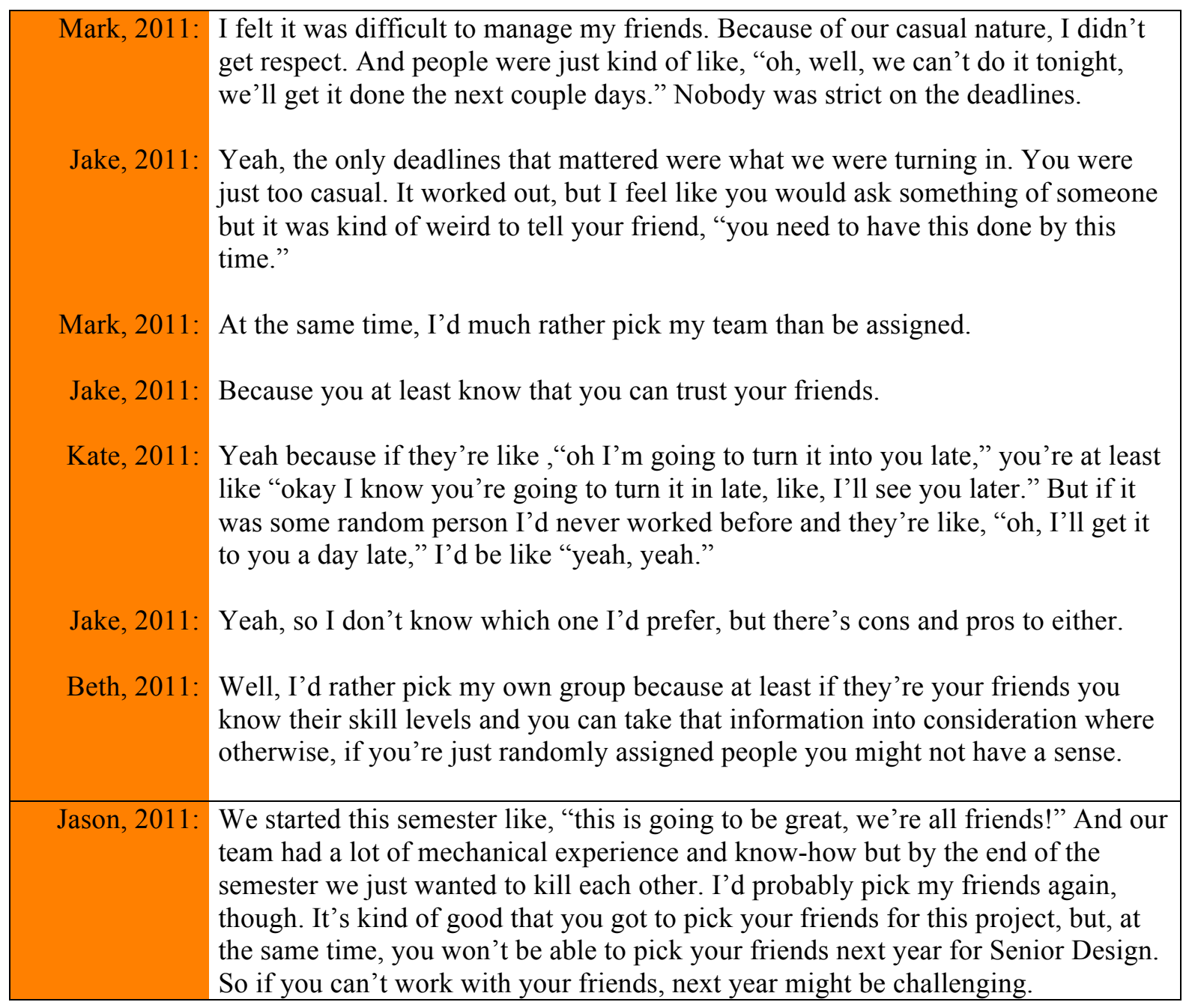




\begin{tabular}{|c|c|}
\hline Aron, 2012: & $\begin{array}{l}\text { You're going to have to work with people that you don't like to work with, } \\
\text { whether you choose them or not, so you have to learn how to do that, so if all you } \\
\text { ever do is pick group with people that you like, you never really have to confront } \\
\text { that. }\end{array}$ \\
\hline Aron, 2012: & $\begin{array}{l}\text { There's the urge to want to pick people that you know, but sometimes the people } \\
\text { you know don't know anything other than how to have fun. }\end{array}$ \\
\hline Sam, 2012: & $\begin{array}{l}\text { Yeah, I ran across that. I would almost try to emphasize and structure more group } \\
\text { picking skills. We kind of rushed into that the first or second day. I kind of picked } \\
\text { the kids carefully but then, too, we got paired with other kids that, I knew they } \\
\text { were my friends, and I knew that would be trouble down the road. So teach more } \\
\text { at the beginning, just a day maybe, on group dynamics, and how to pick a group. }\end{array}$ \\
\hline Ryan, 2012: & $\begin{array}{l}\text { For Senior Design everybody has to fill out a form about what type of person they } \\
\text { are, and how they work, if they are a leader or a follower. I think if that could } \\
\text { happen in this class it could be really beneficial otherwise you just work with your } \\
\text { friends. Dana says in the beginning, "don't work with your friends!" But, you } \\
\text { never know until you try, right? }\end{array}$ \\
\hline Steve, 2012: & $\begin{array}{l}\text { With Component Design there are definitely a lot of people in the class that have } \\
\text { worked in some capacity in industry before. So Dana could just assign one of } \\
\text { those people to every team and then that would be terrific. I just feel that it would } \\
\text { be better if Dana and the TAs worked together to assign the teams. }\end{array}$ \\
\hline Ryan, 2012: & $\begin{array}{l}\text { Yeah and we were only given like three minutes to choose teams and be like, "oh I } \\
\text { guess I'll work with you." }\end{array}$ \\
\hline Jen, 2012: & Yeah! \\
\hline Steve, 2012: & Yeah. \\
\hline Mitch, 2012: & Yeah, if you're sitting next to me then you're on my team. \\
\hline
\end{tabular}

\section{Course and project integration}

Lastly, some students struggled with the way the course and project were integrated. The order in which lecture material was presented did not always match what students "needed" to know for their project. Some might have designed certain components differently had they learned concepts earlier. Even though they were told that they would need to perform independent research and seek counsel from their mentors, students still struggled with having to learn on their own, and they wanted more guidance at certain stages of the project. 


\begin{tabular}{|c|c|}
\hline Matt, 2011: & $\begin{array}{l}\text { One hard thing was how on the very last day of class we learned about shafts and } \\
\text { learned about attaching gears and how you attach to a shaft, and Dana said, "you } \\
\text { don't use set screws." But two days before we had attached our gears to our shaft } \\
\text { with a set screw, then a day later our set screw sheared off and broke. So that was } \\
\text { definitely a good learning experience, but that lecture was needed throughout the } \\
\text { entire project. She said she wanted us to do some outside research and learn it on } \\
\text { our own and talk to our coaches. It makes sense that you have to take that initiative } \\
\text { for yourself, which we ended up doing. But it would have been nice to have some } \\
\text { guidance about these key components that we don't know anything about. }\end{array}$ \\
\hline Bill, 2011: & $\begin{array}{l}\text { Regarding the project and the structure of the course, I found that keys and shafts } \\
\text { would have been helpful if they had been earlier. Made our drive train more } \\
\text { effective and more professional. And also, I think fasteners and keys and shafts are } \\
\text { a very important topic to be covered, and I feel we don't have enough experience } \\
\text { with it to be able to apply it really well. }\end{array}$ \\
\hline Jeff, 2011: & $\begin{array}{l}\text { There wasn't really a lot of incentive to learn anything about keys and fasteners } \\
\text { because the workshops we had we never had to turn in, and we never had a } \\
\text { homework we had to turn in. We had a lecture over it, but we were never tested } \\
\text { and never had anything due. }\end{array}$ \\
\hline Kate, 2011: & $\begin{array}{l}\text { That's one of the big things on the Fundamentals of Engineering exam for a } \\
\text { Mechanical Engineer, and I don't know that much about it. }\end{array}$ \\
\hline Aron, 2012: & $\begin{array}{l}\text { If it were up to me I would reorganize the course. I would do fatigue toward the } \\
\text { middle or the last third and do the gear trains and bearings and shafts up front, so } \\
\text { you would have that leading into the project, and not after the project. }\end{array}$ \\
\hline Sam, 2012: & $\begin{array}{l}\text { I think that would help a lot too with knowing what to buy for your project. As we } \\
\text { learned about fasteners and all that stuff, I was like, "well if I would have known } \\
\text { that before we probably would have purchased different parts because of that } \\
\text { knowledge." }\end{array}$ \\
\hline Mitch, 2012: & $\begin{array}{l}\text { I thought it was kind of strange how the class and the project were together. } \\
\text { Because the class is pretty standard, it's just applying what we've learned in our } \\
\text { other classes to fasteners and beams and things like that. And then there's kind of } \\
\text { like this hidden, other part of the class that's the project. I don't know how you } \\
\text { would combine them more, but it always felt they were like two separate classes } \\
\text { combined. }\end{array}$ \\
\hline
\end{tabular}


Theme \#3: Students' perceptions of the previous years' projects impacted their initial interest and engagement for their own project.

Another challenge worth discussing is the impact of the previous year's project on students' initial interest for their project and how it can positively or negatively impact engagement in the project.

Students in the 2011 cohort viewed the drill-powered vehicle project as more interesting, exciting, and authentic than the previous year's ball launcher and Lego lawn mower mini-projects, which they perceived as less authentic and useful. On the other hand, students in the 2012 cohort expressed a lack of initial interest and enthusiasm for the adapted tricycles project in comparison with the drill-powered vehicle project. This lack of initial interest seemed to hinder their engagement in the project, which didn't increase until later in the semester when they were more engaged in the hands-on aspects of the project and felt confident that their project was going to be successful.

\begin{tabular}{|c|c|}
\hline Jill, 2011: & $\begin{array}{l}\text { A lot of my friends had taken this class last year, so I saw that they had done the } \\
\text { launchers and the little Lego lawn mowers, and I was not very excited to do those } \\
\text { projects. But when I found out what our project was I was really excited to do it. }\end{array}$ \\
\hline Beth, 2011: & $\begin{array}{l}\text { I know the previous year had a slingshot and were like, "cool, I can throw a ball." } \\
\text { It wasn't very useful. I know last year they built the catapult. And after that you're } \\
\text { like, "well, you could put this in a truck box and just start launching stuff at traffic. }\end{array}$ \\
\hline Joey, 2012: & $\begin{array}{l}\text { Initially I wasn't that excited about Component Design while we were building our } \\
\text { projects because I think it's more fun to build things that you're going to play with } \\
\text { later. So the whole time we were like "man I wish we could do the drill-powered } \\
\text { bike. It would be a lot more fun." So it wasn't more engaging until the end when } \\
\text { you actually got to feel like you were accomplishing something for somebody else. }\end{array}$ \\
\hline Sam, 2012: & $\begin{array}{l}\text { Yeah, I definitely thought the beginning was hard for us. But as soon as we hit the } \\
\text { hands-on section everyone was willing to be down in the machine shop. And as we } \\
\text { got toward the end the interest sparked. I think the turning point was once the bike } \\
\text { was painted, everyone wanted to put the bike together. They were chomping at the } \\
\text { bit to get at it! }\end{array}$ \\
\hline Aron, 2012: & I agree with that. It was like, "oh, here you guys are!" \\
\hline Sam, 2012: & $\begin{array}{l}\text { I had put a bunch of days into painting the bike and sanding the bike and getting it } \\
\text { all ready and then as soon as they saw it all done and painted they were like, "get } \\
\text { me at it, get me at it, I'll take these parts and put it together!" That was where } \\
\text { interest really sparked in my group. }\end{array}$ \\
\hline Sam, 2012: & $\begin{array}{l}\text { The interest on my team increased as soon as they like saw that the project was } \\
\text { going to turn out. For a lot of the semester there was a big question mark if the } \\
\text { project was going to turn out cool, so there wasn't that much effort into it. They }\end{array}$ \\
\hline
\end{tabular}




$\begin{aligned} & \text { were like,"well, I don't really want to put my time into this, I'd rather go study for } \\ & \text { another class." But, as soon as they became confident that the project was going to } \\ & \text { turn out sweet then they were all for it and wanted to do everything they could to } \\ & \text { be a part of it. }\end{aligned}$
Joey, 2012: I definitely agree with that.
Aron, 2012:
$\begin{aligned} & \text { I definitely think the interest sort peaked at the end because everybody saw the big } \\ & \text { pieces coming together and they were like "oh wow that is going to be cool - you } \\ & \text { were right!" And I'm like, "yeah, it is going to look cool, help a little bit more." }\end{aligned}$

\section{Theme \#4: The context of the project shaped the experience of the students.}

Evidence presented thus far suggests that project context (service vs. non-service) had less of an impact on student achievement motivation than other factors. At the same time, the project context mattered as it significantly shaped the students' experiences. As each cohort progressed through the project, they developed a dominant group emotion, experienced a different sense of community beyond their peer environment, and had various perspectives about working with a client.

The dominant group emotions in the 2011 cohort were fun and excitement, especially because of the end-of-semester run-off. The run-off also served to engage other CU Boulder students outside of engineering, which inspired a sense of pride and camaraderie among the Component Design students.

Jake, 2011: I think the most valuable thing was the project because it was a lot of fun. Everyone was really willing to work on it. Nobody was ever really like, "oh, this is a drag that we have to build this." Everyone was really excited about it. If you had a project that wasn't fun, you know, you'd dread it, you wouldn't learn.

Erin, 2011: Everyone I talked to was like, "I'm really jealous that you guys are doing this!" And like, "oh! You're doing the drill-powered vehicle? That's sweet. I'm so jealous that I'm not doing that." Like all the other majors are jealous that they're not doing that for their course.

John, 2011: Yeah, like a lot of people outside of mechanical engineering knew about it too. They were like, "oh, is that what you guys are doing? That looks like so much fun." I was like, "yeah, pretty much."

Andrew, 2011: I know. I have a couple fellows I hang around and live with who saw us building it because we always built it at my place. They were like, "oh, look, engineers building something, what a novel idea." 
Kate, 2011: One of the most exciting things about the project was that we actually built it and saw all of our work coming together. I liked that.

Beth, 2011: The project was awesome. Having a fun project, well, I've talked to plenty of other people who didn't have as fun of a project, and they didn't enjoy the class or learn as much. This project you could talk about it, people were impressed by it. We learned so many more skills.

Kate, 2011: And, it's cool. It made me proud to be a student here because it's like, "yeah, our school did this. What did yours do?"

Mark, 2011: Yeah, I don't think we can emphasize enough how good having a fun project was. You know, having a fun and interesting final design. That made all the difference in the course. If I were you guys, I wouldn't change it at all.

Students in the 2011 cohort also valued the competitive aspect of the run-off as it gave them a strong sense of accountability to follow through with the project and produce a fully-functioning vehicle.

\begin{tabular}{|c|c|}
\hline Bill, 2011: & $\begin{array}{l}\text { I thought it was great that everybody had the same goal. They had to go around the } \\
\text { same course. }\end{array}$ \\
\hline Jake, 2011: & Yeah, because it was pretty easy to compare yours. \\
\hline Bill, 2011: & Yeah, because then you have a benchmark to look at what other people did. \\
\hline John, 2011: & $\begin{array}{l}\text { There was a lot of competition that came out that wouldn't have if people were } \\
\text { building a launcher or something, because people were like "what's the fastest } \\
\text { time, what's the fastest time?" Some people took it really far, but it was really fun } \\
\text { to see people get into it and get competitive and get excited about doing } \\
\text { something. To have people high-fiving and stuff when you're done. You don't see } \\
\text { that that much in engineering school. It motivates you when you are working. } \\
\text { You're like, "let's build a really nice bike" because people are seeing it. If you are } \\
\text { building something that nobody sees you're like, "who cares if it looks badly as } \\
\text { long as it works?" But if it does work you want it to be spray-painted or have } \\
\text { tassels and bedazzles, and that gets people excited. }\end{array}$ \\
\hline Sara, 2011: & $\begin{array}{l}\text { I think how we were tested at the end, going through this obstacle course was } \\
\text { pretty exciting. We all wanted to make our vehicles faster, or make them have } \\
\text { different features to get a prize or award or get it through fastest. So I felt that } \\
\text { testing the vehicle and how it was graded motivated the project. It helps get other } \\
\text { people involved as well from engineering and from not engineering. Sharing that } \\
\text { we're doing this with our friends who aren't in engineering who come and watch. } \\
\text { It's cool. So that was pretty exciting. }\end{array}$ \\
\hline Jill, 201 1: & $\begin{array}{l}\text { Yeah, the run-off was the big day of the semester, so I really liked that. Whereas I } \\
\text { see my friends in Senior Design, they made this awesome thing, they go to an } \\
\text { expo and people look at it and then it's all done! So, I really liked that there was }\end{array}$ \\
\hline
\end{tabular}




$\begin{aligned} & \text { some sort of challenge, some sort of test at the end where we could compare ours } \\ & \text { to other people's. There was that competitive aspect, like "ours is prettier than } \\ & \text { yours!" Or "ours is going faster than yours!" All that sort of thing. That definitely } \\ & \text { made me excited for Component Design. The competition aspect was a big driver. }\end{aligned}$
Matt, 2011: $\begin{aligned} & \text { Without the competition I think we'd still want to get a working vehicle and still } \\ & \text { want to get a good grade. Both for our grade and to know that we could make this. } \\ & \text { The competition made us make sure that the vehicle actually worked, and we } \\ & \text { couldn't just pretend. }\end{aligned}$

Students in the 2011 cohort thought that not having a real industry client allowed them to focus their efforts on completing the project without having to worry about the demands of a client. Because this was their first experience with a real design project, they felt that it was a good transition into Senior Design, when they will be required to work with a client.

Matt, 2011: $\begin{aligned} & \text { You don't have to appeal to this client who's funding you, and it's not some guy in } \\ & \text { industry you're talking with. Your coach is a senior and you're talking to Dana, } \\ & \text { which is usually pretty easy and not too stressful. I think it's good in that sense, to } \\ & \text { slowly ratchet it up to a more professional, real-world experience. }\end{aligned}$
Jill, 2011: $\begin{aligned} & \text { I think working with a client, I agree, we'll get to do that in Senior Design. And a } \\ & \text { lot of complaints I've heard from people in Senior Design is working with } \\ & \text { bureaucratic red tape with their clients. I feel like for this semester, just for one } \\ & \text { semester, we don't have any time to mess with that. }\end{aligned}$

One student, however, thought the absence of a client detracted from the authenticity of the project.

Matt, 2011: You almost just don't really care. Not like you don't care about the project. I
mean, I'm working on this project to get it done and to function, and there's a lot
going on with that. But, thinking about sustainability, that doesn't really come into
play. It's not like this is really going on any further. You don't have to think about
the consequences of your actions. If you waste a foot-long section of metal it
doesn't matter in this application because it's five dollars. But if you're building
six million of these that five dollars adds up. It's definitely not the same. I mean
the project was definitely good, I really liked it, but it's still obviously different
from full-scale, true engineering.

Turning to the 2012 cohort - the dominant group emotion was quite different. The 2012 cohort expressed strong feelings of altruism from doing something for someone else, which was empowering, meaningful, and more intrinsically motivating than simply working to earn a good grade or to please a 
supervisor. The addition of the real-world client also significantly contributed to their sense of accountability to produce a safe and reliable finished product.

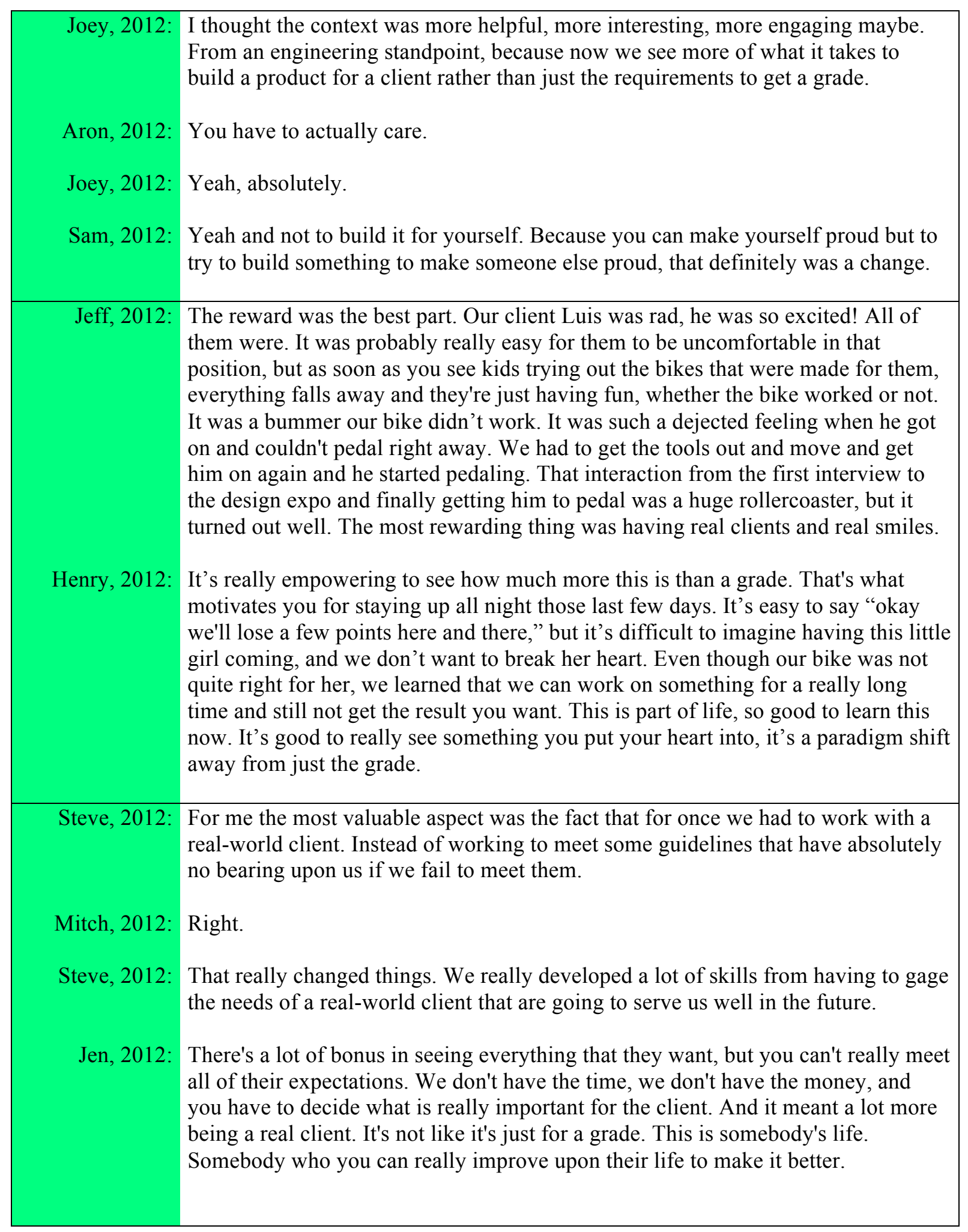




\begin{tabular}{|c|c|}
\hline Jen, 2012: & $\begin{array}{l}\text { It was a lot cooler in the end seeing an actual child on our trike riding it instead of } \\
\text { just handing it over to industry. }\end{array}$ \\
\hline Mitch, 2012: & Yeah. \\
\hline Jen, 2012: & $\begin{array}{l}\text { Seeing that made the whole semester worth it. Every hour spent in the machine } \\
\text { shop. }\end{array}$ \\
\hline Ryan, 2012: & I think also that since they're younger, it's like giving a gift. \\
\hline Steve, 2012: & Yeah. \\
\hline Ryan, 2012: & $\begin{array}{l}\text { Because if our clients were much older than us, then you get that dynamic of who's } \\
\text { above. If they're older then you are doing a job for someone, but for this it's like } \\
\text { this kid has no resources so you're kind of handing it down to them, you're giving } \\
\text { it to them. }\end{array}$ \\
\hline Steve, 2012: & $\begin{array}{l}\text { I definitely agree. The altruistic aspect of it really, really added to my desire to } \\
\text { want to get this done. }\end{array}$ \\
\hline Jen, 2012: & $\begin{array}{l}\text { Having real-life clients is something I think you should keep. I know it's a lot more } \\
\text { difficult to find clients and to deal with that, but I think it really helped. It made it } \\
\text { mean something. }\end{array}$ \\
\hline Mitch, 2012: & $\begin{array}{l}\text { We had Brandon, and we didn't realize how difficult alternating motion would be } \\
\text { for him. And I guess that has more to do with his cerebral palsy than his age. But it } \\
\text { definitely impacted our factor of safety. }\end{array}$ \\
\hline Steve, 2012: & Yeah. \\
\hline Ryan, 2012: & $\begin{array}{l}\text { They weren't too heavy except for the } 21 \text { year old. They were mostly really small } \\
\text { kids, so we don't have to deal with huge stresses as opposed to adult, who, you'd } \\
\text { have to build more. So it's kind of like a mini-project. }\end{array}$ \\
\hline Jen, 2012: & Knowing it was going to a three year old, safety was a priority. \\
\hline Steve, 2012: & Yup. \\
\hline Jen, 2012: & $\begin{array}{l}\text { Because you don't want a special needs kid falling off of the trike or something } \\
\text { horrible, so you want to make sure that's its safe first. So that was a really } \\
\text { important concern. }\end{array}$ \\
\hline Steve, 2012: & $\begin{array}{l}\text { It provides a whole different perspective. You just learn a different perspective on } \\
\text { how to approach the project through having to work with a younger client. I mean, } \\
\text { every set of clients is going to have their own set of special needs, and it's always } \\
\text { going to be different. But working with this particular case was very interesting. } \\
\text { Like you don't always work with this in industry. So that helped to provide some } \\
\text { very valuable perspective. }\end{array}$ \\
\hline
\end{tabular}


Mitch, 2012: I think it also let us get a little more creative. I feel like an adult would like a pretty standard looking bike, but a little kid, if it's fun to use they're going to love it.

Ryan, 2012: You can't get much judgment or feedback from a little kid, so you don't have to consider it. You can really just focus on what is the problem.

Mitch, 2012: Yeah, you're not thinking about their expectations all the time. As long as it's safe their parents will be happy and as long as it works then they'll be happy.

While students in the 2012 cohort greatly valued the addition of a client, they did express frustration regarding the lack of client interaction. This resulted in teams needing to base important design decisions on a single introductory meetings. Hence, as the students progressed through the project, it was difficult to refine their designs without being able to meet face-to-face with their clients.

\section{Joey, 2012: Not being able to work with the client was really hard.}

Sam, 2012: Yeah, that was hard.

Joey, 2012: We met her once and then months and months went by and we were still trying to think back to that one meeting thinking "well is her size compatible with this? Is her strength compatible with this?" And we sort of just lost track of what she was capable of. Having only met her once we didn't have a good idea of what she could do, and as a consequence we didn't make a design that was compatible with her. I think that if we had had constant communication and constant access, or at least more access, then we would have ended up with a design that was more compatible.

Sam, 2012: Yeah, I know it's hard to be able to allow a bunch of college kids to see some small little kid because they'd freak out. But watching from a video conference was hard to really quantify anything because you're not there, so your perspective is off. And only having one team member there you kind of had to put everything on him. Even to be that person, that's also a lot on you, because we kind of left the call on him for the frame. It did work out, but if it didn't work out then a whole semester's work would have gone wrong because of one person's call, which kind of took the group aspect out of it.

Aron, 2012: So, I didn't really see it as an incredibly challenging aspect, but I can definitely see how it is. I think it's a good learning experience in terms of letting everybody know that the first meeting is everything. I made sure that when I sent Robby off I said, "Robby you have to measure all of the dimensions even the ones you don't think are important, just write them down, because we're going to need all of it. We're going to have to base everything off of it." So take lots of pictures, measure everything, and keep a record. I mean you go in and think, "oh, we're going to meet her, it's going to be great!" But then two months in you're like, "oh, this is a really big deal now". You're making hard choices and big calls because you have to move the project forward. 
Sam, 2012: Yeah, I definitely think if it's a one-time meeting just emphasize at the beginning, "this is your one shot, you won't see them for two months." That would make it a lot better. That would stress it a lot more. You never realize that the little measurements that you don't have are the ones you really wish you did.

In the end, despite its added complexity, working with a client contributed to students feeling connected and related to a community beyond CU Boulder. They also gained a new and refreshing perspective on what is possible through engineering design.

Henry, 2012: It's also amazing how much people in a community support a project like this. It was a really wonderful experience to see the expo in the newspaper and all. That was really rewarding. People actually care about this.

Jeff, 2012: This is the second assistive technology project I have done here. That vein of projects is the best possible thing you can do. It gets school involved in community and interacting with people that aren't easy to interact with. We're a little older. I'm 27, and we've been involved with other experiences. But the first exposure to this type of activity and set of circumstances, that was really fun for a lot of people too. One kid in my group was like, "I've never thought of doing a project for someone like this." I think of my own bike and how I could build several of those for the physical therapists and that would be fun. It's a cool realization, motivating, that a bit of volunteerism is cool and fun, and maybe something people haven't thought about. This taking your experience as an engineer into the real world, like it's not just a job but improving the community around you.

Henry, 2012: Engineers Without Borders is another example but this is a mandatory project. I saw a benefit that engineers can have on society at a very tangible level. It made me realize more clearly how engineers can really make society better and really add value.

Jeff, 2012: A lot of those clubs though, we mechanical engineers and electrical engineers are down our rabbit holes and can't do those things. Especially now junior year. I thought it was rough before, but now I have no time.

Henry, 2012: I feel the civil department is more involved, but maybe a lot of those people who become civil engineers do it because they want to help people. Or maybe it's just the terminology, "civil," or a different demographic. When it comes to mechanical engineering a lot of the motivation is building cool stuff and making money. But when we get a project like this we see we can build something cool and change someone's life. It's thinking on a whole different level about what is possible as an engineer and what you can accomplish.

Henry, 2012: This group of 130 students, I think we view each other differently, but we are all in this and we have this goal in common and a mutual task that we are trying to accomplish, the ultimate goal to enhance someone's life. Whoever wins, great, but we're making a difference in society. It's definitely interesting, and I 
feel like I connected on a more personal level with the people in the class, even people I don't know. I'm thankful for our group and had interesting relationships with my group.

Theme \#5: Design is intertwined with students' values and ability-related beliefs.

\section{Learning the Design Loop}

Students in both cohorts found the experience of learning to follow a process for design to be exciting, empowering, and valuable. It was exciting to learn the design loop from design to fabrication to testing, and the experience was valuable because it increased students' ability-related beliefs. Students found value in breaking out of the tinkering or "trial-and-error" phase and following a step-by-step process. Knowing where to begin when they encounter their next design problem will be valuable when they are working as engineers in the future. They also experienced a shift in their perceptions of design - that the purpose of design is not to simply arrive at a number but to understand how different components and subsystems must operate together for an entire system to function.

\begin{tabular}{|l}
\hline Sara, 2011: $\begin{array}{l}\text { Building and putting everything together and seeing that design loop. That's kind } \\
\text { of as engineers what we have to do. }\end{array}$ \\
Bill, 2011: $\begin{array}{l}\text { It was great to be like, "this iteration isn't just to arrive at a number, it's an } \\
\text { iteration in the design process, and it's really about getting things right and } \\
\text { working and complete." So that was pretty exciting. And to be working } \\
\text { continuously working throughout the semester and continuously improving it was } \\
\text { also really nice. }\end{array}$ \\
\hline Erin, 2011: $\begin{array}{l}\text { It's really hard to apply what we learn in class to designing something, and going } \\
\text { to the hardware store and picking out things that are going to actually work. Now I } \\
\text { can kind of understand a lot more about design, rather than just like trial-and-error } \\
\text { and trying to find things that will work. Now from this class I feel like I have more } \\
\text { of a knowledge of where to start from rather than just picking something random } \\
\text { and seeing if it will work. }\end{array}$ \\
\hline Aron, 2012: $\begin{array}{l}\text { For me now, having a good footing and having the textbook and the course and the } \\
\text { resources behind me I can sort of look ahead at my other project and say "these are } \\
\text { the things that I know I need to tackle first, these are the things I know I need to } \\
\text { hammer out first rather than two months in, so it kind of forces me to reshuffle my } \\
\text { priorities, which is more big picture to me because there are certain things that are, } \\
\text { not just the pure functionality of the design, but how the pieces really work } \\
\text { together, not just mechanically, but in the physical world. How they interact, how } \\
\text { they align, can you take them apart to do maintenance on them, can you remove } \\
\text { them at all. So just other things that you don't always consider. }\end{array}$ \\
\hline
\end{tabular}




\begin{tabular}{|l}
\hline Henry, 2012: $\begin{array}{l}\text { The project did a great job of giving us the knowledge of what to expect, like } \\
\text { knowing the standard, the process, the protocol to go through. The first time I just } \\
\text { drew something for Jerry he laughed. It's great to go through this now instead of } \\
\text { as a new hire at a company. }\end{array}$ \\
Jeff, 2012: \\
$\begin{array}{l}\text { The project motivated me to want to be a design engineering a lot more, but I had } \\
\text { to take a step back and see what that meant. When you get a problem you can't } \\
\text { freak out, you have to go through the steps that you know. }\end{array}$ \\
\hline Sam, 2012: $\begin{array}{l}\text { With that building it for someone else, it took out the trial and error because if } \\
\text { you're building it for yourself you just order a part and if it doesn't work, you know } \\
\text { right away. }\end{array}$ \\
\hline Ryan, 2012: $\begin{array}{l}\text { I think just the whole process, being able to sit down with a group and have a } \\
\text { problem and then think about it for a while and then design some stuff and then } \\
\text { draw it up in CAD, going to the machine shop and building it and then putting it } \\
\text { together. Those are the only tools you need to build anything, just the process of } \\
\text { problem, brainstorming, design, build, test, and build again. That was really } \\
\text { concrete, and definitely boosted my confidence on what I could do. }\end{array}$ \\
\hline Mitch, 2012: $\begin{array}{l}\text { Finally getting to see the entire design process from design to fabrication and } \\
\text { testing was good. Because all the other mechanical courses we've taken so far have } \\
\text { basically been number crunching and it's nice to finally get back to what we started } \\
\text { engineering for, to build things. }\end{array}$ \\
\hline
\end{tabular}

\section{Paper to Product}

A major insight gained by students in both cohorts was how long it takes to fabricate everyday objects. Students were also somewhat surprised to realize that designs that work on paper do not immediately translate into a functioning design in real life. Learning this lesson first-hand was challenging, yet exciting and valuable, and served to increase students' ability-related beliefs because it gave them a sense of the scope of real engineering projects.

Matt, 2011: I think it's great that students can learn this now and see what it takes to build. They don't just make a drawing and then it gets made. A lot has to go into it to actually make the product.

Jason, 2011: I was kind of just surprised that it is such little elements in an overall big design, which was pretty much what this class was about. It was pretty interesting to see all those little things that have to work together. Like specking out stuff, I never would have thought about that. I would have just bought bearings and put them on.

Mitch, 2012: Now I understand a lot better about when I make a design realizing how much time you have to put in to make it real. 


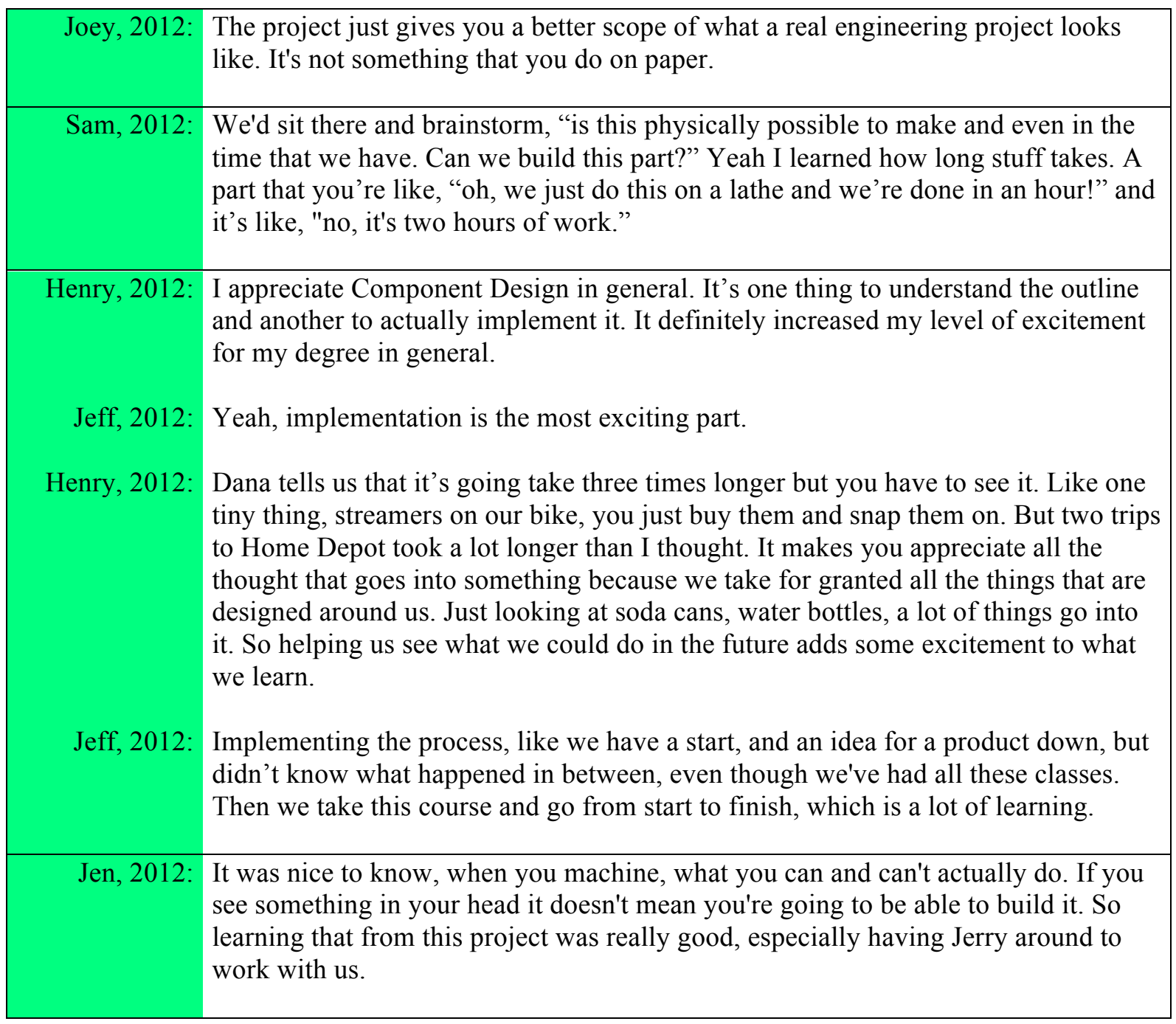

\section{Missing Pieces}

Students in both cohorts spoke about elements of the design process they felt should have been more emphasized in the course, including sustainable design, holistic design, life-cycle analysis, and aesthetics. The absence of these elements may have served to lessen the authenticity of the design experience.

Matt, 2011: I think a section about sustainable design or aesthetics was needed. I definitely
think there are other things than just material strength that should go into
engineering design. And I know this class is really short, you can barely even cram
in everything we need to learn technically, but I think having a day or two
throughout the semester where you learn completely non-technical stuff that is still
applicable. Like, if I'm building something, all the implications that goes into
building it. And also aesthetics of design should be considered, a broad talk about
all sorts of designs.


Ryan, 2012: I think like, utilization of resources, like sustainability was missing. There was hardly any mention of sustainability, which I thought was kind of...

Steve, 2012: Surprising.

Ryan, 2012: Yeah. It should have almost been the underlying fundamental of the course, to design sustainably, because in 50 years if your car is not sustainable, you're not going to drive it.

\section{Feedback on Design}

Students in both cohorts felt they needed more feedback about the design process. Although students were required to meet with their senior mentors, the interactions were often superficial and did not engage the students in meaningful conversations about the complexities of the design process. Also, some students had a difficult time modeling real components as simpler components that could be analyzed using machine design theory. They lacked faith in their engineering textbook actually applying to a realworld design scenario.

Bill, 2011: I felt like there was a lack of complexity at times. I did a SolidWorks analysis of the vehicle and I was like, "well, how would I even really verify this?" It became hard, when you have more complex geometry, how do you go about analyzing that? So I definitely think we need an introduction, or just more resources to explain the next steps, how to proceed.

Kate, 2011: I like what Bill said about giving us an idea about where you can take this in reality because I found that when I was analyzing our vehicle too it was like, "great, I can like say this is a beam, but it's not really a beam."

Bill, 2011: You don't really want to tell people, "these are the things you analyze." But it would also be kind of nice if you showed them what was possible. Because at the end of the report I felt like I wanted to we do more analysis.

Beth, 2011: We had to have two things analyzed by a certain date. We hadn't really had anything ready to analyze, by the first report, and we didn't really have anything to analyze at that point. So we did seat deflections to see if the seat would deflect into the chain.

Jake, 2011: Which we already knew from experience!

Beth, 2011: It wasn't like we were checking anything.

Kate, 2011: I think it's another problem with the objectives though, because our team did tons of analysis before the first report check because we saw it like, "okay, we have to figure out like how thick these beams need to be and what kind of material" and so we made computer programs that could help us figure it out. 
Beth, 2011: Well, we bought our car so we didn't need to analyze anything. It's all pre-made for us, and all we're doing is attaching a drill to it. What do we have to analyze? And the answer is nothing.

Mark, 2011: It's part of the open-endedness.

Bill, 2011: I mean even just like a list of examples from the book showing a bunch of different components. Even if we haven't gone over all of them yet, but they're in your vehicle.

Mark, 2011: Well, I really liked the analysis part because I've worked in a machine shop pretty much all my life, so I have a lot of that kind of experience. I've always made things, but I've never done any kind of analysis or thought about any kind of failure or anything. So actually building something and actually doing analysis on it was a lot different for me. So I really enjoyed that aspect.

Beth, 2011: I kind of liked it because normally you sit on something or you make it and you're always like, "well let's see if it works. It looks thick enough!" I like the analysis part so you can be like, "oh, that should not actually bend," instead of being like, "we'll give it a shot and see. If not, we'll re-do it."

Jake, 2011: You can know the limits and everything. It was nice to figure out how much torque we could put into our system without worrying about breaking stuff. Instead of just like, "let's use the most powerful drill we can find and hope it works."

Beth, 2011: It's kind of nice to verify that you know what you're doing.

Kate, 2011: It's a cool way to check, and it's a neat thing that you can say like, "yeah I learned about springs and I used it."

Jen, 2012: I know it's helpful to do the analysis on different parts of the trike, but we had to do it so early that I don't feel like it really helped my group at all. So maybe make that analysis be done later, because it felt like extra busy work that we just had to make up because we didn't really know like what we were doing yet.

Steve: Yeah.

Mitch, 2012: Since the design wasn't even finalized when we had to turn that analysis in.

Jen, 2012: Yeah, ours definitely wasn't.

Steve, 2012: So I just didn't feel like there was really any point to it.

Jen, 2012: Yeah, and I mean, kind of along those lines, you're taught to analyze rods and cantilever beams. But in the real world, nothing is exactly like the book. So when

Ryan, 2012: we start analyzing these parts it's like, "oh we'll just assume this and we'll just assume that to confine it to what we learned in the book." And by that time it's stupid because our assumptions have no basis. 


\section{Theme \#6: Gaining new skills contributed to increased confidence and excitement for future} engineering experiences.

\section{Confidence as engineer}

Students in both cohorts described how their interest and value increased when they made a connection not just between the course and how it relates to design and analysis of components, but a deeper connection between the course and their future careers as engineers. Developing a greater sense of competency in real engineering practice as well as a clearer understanding of what their future careers may entail served to increase the students' confidence.

\begin{tabular}{|l}
\hline Kate, 2011: $\begin{array}{l}\text { I'm more excited about Component Design because I took Dana's Intro to } \\
\text { Mechanical Engineering class, and that was interesting. We talked about some } \\
\text { of the applications of mechanical engineering but it's a lot different to actually } \\
\text { be applying it and then to think about this project and be like, "wow, if I can do } \\
\text { this I can probably do any entry-level engineering thing." }\end{array}$ \\
Beth, 2011: $\begin{array}{l}\text { This class was the first time that, like Kate said, we're actually being an } \\
\text { engineer. So this was my favorite class. }\end{array}$ \\
\hline Andrew, 2011: $\begin{array}{l}\text { I came from Chemical Engineering and spent the last two years going over } \\
\text { theoretical stuff, fluid flow and heat flow. And it kind of got disheartening after } \\
\text { a while because they always have on the course evaluations things like "my } \\
\text { confidence as an engineer has improved" and I'm like..."no!" But this was the } \\
\text { first class where I was actually able to say "yes, I actually think that, given some } \\
\text { more practice or training, I could be reasonably good at this." }\end{array}$ \\
$\begin{array}{l}\text { There's a major disconnect I've heard, in the real world between the engineers } \\
\text { and the actual manufacturers. The engineer's like, "oh you just need to do this, } \\
\text { this, and this" and the welder's like, "um... you can't really do that." }\end{array}$ \\
\hline Matt, 2011 \\
\hline $\begin{array}{l}\text { Sam, 2012: } \\
\text { an engineer. That applied stuff so you can go into a store and you know how to } \\
\text { have no clue what any of these parts are or do." So that kind of made my interest } \\
\text { grow because I felt like I could talk with people in the industry. }\end{array}$ \\
\hline
\end{tabular}


Jeff, 2012: I've had a hard time figuring out where I fit in engineering. I know I want to be here, but this was the first class where I felt in a more comfortable place in the major. I got to be hands-on in the machine shop and got to see the work flow from CAD model to finished product.

Henry, 2012: It's great to go through this process now instead of as a new hire at a company.

Mitch, 2012: I got more interested in Component Design throughout the semester. I think what really did it for me was at the beginning of the semester I was like "wow I'll finally be able to understand what I will be doing with my career." And I was a little intimidated at first but as the semester went on it kind of felt more natural, how it fit together. I could understand what we would be doing, and I became more interested. Seeing how all the little things in a design work, understanding each little individual part, makes the whole thing less intimidating.

Ryan, 2012: The only tools you need to build anything are the processes of problem solving, brainstorming, design, building, testing, then building again. This project definitely boosted my confidence on what I could do.

Mitch, 2012: The hands-on building was really valuable because we don't get that anywhere else, expect for Freshman Projects, Senior Design, and then in this course. We're taught all this theory, which is good, but it's very rare that you can find engineers that can actually see and visualize and put something together from beginning to end. Applying the course concepts to the project really helped to increase my confidence as an engineering student.

Henry, 2012: It was the most real life experience I've had in a course with team dynamics and working with a client with real needs. It raised my confidence as an engineer and understanding engineering.

\section{Preparation for Senior Design}

Students in both cohorts perceived this course as preparation for Senior Design. They valued the lessons they learned in time management, team management, technical writing and communication, and machining and fabrication. Acquiring these skills and experiences increased their confidence that they will be successful in Senior Design when they are confronted with some of the same challenges.

\footnotetext{
Brad, 2011: I gained some manufacturing skills, which will be helpful for Senior Design. I hadn't done any of that since freshman year.

Jill, 2011: The project was a sort of a stepping stone for Senior Design. So as I was going through the semester my thoughts were kind of transitioning from this project to how this is going to translate to Senior Design. So, I guess that sort of increased my interest in this course.
} 


\begin{tabular}{|c|c|}
\hline Matt, 2011: & $\begin{array}{l}\text { I think I maybe would have preferred to have a real client, but I think we get that } \\
\text { next year in Senior Design, so this is a good transition. Yeah, I think it's probably } \\
\text { a good jump between the two. It's like serious enough but not like super serious. } \\
\text { Yeah, it was a good motivation to want to do a Senior Design project. Something } \\
\text { that's not as strict. Well we did have restrictions of a budget, but I feel like as far } \\
\text { as design we had pretty much all the freedom we wanted. So I think that was a } \\
\text { good preview, and I feel everyone was pretty motivated to do these projects and } \\
\text { thought they were pretty fun in the end. I'm really excited to do Senior Design } \\
\text { now. I know it's not going to be exactly the same, but it will be similar. }\end{array}$ \\
\hline Aron, 2012: & $\begin{array}{l}\text { I think it's a good experience. I feel like at this phase in our education, especially } \\
\text { before Senior Design, this should be something everybody needs to experience, } \\
\text { before you get out into the real world. Because you're going to be in that place, } \\
\text { whether you want to or not. You can't be gluing stuff. We don't glue, we don't use } \\
\text { wood, you have to think, "I have to actually build this." }\end{array}$ \\
\hline Joey, 2012: & Yeah, no duct tape. \\
\hline Jen, 2012: & $\begin{array}{l}\text { Since we don't have any experience for any of this before Senior Design, it was } \\
\text { good to let us to do this so we understand things like time management and how } \\
\text { you think you're only going to spend a couple hours on something in the machine } \\
\text { shop and it's like eight hours on one part. It's just important to learn on a smaller } \\
\text { scale about what you can machine and how long things take. It was a big learning } \\
\text { experience. }\end{array}$ \\
\hline Steve, 2012: & $\begin{array}{l}\text { Yeah. This class was definitely a good learning experience for me in terms of } \\
\text { preparation for Senior Design. Senior Design's going to be a lot more of the same } \\
\text { where we'll be spending a lot of time in the machine shop, a lot of time meeting } \\
\text { not only with our teammates but with our industry mentors and faculty advisors. } \\
\text { So this project really helped. }\end{array}$ \\
\hline Sam, 2012: & $\begin{array}{l}\text { Not to play devil's advocate, but some of these things that we're kind of } \\
\text { complaining about now are almost good to learn because we learn it in } \\
\text { Component Design, not Senior Design. If you baby us too much we'd never learn. } \\
\text { So maybe we should have been directed a little more than we were, but not fix all } \\
\text { of our errors. Because I know if I don't make a mistake, I won't learn. You can be } \\
\text { told, but we're still young and still learning. }\end{array}$ \\
\hline Mitch, 2012: & $\begin{array}{l}\text { I really feel like other courses could learn from this course. We finally got some } \\
\text { real world experience and we're juniors, and it should have happened a little } \\
\text { earlier. I don't know where it would fit in but I really feel it would prepare us a lot } \\
\text { better for our careers if we had experience. }\end{array}$ \\
\hline Henry, 2012: & $\begin{array}{l}\text { It would be nice to see this same thing happening in our courses. Because its all } \\
\text { engineering, and it would increase our motivation to see how it's all related. }\end{array}$ \\
\hline
\end{tabular}


Summary of qualitative results. As illustrated in Theme \#1, the course elements that were most influential in sustaining student achievement motivation were those that gave students real-world engineering design experience in an authentic context, including design-based homework assignments, the in-class use of videos, props, and demonstrations, and PBL. PBL fostered the development of new skills, including machining, fabrication, technical writing, communication, working on a team, time management, and preparing meeting minutes and agendas. Students also valued the autonomy-supportive characteristics of the course instructor, Dana, and the feedback and guidance they received from the course teaching assistants and the design lab foreman, Jerry.

However, as demonstrated in Theme \#2, as much as the students valued the authentic nature of the course and project, they still encountered significant challenges, especially involving team dynamics and solving ill-structured problems. Challenging team dynamics included power struggles with the project manager as well as individual differences in students' attitudes toward the project, perceptions of what constitutes professional behavior, and performance on project activities. The student testimonials outlined in Theme \#2 show how struggles with solving ill-structured problems were a factor of the open-endedness of the project, the varying levels of technical skills and abilities, students' access to project resources, and the integration of the course and the project. It was many students' first encounter solving these types of problems, which some students recognized as problems that they will be required to solve in the workplace.

From the perspective of designing a suitable project context, another challenge worth considering is the impact of the previous years' projects on students' initial interest for their own project, as evidenced in Theme \#3. Whereas the 2011 cohort held high initial interest and excitement for the drill-powered vehicle as compared to the previous year's ball launcher and Lego lawn mower mini-projects, the 2012 cohort reported lower initial interest and excitement for the adapted tricycles project as compared to the previous year's drill-powered vehicle project. This lack of initial interest felt by the 2012 cohort, along with the addition of a real-world client which served to complicate the project, seemed to dampen students initial engagement in project activities. Students' interest and engagement increased, however, 
when they were more immersed in the hands-on aspects of the project, felt more confident in the success of the project, and connected on a personal level with their client.

Another difference between the cohorts was, of course, the context of the project (service vs. nonservice), which served to shape the students' experiences. As illustrated in Theme \#4, each cohort developed their own dominant group emotion, cultivated a different sense of community, and had contrasting perspectives about working (or not working) with a client. The 2011 cohort characterized their project as fun and exciting and felt a strong sense of pride and community among their Component Design peers, in part because they perceived the project as enviable by students in other majors. The friendly competition in the end-of-semester run-off also served to strengthen this sense of community and camaraderie. Also, not having to work with a real-world client was, for the most part, desirable as it allowed the students to focus on their designs without having to respond to the needs of a client.

In contrast, the 2012 cohort characterized their project as evoking feelings of altruism as well as a sense of accountability to design in accordance with the needs of another human being. Although it served to complicate the project, most students gleaned valuable skills from the addition of a real-world client. Overall, the altruistic nature of the project connected the students with a community beyond their immediate peer environment and provided a new perspective on how engineering design can have an immediate positive impact on the lives of others and the well-being of communities.

Theme \#5 illustrated how experiencing the design process in an authentic context was influential on students' ability-related beliefs and values - both the levels of value students attached to different project activities and outcomes as well as the personal values students held regarding design. Namely, how students define the objective or purpose of doing design. The students felt that learning to follow a process for design was exciting, empowering, and valuable. Experiencing the design loop caused the students to realize that the purpose of design is more than arriving at a number and that substantial effort is required to transform a design on paper to a functioning product in real life. They also realized the value of feedback, especially from experienced individuals, when engaging in design activities. 
Lastly, Theme \#6 illustrated how acquiring new skills and competencies increased students' confidence and excitement for future engineering experiences. They were able to form a deeper connection between the knowledge they have acquired thus far as engineering students and how it relates to real-world engineering practice. This helped the students develop a clearer understanding of what their future careers may entail and a engender a stronger sense of confidence that they will succeed in those future careers.

Connecting quantitative and qualitative phases. Overall, this study strongly supports the use of mixed methods research design in engineering education research. It's difficult to imagine how a situated description of student achievement motivation thus presented could have emerged out of the quantitative or qualitative data alone. It truly was the synthesis of the two strands that helped answer the two overarching questions of this study - what factors are most influential on students' motivation to persist in project-based learning experience? And how does the context of service in project-based learning affect student motivation? This section will briefly summarize the major results of this study by connecting the quantitative and qualitative results.

One of the major quantitative results was that student achievement motivation was sustained in both cohorts as evidenced by students' post-course levels of value, interest, engagement, and ability-related beliefs. The qualitative results helped identify the elements that supported student achievement motivation, which were those that facilitated the gain of real-world engineering design experience in an authentic context. Experiencing the design process first hand had significant positive impacts on students' interest, value, and ability-related beliefs. Gaining new skills contributed to increased confidence, excitement for future engineering experiences, and a deeper understanding of what career possibilities are possible.

The next significant quantitative finding showed how student achievement motivation was sustained in both cohorts and that post-course levels of achievement motivation were similar between the cohorts. In fact, there was no statistically significant difference between the cohorts in post-course levels of project 
value, interest, engagement, or ability-related beliefs. Furthermore, the most important variables for predicting student motivation - engagement, interest, value, ability-related beliefs, and initial experience - were similar between the cohorts. The qualitative results were instrumental in understanding this trend and provide strong evidence to support the claim that the authenticity of both project contexts seemed to impact students' motivation more than the project context itself. The quality of authenticity gave students the opportunity to develop skills and competencies that they perceived as relevant to the real world.

In terms of skills and competencies, another quantitative result observed in both cohorts was the statistically significant increase in students' pre-course to post-course technical and non-technical skill confidence levels. Also, students had significantly higher confidence in their technical skills than their non-technical skills at the beginning of the semester, but at the end of the semester their confidence levels in these two set of skills were most similar to each other. Students in the focus groups identified machining and fabrication as the most important technical skills developed. Communication, working on a team, time management, and preparing meeting minutes and agendas were the most important nontechnical skills developed. Students perceived the project as the primary vehicle for developing new nontechnical skills; however, the group dynamic of the lecture (i.e. working in teams to solve problems) also contributed to their development of non-technical skills.

Developing these skills, however, required the students to experience a significant amount of struggle, discomfort, and unanticipated roadblocks. This was evident in both the quantitative and qualitative results. First, the quantitative results showed a decrease in pre-course to post-course level of value students felt for the course and the project. Next, the focus group testimonials illustrated how students encountered significant challenges surrounding team dynamics and solving ill-structured problems, both of which required students to develop, strengthen, and apply new non-technical skills. It's also important to keep in mind that students completed both the online surveys and participated in the focus groups immediately following the project; hence they were still processing some of the difficult emotions from the PBL experience. 
Another interesting quantitative result showed how the 2012 cohort reported lower levels of initial project interest than the 2011 cohort. The qualitative data was instrumental in explaining this trend. Students in the 2012 cohort expressed a lack of initial interest in the project for two major reasons: one, some students initially perceived the adapted tricycles project to be less fun and exciting, and possibly less challenging, than the drill-powered vehicles project. Two, the addition of a real-world client added a layer of complexity to the design process, which seemed to impede students' early engagement and participation in the project. However, students in the 2012 cohort seemed to experience an increase in their interest and engagement in the project once they were more immersed in the hands-on aspects of the project, gained greater confidence in their design abilities, and felt a deeper personal connection with their client.

Another difference between the cohorts was, of course, the context of the project (service vs. nonservice), which served to shape the students' experiences. As illustrated in the qualitative results, each cohort developed their own dominant group emotion, cultivated a different sense of community, and had contrasting perspectives about working (or not working) with a client. The 2011 cohort characterized their project as fun and exciting and felt a strong sense of pride and community among their Component Design peers, in part because they perceived the project as enviable by students in other majors. The friendly competition in the end-of-semester run-off also served to strengthen this sense of community and camaraderie. Also, not having to work with a real-world client was, for the most part, desirable as it allowed the students to focus on their designs without having to incorporate the needs of somebody else.

In contrast, the 2012 cohort characterized their project as evoking feelings of altruism as well as a sense of accountability to design in accordance with the needs of another human being. Although it served to complicate the project and frustrate some students, they gleaned valuable skills from the addition of a real-world client. Overall, the altruistic nature of the project connected the students with a community beyond their immediate peer environment and provided a new perspective on what is possible through engineering design. 
The last significant comparison to make between the cohorts is that, although there was a similarity between the cohorts in terms of most important variables for predicting student achievement motivation, the random forest analysis showed how there was a difference in the top most important predictor variables. For the 2011 cohort, the most important variables was a tie between overall initial abilityrelated beliefs and overall initial experience. The qualitative data reveals how the 2011 cohort spoke to a greater extent about how their ability-related beliefs and experiences factored into their motivation toward the project. For the 2012 cohort, on the other hand, the random forest analysis showed the most important variable was overall initial value. Indeed, a strong sense of altruism emerged as a dominant theme in the qualitative results from the 2012 cohort in terms of influencing their motivation to persist in the project. Also supporting this trend was a quantitative increase in 2012 students' positive attitude toward service learning. 


\section{Chapter Six}

\section{Discussion, Implications, and Future Research}

"Words mean more than what is set down on paper. It takes the human voice to infuse them with shades of deeper meaning." Maya Angelou

\section{Creating the Foundation for PBL}

Student achievement motivation was sustained in both project contexts (conventional and service) as evidenced by students' post-course levels of value, interest, engagement, and ability-related beliefs. This result is significant as it suggests that the project context itself had less of an impact on student achievement motivation than did other elements such as students' overall positive experience in the course, the supportive role of course faculty, the classroom climate, and students' perceptions of project authenticity and the relevancy of the project to real life.

Scaffolding. The students highly valued the way the course gave them real-world engineering design experience in an authentic context. From the students' perspective, this was in part supported by the way the course was scaffolded to link machine design concepts to real life through the use of designbased homework, videos, props, and demonstrations. This use of scaffolding by the course instructor helped prepare the students for the project experience, hence contributing to students' feelings of value toward these activities.

Course faculty. Another significant factor influencing students' achievement motivation was the role of the course faculty. Truly, the role of faculty in supporting achievement motivation in PBL cannot be overstated. As Blumenfeld (1991) states, “even well-defined projects cannot sustain student motivation themselves; teachers play a critical role." Blumenfeld's statement certainly holds true for this study; the role of the course faculty had a significant impact on students' feelings of value, interest, and abilityrelated beliefs. Besides valuing the way the course instructor was approachable, knowledgeable, and caring, the students valued the way she provided important feedback as they tackled the project. Similarly, the students valued the support and feedback they received from the course teaching assistants and machine shop foreman as they helped them transition from design to building. Self-determination theory tells us that teachers who exhibit these autonomy-supportive characteristics positively influence their students' intrinsic motivation, curiosity, and desire for challenge.

Course climate. The instructor also has a significant impact on creating the right classroom climate for PBL. Again, self-determination theory explains how a person's social environment can support or thwart his or her motivation depending on the relative degrees of autonomy, competence, and 
relatedness that person feels. In the classroom setting, the instructor can help create a supportive environment by engaging students in activities that offer variety and diversity, providing students with opportunities to develop new skills, and emphasizing personal relevance. Not only do these elements help support motivation, they also encourage students to develop a mastery goal orientation, which is conducive to a person's long-term and high-quality involvement in learning, preference for challenging work, ability and comfort in taking risks, intrinsic interest, developing new skills, positive attitude toward learning, and quality of engagement in learning. The instructor can also encourage students to adopt a mastery goal orientation by minimizing social comparison that is externally imposed (i.e. public displays of students' grades, scores, and abilities).

The students in this study expressed how they perceived the classroom climate to be a positive environment for PBL. In addition to the supportive course faculty, the project activities were varied and diverse and included project planning, technical writing, creating meeting minutes and agendas, design, fabrication, testing, and in the case of the PBSL cohort, client interaction. Both projects challenged students to develop new skills, both technical and non-technical, and the students perceived the project to be relevant to their own lives. The students did engage in social comparison, especially at the 2011 drillpowered vehicle run-off and the 2012 adapted tricycle design expo; however, the social comparison was not externally imposed. Evidence from the focus groups shows how many students actually valued these public events as they provided a mechanism of personal accountability, a way to compare the performance of their final designs, and encouraged students to internally reflect on their own success. Hence, one of the most important roles of the course instructor is to work to create a supportive environment that helps sustain student motivation in PBL and in the course itself.

Authenticity. The quality of authenticity seemed to have the most profound impact on student motivation in PBL. This, perhaps, is one of the most significant findings of this study. Students interviewed in the focus groups identified the following qualities of the PBL experience that made it feel authentic: 1) the project was a vehicle to apply course concepts to real life; 2) the project was open-ended; 3) the project encouraged creativity; 4) the project fostered the development of new skills; 5) the project culminated in a realistic product.

These project qualities are authentic because they describe a school task that is congruous with a real life situation. Palm (2007) describes authenticity as how much a school task simulates an event, problem, or other task or circumstance in the real world, and it has a significant impact on students' motivation and choice of learning strategies applied in problem-based and project-based learning situations. As Blumenfeld (1991) states, students' interest and perceived value of an activity are increased 
when the problem at hand is authentic. The problem must be relevant to the students, such as personal health, welfare, community concerns, or current events.

Likewise, Thomas (2000) states that realism (similar to authenticity) is one of the pillars of PBL. Students are more engaged, and their learning is enhanced, in non-school like contexts. Palm (2007) explains how students become so accustomed to solving textbook problems devoid of any real-world context that they develop the tendency to offer unrealistic solutions - solutions that don't actually work in the real world. However, when presented with real life challenges, students activate their knowledge of real situations and apply more appropriate problem-solving strategies to generate a solution to the problem in a way that makes sense in the real world.

This trend was evident for both cohorts in this study. Students in the focus groups described encountering problems that they had not previously encountered in their academic career and how they often had to respond to these problems by thinking creatively and "outside the box." Several students expressed how they came to see creativity as one of the most important qualities of an engineer. Students in the 2012 cohort, especially, described how working to meet the needs of a client versus working to earn a good grade caused them to develop a new set of problem-solving strategies. They had to consider the long-term reliability of their design, various safety concerns, and how their design might be used in unintended ways. There was a sense that the students had to put themselves in the shoes of the client to truly understand the design problem, which represented a radically different problem-solving perspective than they had utilized in previous courses.

\section{Supporting Student Achievement Motivation in PBL}

Interest, value, and ability-related beliefs. In this study, the project significantly contributed to an increase in students' ability-related beliefs. This was quantitatively observed as a significant increase in both cohorts' pre-course to post-course technical and non-technical skill confidence levels. Statements made by focus group participants also described how the project experience increased their confidence in succeeding in future engineering experiences such as Senior Design and working in industry. Students in both cohorts described machining and fabrication skills and gaining general competency in the design lab as the most significant technical skills they acquired. The most significant non-technical skills gained were technical writing, communication, working on a team, and time management.

The majority of these students, of course, have acquired new skills, competencies, and knowledge from their other engineering courses. However, a significant number of students interviewed in the focus groups described Component Design in particular as one of their most valuable, memorable, and relevant courses. What, then, was unique and valuable about the skills, competencies, and knowledge gained by 
students in this course? Turning to motivation theory: self-determination theory puts forth that one of a person's basic needs is to feel competent in his or her social environment. Hence, gaining real-world engineering skills - actually being able to design and fabricate a tangible artifact - contributed to students' sense of competency in the social environment of engineering. Students in this study perceived the social environment of real world engineering to be one that exists beyond the university walls, and one in which knowledge beyond engineering theory is required to be successful in that environment.

Another interesting trend was how students in both cohorts had significantly higher confidence in their technical skills than their non-technical skills at the beginning of the semester, but at the end of the semester their technical and non-technical skill confidence levels were more similar to each other. The project experience was instrumental in helping students develop and strengthen these non-technical skills. This is a desirable outcome if engineering graduates are to be prepared for future careers in which nontechnical skill competency is critical.

A study by Jonassen, Strobel, and Lee (2006) identified the parameters of everyday problems solved by engineers in the workplace by interviewing over 100 practicing engineers. One of the major recommendations made by the practicing engineers was to integrate more communication skills in engineering curricula. It was agreed that workplace problem-solving teams must rely on and trust each other and that no single person holds all of the information needed to make a decision. Knowledge is always distributed among team members, and it is useless unless shared and communicated effectively. The engineers interviewed in this study seldom recommended more engineering theory in engineering curricula; rather they recommended more instruction on client interaction, collaboration, oral presentation skills, writing, and learning to work with complexity and ambiguity.

The focus groups illustrate how the project was one of the students' first experiences having to rely in part on their non-technical skills to succeed in an academic setting, which typically places extremely high value on students' technical skill competency. This was an important milestone in many of the students' path to a career in engineering. Expectancy-value theory suggests that as people mature they begin to attach more value to activities in which they do well because 1) the positive feeling a person experiences after doing something well becomes attached to the successful activity, and 2) lowering the value one attaches to difficult activities can help sustain self-efficacy and self-esteem. Hence, the more opportunities students have to develop and demonstrate non-technical skill competence, the more they will come to value these essential skills.

The students in this study were indeed challenged to develop and strengthen their non-technical skills, and they learned first-hand how non-technical skills are critical to succeed in the engineering workplace and more immediate future experiences such as Senior Design. Hence, the project helped them develop a 
more holistic sense of competency in real engineering practice as well as a broader understanding of what their future careers may entail. In both cohorts this served to increase the students' confidence and abilityrelated beliefs, which was valuable to the students and had a positive impact on students' achievement motivation.

Not only was it sustained in both cohorts, student achievement motivation was also similar between the cohorts in that many of the most important predictors of student achievement motivation were the same. Students' initial course and project value, initial course and project interest, initial confidence in technical and non-technical skill levels, and prior course- and project- related experiences were the most important predictors of student achievement motivation.

This is a significant result as it suggests that, among other factors, students' motivation to persist in PBL is strongly linked to their initial perceptions of the project experience and to their perceptions of their own abilities to succeed. This result is not surprising when evaluated from the perspective of expectancy-value theory, which postulates that a person's initial value, interest, and ability-related beliefs are important drivers of their achievement motivation. This result is also similar to the following claim made by Blumenfeld (1991):

"A number of factors should be considered in project design that affect whether students will be motivated to do projects in a manner that fosters understanding. These factors include whether students find the project to be interesting and valuable, whether they perceive that they have the competence to engage in and complete the project, and whether they focus on learning rather than on outcomes and grades. Although there certainly are individual differences that influence what students find interesting and valuable, we can explore how projects might be designed to increase the likelihood that most students will be motivated by them."

Evidence from the focus groups suggests that students in both cohorts were initially interested in the project and perceived it as being a valuable experience because they were excited about designing and building something real, something they could touch and feel and relate to everyday experience. They envisioned the project as being an opportunity to develop new and useful skills that would be relevant to their future careers and experiences as engineers.

Another reason to explain the similarity in students' achievement motivation between the cohorts is that the daily project activities were largely the same. In both project contexts students were exposed to the design process and were tasked with creating a life-sized prototype that could be ridden. Both projects required students to apply Component Design course concepts at a high level and to learn and apply many of the same fabrication skills. Both projects also featured a culminating event at the end of the semester that gave students an opportunity to both test and evaluate their designs in "real time," and students in both cohorts grappled with some of the same challenges related to team dynamics and the concept of design. 
This result suggests that designing a successful PBL experience requires careful consideration of how the daily project activities will positively impact students' ability-related beliefs and be interesting, valuable, and challenging enough to sustain student motivation to persist in the project. We can imagine how the motivation levels of the 2012 cohort may have been different had the service project been, for example, the design of a stationary educational exhibit for the community library. Even with the altruistic nature of such a project, when compared to the drill-powered vehicle project, which students found to be fun, exciting, interesting, valuable, and challenging, a library exhibit project may not have sustained student motivation at a high level.

At the same time there is danger in arousing students' initial interest in a project by too many "bells and whistles" such as vivid and dramatic examples or flashy technology. According to situational interest theory, these techniques can trigger students' interest so that they focus on the material while it is present, but their interest can be short-lived if the environment does not continue to support it. Maintaining students' interest requires students to form a meaningful connection with the project activities, realizing their deeper significance, and feeling empowered by what they learn. Maintained interest often develops into a more enduring individual interest, characterized by students valuing the material beyond the course and by their efforts to seek out new opportunities to expand their skills and knowledge in that domain.

In this study students described the use of in-class props, demonstrations, and videos as triggering their initial interest in the course material. However, there is ample evidence that shows how this triggered interest was maintained by the course faculty, classroom environment, and various project activities. And, of course, by the end-of-semester events which gave the students something to eagerly anticipate, encourage friendly competition, and provide a sense of accountability to finish the project successfully.

One last plausible reason to explain why students' motivation levels were similar is that the majority of students in both cohorts identified with a mastery goal orientation at the beginning of the semester. According to achievement goal theory, students who adopt mastery goals are focused on mastering and understanding content and are eager to engage in the process of learning. They tend to be more engaged, prefer challenging work, demonstrate ability and comfort in taking risks, like to develop new skills, and show a positive attitude and intrinsic interest toward learning.

To varying degrees, these qualities were present in the students in this study. The focus groups illustrate how many students were willing to develop new skills and exert genuine effort to persist PBL, even though it was often difficult and uncomfortable. Of course, this was not true for all students, and evidence from the focus groups also shows how some students needed more guidance and were more comfortable utilizing pre-existing skills rather than learning new skills to complete project tasks. However, the fact that the majority of students were mastery goal oriented is significant because it 
suggests that, regardless of the project context, students who are mastery goal oriented are more likely to succeed in PBL. In fact, Blumenfeld (1991) states that the success of PBL actually depends on a classroom climate that promotes inquiry and a mastery goal orientation. Recall from Chapter 2 that one of the criticisms of PBL was that ill-structured pedagogy may not be effective for teaching students to solve ill-structured problems (Kirschner, Sweller, and Clark, 2006). This may very well be the case for students who are not mastery goal oriented and avoid risk taking, struggle with ambiguity, and prefer the use of superficial learning strategies (memorizing and rehearsing). Hence, students' achievement goal orientation is an additional factor of importance in PBL.

Another significant consideration regarding similarities in student motivation is the factors that were not present as important predictors of achievement motivation in this study, especially gender, which was not a significant predictor of achievement motivation in either cohort. Initially this result was quite surprising to the researcher, especially given previous research on how service-learning can attract and retain female students in engineering. Only one female student volunteered to participate in the 2012 PBSL focus groups. The researcher had expected more female students to be in attendance to discuss their experiences with service-learning; however, there were proportionately more female students in the 2011 PBL focus groups. The one female who did participate in a service-learning focus group made strong statements about how the altruistic elements of the project affected her achievement motivation, but male students made equally-compelling statements about the impact of service on their achievement motivation.

This study does not contradict previous research on female engagement in and preference for servicelearning; however, it does suggest that not all engineering students are alike in terms of their preference for service-learning. In fact, another surprising result of this study was that students in the 2012 cohort reported significantly less initial interest in the project than the 2011 cohort. Students in the 2012 focus groups expressed some initial disappointment that they would not be completing the drill-powered vehicle project, which seemed to be perceived as more fun and exciting than the adapted tricycles project. This lack of initial interest is important to note due to the fact that it served to decrease students' initial engagement in the project. Students' interest and engagement increased, however, once they were immersed in the hands-on aspects of the project, felt confident that the project would be successful, and felt more connected to their client. At the end of the semester, there was no significant difference in final project interest between the cohorts. Hence, it may be the case that students who are further along in their engineering career in a major with less of a "humanitarian" focus are more motivated to engage in projects that are authentic and provide opportunities for useful skill development regardless of a service vs. non-service project context. 


\section{Expected Challenges in PBL}

Team dynamics and solving ill-structured problems. So far this chapter has shown PBL in the most favorable light. However, most know from experience that learning is seldom easy. Most often learning is uncomfortable, involves risk-taking, and requires practice and persistence. Indeed, students in this study struggled considerably when the project presented authentic and real-world problems that many students had not experienced. This helps to explain the significant decrease in post-course project value as well as student testimonials describing the project challenges and setbacks.

When considering the observed decrease in project value, it's important to note that students' pre-course value was quite high; hence there was more potential for student value to decrease than to increase. Also, the students participated in the post-course survey and focus groups immediately after the project and were still processing both the positive and negative aspects of the experience, especially the challenges involved in team dynamics and solving ill-structured problems.

Jonassen, Strobel, and Lee (2006) define "ill-structured" problems as having vaguely defined goals and unstated constraints, posses multiple solutions and solution paths, involve multiple criteria for evaluating solutions, and require learners to make judgments and express personal opinions or beliefs about the problem. By nature, the design process is an ill-structured process and consists of many illstructured problems. In this study both project contexts challenged the students to grapple with openendedness and ambiguity, individual differences in backgrounds, skills, and abilities, and team dynamics. Solving these types of problems was difficult for the students who have become adept at solving wellstructured problems (i.e. textbook problems).

While students expressed that they did value how the project allowed for multiple solution paths, this open-endedness was at the same time problematic. Some students were uncomfortable defining the project scope and constraints and struggled with not knowing what, specifically, each of them were expected to be learning from the project. It seems that some students ventured out of the their comfort zones to acquire new skills and knowledge while others utilized prior skills and knowledge to complete project tasks. Having assigned project roles did help define the required tasks and duties, but some students expressed that they needed even more guidance in the initial project role selection process to best match their skills to a project role.

Also related to skills was the challenge students faced with leveraging each other's different backgrounds and abilities to optimize team performance. Students were quick to perceive that they all possessed varying levels of ability and types of skills, especially prior machining skills. Students felt that teams with at least one person who had prior machining and fabrication skills or access to external 
resources were at a significant advantage compared to teams which didn't. Also, most students felt that their previous coursework had not adequately prepared them to engage in a real-world design project.

It was also evident from the focus group testimonials that students were not prepared, or at least not expecting, the difficulty of team dynamics. Students struggled with what they perceived to be poor or unprofessional attitudes, behavior, and performance of their teammates. A tough realization for the students was how people have different standards of good work, varying levels of motivation to engage in work, and diverse problem-solving strategies. Friendships among teammates were strained and some broken, which caused students to question whether they should be allowed to choose their teams in the first place as many students chose to work with their friends.

Another area of sensitivity was the power struggle between the project manager and the rest of the team. Students who were not a project manager expressed mostly negative emotion toward their project managers, whom they characterized as inflexible, unreasonable, domineering, and poorly-suited for a leadership role. The project managers, in turn, expressed the difficulty they experienced delegating project tasks, enforcing deadlines (especially when their teammates were friends), giving teammates feedback, and engaging all team members in project tasks, especially given students' diverse skills and abilities.

Another challenge was the way the course and project were combined. For the most part, students perceived the project to be an integral part of the course. However, they did struggle with the order in which the lecture material was presented, as it did not always match what they thought they needed to know at certain stages of the project. Students described how they might have designed components differently had they learned certain concepts earlier. They acknowledged they were expected to perform independent research and seek counsel form their mentors, yet this self-directed learning proved difficult and at times overwhelming. Some students also felt that topics such as sustainable design, holistic design, life-cycle analysis, and aesthetics should have been more emphasized in the course. Students perceived these topics to be directly relevant to their project and felt that not covering these topics in course detracted from the authenticity of the project.

The last issue mentioned by the students was the ability of the teaching assistants to adequately answer the students' design-related questions. Although the instructor worked closely with her teaching assistants to help prepare them to serve as mentors to the student teams, the students still found the teaching assistants to be quite helpful in answering their textbook and homework-related questions (well-structured problems) but less helpful in answering students' design project questions (more ill-structured problems). The students suggested that the reason for the variation in TA helpfulness may have had to do with the 
fact that the TAs didn't know exactly what was expected of them when it came to serving as mentors for design and also just because some TAs were less knowledgeable and experienced when it came to design.

Taken together, these types of ill-structured problems are the kind of problems students can expect to encounter in workplace settings and future team-based design experiences. Although the process was often awkward and discouraging for the students, learning to solve ill-structured problems is essential to transition from the university to the workplace. Jonassen, Strobel, and Lee (2006) state that engineering educators often assume that learning to solve well-structured problems positively transfers to solving illstructured problems; however, this is not the case. Learning to solve ill-structured problems requires different skills, cognitive processes, and experience. Practicing engineers actually come to rely more on their historical knowledge of problems they have solved than on their conceptual understanding; hence, solving ill-structured workplace problems requires experience.

At the same time, students need not become overwhelmingly discouraged when learning to solve illstructured problems such as those presented in PBL. As this thesis has already discussed, there are a variety of instructional techniques and guidelines to help sustain student achievement motivation in PBL. However, students should be expected to work through significant challenges, especially those presented by ill-structured problems. Referring again to a statement made by Thomas (2000) when describing the five criteria of PBL: "if students can complete the project activities by applying prior understanding and skills, the project is not PBL." Furthermore, Blumenfeld (1991) states: "teachers and students who conceive of errors only as failure to learn will have extraordinary difficulties succeeding at PBL." Hence, PBL actually depends on students' learning from their challenges, setbacks, and mistakes.

Thomas also argues that providing students with constant feedback is critical. Students in the focus groups expressed how much they valued feedback from course faculty. Hence, when engaging students in PBL, it is important for the course faculty to be aware of some of the anticipated challenges involved in order to respond to students' questions and concerns in a way that still leaves the solution path to be forged by the students.

\section{Shaping the PBL Experience}

The role of context. The majority of this chapter has focused on the similarities in student achievement motivation between the cohorts and on the foundation for a successful PBL experience, which includes scaffolding to effectively link the course and the project, positive course faculty and course environment, and authenticity. The supports for PBL include triggering and maintaining student interest and value, increasing students' ability-related beliefs, and providing students with feedback, 
especially when they encounter challenges. These elements must be in place to create the basic structure of PBL. But it is the project context, as we will discuss, that can give this structure its unique shape.

As evidenced by the focus group testimonials, the context of the project significantly shaped the students' experiences. The dominant group emotions of the 2011 cohort were pride, fun, excitement, and camaraderie. The dominant group emotion of the 2012 cohort was a sense of altruism from doing something significant for someone else. For students in the 2011 cohort, it was the competitive aspect of the run-off and preparing for the run-off that contributed to their sense of accountability to complete the project. For the most part students in the 2011 cohort were sufficiently challenged without the addition of a client. Students in the 2012 cohort, however, described the client as contributing to the authenticity of the project as well as to their feelings of accountability not just to complete the project but to create a safe and reliable product.

The project context also influenced the top most important variables for predicting student achievement motivation. Although, as stated earlier, there was a similarity between the cohorts in terms of the group of most important variables for predicting student motivation, there was a difference in the top most important predictor variables. For the 2011 cohort, the top most important variable was a tie between overall initial ability-related beliefs and overall initial experience. For the 2012 cohort, the top most important predictor variable was overall initial value. This means that students in the 2011 cohort who had high confidence in their abilities to succeed in the course and project and had some initial course and project-related experience were most likely to be highly motivated by the drill-powered vehicle context. Students in the 2012 cohort who perceived the course and project to be of high value were most likely to be motivated in the adapted tricycles project.

This result indicates that although both cohorts perceived the course project as valuable, the nature of how students valued the project experience was different in some respects. The focus groups offer several plausible explanations for this result. It seems as though students in the 2011 cohort had an easier time getting started on the hands-on activities of their project. There was no project client with whom to arrange meetings, no physical disability to take into account, and no delay between building and testing as they were essentially building a vehicle to be ridden by one of their own team members. Because the design process was less circuitous as compared to the adapted tricycles project, it's likely to assume that students who had high confidence in their abilities to succeed in this context and similar prior experiences found it easier to engage in the project early on, thus increasing their achievement motivation.

Students in the 2012 cohort, however, experienced more difficulty initiating the hands-on aspect of their project. Students in the focus groups described how difficult it was to obtain the necessary data 
such as their clients' dimensions, range of motion impaired by physical disability, and strength limitations. Not only was it difficult to obtain this information as the basis for their designs, students found it nearly impossible to simulate their clients' conditions in order to test their tricycles. There were also additional factors to consider such as reliability, safety, and possible unintended uses of the tricycle (i.e. siblings riding the tricycle). Overall, these factors served to complicate the design process and made it difficult for the students to dive into the hands-on project activities.

The service context also required more time and effort on the part of the course faculty. This result is similar to a study referenced in Chapter 2 in which SLICE (Service-Learning Integrated throughout the College of Engineering) faculty indicated that time constraints, reward and recognition challenges, skills required, and an increase in workload were associated with PBSL (Burack, 2008). Another study referenced in Chapter 2 involving students in the D80 (Development for the Other 80\%) Center at Michigan Technology University found that the top three reasons for not participating in PBSL are lack of money, lack of time, and a concern to do well in "major studies" (Paterson and Fuchs, 2008).

Hence, due to the additional layer of complicacy involved in PBSL, students (and perhaps faculty) in the 2012 cohort seemed to have to fuel their persistence in the project from a sense of delayed gratification. In other words, they had to cultivate a vision of how what they were doing was valuable both in terms of how the project would benefit them and also how it would benefit another human being in order to sustain their achievement motivation. Several students in the focus groups described envisioning the act of giving their tricycle to their client and how it was this vision that motivated them to persist through project hardship. Other students described how it was motivating to learn how engineering can have an immediate impact on the local community. This gave them a new perspective on what is possible through engineering design. This result is similar to a study involving EPICS (Engineering Projects in Community Service) students referenced in Chapter 2 that found awareness of the customer in an engineering project to be among the top outcomes of the program (Coyle, Jamieson, and Oakes, 2005). Jeff, a participant in one of the 2012 focus groups, described the project as being the first servicelearning experience for some of his teammates and how profound it was for them to discover an alternative outlet for their engineering skills and knowledge - one that is directed toward the betterment of the surrounding community. Henry, another 2012 focus group participant, suggested that the context of service may be less emphasized in mechanical engineering than it is in majors with a more humancentered focus, such as civil engineering. Exposing mechanical engineering students to PBSL through a required course may, therefore, open exciting opportunities and pathways. 
Hence, the fact that the 2011 cohort and 2012 cohort displayed different patterns in terms of what they valued is significant as it illustrates how students, like any other subset of people, will value different elements of an experience, in part depending on the context. And, like the construct of motivation, the construct of value has several components. According to expectancy-value theory, these components are: attainment value (the personal importance of doing well on a given task); intrinsic value (the enjoyment a person feels from performing a given task or the interest a person has in the subject; utility value (how well a task relates to a person's current and future goals); and cost (conceptualized in terms of the negative aspects of engaging in a task).

Feelings of high attainment value can likely be attributed, at least to some degree, to the fact that the majority of the students in both cohorts were mastery goal oriented. By nature they place high personal value on succeeding in academic contexts. Although the 2012 cohort was characterized as more performance goal oriented than mastery goal oriented, the element of altruism in the project context enhanced these students' sense of personal value on succeeding.

Both cohorts expressed different feelings of intrinsic value for the project. For the 2011 cohort, intrinsic value seemed more related to fun and excitement. For the 2012 cohort, intrinsic value seemed more related to a sense of altruism. Both cohorts, however made compelling statements about the intrinsic value of feeling connected and working collaboratively in a team setting.

Students in both cohorts felt a high degree of utility value for the project because of the various technical and non-technical skills they learned that will help them succeed in future design experiences. Working with a real-world client certainly added another dimension of utility value for students in the 2012 cohort. They learned how difficult it can be to design to meet the needs of a client - a lesson they felt will serve them well in the future. Lastly, both cohorts experienced a sense of cost, described in the focus groups as the various challenges encountered.

The point is that students valued various aspects of the project experience. Their sense of value was just as much derived from the elements that were challenging, demanding, and discouraging as it was from the elements that were fun, exciting, and uplifting. As stated by Sam, a participant in the 2012 focus group:

"Some of these things that we're kind of complaining about now are almost good to learn because we learn it in Component Design, not Senior Design. If you baby us too much we'd never learn...Because I know if I don't make a mistake, I won't learn. You can be told, but we're still young and still learning."

Sam's quotation captures what many of the focus group participants expressed - strong feelings of value for experiences that lead to the development of new skills and knowledge, enhance students' beliefs about their abilities, and expand their perceptions of themselves as future engineers. 
By no means was this a perfect PBL experience for the students, nor is the point of this study to prescribe a set of conditions or guidelines for the "perfect" PBL experience. From the beginning, the purpose of this study was to isolate the context of service to better understand its influence on students' feelings of achievement motivation in PBL and also to generate a set of best practices with regard to student achievement motivation in PBL.

The results show that the context of service did not influence student achievement motivation any more or any less than the conventional project context for both men and women students. Students were motivated by many of the same foundational elements in each context, and their motivation was supported by similar features. The project context, however, shaped the students' experiences, which in turn influenced their value and ability-related beliefs. Hence, the significant result is not how one context was more or less motivating than the other, but how the contexts worked in different ways to inspire students' persistence in PBL.

The bottom line is this: building a successful PBL experience requires immediate attention to the foundational elements. Next, the supports to sustain student motivation must be constructed. Once this groundwork has been laid, the context can be used to bring a unique shape, texture, and character to the experience. Based on this model, the next section summarizes a set of best practices in PBL with regard to student achievement motivation.

\section{Forming the Foundation}

Course faculty. By minimizing social comparison and engaging students in diverse activities that provide opportunities to develop new skills and emphasize personal relevance, course faculty can encourage students to develop a mastery goal orientation. Course faculty must also feel motivated to engage in PBL, as it often requires substantially more time, resources, and effort than delivering a traditional course.

Scaffolding. If the project is part of a more traditional course with a lecture component, consider the use of media, props, hands-on examples, and group activities that can help students connect the course material and the project and also help students develop skills or problem solving strategies that are successful to complete the project. Intentional scaffolding can contribute to the course and the project being perceived as mutually enhancing versus separate activities.

Authenticity. The project must feel authentic to the students in that the project activities and skills required are congruous with real-life situations. Other factors influencing authenticity can include the degree to which the project is a vehicle to apply course concepts to real life, is open-ended, offers 
opportunities to be creative, and fosters the development of new skills. Engaging in an authentic project stimulates students to offer solutions that make sense in the real world.

\section{Supporting Motivation}

Interest. It is arguably easier to trigger interest in PBL than it is to maintain it. Triggering interest by introducing a project that is exciting, tangible, and relevant can increase students' early engagement in the project. Maintaining interest involves the students coming to value the project and perceiving it as enhancing their ability-related beliefs. Students may also respond well to elements of the project that are fun and encourage friendly competition. Maintaining students' interest in a domain can lead to students developing long-term individual interest.

Value and ability-related beliefs. Careful consideration should be given to the link between value and ability-related beliefs. Students will value activities that provide opportunities to develop skills that they perceive to be relevant and contribute to their competence and confidence in the real world. Keep in mind that there are several dimensions to the construct of value. A student can value an activity because he or she attaches personal value to doing well in the activity, finds it intrinsically interesting, and/or perceives the activity as serving him or her well in the future. When designing a PBL experience, a useful question to ask is how the project activities appeal to each of these dimensions of value.

Challenges and feedback. Due to a natural tendency to value what they're already good at, students may be resistant to engage in project activities for which they feel inadequate or unskilled. Solving ill-structured problems and grappling with team dynamics can present the greatest challenges, especially because they represent unfamiliar problem solving scenarios. The instructor can encourage persistence in these activities by working to maintain a mastery-goal oriented classroom environment and by providing constructive feedback. At the same time, students should be given room to learn from their own mistakes. Acquiring skill in solving ill-structured problems can prepare students for the workplace or future design experiences.

\section{Shaping the Experience}

Context. When selecting the project context, carefully consider the more subtle learning goals. If the goal of the project is to teach students about citizenship, the role of service in society, how engineering can positively impact communities, and the intrinsic rewards of delayed gratification, the context of service may be an excellent choice. If the goal of the project is for students to have fun, be excited, and quickly engage in the hands-on aspects of the design process, a more appropriate context may be one with qualities similar to the drill-powered vehicle project. However, above all else, the project context should feel authentic to the students. 
Client. The introduction of a client can enhance authenticity, contribute to students' feelings of accountability to finish the project, and a new experience of designing to meet the needs of someone else versus simply earning a course grade. Working with clients, however, can require substantially more time and effort on the part of the course faculty; hence the reasons for including a client should outweigh the extra resources required.

Service. The context of service can enhance students' intrinsic interest and value by inspiring a sense of altruism, connecting students with the broader community, and providing a new perspective on how engineering design can complement public spiritedness. Service by itself, however, may not be sufficient to sustain student motivation if not supported by the foundational elements of PBL.

\section{Study Limitations and Future Work}

There are two significant limitations to this study. First, although the surveys were adapted from existing surveys pertaining to student motivation, the surveys used were not validated. Validating and refining the surveys based on the adapted motivation framework developed by the researcher is an area for future work. Second, this study involved students from a single institution and a single major; hence the results are generalizable to similar contexts although they are not generalizable in an absolute sense. Future work planned by the researcher includes a similar study with students at another institution.

Another area of future work would be to interview some of the participants of this study one or two years after their first PBL experience in Component Design to consider how it impacted their engagement and success in Senior Design or their first job out of school. Did PBL in Component Design sustain an increase in students' ability-related beliefs? Did it contribute to greater expectancies for success when the students were confronted with real-world design problems? Lastly, for the students who were inspired by PBSL - were they motivated to seek out additional service-learning experiences?

The researcher certainly feels compelled to continue exploring these questions in her career as an engineering education researcher and practitioners to further our understanding of how to design the design experience. 


\section{Bibliography}

Ames, C. (1992). Classrooms: goals, structures, and student motivation. Journal of Educational Psychology, 84(3), 261-271.

Archer, J. (1994). Achievement goals as a measure of motivation in university students. Contemporary Educational Psychology, 19, 430-446.

Astin, A., Vogelgesang, L., Ikeda, E., and Yee, J. (2000). How Service Learning Affects Students. Higher Education Research Institute. University of California, Los Angeles.

Bandura, A. (1997). Self-Efficacy: The exercise of control. New York: Freeman.

Barrington, L., and Duffy, J. (2007). Attracting underrepresented groups to engineering with servicelearning. Proceedings of the 2007 American Society for Engineering Education Annual Conference and Exposition.

Bartscher, K. (1995). Increasing student motivation through project-based learning. Masters thesis, Saint Xavier University, Chicago, IL. ERIC Number: ED392549

Bielefeldt, A. (2009). Gender differences in the attitudes of students in freshman engineering courses. Proceedings of the 2009 American Society for Engineering Education Annual Conference and Exposition.

Blumenfeld, A. (1991). Motivating project-based learning: Sustaining the doing, supporting the learning. Educational Psychologist, 26(3and4), 369-398.

Breiman, L. and Culter, A. Random Forests. Retrieved on August 13, 2012. http://www.stat.berkeley.edu/ breiman/RandomForests/

Brescia, W., Mullins, C., and Miller, M. (2009). Project-based service-learning in an instructional technology graduate program. International Journal for the Scholarship of Teaching and Learning, $3(2)$.

Case, J., and Light, G. (2011). Emerging methodologies in engineering education research. Journal of Engineering Education, 100(1), 186-210. 
Chism, N., Douglas, E., Hilson, W. (2010). Qualitative Research Basics: A Guide for Engineering Educators. National Science Foundation 2008. Available at $<$ https://cleerhub.org/resources/9/download/RREE_Qualitative_Research_Handbook_ChismDougl asHilson.pdf>

Coyle, E., Jamieson, L., and Oakes, W. (2005). EPICS: Engineering projects in community service. International Journal of Engineering Education, 21(1).

Creswell, J. and Plano Clark, V. (2010). Designing and conducting mixed methods research (3rd ed.). SAGE Publications, Inc.

Crotty, M. (1998). The Foundations of Social Research: Meaning and Perspective in the Research Process. SAGE Publications, Inc.

Deci, E., and Ryan, R. (1985). Intrinsic motivation and self-determination in human behavior. New York: Plenum.

Deci, E., and Ryan, R. (1987). The support of autonomy and the control of behavior. Journal of Personality and Social Psychology, 53(6), 1024-1036.

Deci, E., and Ryan, R. (2002). Handbook of self-determination research. New York: University of Rochester Press.

Dey, I. (1993). Qualitative Data Analysis. New York, NY: Routledge.

Duffy, J., Barry, C., Barrington, L., and Heredia, M. (2009). Service-learning in engineering science courses: Does it work? Proceedings of the 2009 American Society for Engineering Education Annual Conference and Exposition.

Duffy, J., Moeller, W., Kazmer, D., Barrington, L., Barry, C., West, C., and Crespo, V. (2008). Service-learning projects in core undergraduate engineering courses. International Journal for Service Learning in Engineering, 3(2), 18-41.

Eccles, J., (1994). Understanding Women's Educational and Occupational Choices. Psychology of Women Quarterly, 18, 585-609. 
Eccles, J., and Wigfield, A. (2002). Motivational beliefs, values, and goals. Annual Review of Psychology, $53,109-32$.

Eccles, J., (2009). Who am I and what am I going to do with my life? Personal and Collective Identities as Motivators of Action. Educational Psychologist, 44(2), 78-89.

Elliot, A., and Dweck, C. (2005). Competence and motivation: competence as the core of achievement motivation. In Elliot A., and Dweck, C. (Eds.), Handbook of Competence and Motivation. New York, NY: The Guilford Press.

Ertmer, P., and Newby, T. (1993). Behaviorism, cognitivism, constructivism: Comparing critical features from an instructional design perspective. Performance Improvement Quarterly, 6(4), 50-72.

Expeditionary Learning Outward Bound. (1999). Early indicators from schools implementing new American schools designs. Cambridge, MA: Expeditionary Learning Outward Bound.

Eyler, J., and Giles, D. (1999). Where's the learning in service learning? San Francisco, CA: JosseyBass, Inc.

Goetz, J., and LeCompte, M. (1981). Ethnographic research and the problem of data reduction. Anthropology and Education Quarterly, 12, 51-70.

Hastie, T., Tibshirani, R., and Friedman, J. (2011). The elements of statistical learning: Data mining, inference, and prediction ( $2^{\text {nd }}$ ed.). Springer.

Harackiewicz, J., Barron, K., Carter, S., Lehto, T., and Elliot, J. (1997). Predictors and consequences of achievement goals in the college classroom: Maintaining interest and making the grade. Journal of Personality and Social Psychology, 73(6), 1284-1295.

Hokanson, D., Phillips, J., and Mihelcic, J. (2007). Educating engineers in the sustainable futures model with a global perspective: Education, research and diversity initiatives. International Journal of Engineering Education, 23(2), 254-265.

Ivankova, N., Creswell, J., and Stick, S. (2006). Using mixed-methods sequential explanatory design: From theory to practice. Field Methods, 18(1). 
Jonassen, D. (1999). Designing constructivist learning environments. Instructional design theories and models: A new paradigm of instructional theory, 2, 215-239.

Jonassen, D., Strobel, J., and Lee, C. (2006). Everyday problem solving in engineering: Lessons for engineering educators. Journal of Engineering Education, 95(2), 139-151.

Kirschner, P., Sweller, J., and Clark, R. (2006). Why minimal guidance during instruction does not work: An analysis of the failure of constructivist, discovery, problem-based, experiential, and inquirybased teaching. Educational Psychologist, 41(2), 75-86.

Koro-Ljungberg, M., and Douglas, E. (2008). State of qualitative research in engineering education: Meta-analysis of JEE Articles, 2005 - 2006. Journal of Engineering Education, 97(2), 163-175.

Krueger, R. 1994. Focus groups: a practical guide for applied research (2 $2^{\text {nd }}$ ed.). The University of Michigan: Sage Publications

Liaw, A., and Weiner, M. (2002). Classification and regression by randomForest. $R$ News (2/3) 18-22. Retrieved on April 7, 2012, from < http://www.webchem.science.ru.n1/PRiNS/rF.pdf>

Linnenbrink-Garcia, L., Durik, M., Conley, M., Barron, E., Tauer, M., Karabenick, S., and Harackiewicz, J. (2010). Measuring situational interest in academic domains. Educational and Psychological Measurement, 70(4), 647-671.

MacIver, D., Stipek, D., and Daniels, D. (1991). Explaining within-semester changes in student effort in junior high school and senior high school courses. Journal of Educational Psychology, 83(2), 201211.

Matusovich, H., Streveler, R., and Miller, R. (2010). Why do students choose engineering? A qualitative, longitudinal investigation of students' motivational values. Journal of Engineering Education, 99(4), 289-303.

McHenry, A., Depew, D., Dyrenfurth, M., Dunlap, D., Keating D., Stanford T., Lee P., and Deloatch, G. (2005). Constructivism: The learning theory that supports competency development of engineers 
for engineering practice and technology leadership through graduate education. Proceedings of the 2005 American Society for Engineering Education Annual Conference and Exposition.

Meadows, L., and Jarema, S. (2006). An evaluation of the impact of a service learning project in a required first-year engineering course. Proceedings of the 2006 American Society for Engineering Education Annual Conference and Exposition.

Mendez, G., Buskirk, T., Lohr, S., and Hagg S. (2008). Factors associated with persistence in science and engineering majors: An exploratory study using classification trees and random forests. Journal of Engineering Education, 97(1).

Meyer, D., Turner, J. and Spencer, D. (1997). Challenge in a mathematics classroom: students motivation and strategies in project-based learning. The Elementary School Journal, 97(5), 501521.

Mills, J., and D. Treagust. (2003). Engineering education - is problem-based or project-based learning the answer? Australasian Journal of Engineering Education, online publication. Available at: $<$ http://www.aaee.com.au/journal/2003/mills_treagust03.pdf $>$

National Service Learning Clearing House (2005). Service Learning Guide: Introduction. Retrieved July 19, 2012, from <http://www.sagepub.com/leonguerrero/service_learning_guide/introduction.htm> National Survey of Student Engagement. Classroom survey of student engagement. Retrieved November 7, 2011 from <http://nsse.iub.edu/_?cid=211>

Navidi, W. (2010). Statistics for Engineers and Scientists ( ${ }^{\text {rd }}$ ed.). New York, NY: McGraw-Hill.

Niemiec, C. and Ryan, R. (2009). Autonomy, competence, and relatedness in the classroom: Applying self-determination theory to educational practice. Theory and Research in Education, 7(2), 133144.

Paterson, K., and Fuchs, V. (2008). Development for the other 80\%: Engineering hope. Australasian Journal of Engineering Education, online publication. Available at $<$ http://www.engineersmedia.com.au/journals/aaee/pdf/AJEE_14_1_Paterson.pdf $>$ 
Palm, T. (2007). Features and impact of the authenticity of applied mathematical school tasks. In P. Galbraith, H. Hans-Wolfwang, and N. Mogens (Eds.) Applications and modeling in mathematics education. Springer, 201-208.

Prasad, A., Iverson, L., and Liaw, A. (2006). Newer Classification and Regression Tree Techniques: Bagging and Random Forests for Ecological Prediction. Ecosystems, 9, 181-199.

Ryan, R., and Deci, E. (2000). Self-determination theory and the facilitation of intrinsic motivation, social development, and well-being. The American Psychologist, 55(1), 68-78.

Schunk, D. (1991). Learning Theories: An educational perspective. Boston, MA: Pearson.

Seymour, E. and Hewitt, N. (1997). Talking about Leaving: Why Undergraduates Leave the Sciences. Boulder, CO: Westview Press.

Stolk, J., Savage R., and Vanasupa, L. (2007). Collaborative design of project-based learning courses: How to implement a mode of learning that effectively builds skills for the global engineer. Proceedings of the 2007 American Society for Engineering Education Annual Conference and Exposition.

Strauss A., and Corbin, J. (1994). Grounded theory methodology. In N. Denzin and Y. Lincoln (Eds.) Handbook of Qualitative Research. Thousand Oaks: CA: SAGE Publications.

Swan, C., Paterson, K., and Bielefeldt, A. (2009). Measuring the impacts of project-based service learning in engineering education. Proceedings of the 39th ASEE/IEEE Frontiers in Education Conference.

Thomas, J. (2000). A Review of Research on Project Based Learning. Available at $<$ http://www.bobpearlman.org/BestPractices/PBL_Research.pdf $>$

Wigfield, A., and Eccles, J. (2000). Expectancy-value theory of achievement motivation. Contemporary Educational Psychology, 25(1), 68-81. 
Appendix A: ASSESSMENT INSTRUMENTS 


\section{MCEN3025 PRE Course Survey}

Hello! Thank you in advance for completing this survey. The survey consists of 26 questions and should take you about 20 minutes to complete.

\section{*1. Full Name:}

\section{Please indicate the degree to which the following statements apply to you.}

I have a lot of experience with Component Design.

I have a lot of experience with Mechanical Engineering design projects.

I already have some experience with Mechanical Engineering design projects.

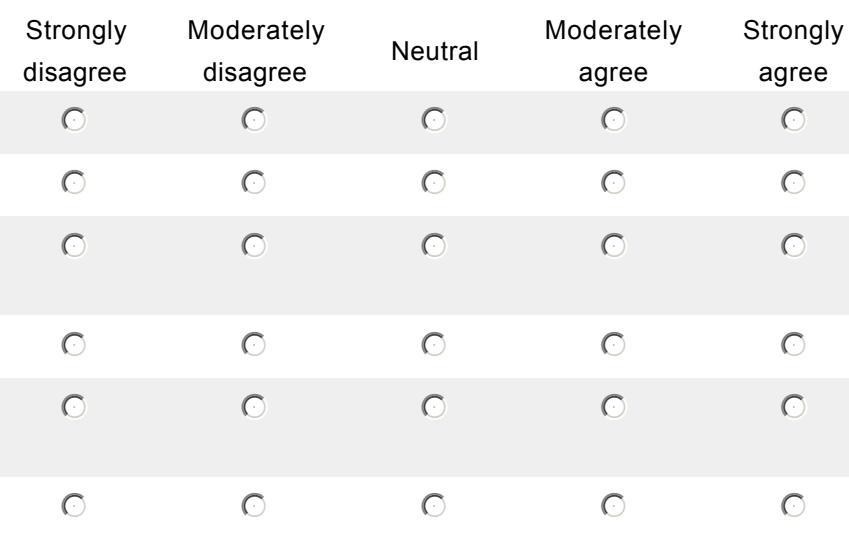

Engineering design project.

\section{Please indicate the degree to which the following statements apply to you.}

I think what we will learn in Component Design will be worthwhile for me to know.

Strongly disagree

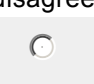

I've always been interested in Mechanical Engineering design projects.

I think our course project will be a valuable experience.

I'm excited about our course project.

I've always been interested in Component Design.

I'm excited about taking this class.
Moderately disagree

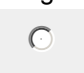
Neutral

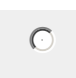

Moderately agree

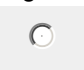

Strongly agree
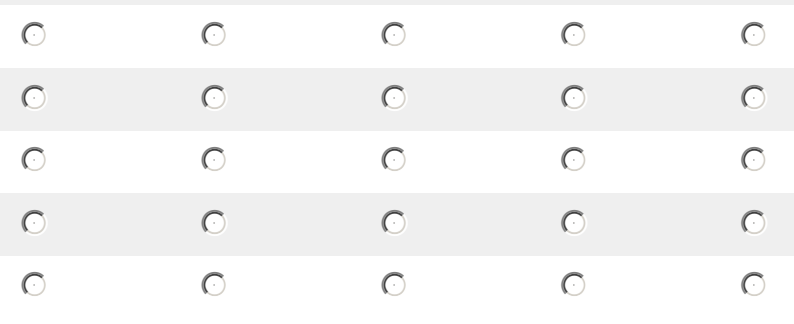


\section{Please indicate the degree to which the following statements apply to you.}

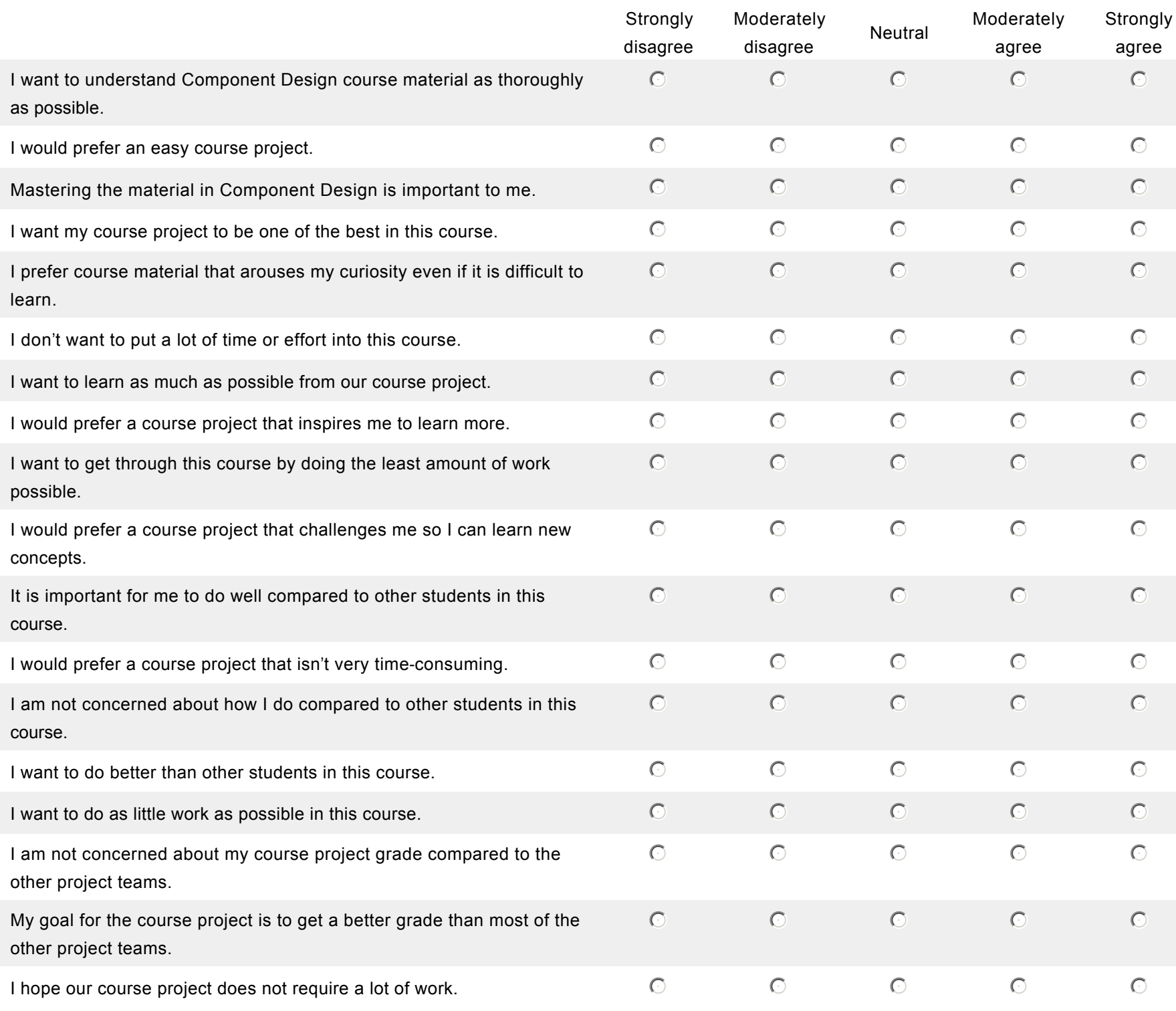

\section{Please list up to three devices of Mechanical Engineering that interest you. For example: aircraft, robots, prosthetic limbs, toys, wind turbines, water desalination plants, etc.}




\section{MCEN3025 PRE Course Survey}

6. Please indicate the degree to which you believe that community service and your engineering coursework should be combined? (For example, a class project that benefits a local community).

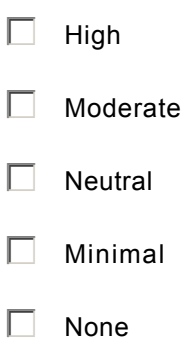




\section{MCEN3025 PRE Course Survey}

7. What does it mean, to you personally, to succeed in this course? In other words, what kinds of goals, tasks, or achievements will you need to accomplish to feel successful in this COURSE?

8. What does it mean, to you personally, to succeed in the COURSE PROJECT? In other words, what kinds of goals, tasks, or achievements will you need to accomplish to feel successful in the COURSE PROJECT?

9. Please rate your level of confidence in successfully learning the COURSE MATERIAL.

High

Moderate

Neutral

Minimal

None

10. Please rate your confidence in succeeding in the COURSE PROJECT.

High

Moderate

Neutral

Minimal

$\bigcirc$ None 
MCEN3025 PRE Course Survey

11. In choosing a career, what factors are most important to you? Rank all of the following 10 options in order of their importance to you, with 1 being MOST important and 10 being

\section{LEAST important.}

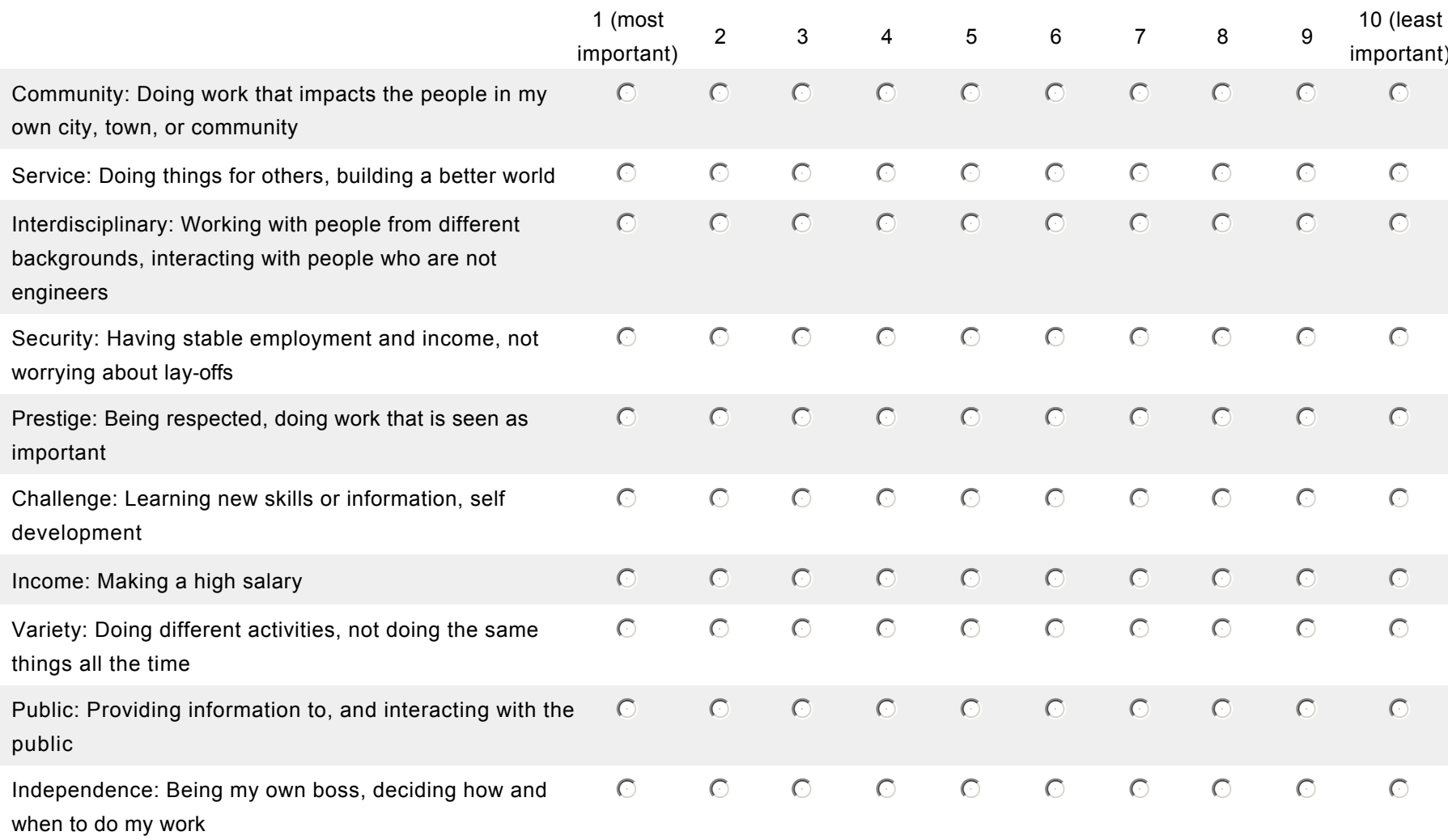




\section{MCEN3025 PRE Course Survey}

12. Please rate yourself on the following skills and abilities as compared to your peers. Try to provide the most accurate estimate of how you see yourself.

Technical writing skills
Aral presentation skills
Ability to present ideas to a non-technical audience
Abilitity to apply Component Design concepts to real design scenarios to work work on a team




\section{Please select the option which indicates your confidence in the following areas.}

I specify a design factor in a real design scenario
I understand how to apply shaft design guidelines in a real design
scenario.

I understand the different applications of bearings in machinery.

In real life, I would be able to identify a complex loading situation.

I understand the relationship between a column's geometry and its tendency to buckle.
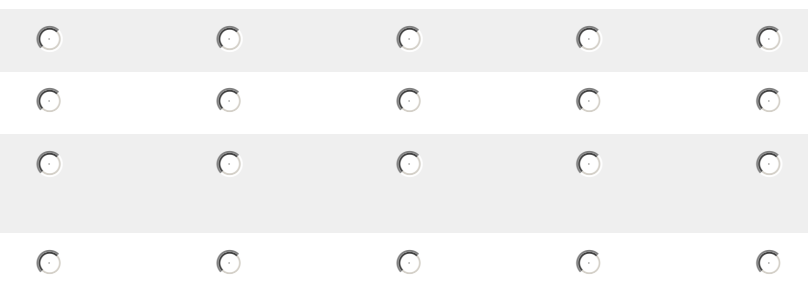

I understand how to factor material properties into the design of a part or system.

I can explain the characteristics of different torque transmission devices (keys, splines, pins, and clamps) to one of my peers.

I can describe a situation in which preloading a bolt would be desirable.

I have an idea about how to identify stress concentrations in a real life design scenario.

I understand how to account for different geometries when performing a stress analysis of a part.

I can explain the theories of static failure to one of my peers.

I understand the relationship between principle shear stress and principle normal stress.
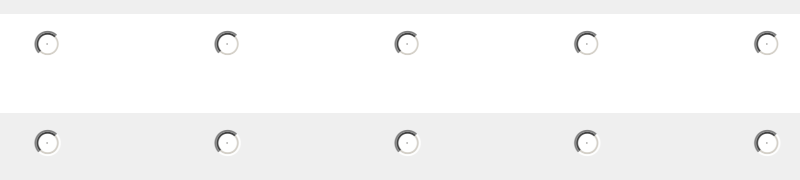

$\bigcirc$
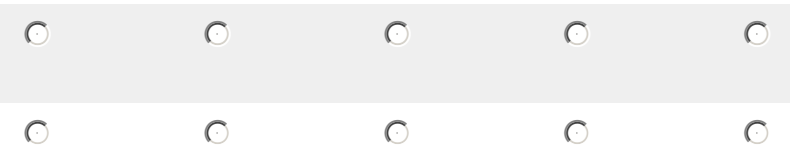

$\bigcirc$

O
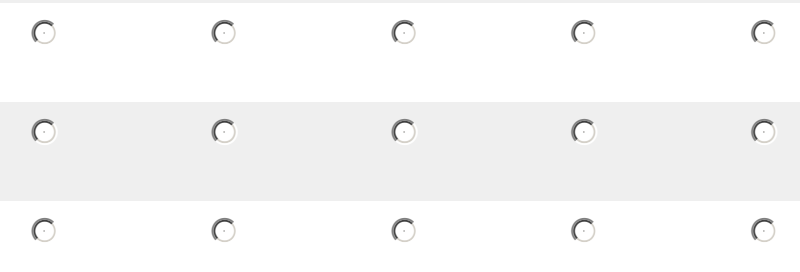

$\bigcirc$

O

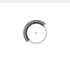

I can identify the factors that affect a part's fatigue strength.

I know how to perform a stress analysis for different types of springs subjected to various loading conditions.

I know how to perform a deflection analysis for different loading conditions.
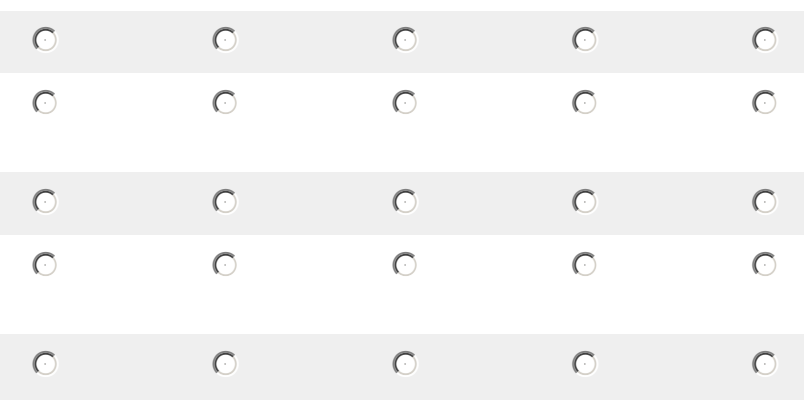

I understand the relationship between torsion and shear stress.

I can specify the appropriate gear (type, geometry, etc.) for a given design application.
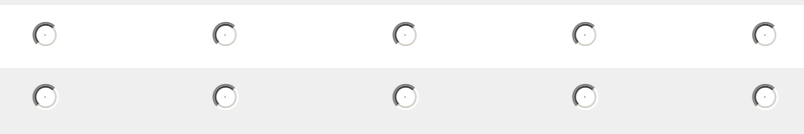


\section{MCEN3025 PRE Course Survey}

14. Please select the option which indicates your level of understanding in the following Component Design course topics.

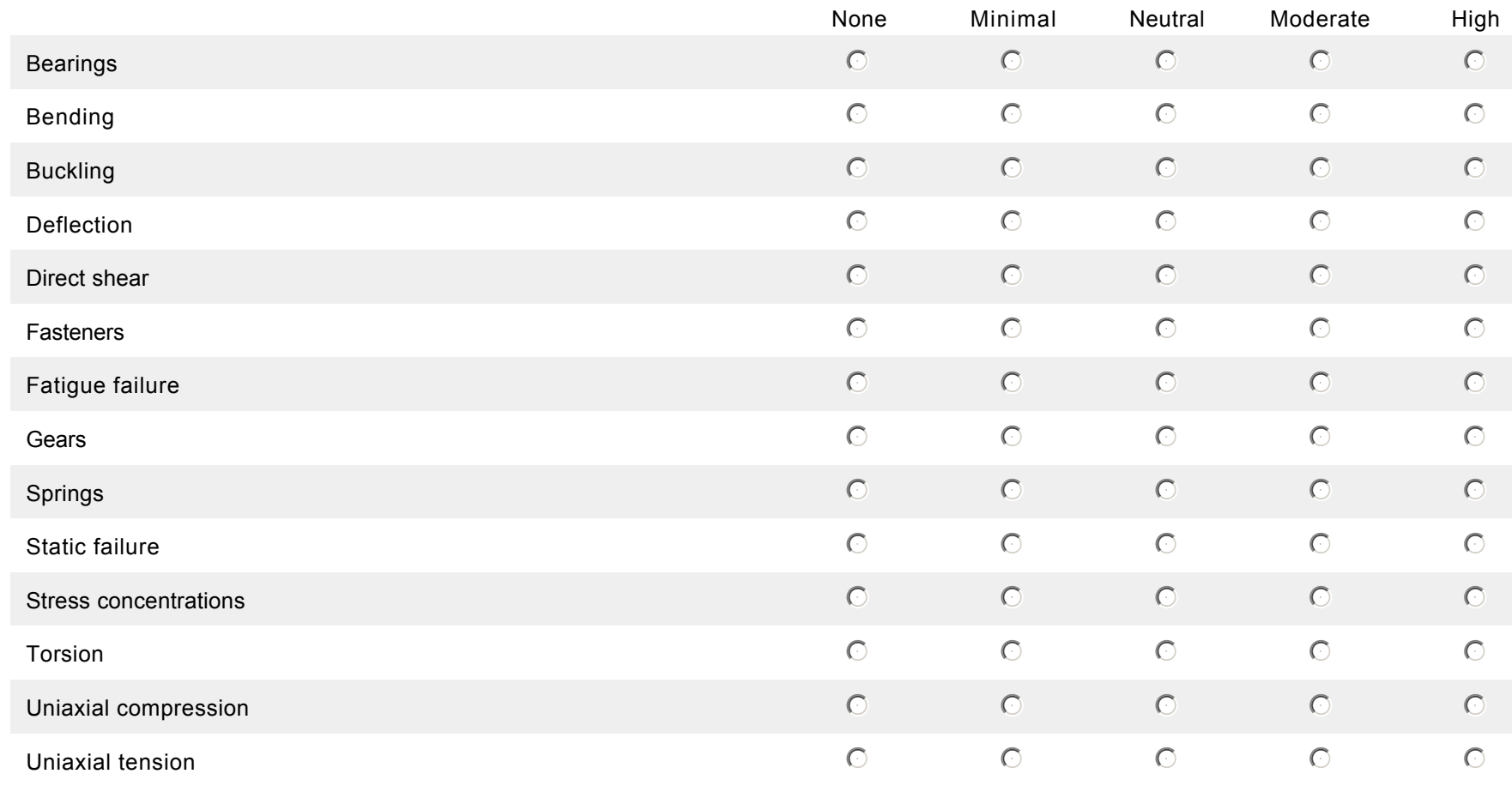


15. How many hours per week do you participate in student engineering activities such as engineering clubs or societies?
$\bigcirc 11+$
7-10
-4-6
$\bigcirc 1-3$
$\bigcirc 0$

16. How many hours per week do you participate in non-engineering activities such as sports, fraternity or sorority, church, or campus groups/clubs?
$\bigcirc 11+$
7-10
(4-6
$\bigcirc 1-3$
$\bigcirc 0$

17. What are your plans after graduation?
$\bigcirc$ Pursue a career as a practicing engineer
Graduate school in a different field
$\bigcirc$ Medical school
$\bigcirc$ Pursuing a career outside of engineering
Law school
$\bigcirc$ Travel
MBA program
Not yet sure
Graduate school in engineering 


\section{MCEN3025 PRE Course Survey}

18. Gender:

$\bigcirc$ Female

$\bigcirc$ Male

Prefer not to answer

19. Are you: Hispanic, Chicano, Mexican, Latino, Cuban, Puerto Rican, South or Central American, or Spanish origin?

$\bigcirc$ Yes
No
Prefer not to answer

Other (please specify)

\section{Check one or more:}

American Indian or Alaska Native

Black or African American

Native Hawaiian or Other Pacific Islander

Asian

White

Prefer not to answer

\section{Age:}

$\bigcirc 18-21$

22-25

26-29

30-39

$\bigcirc 40+$

$\bigcirc$ Prefer not to answer 


\section{MCEN3025 PRE Course Survey}

22. What is your cumulative GPA?

Below 2.0

$\bigcirc 2.0-2.4$

$\bigcirc 2.5-2.9$

$\bigcirc 3.0-3.4$

○ 3.5 or above

Prefer not to answer

23. Have you ever had an engineering-related job or internship?

$\bigcirc$ Yes

$\bigcirc$ No

24. Would you describe your family as:

Low income

Moderate income

$\bigcirc$ High income

Prefer not to answer

25. Are you a first generation college student? (First in your immediate family to attend college).

Yes

$\bigcirc$ No

Prefer not to answer

26. Would you be willing to participate in an interview about your experience in this course?

Y Yes

$\bigcirc$ No

Thank you for taking the time to complete this survey. Your participation and thoughtful input is very much appreciated! 


\section{MCEN3025 POST Course Survey}

Hello! Thank you in advance for completing this survey. The survey consists of 17 questions and should take you about 15 minutes to complete.

*1. Full Name:

2. Please indicate the degree to which the following statements apply to you.

I am excited to participate in Mechanical Engineering design projects
in the future.
What I learned in the course is valuable.
I am excited to continue learning about Component Design.
I had a very positive experience working with my team members to
I found the content of this course to be personally meaningful.
I found the project to be personally meaningful.

3. Please list up to three devices of Mechanical Engineering that interest you. For example: aircraft, robots, prosthetic limbs, toys, wind turbines, water desalination plants, etc.

\section{This semester in Component Design, how often did you do each of the following?}

Asked questions during class
Contributed to a class discussion
Synthesized ideas or concepts from different courses when completing
project tasks
Tutored or taught other students in the course
(students, friends, family, coworkers, etc.)
Worked harder than you thought you could to meet course expectations

5. NOT INCLUDING the project, how much time (on average) did you spend doing work for this course (homework assignments, workshop, exam preparation, etc.)?

0-3 hours per week

4-7 hours per week

8-11 hours per week

12+ hours per week 


\section{MCEN3025 POST Course Survey}

6. How much time (on average) did you work on your TEAM PROJECT (meeting with your team members, completing design and manufacture tasks for your project, etc.)?

0-3 hours per week

4-7 hours per week

8-11 hours per week

12+ hours per week 


\section{MCEN3025 POST Course Survey}

7. According to your OWN initial expectations, how well did you succeed in this course? What kinds of goals, tasks, for other achievements did you accomplish in this course?

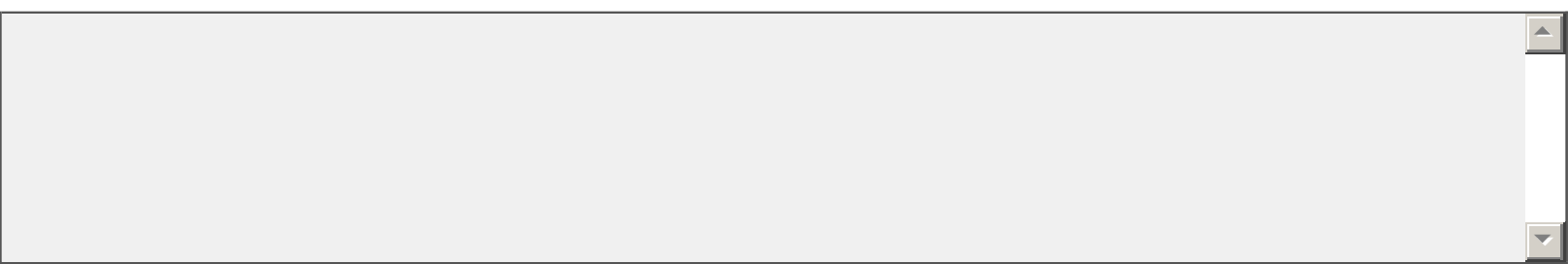

8. How well did you succeed in the course PROJECT? Did you meet your OWN initial expectations for the final product?

9. According to your initial expectations, please rate how successfully you feel you learned the course material.

$\bigcirc$ High

$\bigcirc$ Moderate

$\bigcirc$ Neutral

$\bigcirc$ Minimal

$\bigcirc$ None

10. According to your initial expectations, rate how successfully you feel you completed the course PROJECT.

$\bigcirc$ High

$\bigcirc$ Moderate

$\bigcirc$ Neutral

$\bigcirc$ Minimal

$\bigcirc$ None 


\section{MCEN3025 POST Course Survey}

11. With regard to team dynamics, briefly describe the most significant challenges you encountered while completing the course project.

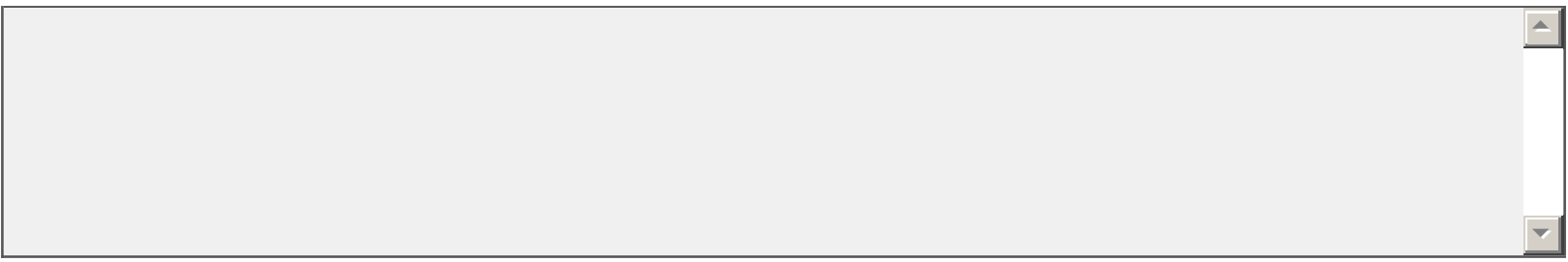


12. Please indicate the degree to which you believe that community service and your engineering coursework should be combined? (For example, a class project that benefits a local community).

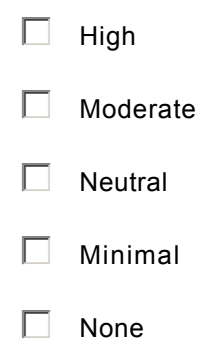

13. Please rate yourself on the following skills and abilities as compared to your peers. Try to provide the most accurate estimate of how you see yourself.

Oral presentation skills
Ability to work with people who are not engineers
Ability to work on a team
Abilitity to identify the needs of a client




\section{Please select the option which indicates your confidence in the following areas.}
I understand how to factor material properties into the design of a part or system.
0 conditions.
I can describe a situation in which preloading a bolt would be
desirable.
I know how to perform a stress analysis for different types of springs subjected to various loading conditions.
I can identify the factors that affect a part's fatigue strength.
I can explain the characteristics of different torque transmission devices (keys, splines, pins, and clamps) to one of my peers.
Minimal
Neutral
Moderate
High

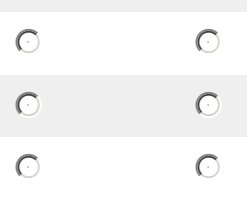
$\bigcirc$

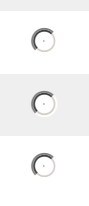
0
0
O
○
0
$\bigcirc$
0
0
0
0
0

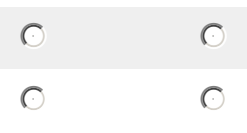
$\bigcirc$
$\bigcirc$

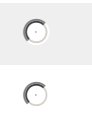

I can explain the theories of static failure to one of my peers.

I have an idea about how to identify stress concentrations in a real life design scenario.

I can specify the appropriate gear (type, geometry, etc.) for a given design application.

I understand how to apply shaft design guidelines in a real design scenario.

I specify a design factor in a real design scenario

I understand how to account for different geometries when performing a stress analysis of a part.

I understand the relationship between principle shear stress and principle normal stress.

I understand the relationship between a column's geometry and its tendency to buckle.

I understand the relationship between torsion and shear stress. $\bigcirc$

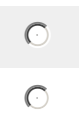

$\bigcirc$

$\bigcirc$

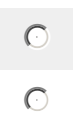

0

0

0

0

O

0

0

0

0

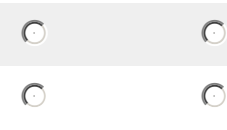

$\bigcirc$

$\bigcirc$

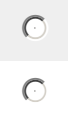

0

0

0

0

0

0

0

0

0

0

0

0

0

0

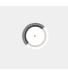




\section{MCEN3025 POST Course Survey}

15. Please select the option which indicates your level of understanding in the following Component Design course topics.

Bearings
Fatigue failure
Gears
Springs
Static failure
Stress concentrations
Torsion
Uniaxial compression
Uniaxial tension


16. In choosing a career, what factors are most important to you? Rank all of the following 10 options in order of their importance to you, with 1 being MOST important and 10 being

\section{LEAST important.}

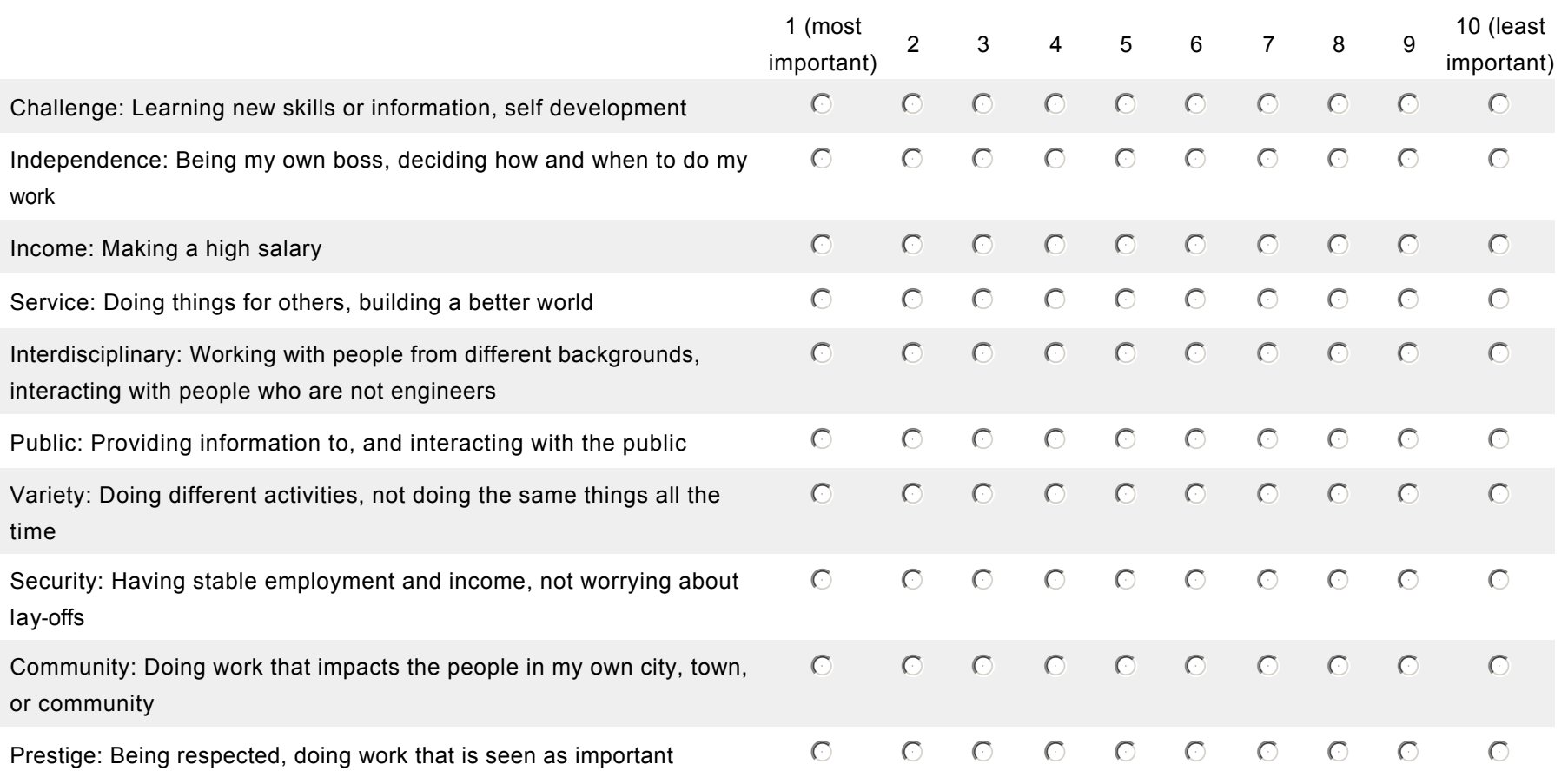

\section{What are your plans after graduation?}

Pursue a career as a practicing engineer

Graduate school in a different field

$\bigcirc$ Medical school

$\bigcirc$ Pursuing a career outside of engineering

Law school

$\bigcirc$ Travel

$\bigcirc$ MBA program

$\bigcirc$ Not yet sure

Graduate school in engineering

Other (please specify)

Thank you for taking the time to complete this survey. Your participation and thoughtful input is very much appreciated! 


\section{Student Focus Group Interview Protocol MCEN3025 Component Design}

\section{Focus group participants:}

Date:

Location:

Focus group \#:

Introduction: Through this study I am hoping to gain a better understanding of how you are learning. As a student who participated in Component Design, your perspectives are valuable. Your participation in this focus group is completely voluntary, and you may choose to not answer any of the questions I pose today. There are no right or wrong answers. I am most interested in hearing about your experiences, your perspectives, your beliefs, and your stories. Do you have any questions before we begin?

\section{Student Learning (general):}

a. What aspects of the course were most/least valuable to you?

b. How did your interest in Component Design change over the course of the semester?

c. Describe what you thought was special or unique about this course.

\section{Student Team Project:}

d. What was the most/least valuable aspect of the project?

e. Describe any skills (technical and/or non-technical) you gained from the project.

f. Did the project impact your excitement for Component Design?

g. What types of challenges did you encounter when working with your project team?

- c. Were you surprised by these challenges?

Closing: What other comments do you have on any of the issues we have discussed today?

Thank participants. Ask permission to contact them for any follow-up questions if necessary at the end of the data collection process. 
Appendix B: HISTOGRAMS AND BOXPLOTS 


\section{DEMOGRAPHICS}

Gender, age, family income, first-generation college student, underrepresented minority
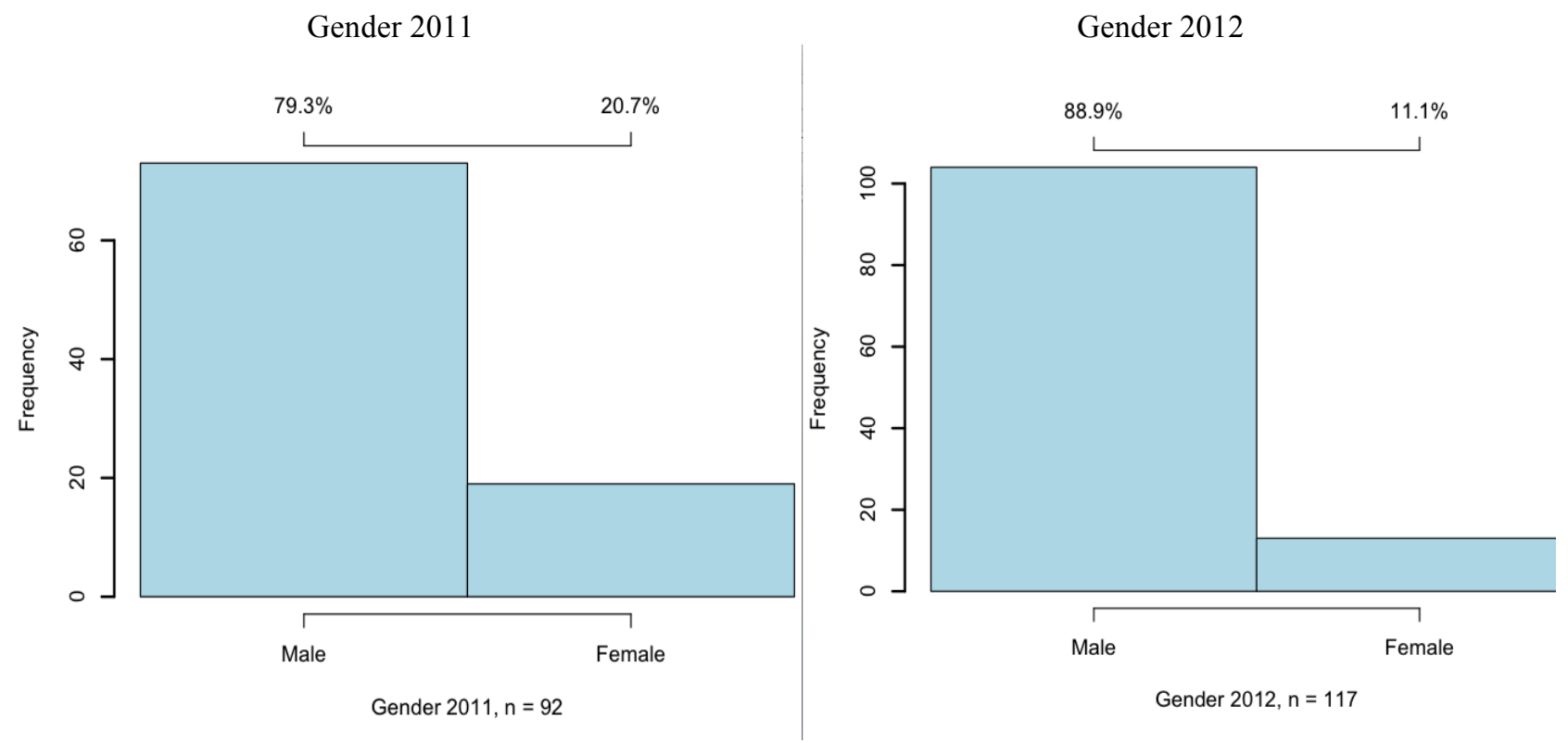

Age 2011

Age 2012
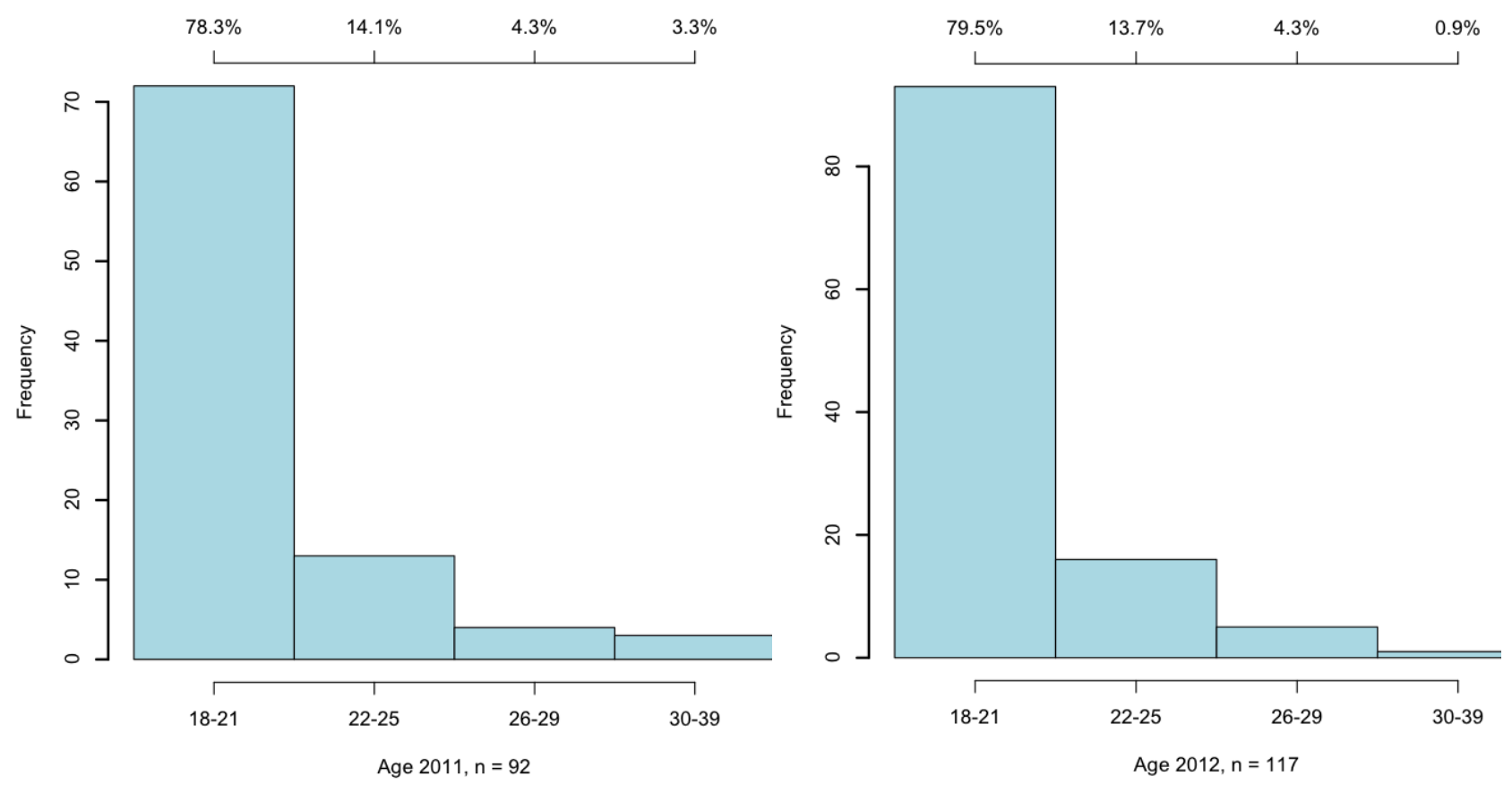
Family income level 2011

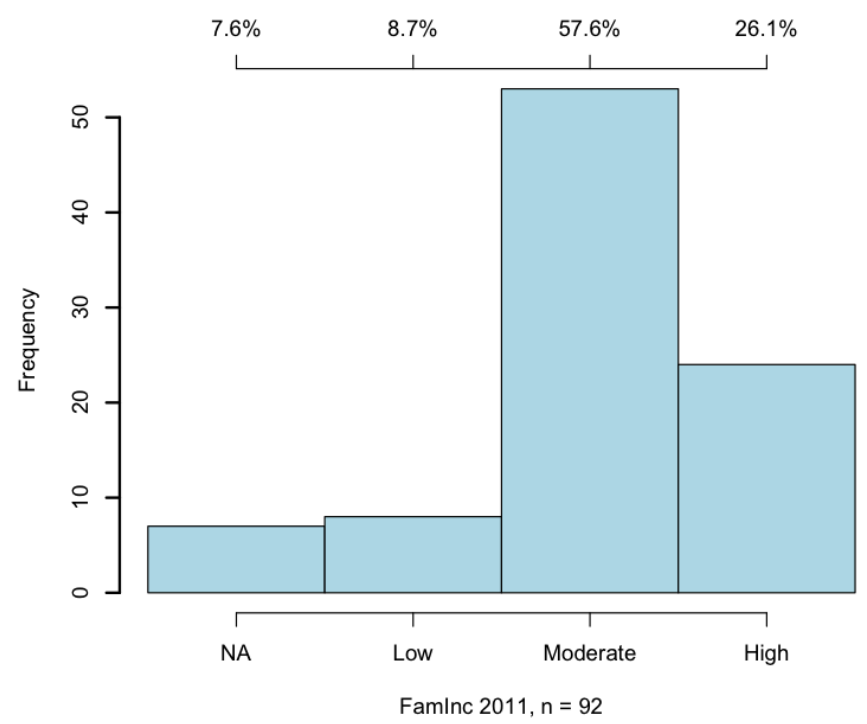

First-generation college student 2011

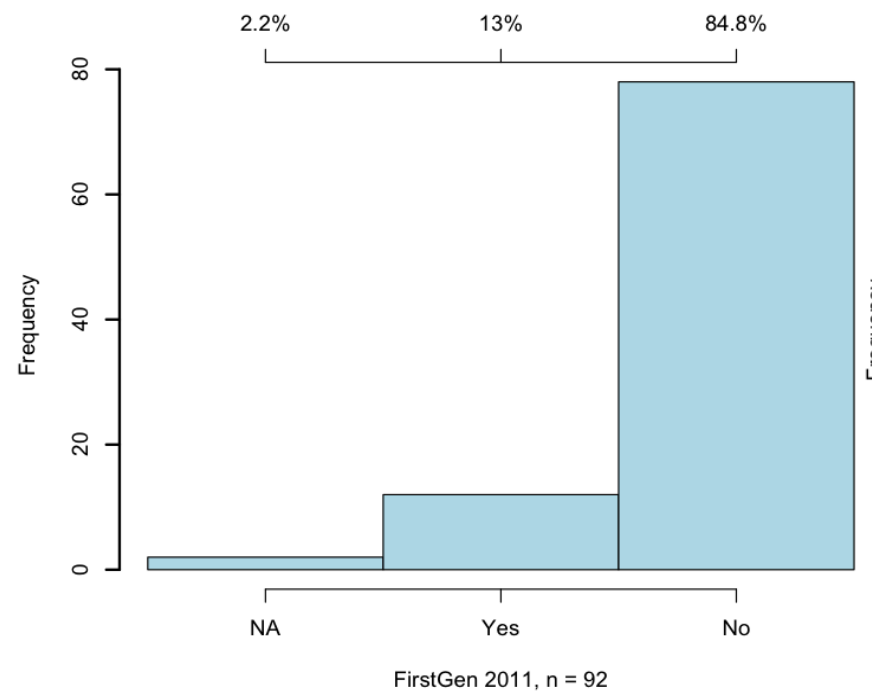

Family income level 2012

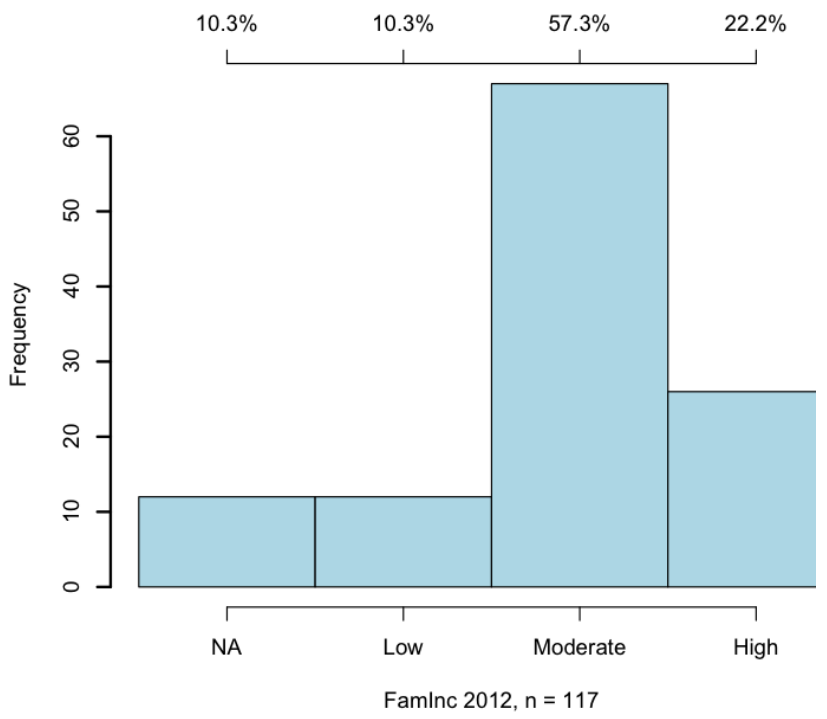

First-generation college student 2012

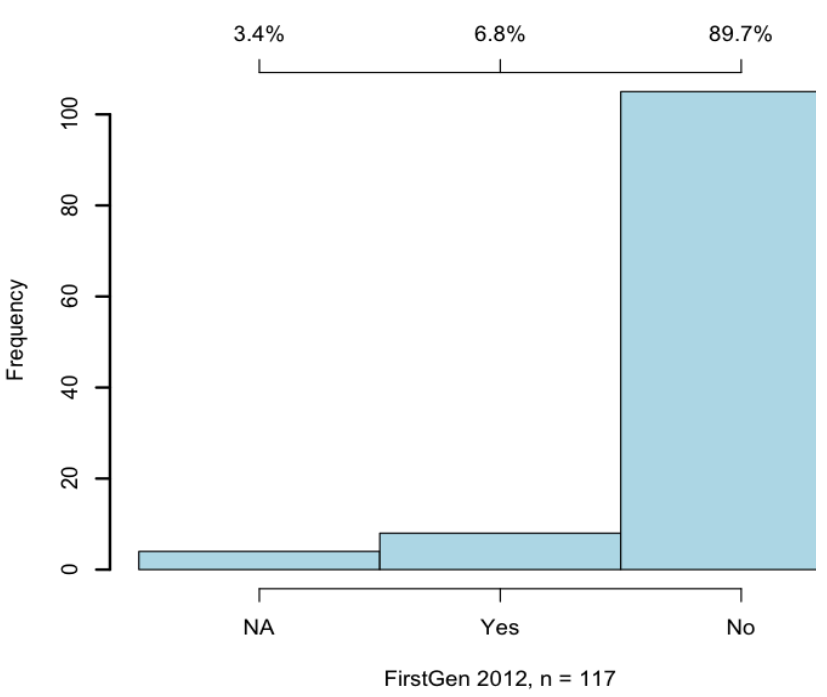


Underrepresented minority 2011

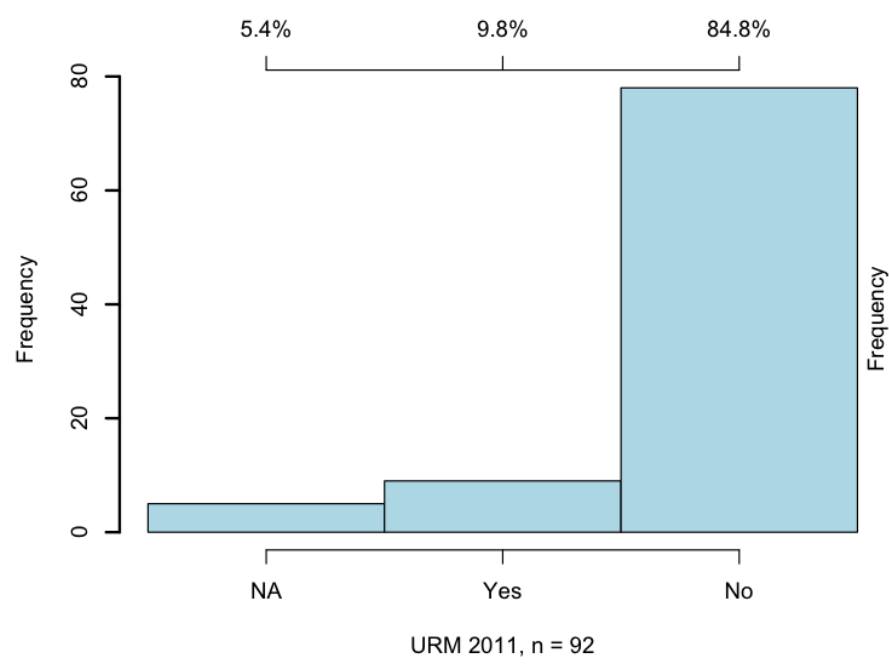

Underrepresented minority 2012

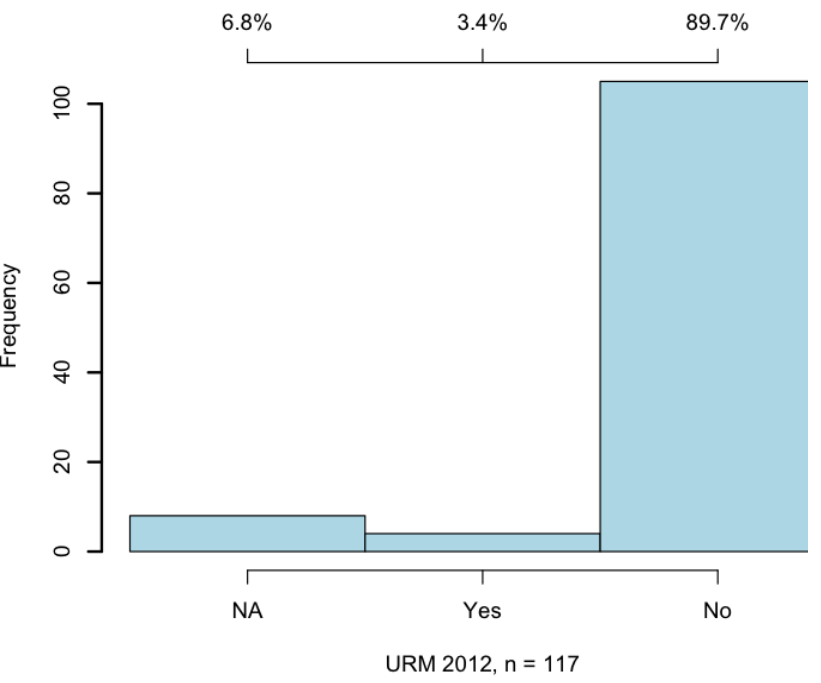


GENERAL CHARACTERISTICS (pre-course)

Achievement orientation, GPA, support for service-learning

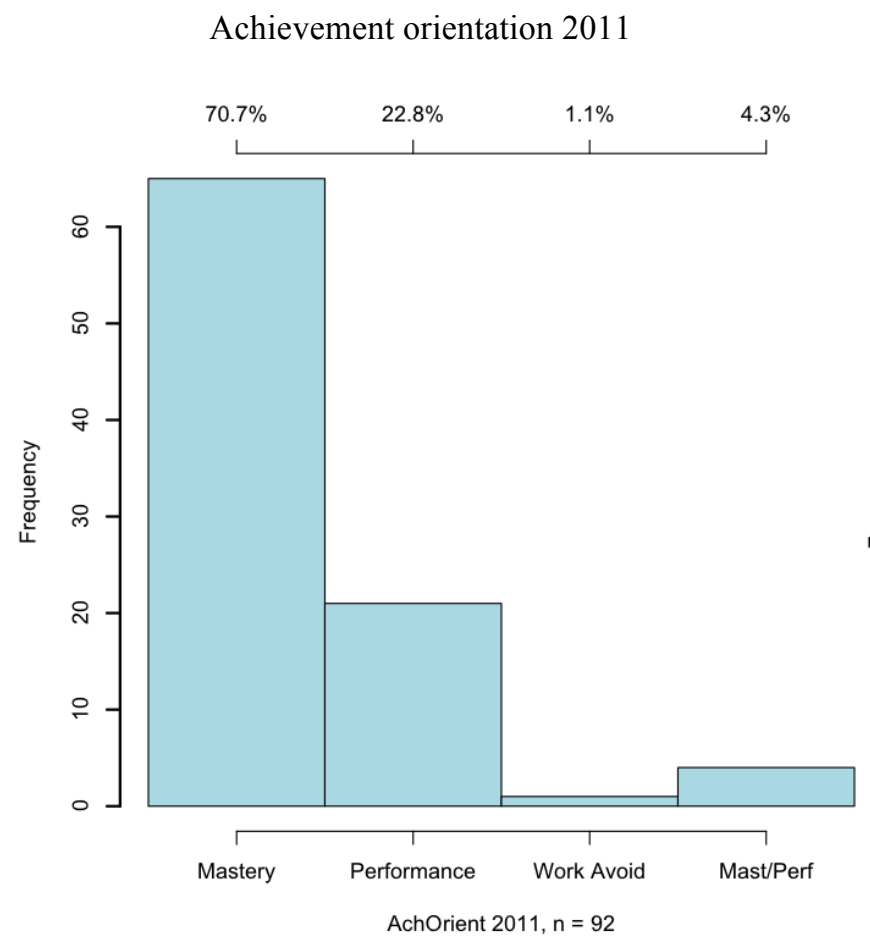

Achievement orientation 2012

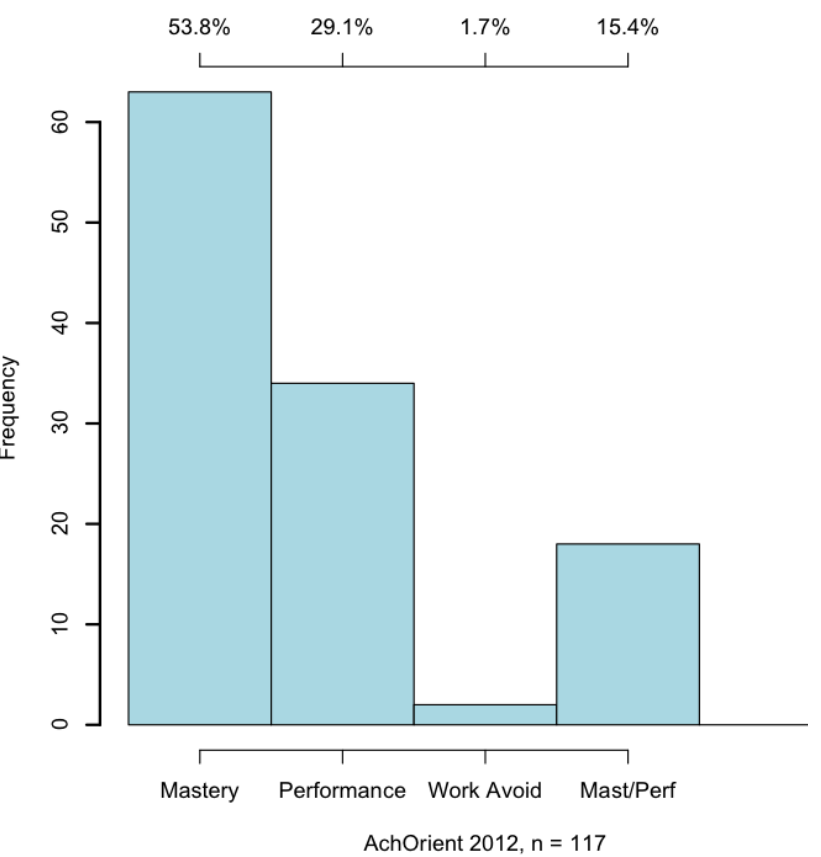

GPA 2011

GPA 2012
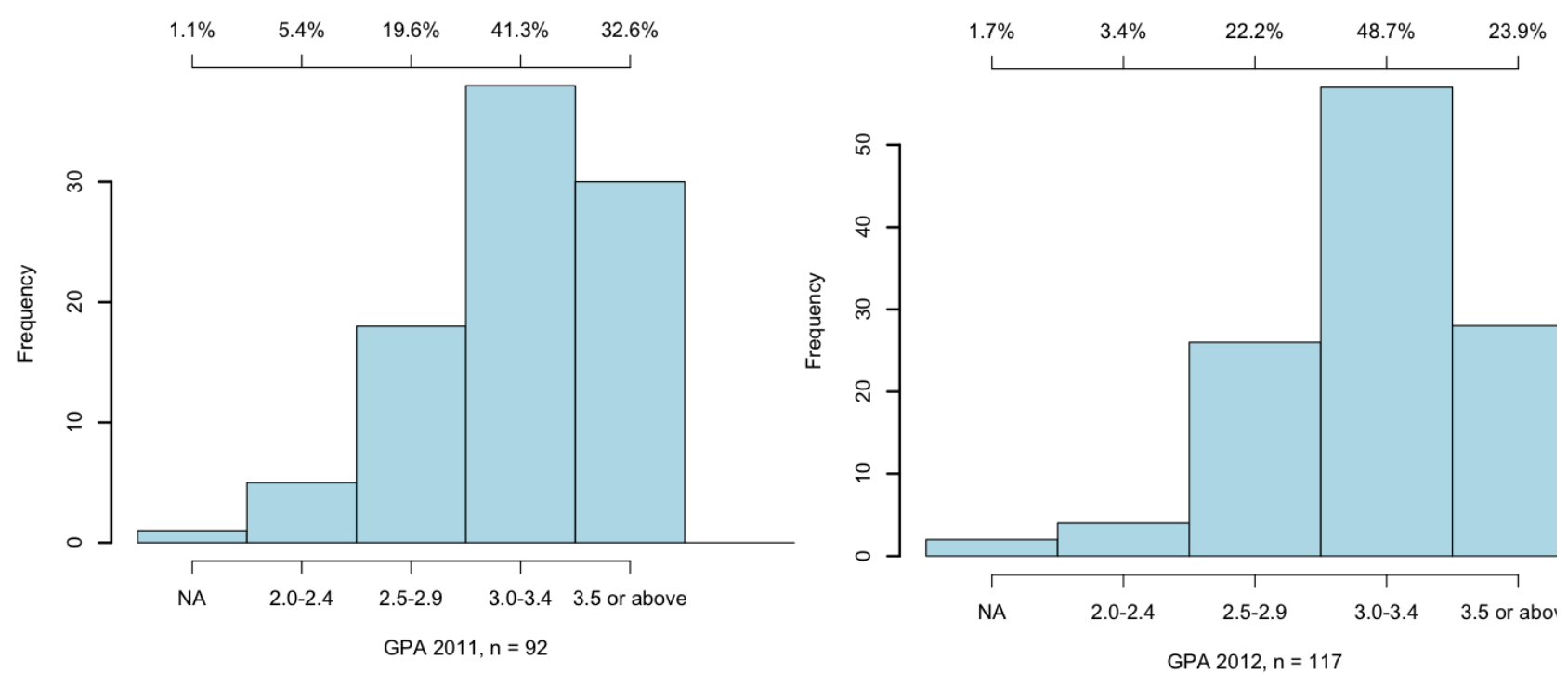
Initial support for service-learning 2011
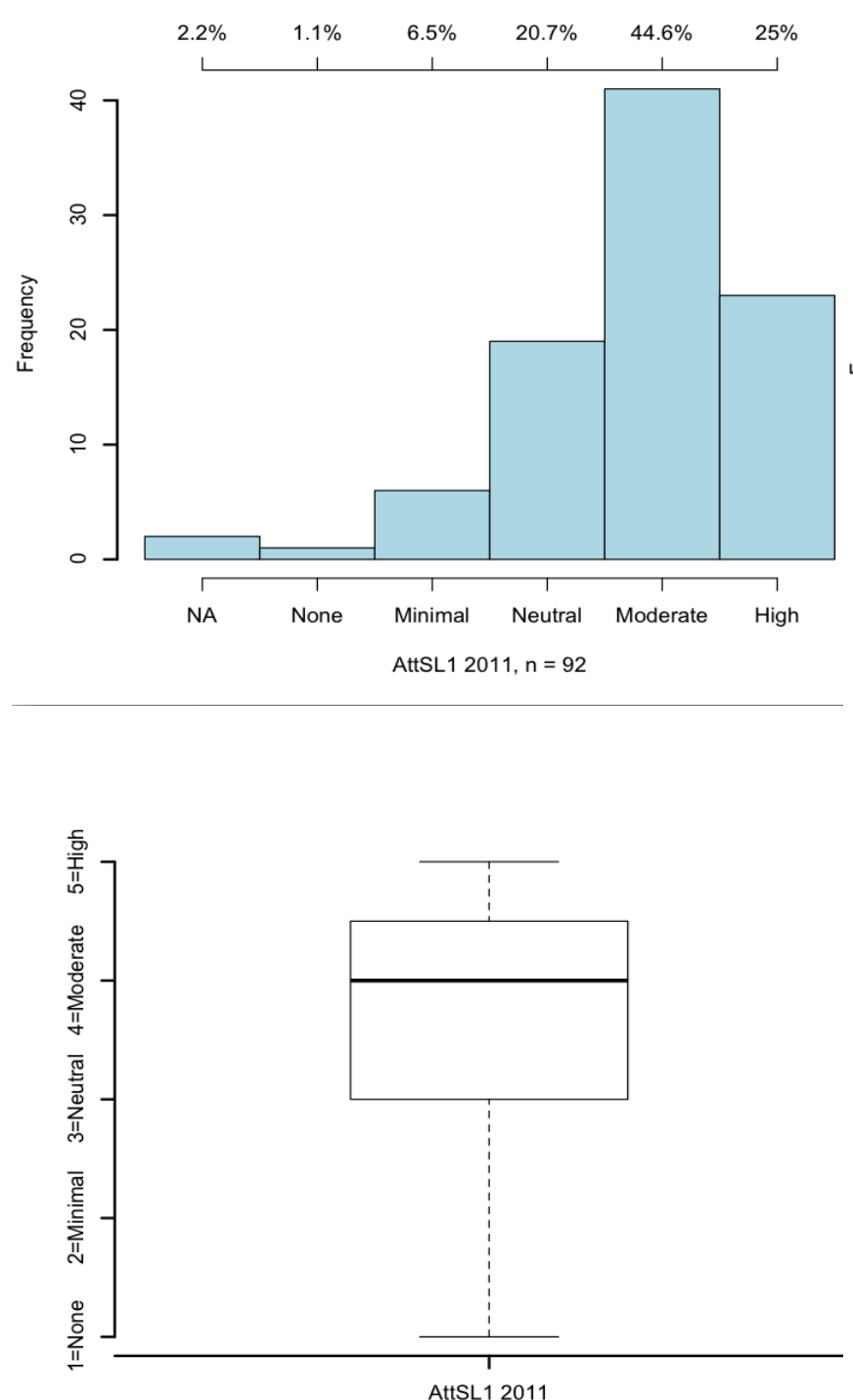

Initial support for service-learning 2012
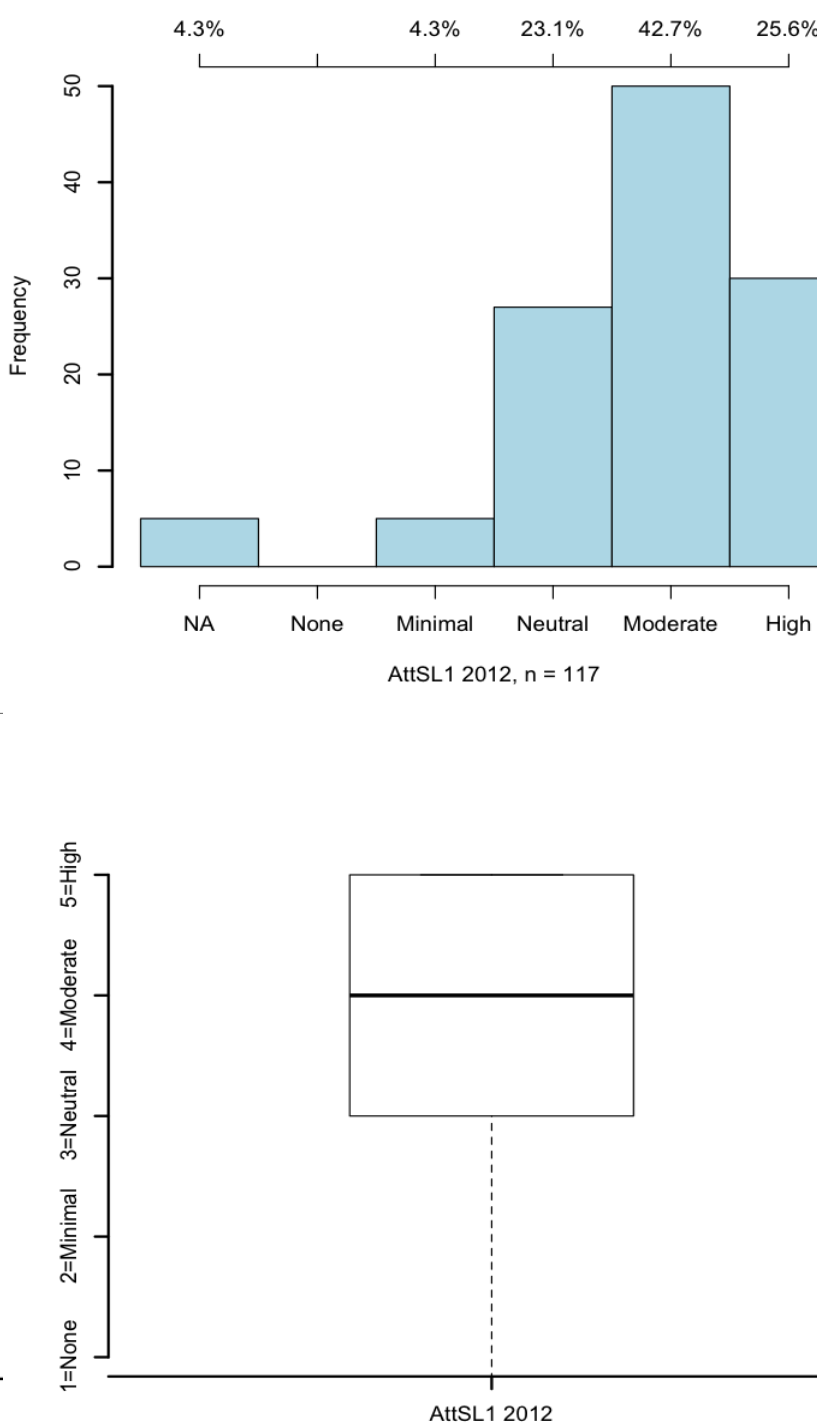
INITIAL ATTITUDES AND SKILLS (pre-course)

Prior course/project experience, initial course/project interest, initial course/project value, expectancy for success in course/project, confidence in technical/non-technical skills

Prior course experience 2011
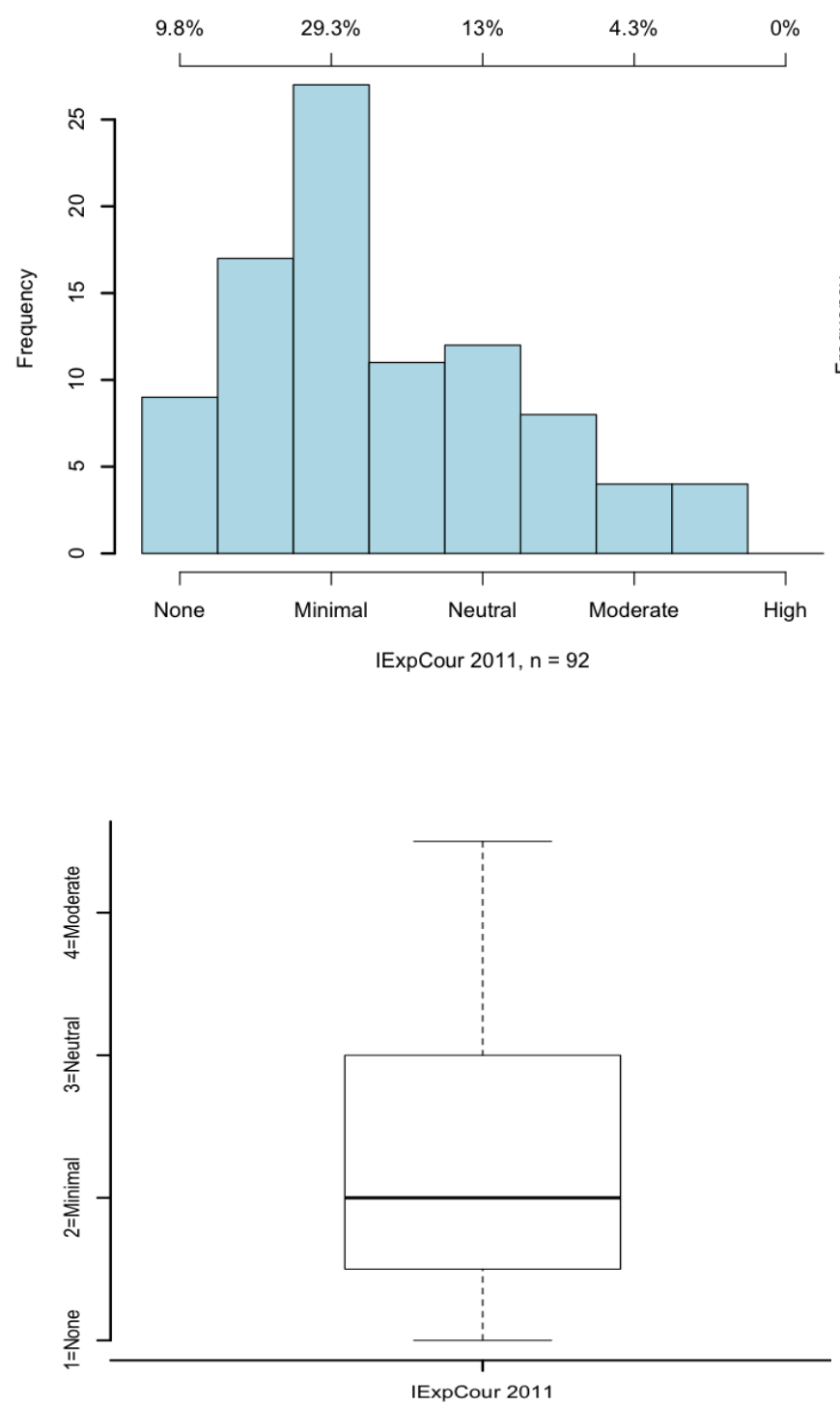

Prior course experience 2012
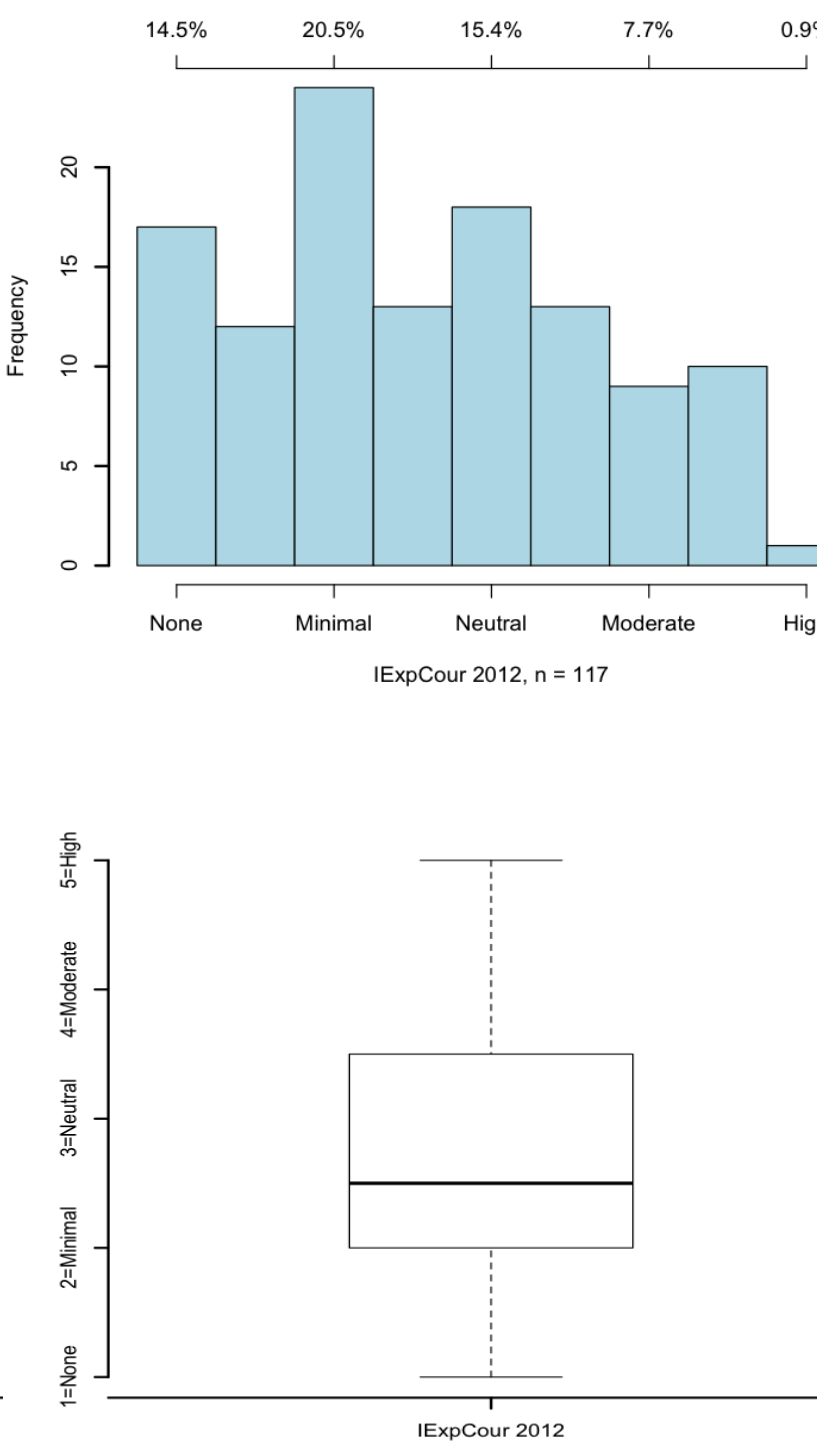
Prior project experience 2011
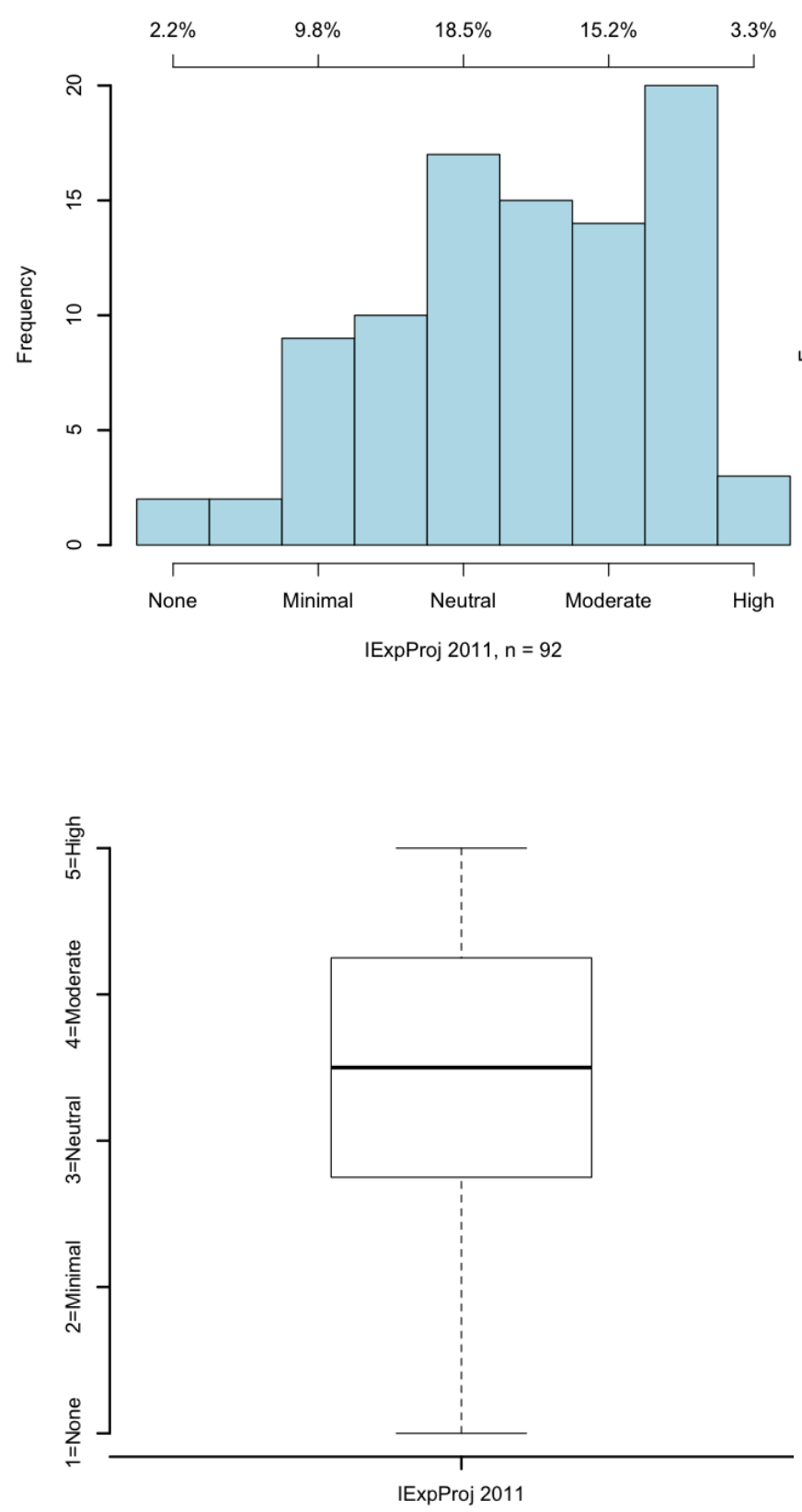

Prior project experience 2012
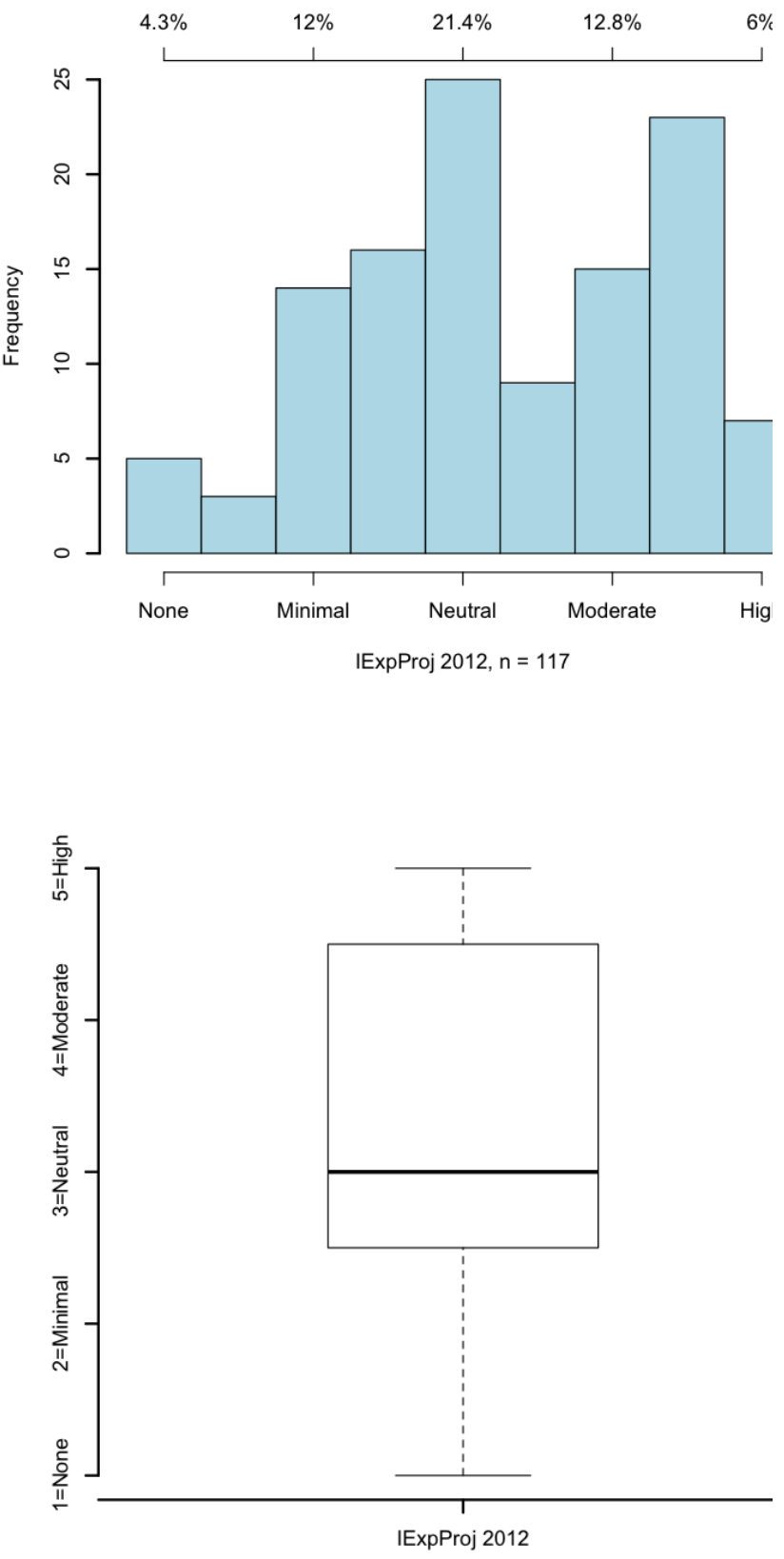
Initial course interest 2011
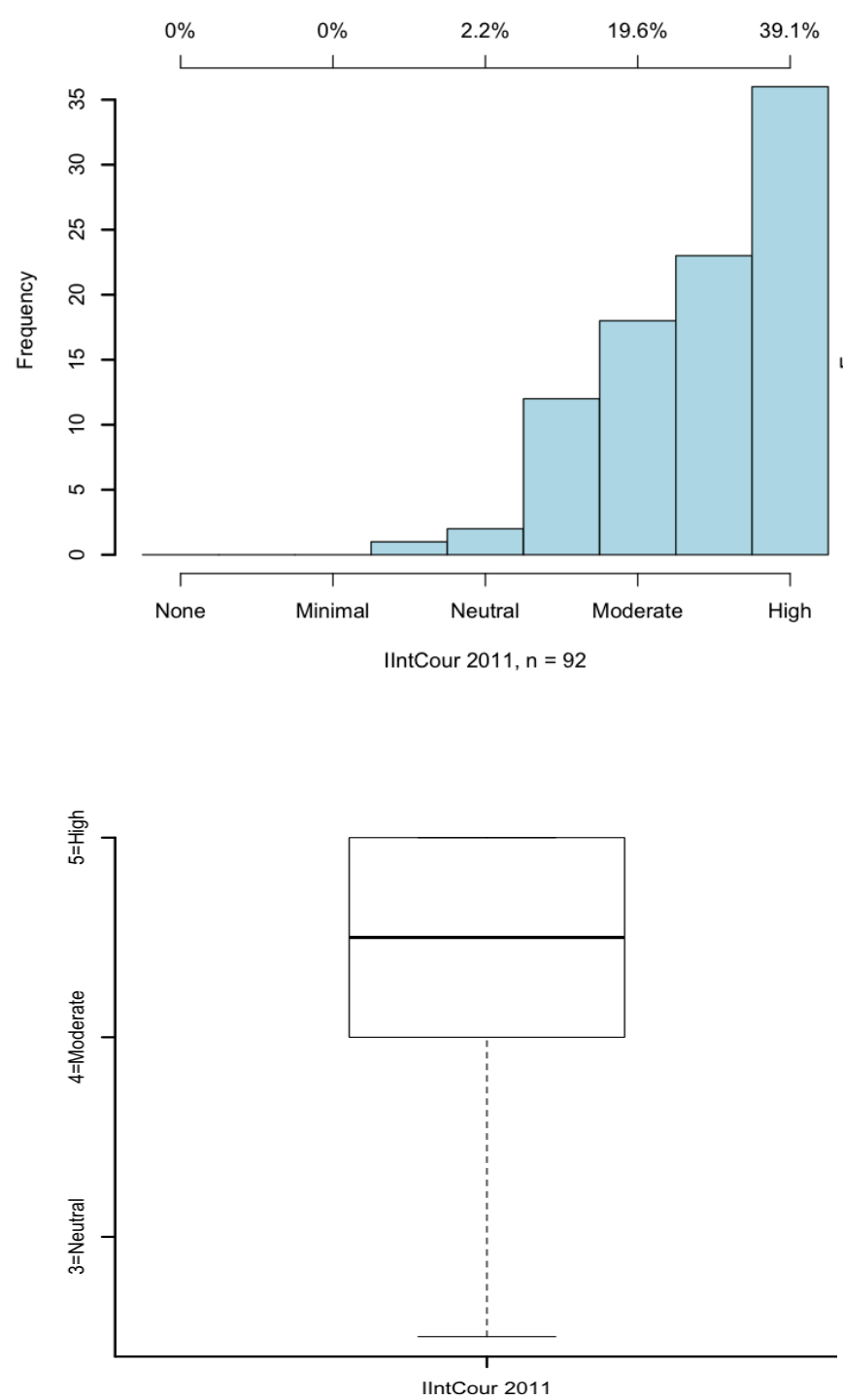

Initial course interest 2012
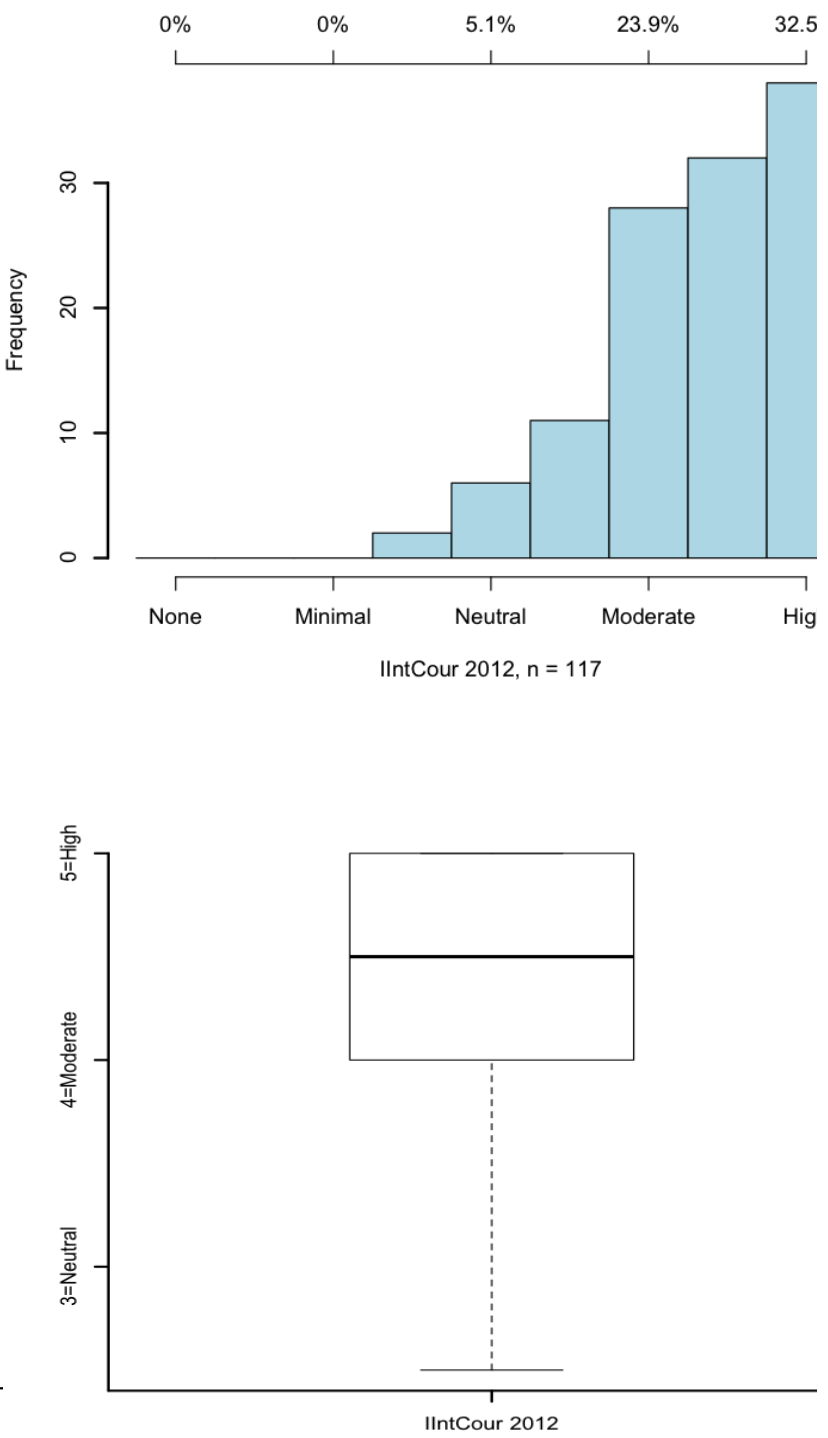
Initial project interest 2011
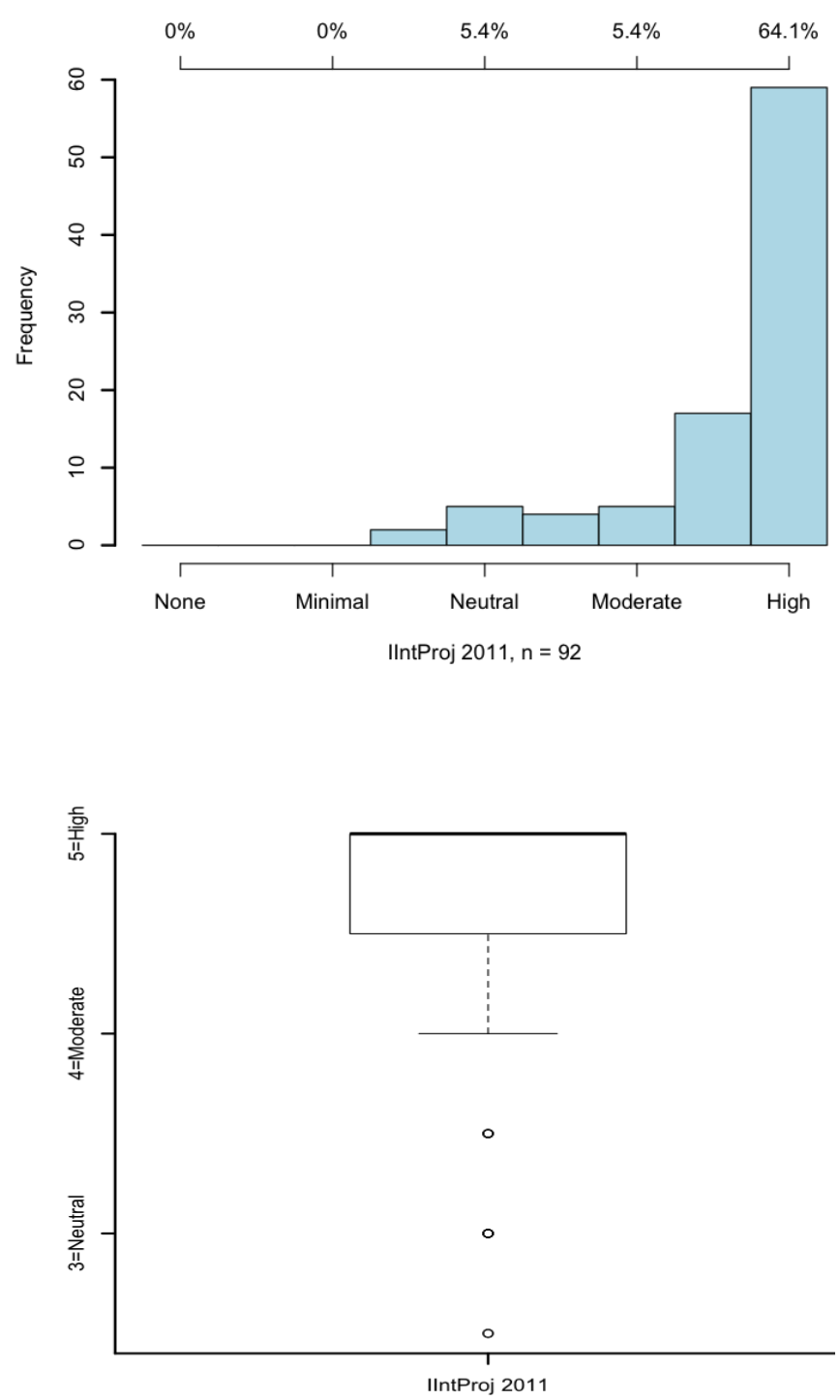

Initial project interest 2012
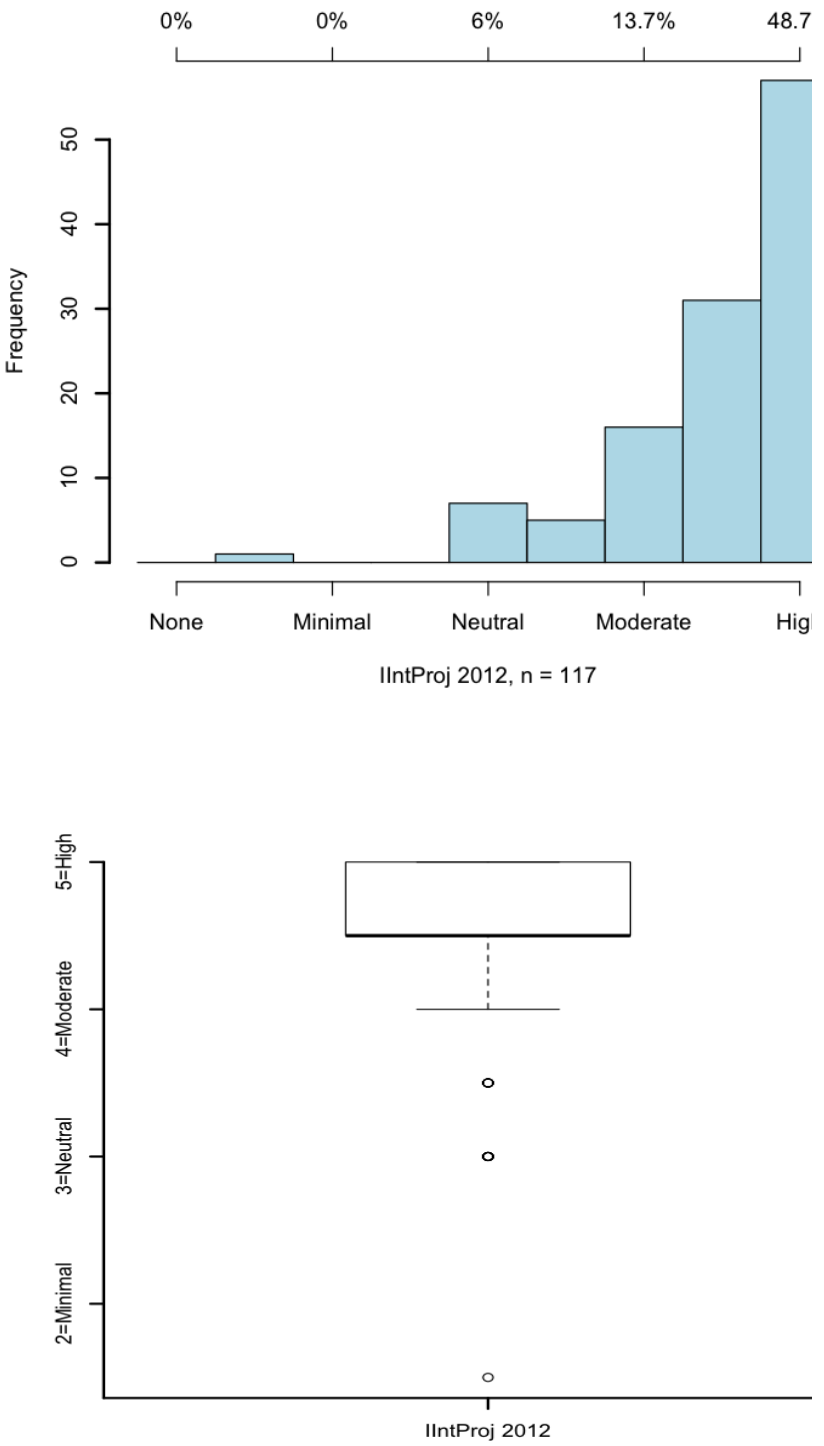
Initial course value 2011
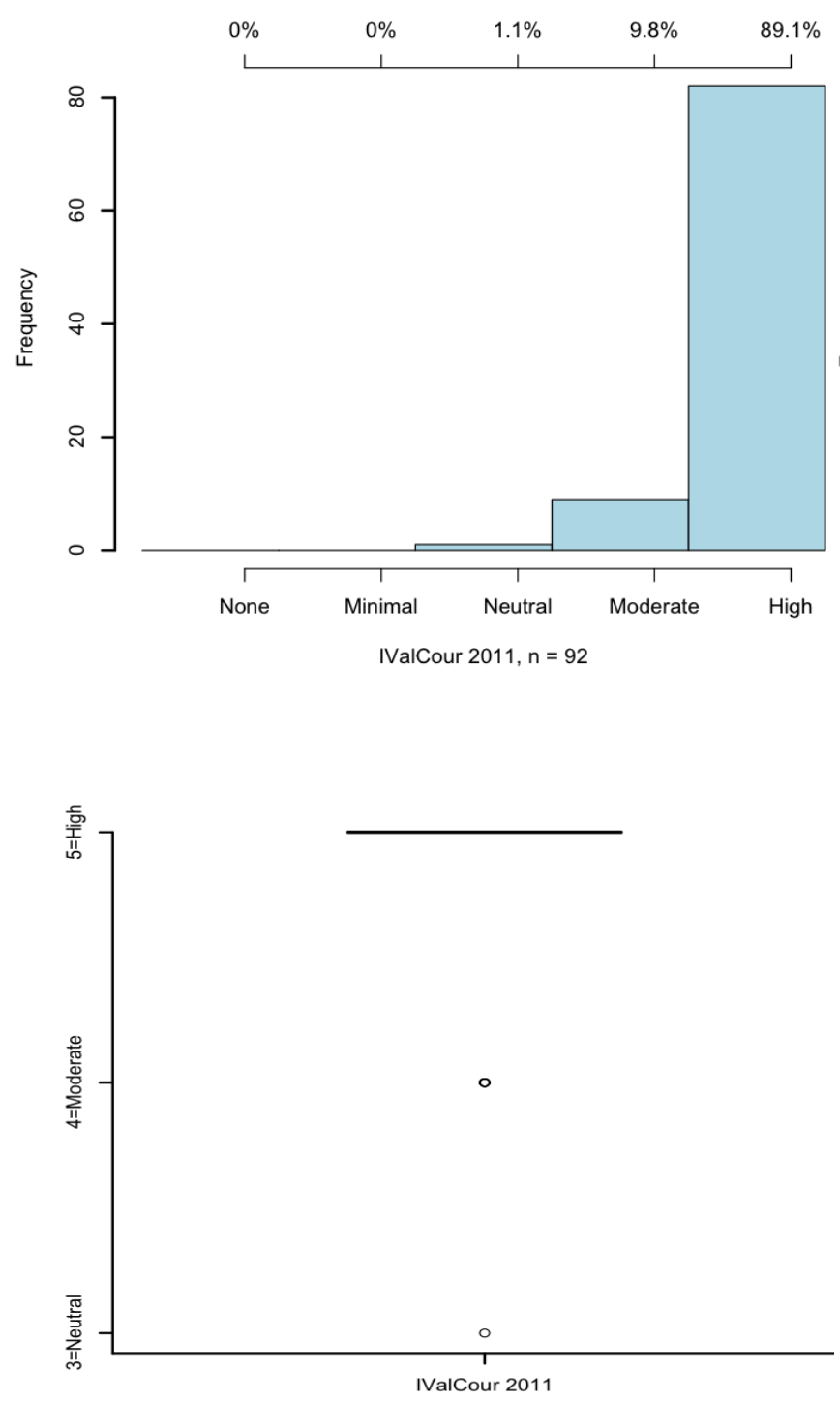

Initial course value 2012
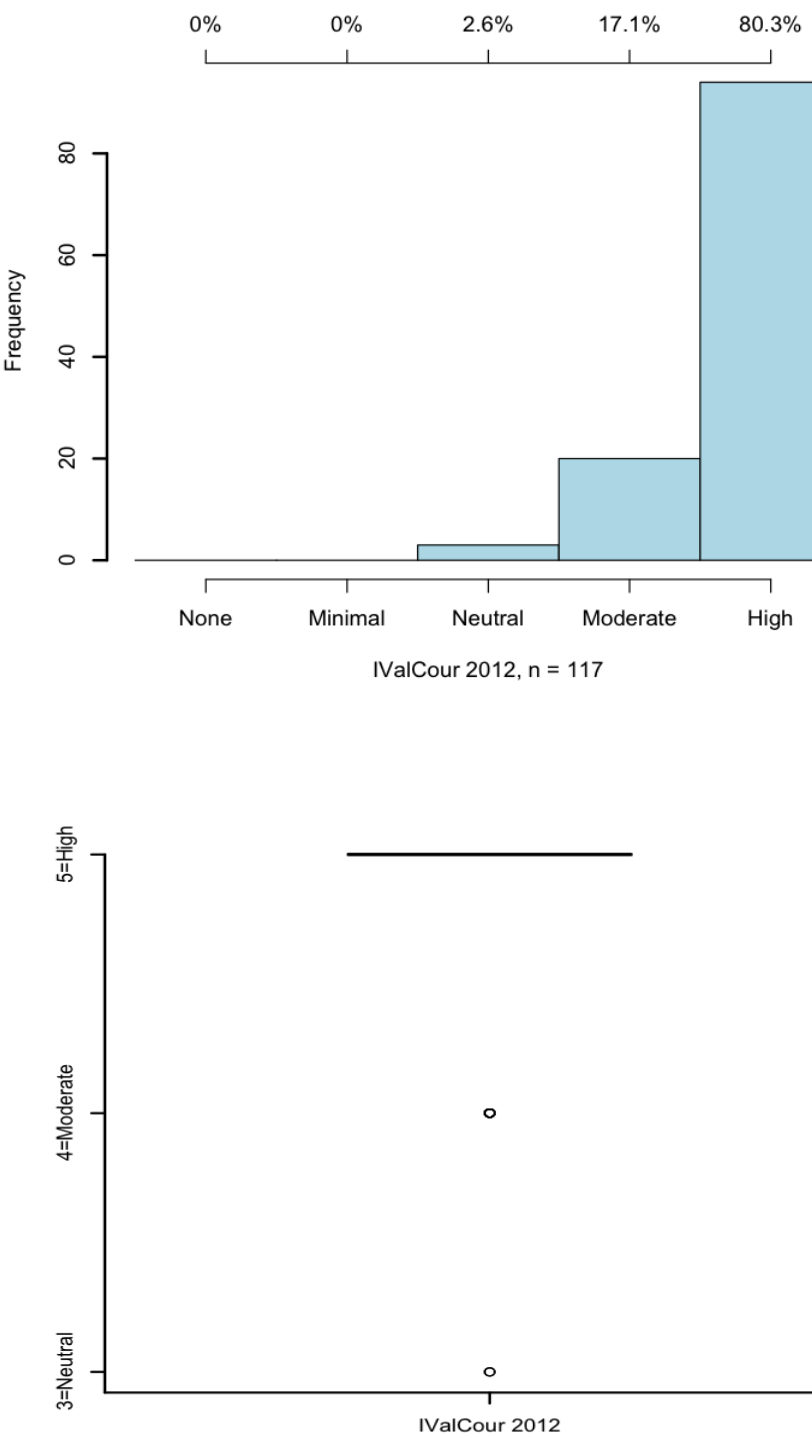
Initial project value 2011
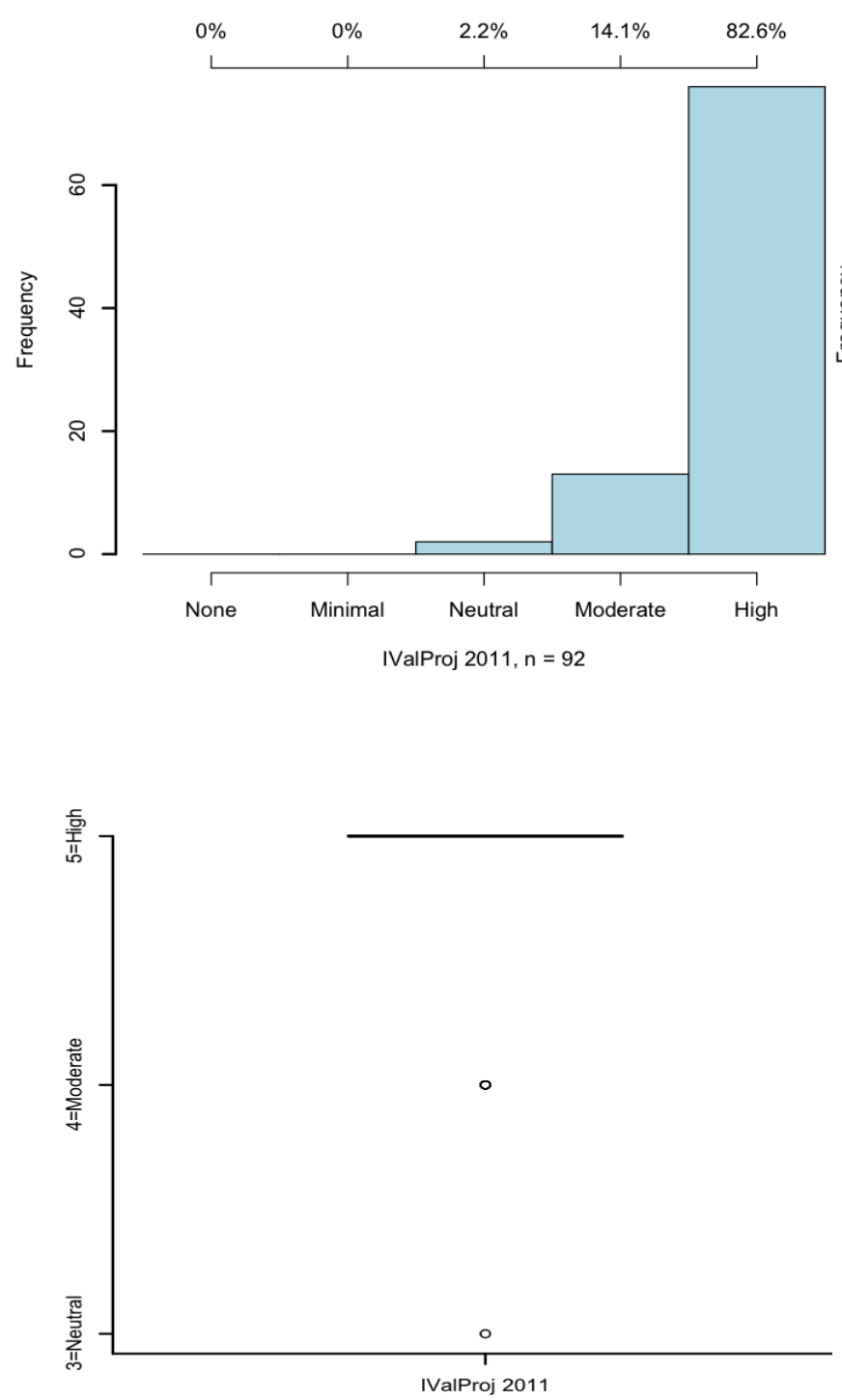

Initial project value 2012
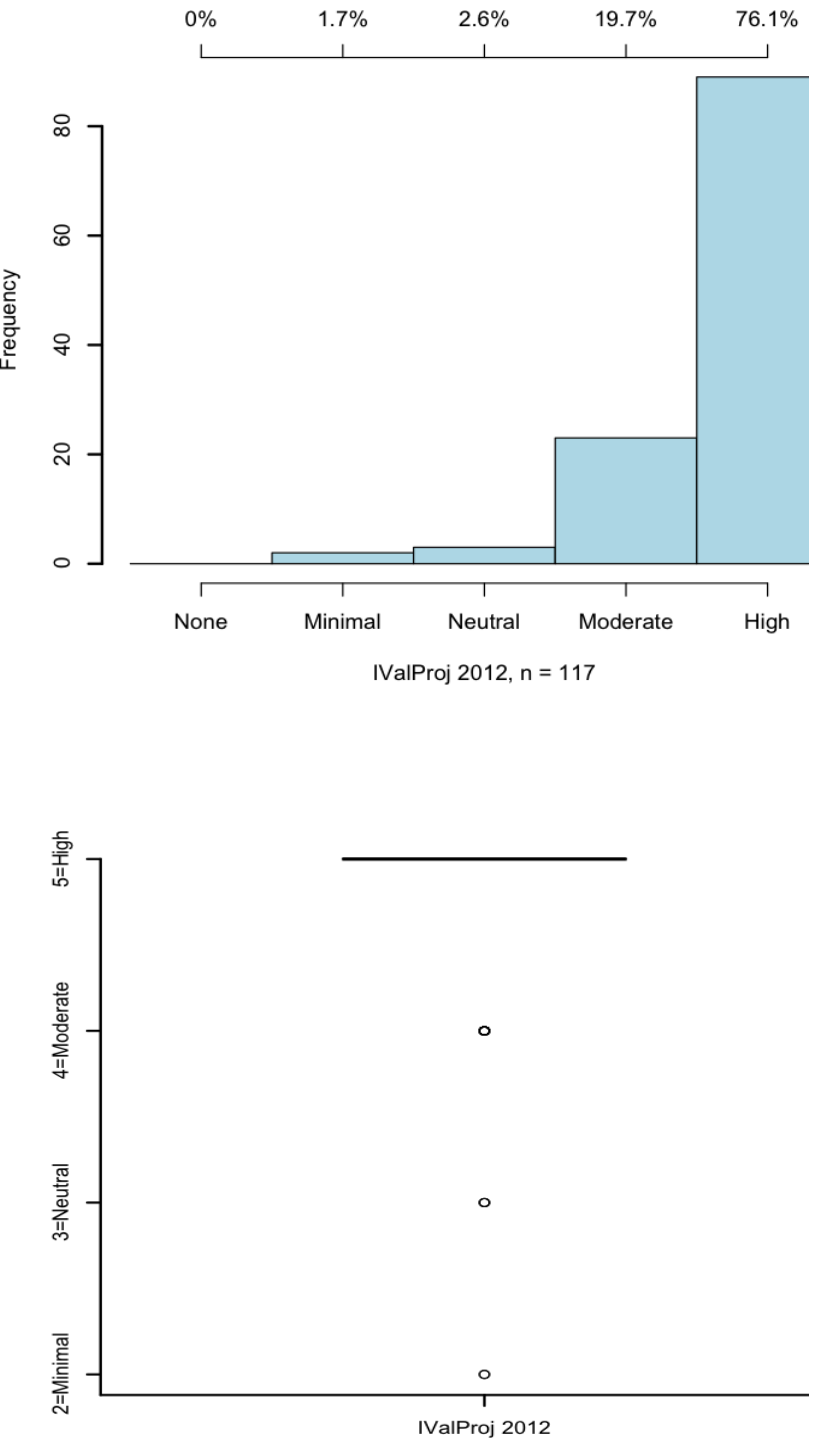
Expectancy for success in course 2011
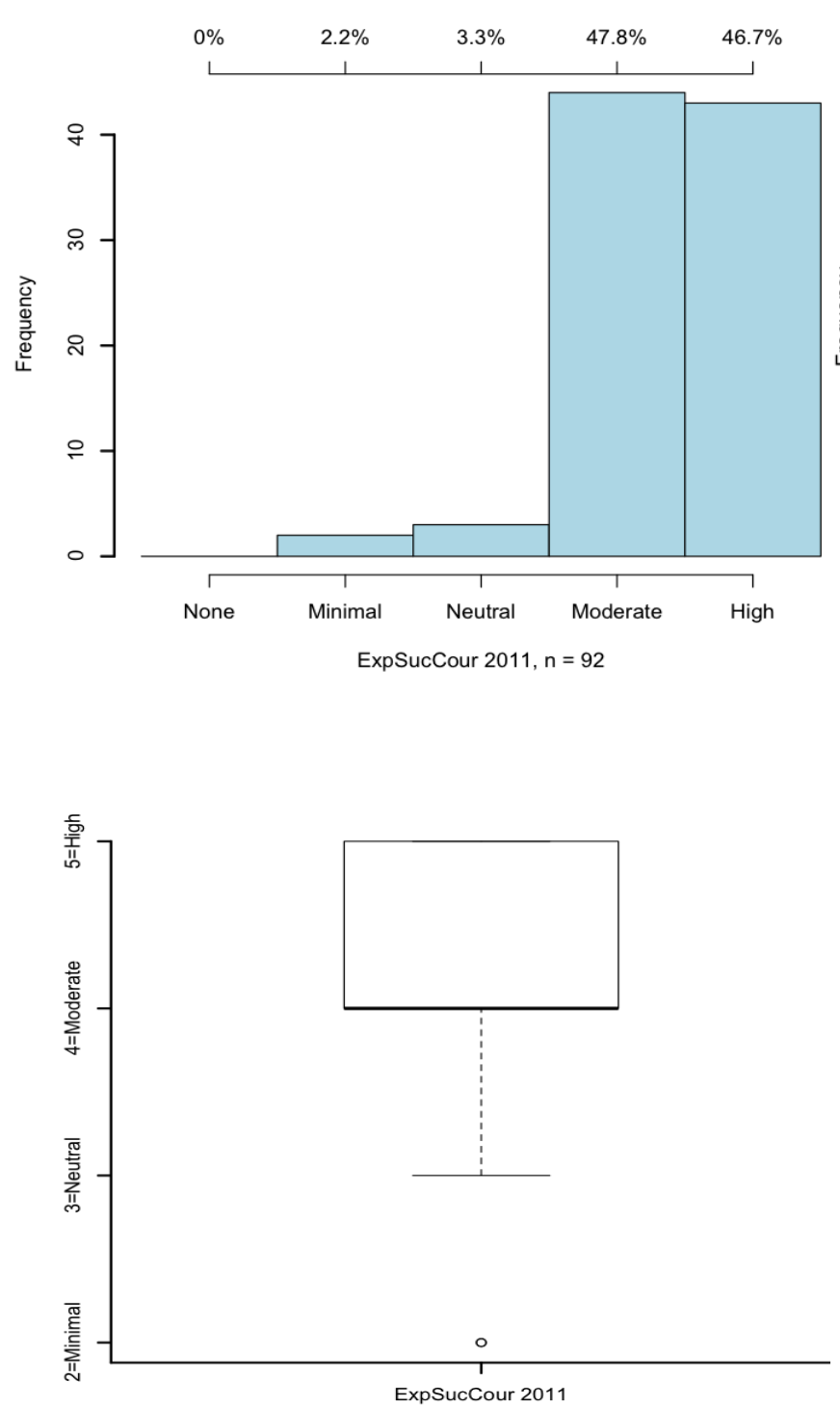

Expectancy for success in course 2012
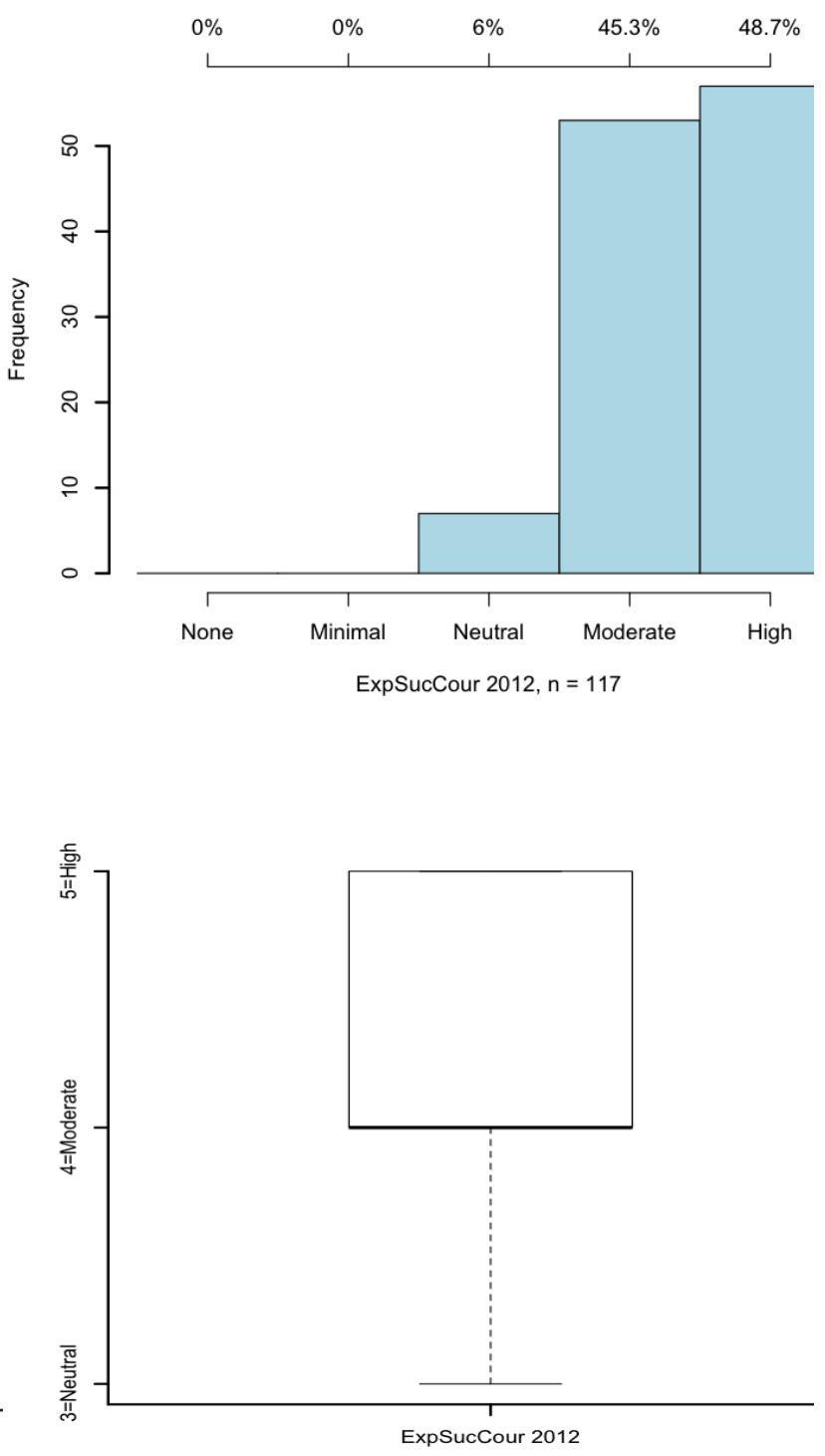
Expectancy for success in project 2011
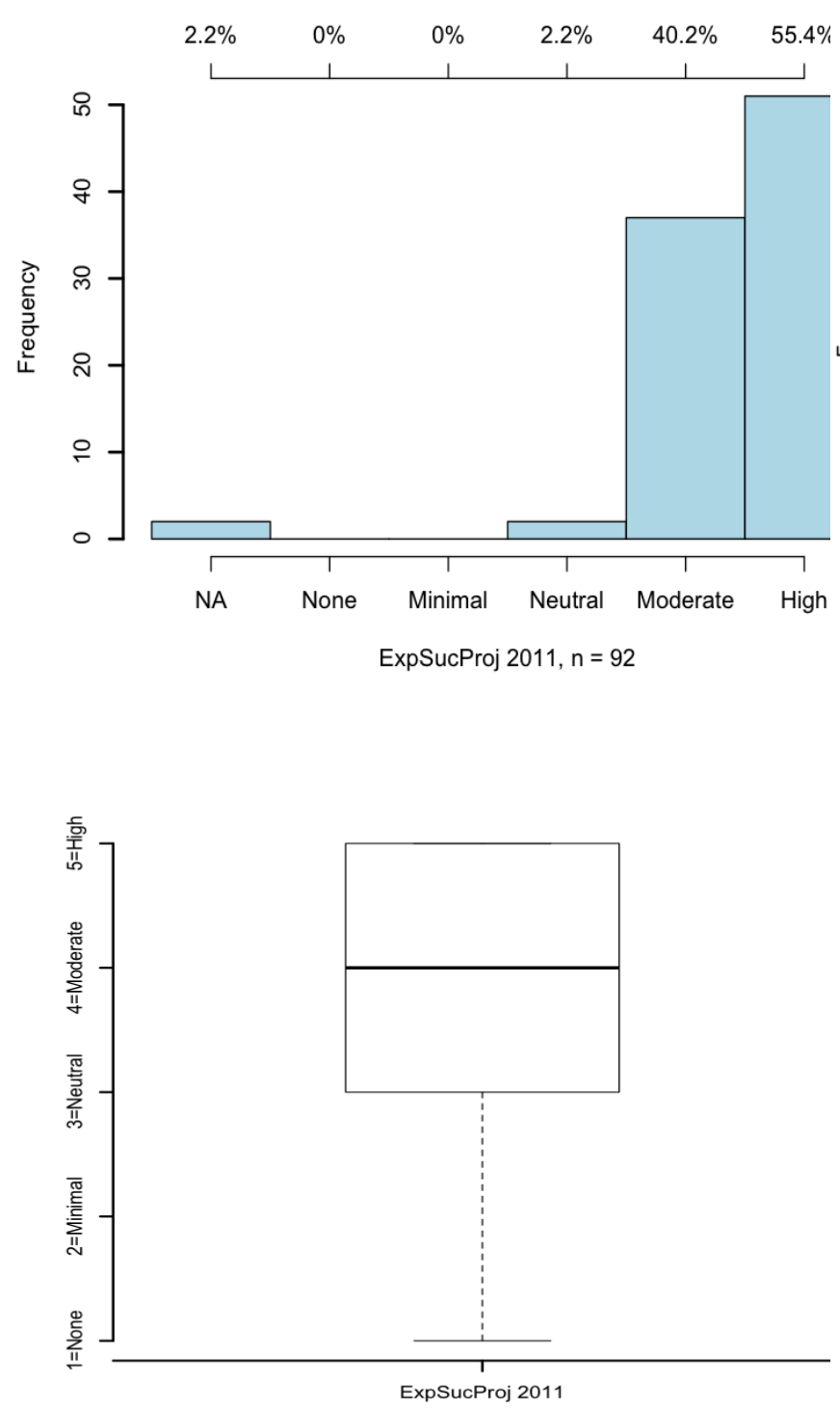

Expectancy for success in project 2012
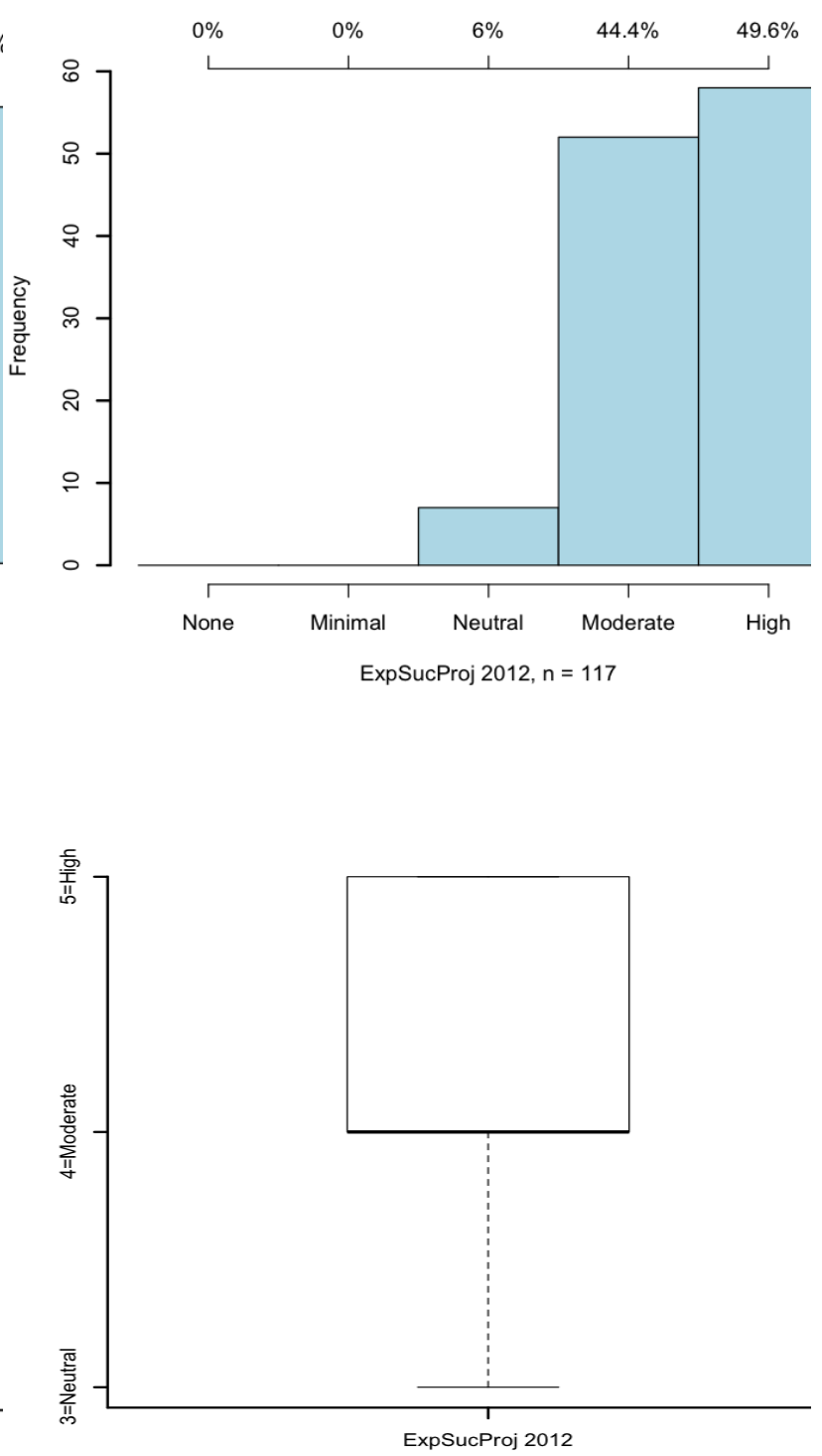
Initial confidence in non-technical skills 2011
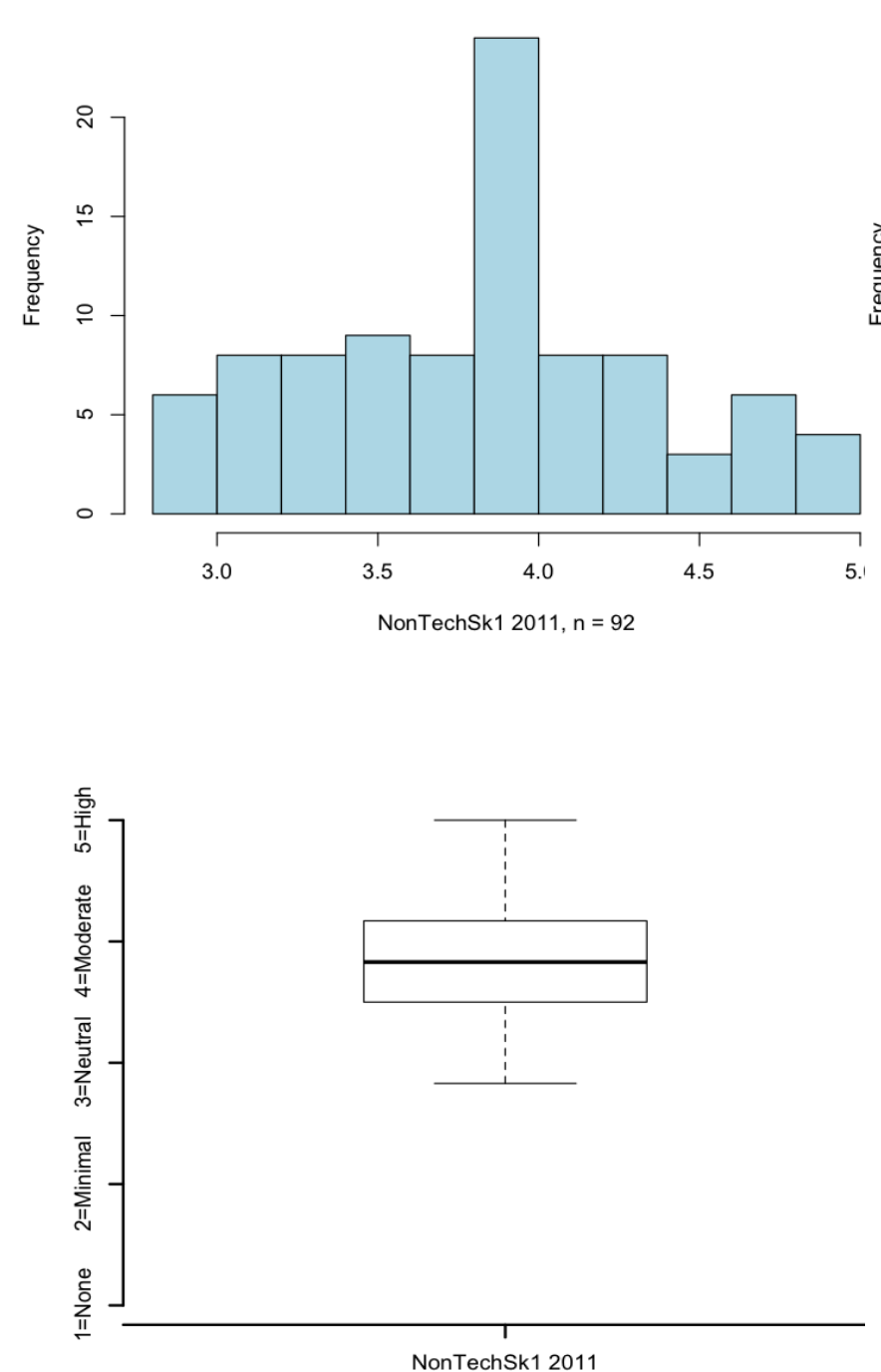

Initial confidence in non-technical skills 2012
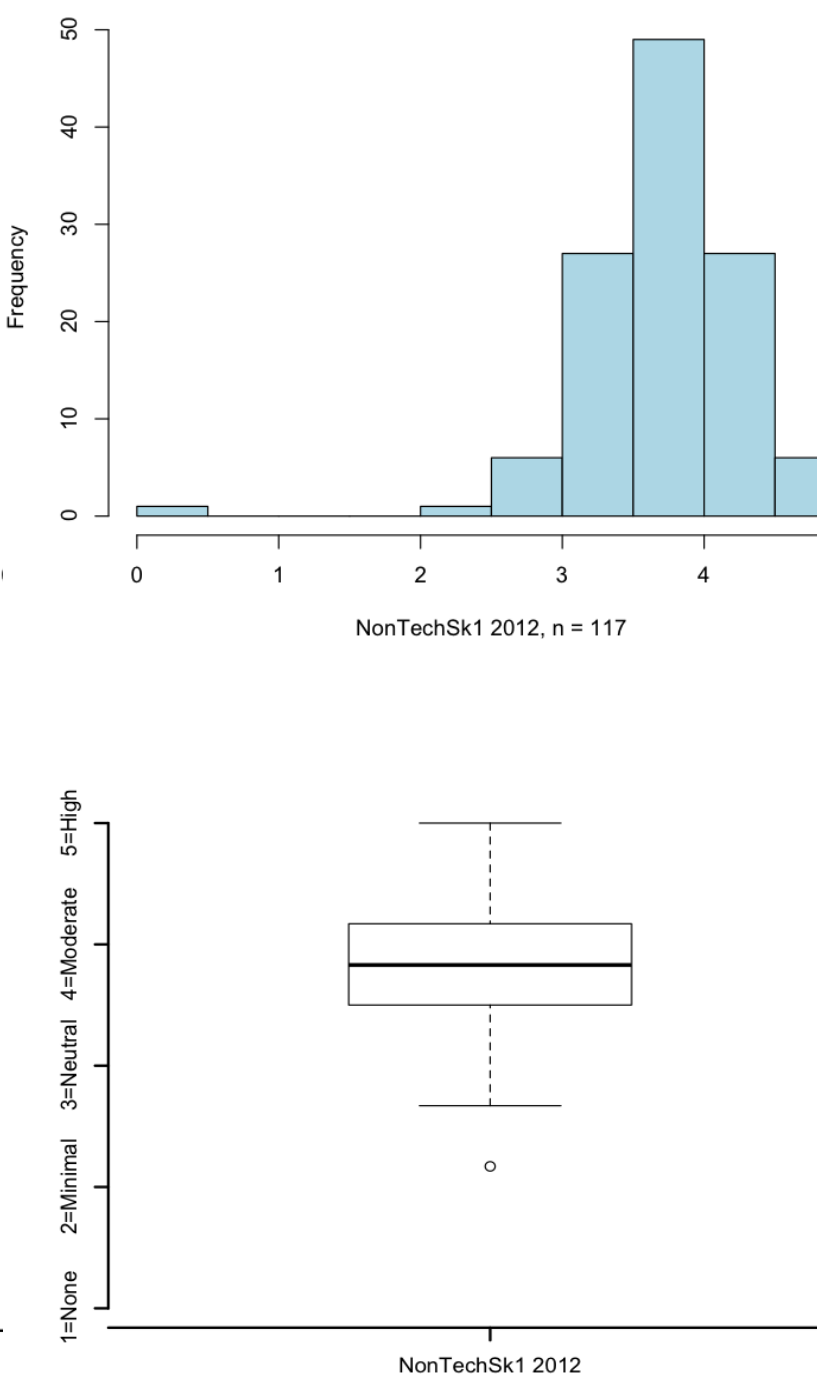
Initial confidence in technical skills 2011
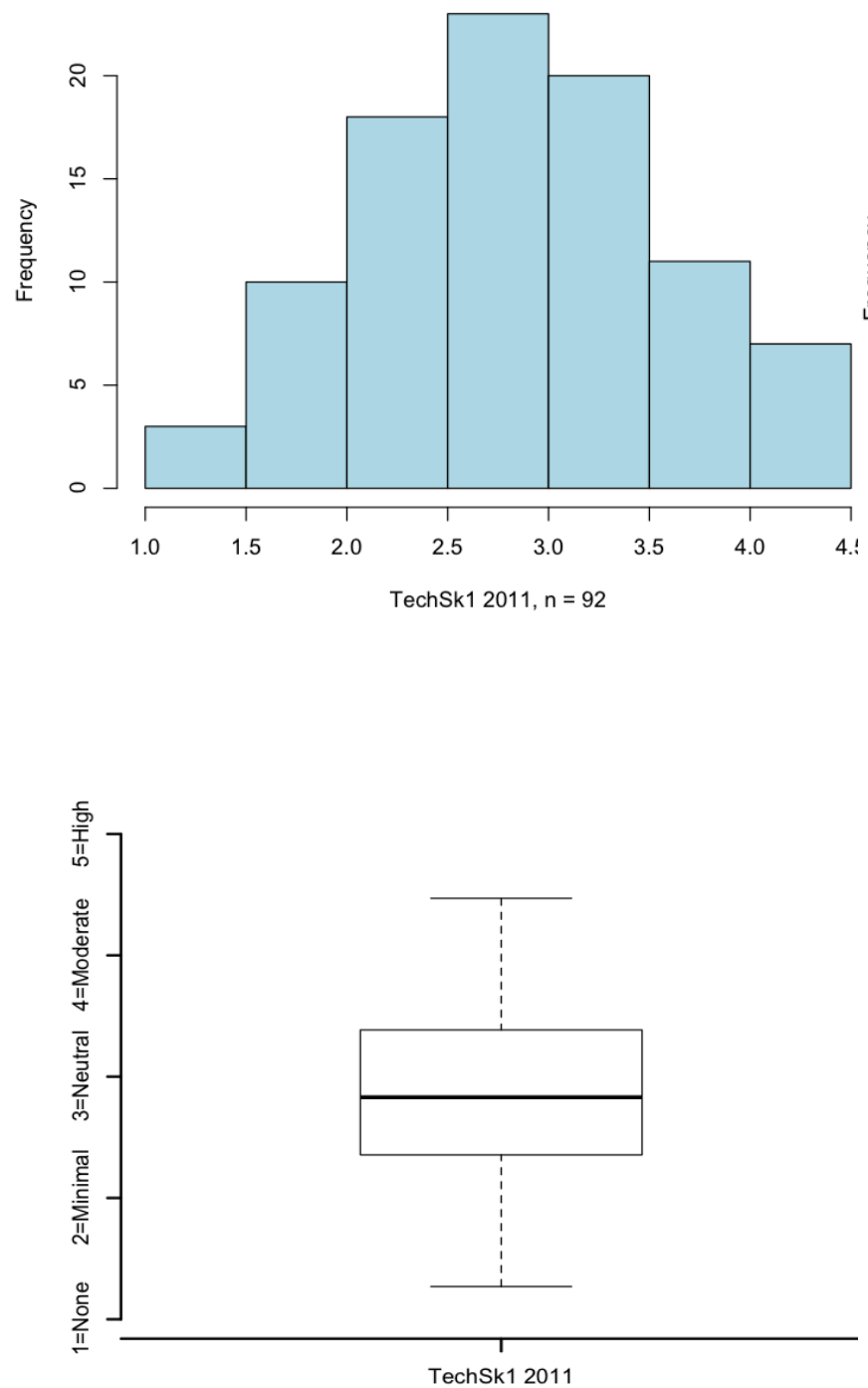

Initial confidence in technical skills 2012
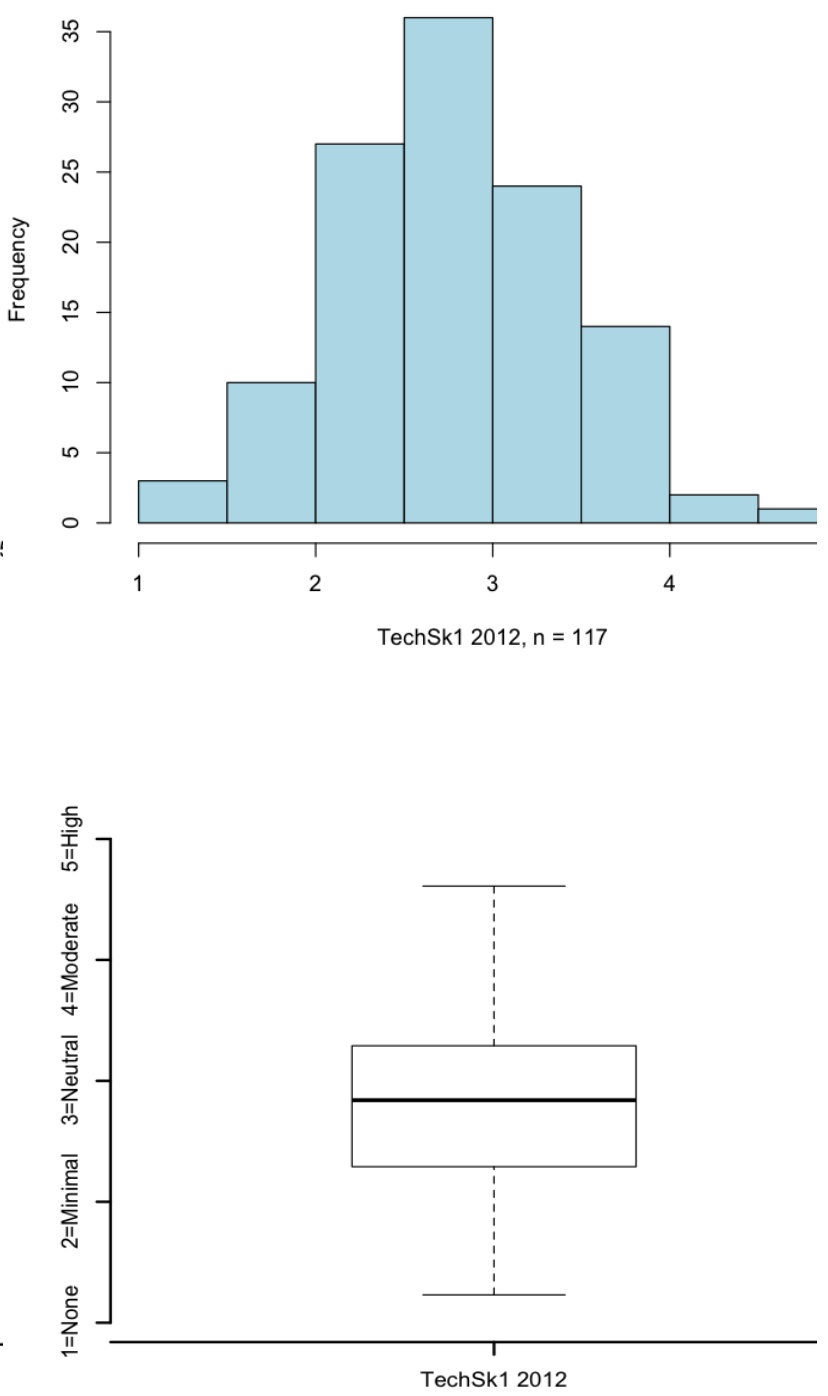
FINAL ATTITUDES AND SKILLS (post-course)

Final course/project interest, final course/project value, feelings of success in course/project, confidence in technical/non-technical skills, feelings of engagement, and support for service-learning

Final course interest 2011
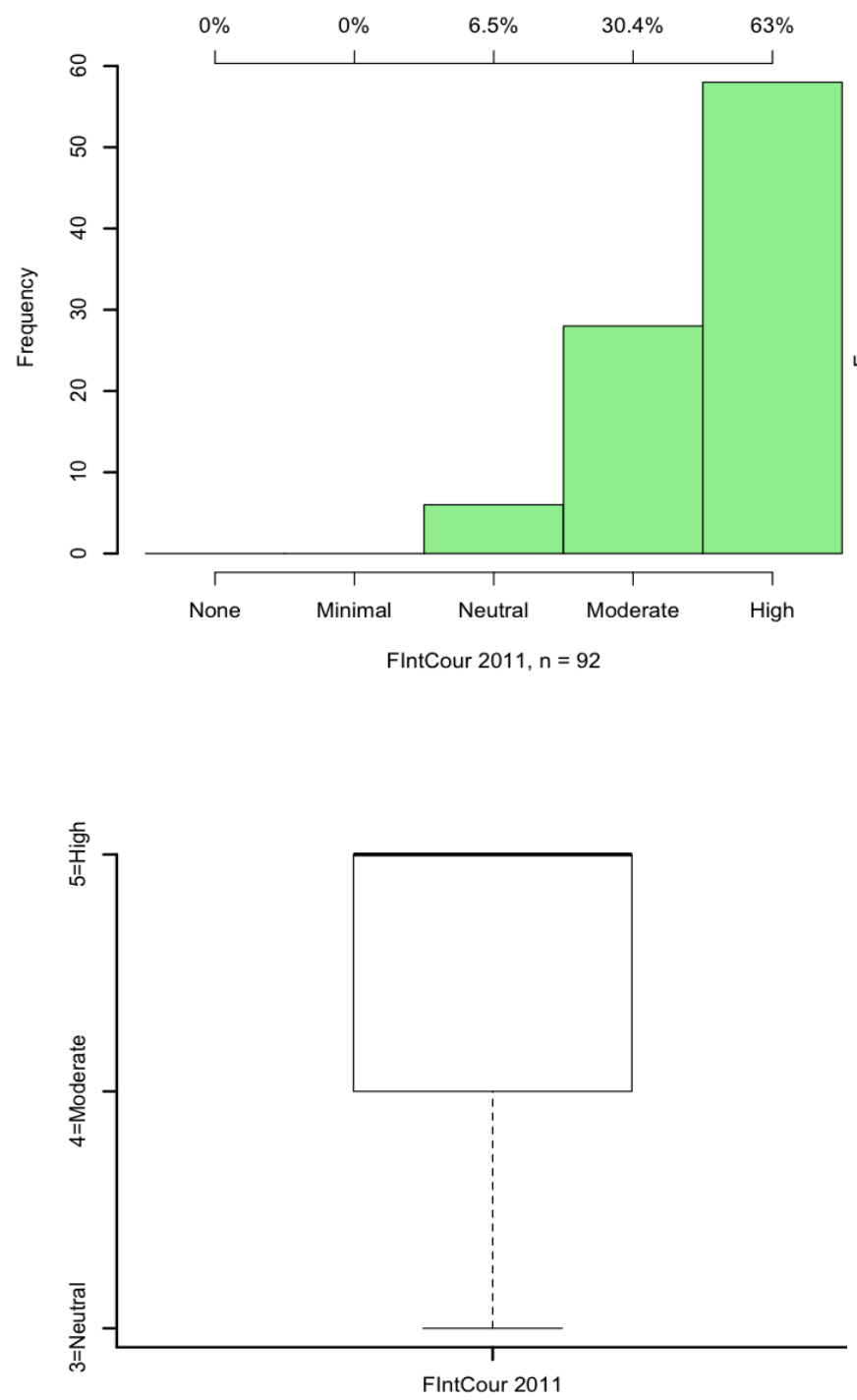

Final course interest 2011
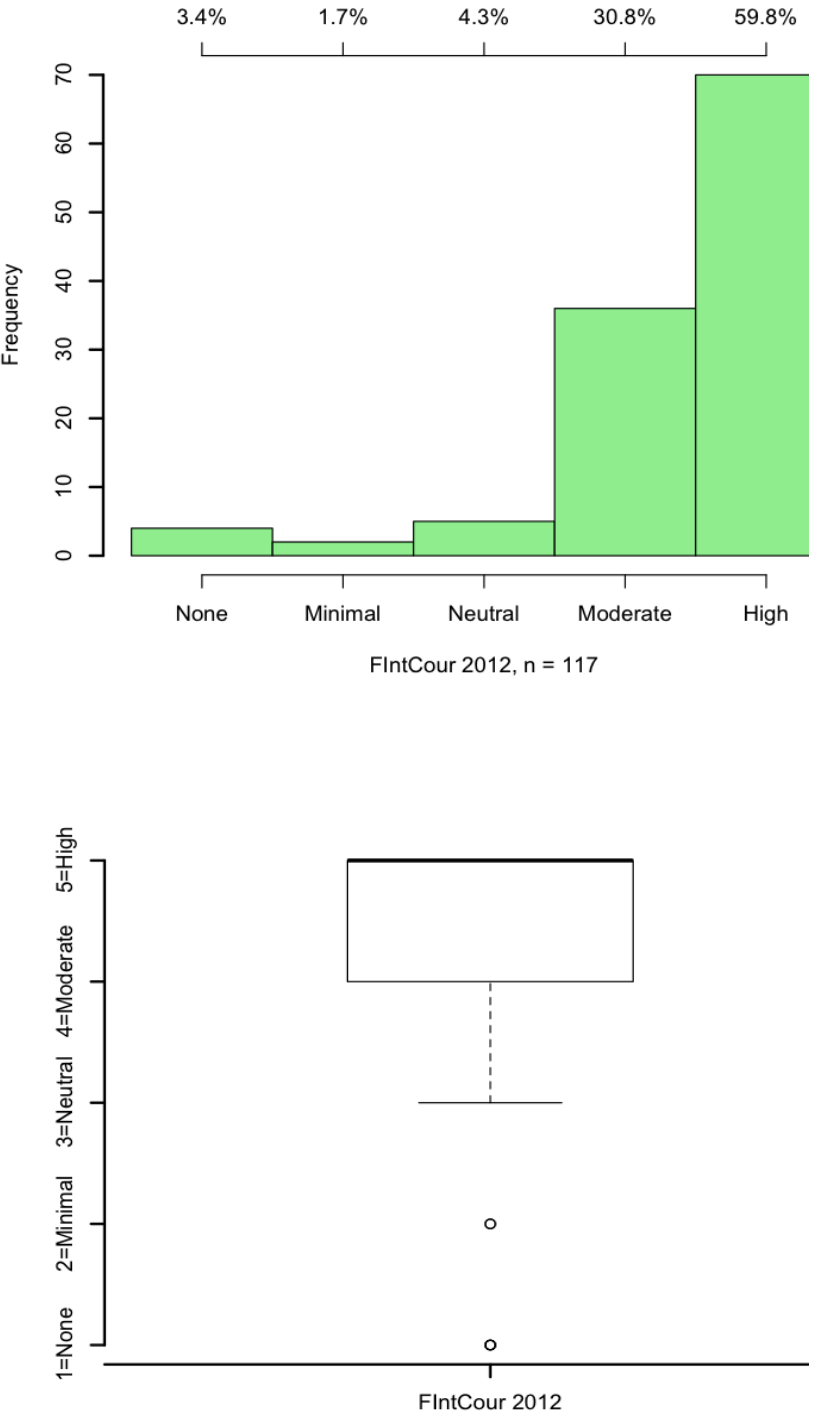
Final project interest 2011
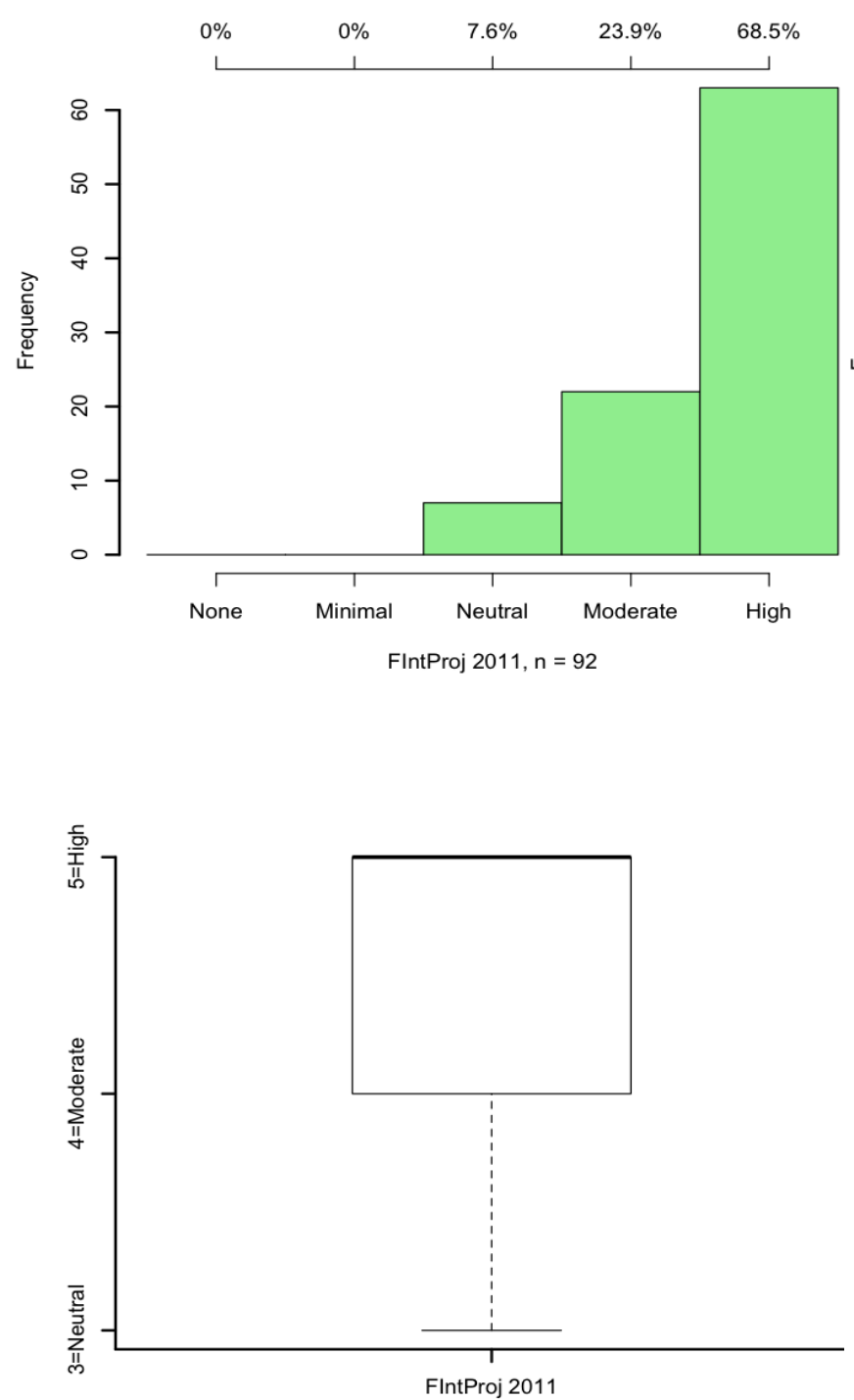

Final project interest 2012
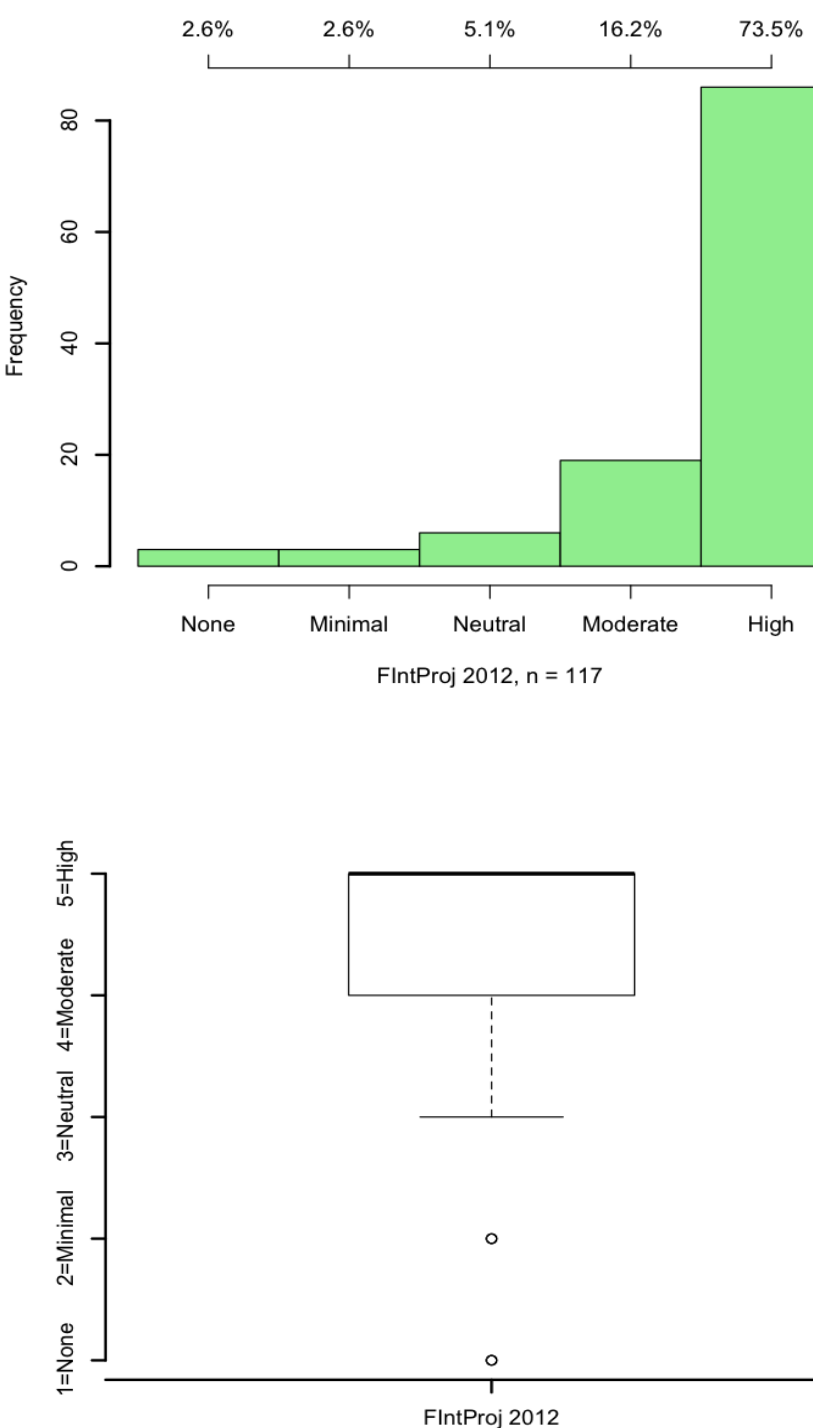
Final course value 2011
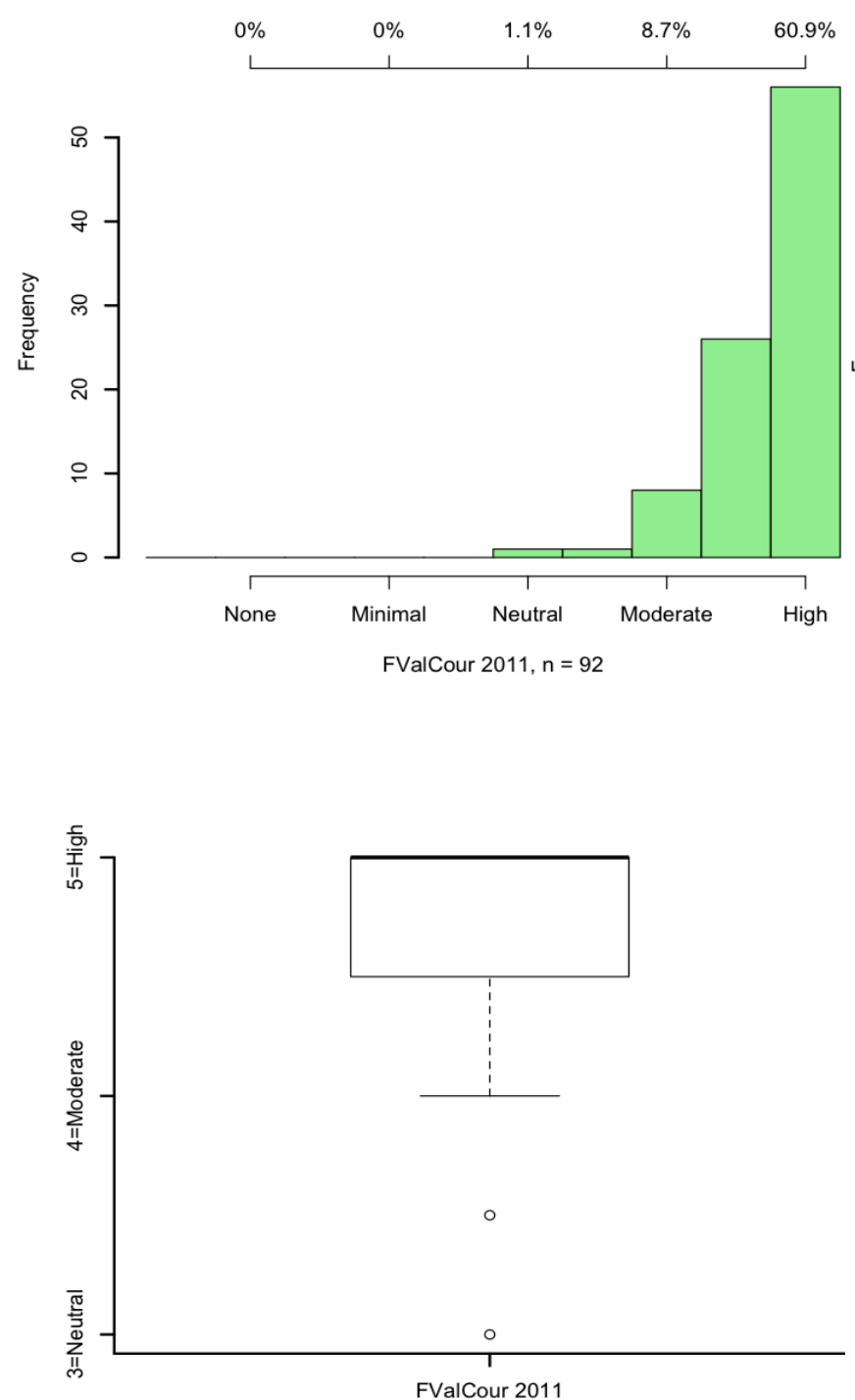

Final course value 2012
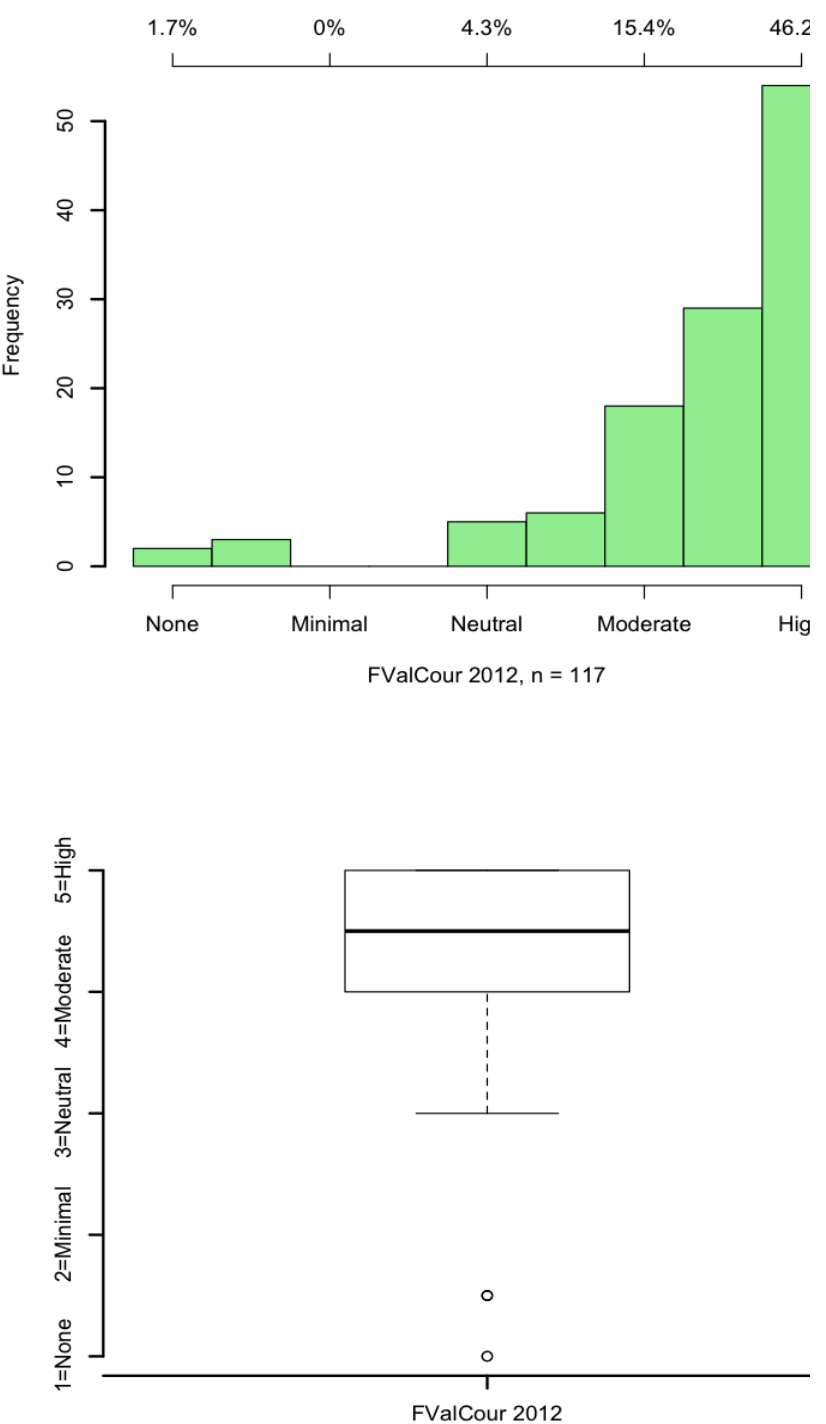
Final project value 2011
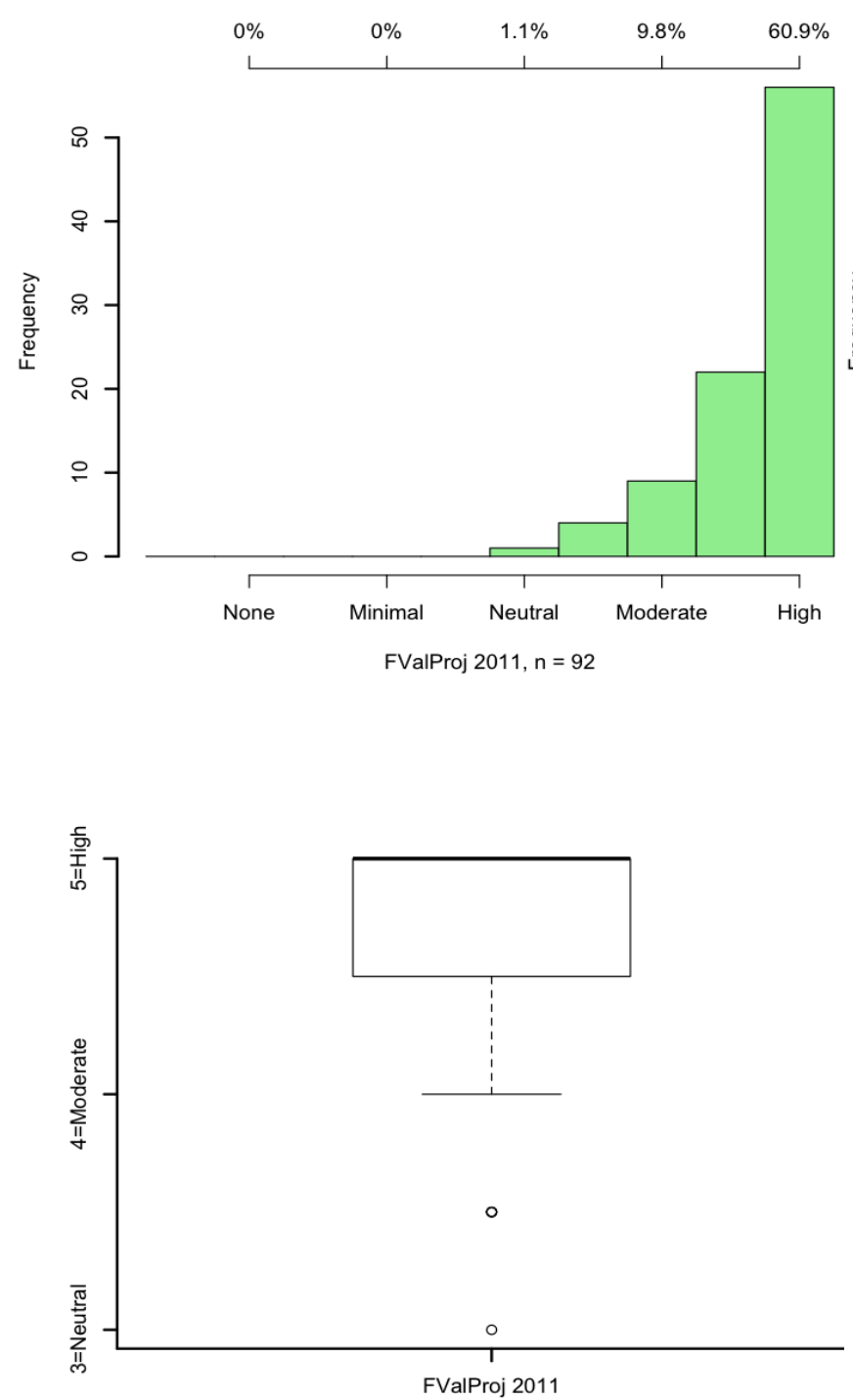

Final project value 2012
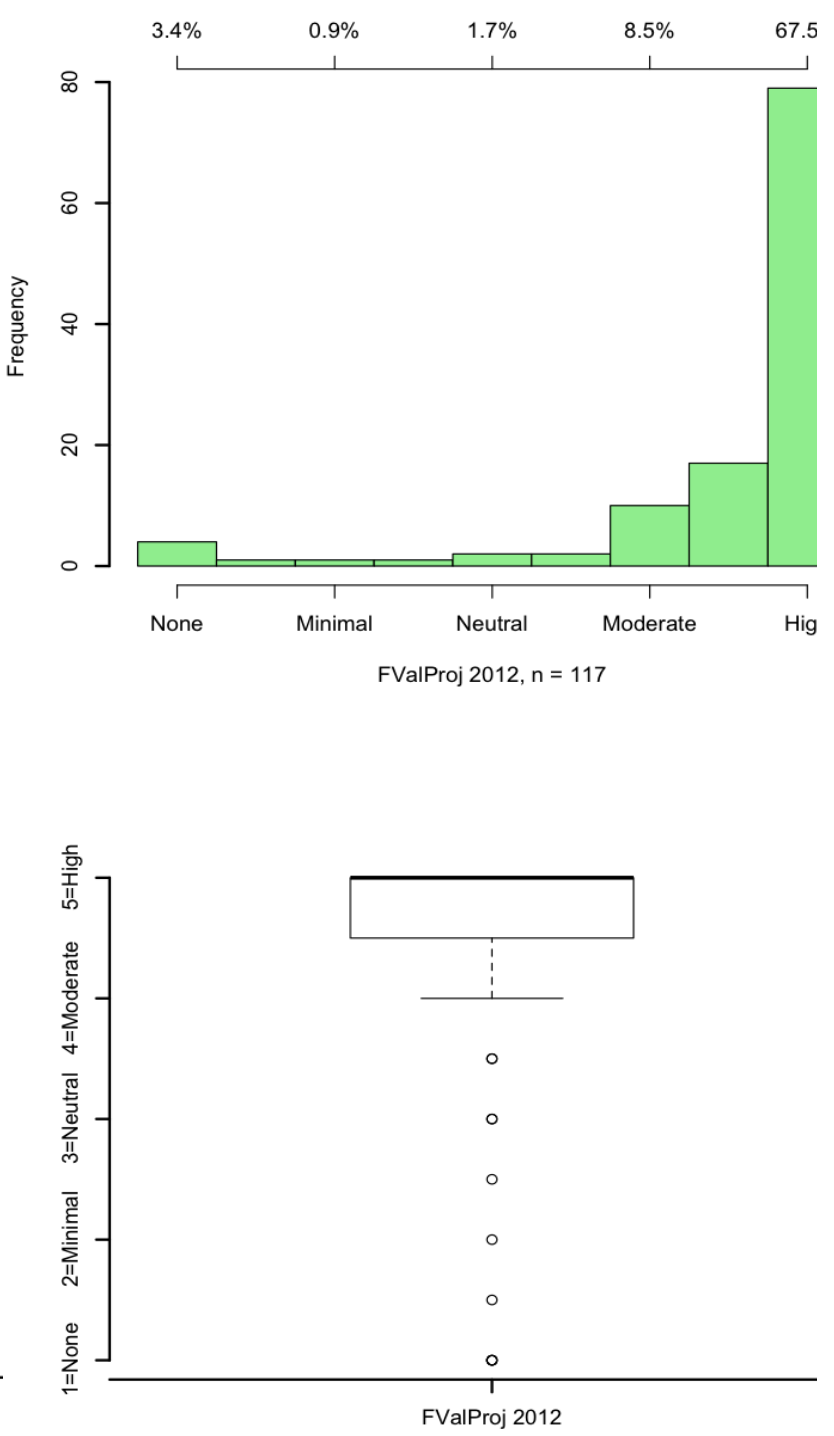
Feelings of success in course 2011
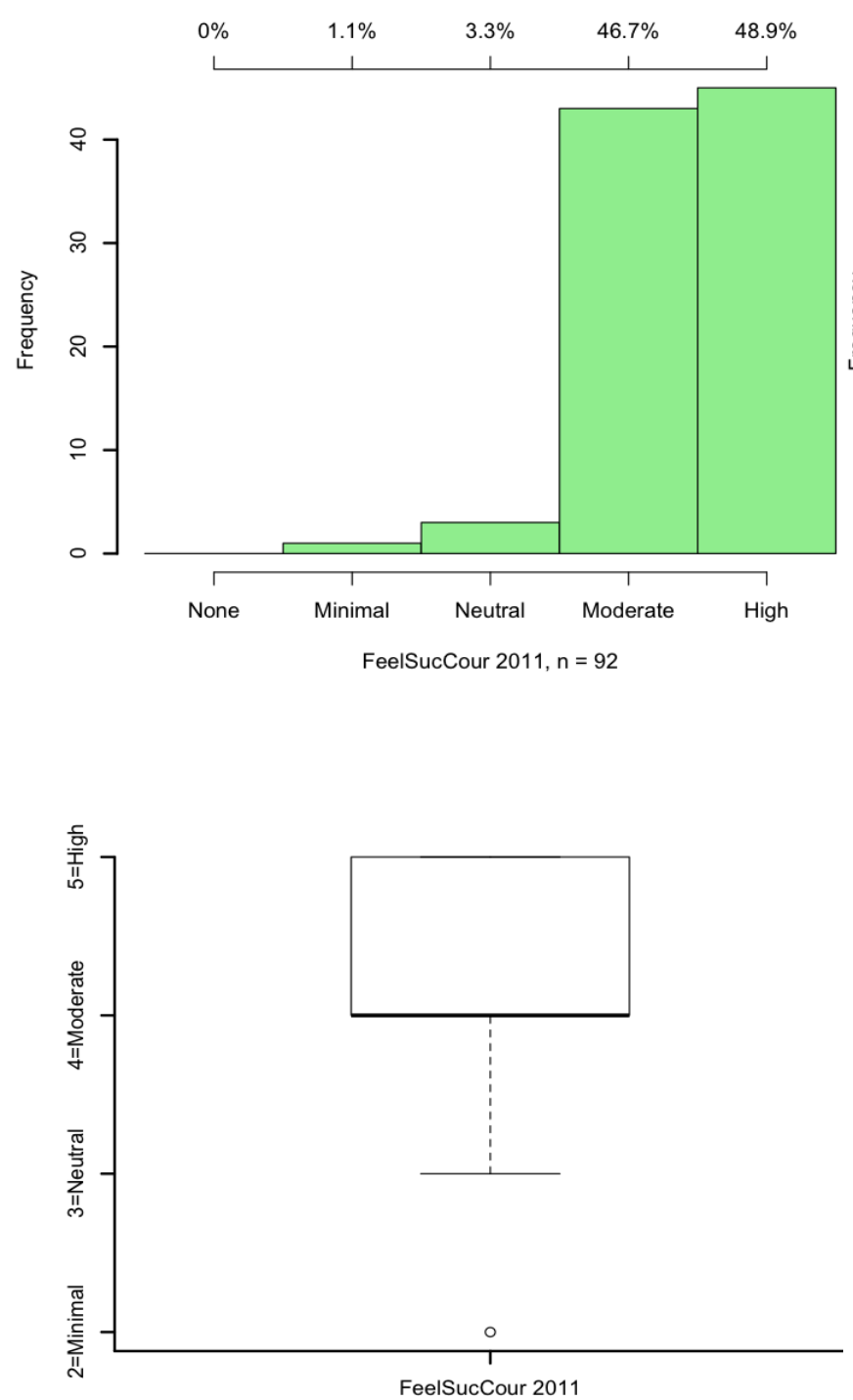

Feelings of success in course 2012
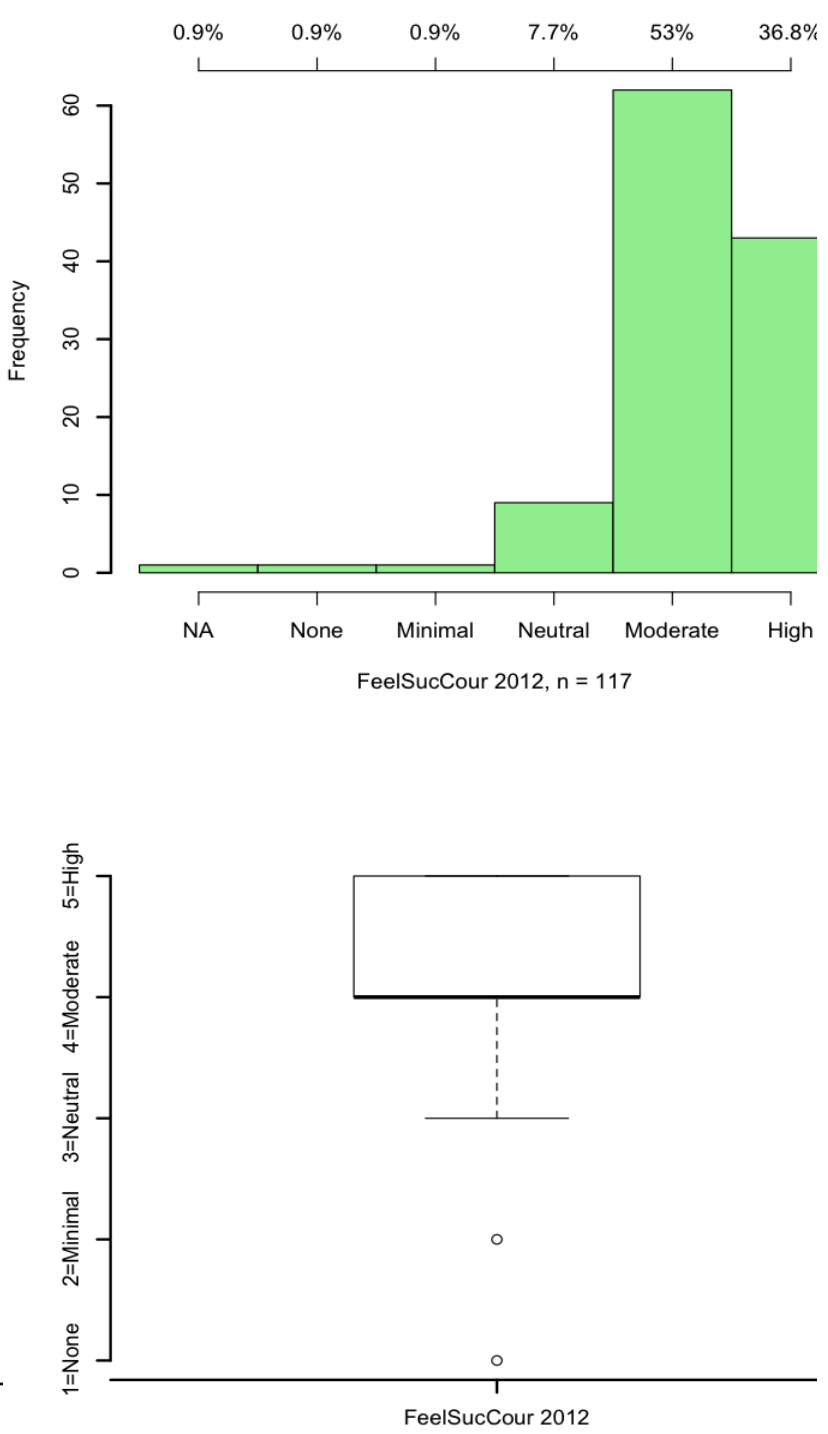
Feelings of success in project 2011
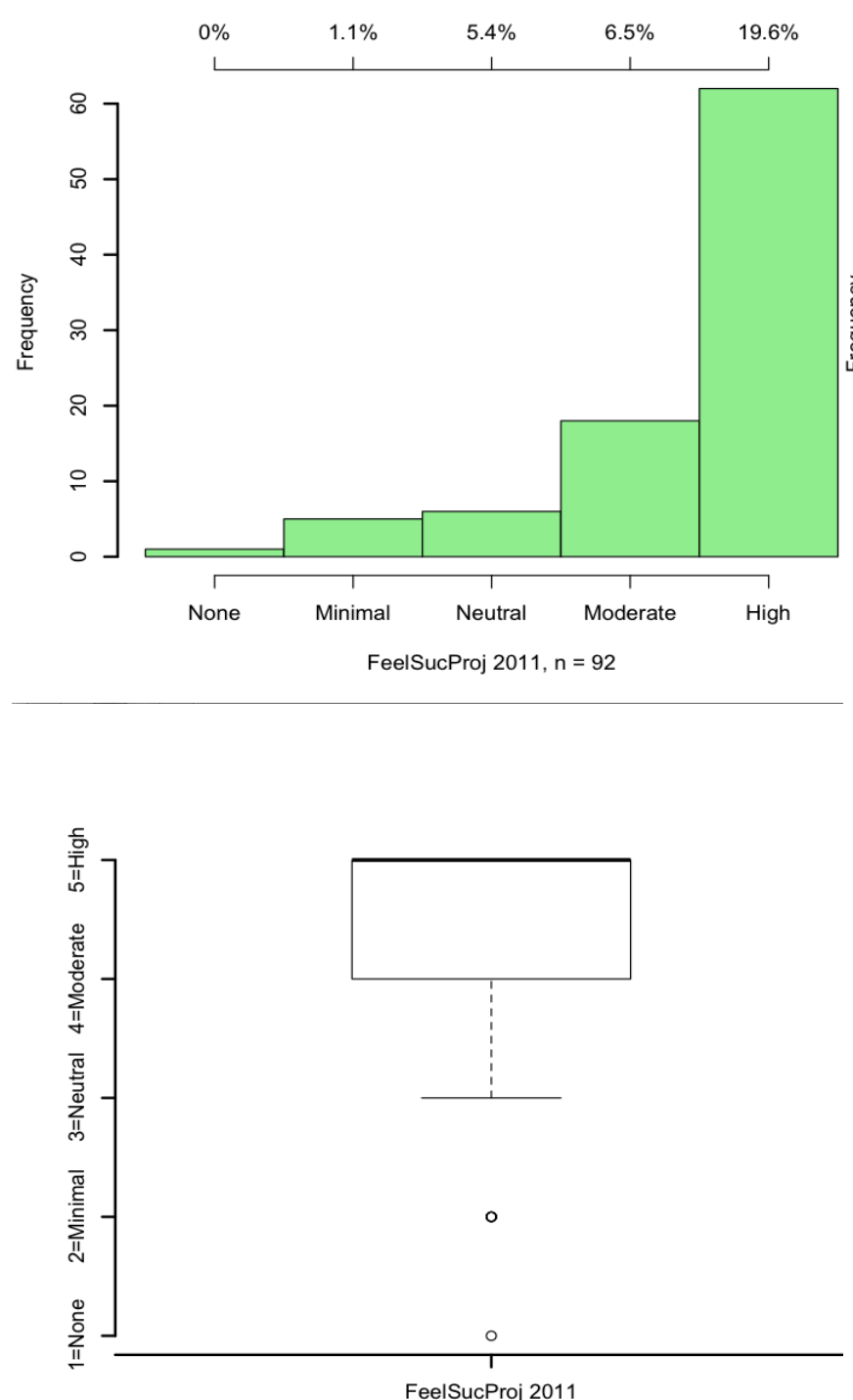

Feelings of success in project 2012
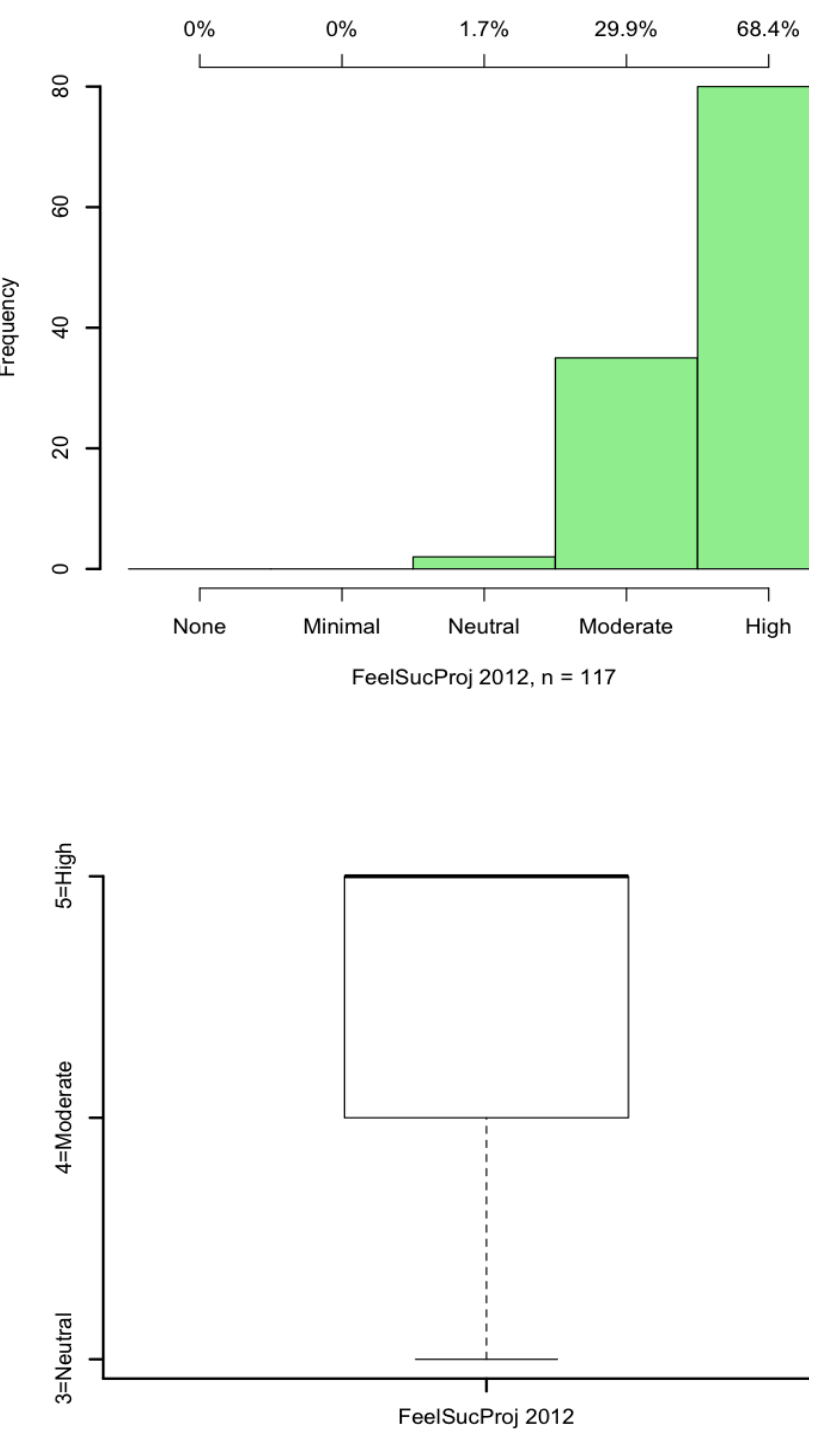
Final confidence in non-technical skills 2011
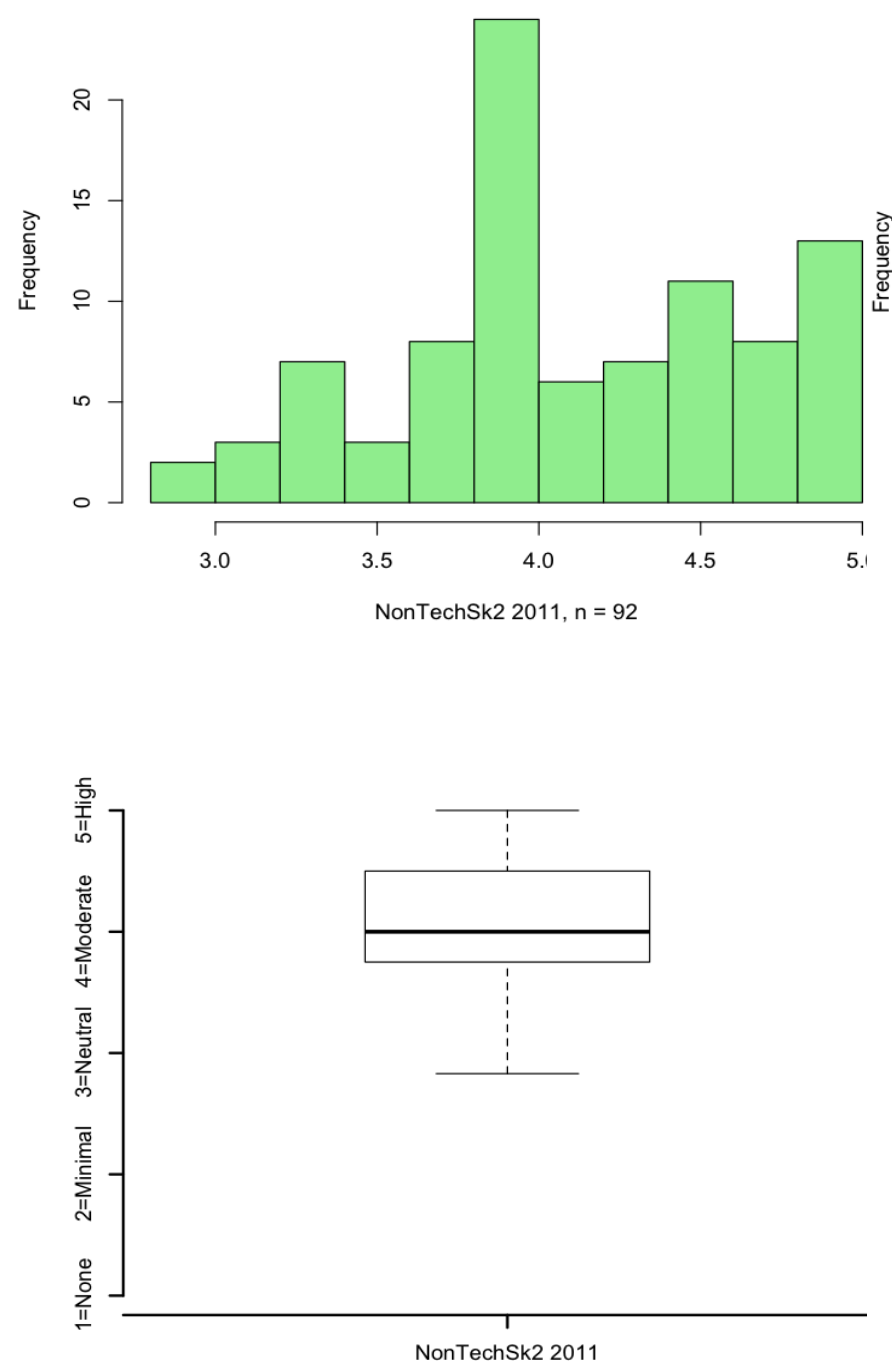

Final confidence in non-technical skills 2012
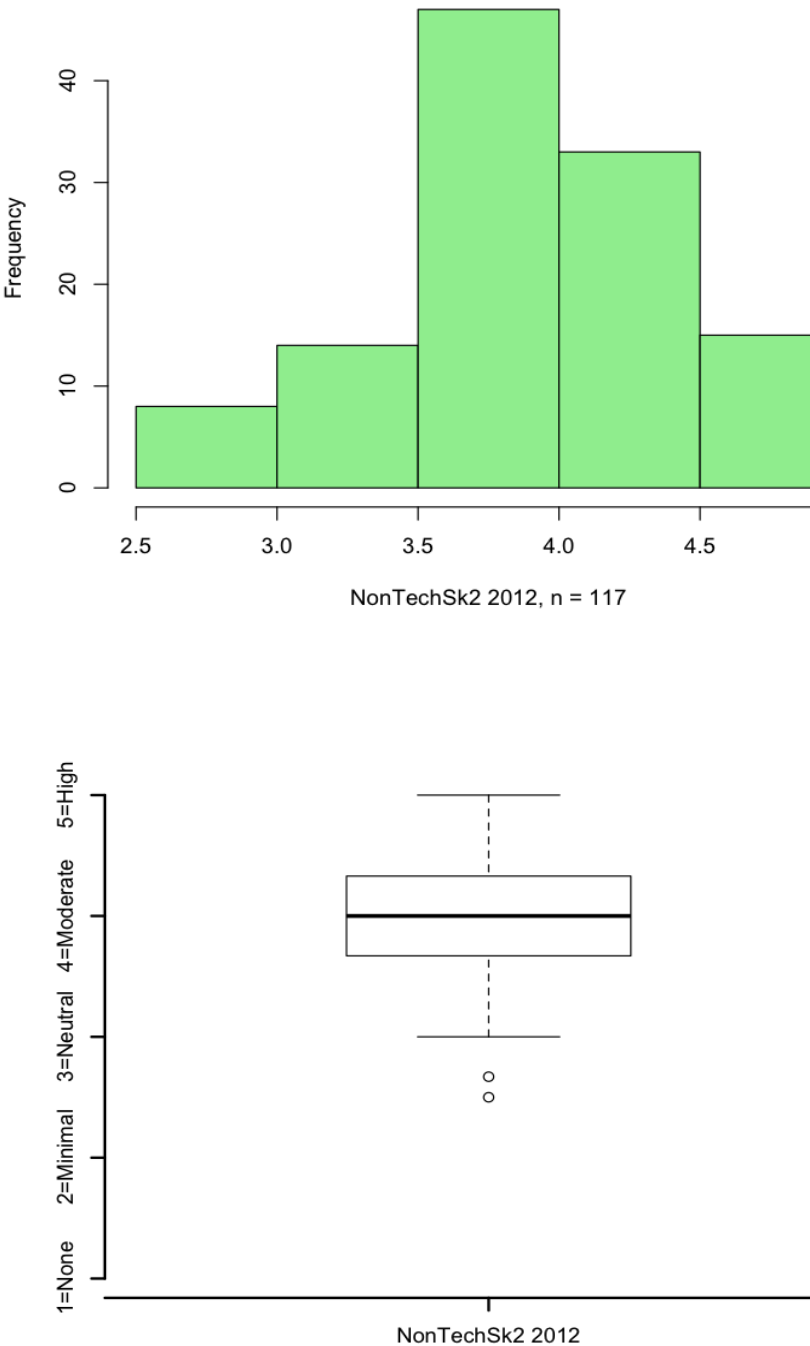
Final confidence in technical skills 2011
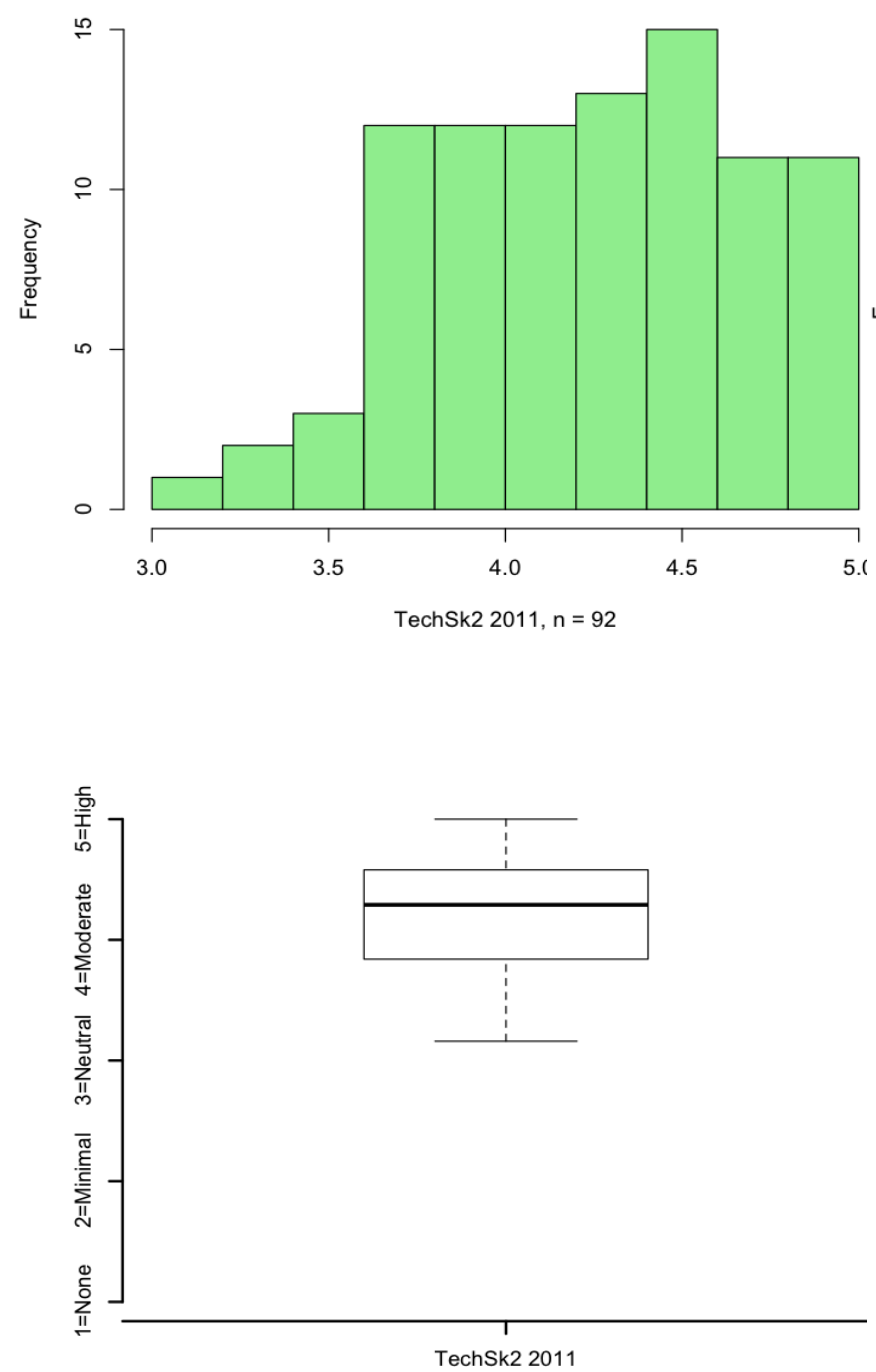

Final confidence in technical skills 2012
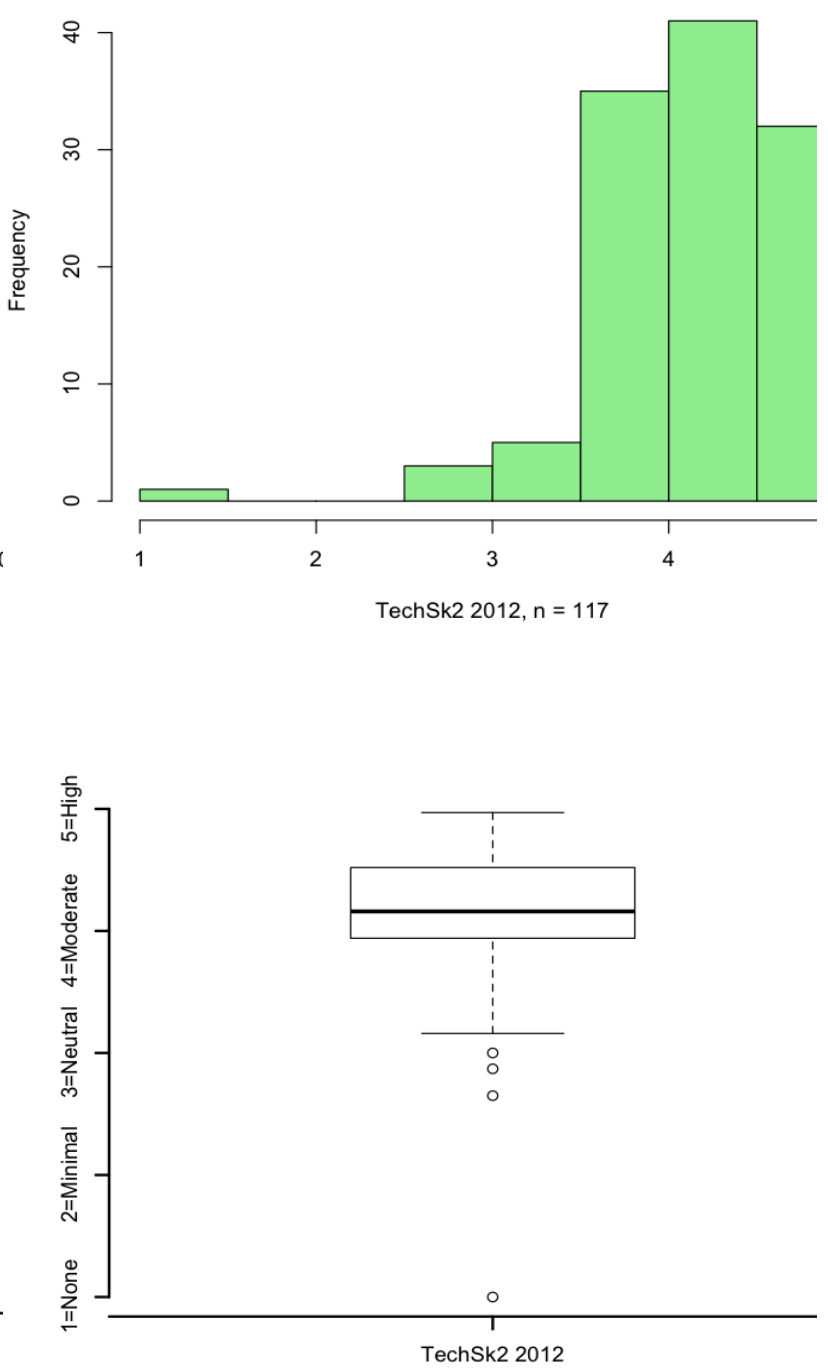
Indicators of engagement 2011
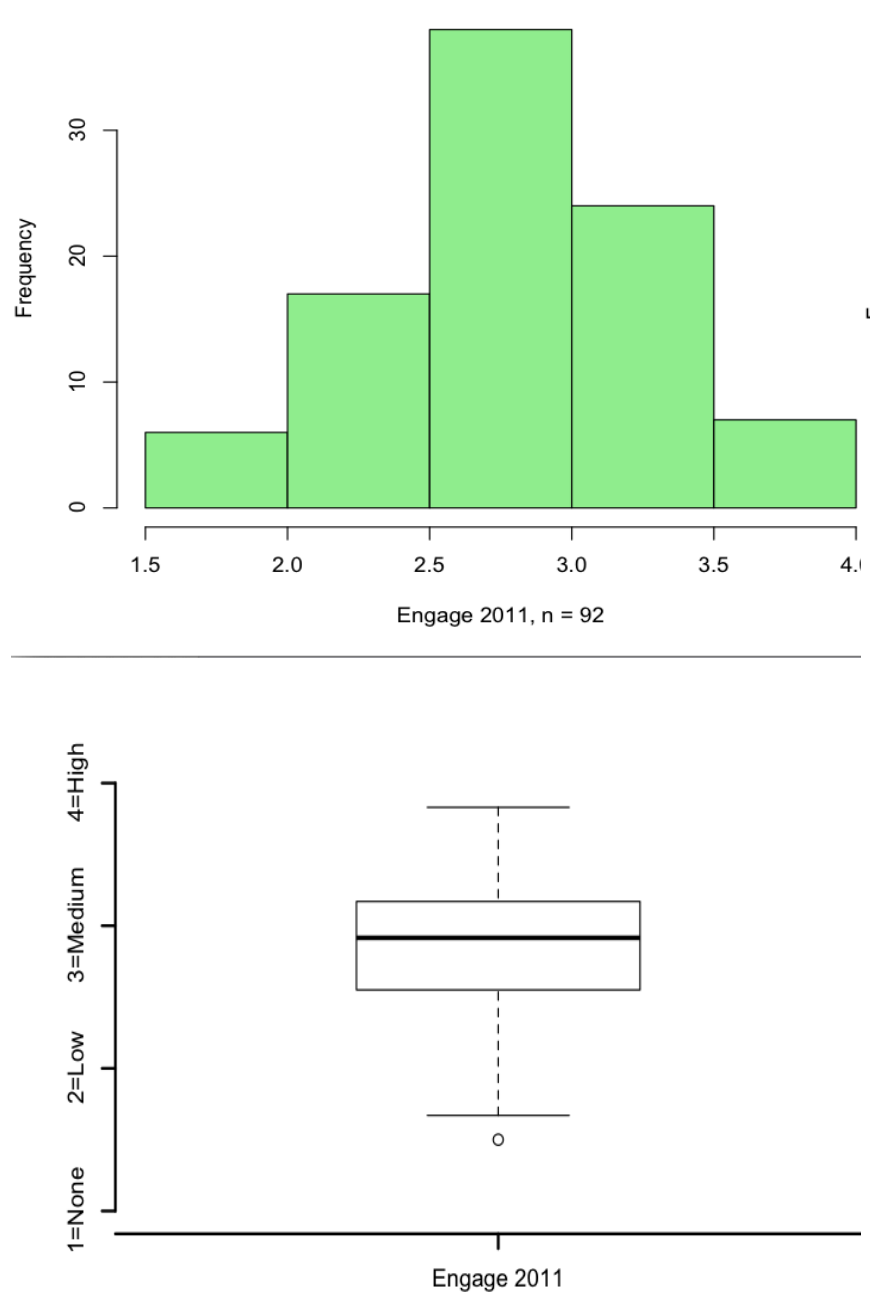

Indicators of engagement 2012
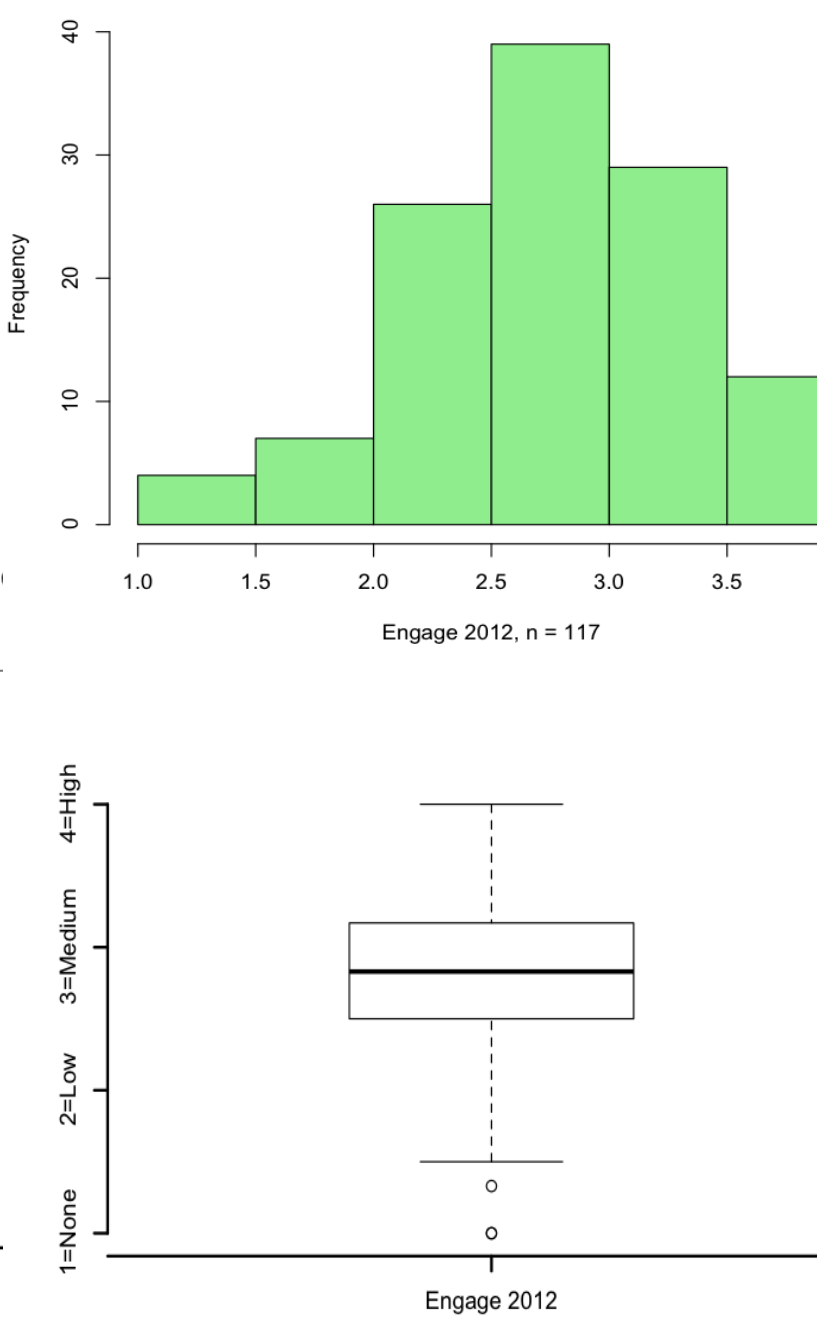
Final support for service-learning 2011
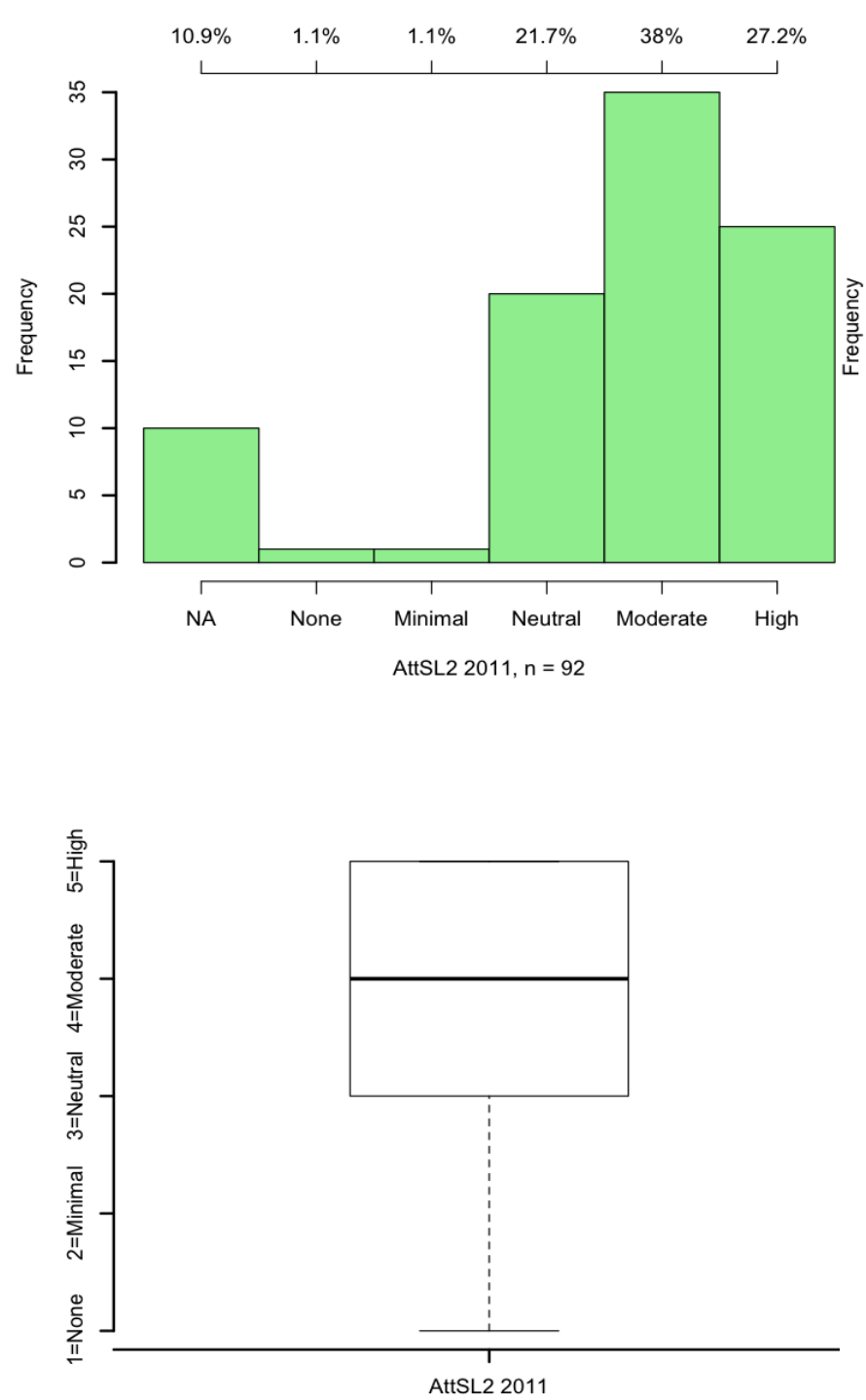

Final support for service-learning 2012
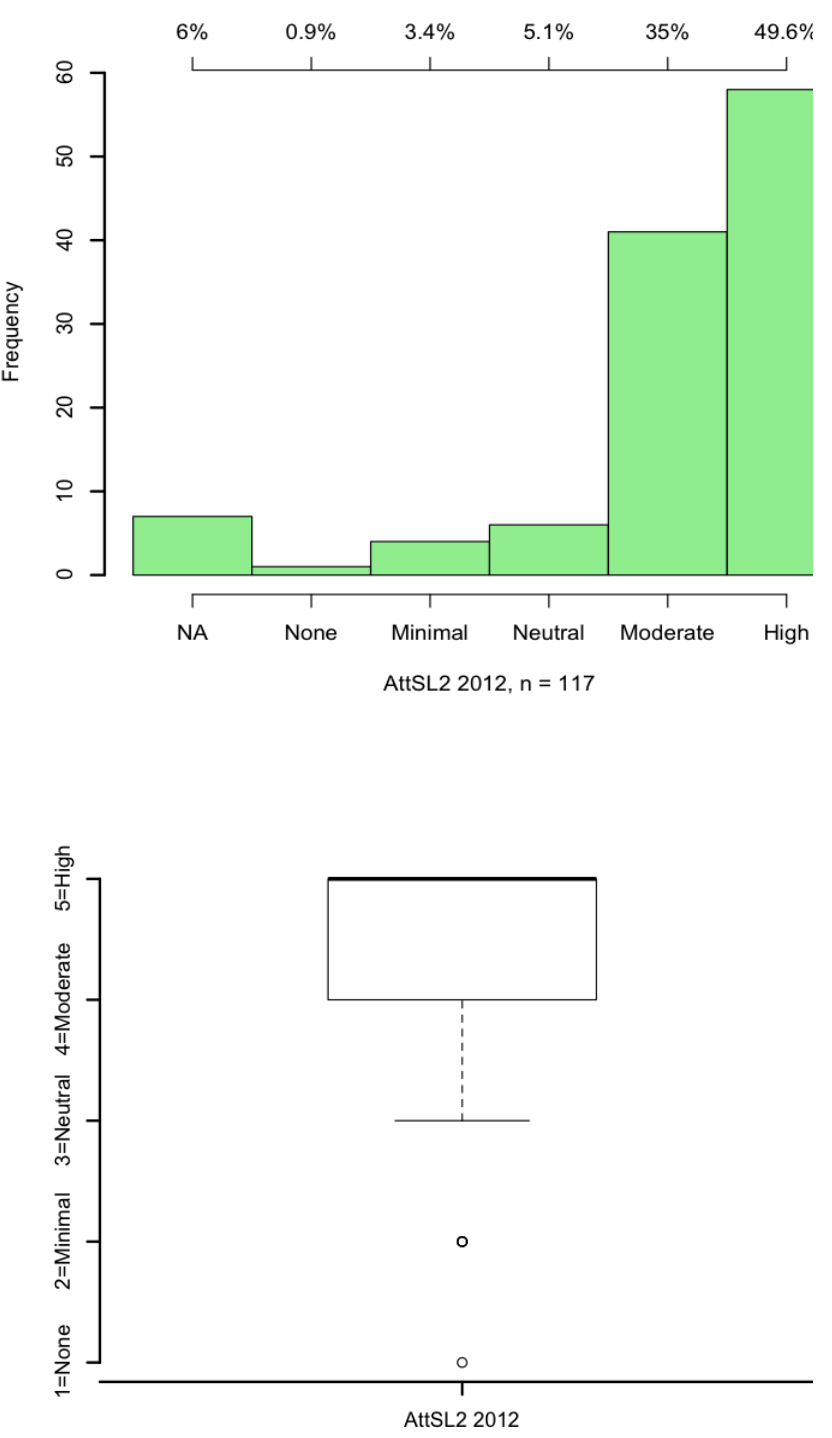
Appendix C: FOCUS GROUP SUMMARIES 


\section{SUMMARY OF FOCUS GROUP 01 - SPRING 2011}

There were three students in this focus group: Matt, Jill, and Sara.

The students are first asked to describe which aspects of the course they found to be most valuable. All three students respond that the in-class workshops were valuable in terms of helping them complete the homework assignments and prepare for exams. Sara mentions the oral review sessions with the course instructor, Dana, and the teaching assistants (TAs) were also helpful for exam preparation. The students agree that having six TAs who were organized, knowledgeable about the material, and could answer the students' questions was quite valuable. Matt mentions that they were the best TAs he's ever had in a course. Jill and Sara agree.

Sara mentions that she thought the class time could sometimes have been better used and felt that occasionally the students were just "hanging around." Jill, however, thinks the class was used effectively and enjoyed the way Dana warmed up at the beginning of the class by doing or something funny to engage the students. Jill and Matt think that Dana had her high energy and entertaining demeanor was a valuable course component.

Next, students are asked to describe how their interest in Component Design changed over the course of the semester. Matt says he had high interest coming into the course, especially for topics like fasteners, springs, and shafts. He felt less interested in the course when review topics from Mechanics of Solids were covered. He mentions it was a hard course to keep up with in addition to his heavy course load and also expressed a desire to have learned more in the course about professionalism, sustainable design, and design aesthetics. When asked if he felt that he learned about these topics as he progressed though the project, he says he learned some but that he felt the project was not as authentic as a full-scale engineering project. He mentions it was difficult to truly "care" about the project consequences or outcomes because the project wasn't going any further than the semester; hence there are less consequences.

Next, Sara describes how the visual and tangible aspects of the course helped sustain her interest. Jill agrees with this statement and says her interest grew when she found out that the project was something large and tangible. She mentions not being interested to do the previous year's Lego lawn mower project and was really excited when she learned that this year's project was drill-powered vehicles. She, like Matt, mentions that it was difficult to keep pace with the course. She wishes it could have been offered at a time when she could have invested more, as this was one of the most valuable courses she had taken that semester.

All three students wish there had been more opportunities to learn more fabrication skills like welding. It would have helped them succeed more in Component Design and also have prepared them for Senior Design. They don't have these opportunities between First-Year Engineering Projects and Component Design, so some sort of fabrication lab to learn these skills would have been helpful. Matt emphasizes this would be important as he has heard that there is a disconnect in the real world between engineers and manufacturers.

The students are then asked to describe the aspects of the project that they found to be the most or least valuable. The first topic that surfaced was the team meetings. There is some disagreement about how valuable the required team meetings were. Matt, who was Project Manager in his group, found them to be 
valuable at the beginning in order to get everyone on the same page but found them less valuable as the semester progressed. Jill, who was Communications Director in her group, found team meetings to be very valuable and also enjoyed the way the meetings facilitated peer networking so that students could work together on assignments for other classes. Sara mentions that the resources that were made available to them were helpful, especially Jerry, who supervises the design lab. She found Jerry to be approachable and willing to answer the students' design and fabrication questions. Jill agrees that Jerry was very helpful. She describes being scared of visiting the machine shop initially but that working with Jerry greatly increased her confidence in her ability to use power tools. Jill also values the sense of camaraderie that developed among her teammates.

Next, students are asked to describe any technical or non-technical skills they gained from the project. All three students mention the acquisition of machining and fabrication skills. Matt and Sara had some prior fabrication experience, but Jill did not. Sara mentions she learned a lot from seeing the design loop in practice. Matt mentions gaining non-technical skills such as managing people and getting everyone to work together. Sara agrees and adds that she learned how to write meeting minutes. Jill describes gaining greater skill in technical writing, especially with the "staged report" structure where students received feedback on their technical writing along the way. Sara adds that they aren't exposed to technical writing prior to this course.

Next, students are asked if the project impacted their excitement for Component Design. All three students indicate that it did. Matt liked having something practical that he could drive around and show to his roommates. Sara agrees that she liked having a practical project she could drive around. Both Sara and Jill found the way the project was evaluated as exciting. Having an obstacle course served as way for the students to compare their design to others and also pushed the students to generate a fully-functioning project, thus creating an element of accountability. It was also exciting that the project attracted people from outside engineering who came to watch the run-off and also their friends who thought the project was "cool." Jill thinks the competition aspect of the project was a driving motivator. Matt and Sara think that producing a running vehicle was their main motivator, not the competition itself.

Students are then asked to describe the most significant challenges they encountered during the project. Matt mentions team dynamics, including difficulty in getting everyone on the same page, agreeing how the fabrication should be completed, especially among team members with different technical backgrounds. Sara mentions her team struggling through different iterations of the drive train but overall having a really good team. Jill feels her team also had a good dynamic and mentions their greatest challenge in transitioning from design to fabrication, which took some strong prompting from Dana. Her team also faced a few communications challenges at the end of the semester as the students became busier.

Lastly, students were asked if they pictured themselves using the skills they learned from the project in real life. And whether they would have preferred a more "real project" with a client. Matt feels that completing this project without a client was a good transition, or "stepping stone" to Senior Design because it gave them real objectives and constraints but they did not have to worry about the needs of a client and could focus more on the project itself and on being creative. He feels that speaking and working with Dana was less intimidating than what he imagined interacting with a client will be. Sara agrees that this project was a good transition and motivated her greatly for Senior Design. Jill responds 
that she does see how their skills could be applied in the future, especially in Senior Design. She likes how this project provided constraints and an objective but also allowed the students to generate creative and open-ended designs. She has friends in Senior Design who complain about the "bureaucratic red tape" associated with working with a client and feels that there wouldn't have been enough time in one semester to worry about that.

\section{SUMMARY OF FOCUS GROUP 02 - SPRING 2011}

There were five students in this focus group: Kate, Jake, Bill, Mark and Beth.

The students are first asked to describe which aspects of the course they found to be most and least valuable. Kate and Jake mention the workshops as being helpful in reinforcing the material that was just covered and forcing the students to pay attention in class. Bill and Jake think the videos that covered how components are made were also helpful in solidifying the course material. Kate found the original homework problems valuable, but Bill wishes there had been additional problems and solutions outlined to help them study for the exam. Mark, Kate, and Bill all agree that having orals before the exams was really important.

In terms of the least valuable element of the course, Mark, Kate, and Bill think that learning about keys and shafts would have been helpful earlier in the semester, prior to beginning the project. Kate feels she does not have an adequate understanding of this material for the Fundamentals of Engineering exam. Jake agrees. Jake then comments that the project was the most valuable aspect of the course because it was really fun.

Next, the students are asked to describe how their interest in Component Design shifted over the course of the semester. Bill says that his interest and value increased over the course of the semester, largely as a result of Dana showing actual examples of component failures and teaching the course in a hands-on manner. Kate, Jake, and Mark agree that seeing and tangibly experiencing how components relate to everyday life helped increase their interest. Jake and Mark feel the homework problems that were designbased and challenged students to select actual components for a given design scenario were also helpful. Mark and Kate express a lack of confidence in their ability to perform more complex stress analysis and wish there had been more instruction on this topic.

The students were then asked which aspects of the project were most or least valuable. Bill and Beth liked that the project was open-ended. Bill and Jake liked the run-off event, which served as a way for students to compare their designs to others. Jake and Beth described the senior mentors as least valuable because they were not available to help the teams. Bill disagrees and comments that he found his team's senior mentor to be very helpful. After some discussion, the students agree that one of the problems may have resulted from the seniors not understanding what was expected of them.

Jake feels that a less valuable aspect of the project was the way his team members gravitated to the skills they were already good at and hence didn't learn new skills. Beth agrees. Mark says this was not the case with his team, whose members worked together. Beth replies that her team was most focused on completing the project and hence wasn't concerned with who learned what. Bill agrees, explaining that the heavy course and workload made it difficult for the students to collaborate to learn new skills 
together. Beth suggests that adding some sort of personal goal would help prompt students to actively engage in learning new skills.

Bill and Beth then discuss the issue of being rushed into analyzing components of their vehicle before their designs had progressed to the point that this would have been a useful exercise. They also expressed uncertainty in knowing what to actually analyze. Jake agrees. Kate disagrees and said the early analysis helped her team a lot. Mark states that he really enjoyed the analysis aspect of the project because he's worked in a machine shop his whole life but hadn't been exposed to analysis before. Beth says that she did like the analysis part somewhat because it removed the trial-and error process. Jake agrees and appreciates how analysis provides some design constraints. Beth and Kate agree.

Next the students are asked to describe the technical and non-technical skills they gained from the project. Jake, Mark, and Bill mention technical writing. It was helpful to receive so much feedback on their technical writing. Bill also mentions strengthening his computer-aided engineering skills. Beth mentions improving her general problem solving skills like coming up with a complicated design idea and then realizing a simple approach could work better. Bill agrees that it requires iteration to improve a design. He describes an approach of initially striving for a lot of complexity and then narrowing and simplifying from that original "wild" idea. Bill and Kate also mention learning more about team dynamics like communication issues, and Kate says she learned that it's important for teammates to state their expectations of each other early on. Jake says he learned how to influence people to do better work.

Next the students were asked to describe how the project impacted their excitement for Component Design. Kate says it was exciting to actually build something and that the project helped her realize that she could be successful at any entry-level engineering job. Beth describes this class as her favorite class because it was also the first time she felt like she was being an engineer and because the project was so fun. She says she's talked to students from last semester who didn't enjoy the project as much, and she feels that they didn't learn as much as this year's students did. Jake says the project increased his interest in the homework and the course because he realized that the material was relevant. Mark agrees and states "these aren't just numbers we're getting. These are actual stresses we're analyzing in our main beam." Bill was excited about having learned about iteration in design.

The last question asked student to describe the challenges they encountered while working with their team. All students mentioned encountering technical writing challenges. Some were disappointed in the quality of writing of their team members and felt that technical writing should be taught earlier in their undergraduate courses. Another challenge mentioned by Bill was team members not fulfilling their given roles. Mark, Jake, and Kate also found it difficult to work with friends, especially when it came time to enforce deadlines. This felt awkward. Still, they would prefer to pick their teams because that way at least they would have an idea of what to expect in each other.

Lastly, the students are given the opportunity to make any last remarks about the course or the project. Beth says the project was "cool" because she learned so many skills and she could drive it around, which made her feel good about herself. She perceived the project was useful in contrast to the previous year's slingshot project. Kate said the project made her feel proud to be a student at this university. Mark reiterated that having a fun and interesting project made all the difference in the course and that he wouldn't change the project at all. 


\section{SUMMARY OF FOCUS GROUP 03 - SPRING 2011}

There were six students in this focus group: Erin, John, Brad, Tyrone, Jason, and Andrew.

The students are first asked to describe which aspects of the course they found to be most valuable. Erin, John, Brad, Jason, and Tyrone reply that the videos and props of bearings, gears, differentials, and how components can break increased their real-world understanding and hence were perceived as valuable. Brad and Erin comment that Dana tried to do too much during class, and they didn't gain as much value from the lectures, explaining that too much time was spent on administrative tasks and answering questions that would have been better answered during office hours. This resulted in less time available for students to complete the in-class workshops. Overall, however, Dana was perceived as well-prepared and helpful during office hours.

Next, the students are asked to describe how their interest in Component Design shifted over the course of the semester. Erin explains that she initially hated the class because she had a weak understanding of the prerequisite material in Mechanics of Solids and failed the first Component Design exam. However, when the course moved into new material, such as springs and bearings, it was easier for her to learn, especially when she could apply what she was learning in class to the manufacturing of the trike. John and Jason comment that they were surprised to learn how many different components must work together in a system. They gained an understanding and appreciation of crucial components like bearings and springs in a mechanical system. Tyrone believes that, unlike previous courses, he'll retain an understanding of the material learned in this course. Jason and Erin mention that the homework problems that involved identifying a design specification were most interesting. For example, homework problems that challenged the students to select an appropriate component (i.e. a bearing) from the Internet that met a specific design need.

Andrew describes having become discouraged in engineering due to the heavy focus on equations and theory, which he felt did not increase his confidence to be an engineer. After this course, however, he thinks with more experience and practice that he could be good at engineering. In contrast, Brad comments that this course helped him realize that he didn't want to be an engineer who just selects parts. To this, Erin responds that she feels the more she and her peers practice engineering the more they realize that engineering is less about designing cool things and much more about doing what your boss tells you to do.

The students are then asked which aspects of the project were most or least valuable. Erin describes time management being the most valuable lesson she learned, especially since her group almost didn't complete the project on time. Teamwork was the next element mentioned. Erin, John, and Jason each described specific teamwork problem they had encountered: being surprised by the quality of their teammates' work and follow-through on various tasks, problems with project managers being too dominant and not allowing participation from other team members, and also the problem of teammates being rigid about not completing tasks perceived as outside of their defined role. Tyrone comments that he did like the way the project had defined roles because it's more like the real world. Jason describes frustrations and challenges from working with friends and has mixed feelings about having the option to work with friends in the future. Andrew, on the other hand, comments that he has never felt so connected to a group before and experienced a high degree of confidence in his team members' abilities. His greatest challenge on his team was reigning in his team's ambition. 
Next the students are asked to describe the technical and non-technical skills they gained from the project. Every student mentions something different. Erin says this class helped her transition from "trial and error" to understanding that there is a process to design. Tyrone says that learning how to write a technical report will be useful in the future, and Andrew agrees that knowing how to convey ideas is very important. Brad mentions skills such as milling and welding. Jason indicates that he gained a more realistic expectation of working with other people on a team and feels like you can't rely on people at times.

There was time at the end for one additional question, so the students were asked how fun they perceived the project to be. Erin, Jason, John, and Andrew agree that the run-off was a lot of fun. Erin and Jason think that everyone was excited to show off their project. John thought it was fun to see so many different and creative designs and also to see his peers get excited for engineering, which he doesn't see much in engineering school. He also mentioned that the competition of the run-off fostered a sense of accountability because none of the students would have liked to show up to the run-off with an unfinished project. Jason also thought it was also fun to apply theory to the real world. Erin and John mention that other students outside of Mechanical Engineering seemed jealous of the project. Andrew mentions that he appreciated building something he could actually use and had fun driving his drill-powered vehicle around with his friends. There is a sense of pride among the students.

\section{SUMMARY OF FOCUS GROUP $01-2012$}

There were three students who participated in this focus group: Sam, Aron, and Joey.

The students are first asked to describe which aspects of the course they found to be most and least valuable. Sam enjoyed learning about components actually found in the field such as springs and fasteners and found it helpful to have a number of TAs available to help answer questions during class. Joey thinks the workshops were helpful because they provided the opportunity to practice applying material they had just learned. Aron enjoyed the diversity of the project and found it interesting to learn how to combine all the separate class topics into one physical system. This encouraged a "big-picture" systematic approach to the problem rather than just "flying blind".

Aron, Sam, and Joey all comment that the workshops were not as valuable when they were due on the same day that they were assigned. Aron and Sam described the stress of having to turn something in due that same day reduced their ability to focus and to carefully think through each problem. The workshop experience was improved when more time was given to complete them. Sam thinks it would have been helpful if there had been a more extensive introduction to the design lab and the type of machining capabilities available.

Next, students are asked to describe how their interest in Component Design shifted over the course of the semester. Aron had high initial interest and became more interested when he found he could actually use the material, especially when they moved into the project. He wished that gear trains and bearings could have been taught sooner (instead of fatigue) because he found that information more relevant for the project. Sam student agrees that he had high initial interest for the course and says that he has always been more "hands-on." His interest continued to grow as he learned about actual components and began to feel 
confident as an engineer and able to speak with people in industry. However, like Sam, learning certain machine design concepts earlier in the course would have helped him know what to buy for the project. Joey describes his interest shifting from the course to the project as he learned about the actual components, which he found to be more useful.

Next, students are asked to describe what they found to be special or unique about the course. Sam mentions the fact that the course was structured as a "group course" with a focus on group work and getting to know each other. The conversation then shifts to the format of the exams, which were given in class and didn't align with the "real-world" theme of the course, where students have extended time to solve problems. All three students remark that this was a less positive aspect of the course. It was also suggested that more time be spent teaching the step-by-step process for how to solve Component Design problems.

The students were then asked which aspects of the project were most or least valuable. Aron feels that designing and building something for someone else was valuable. He thinks that building for someone else required more effort and consideration in the initial design phase. Sam agrees that it eliminated the option to simply buy components and determine their functionality through trial and error. Instead, they were challenged to scale down their design to build a trike that would actually work for a child with different physical aspects and abilities than themselves. Joey agrees that this gave him a better scope of what a real engineering projects looks like.

Another valuable aspect mentioned by Aron was the challenge of designing for reliability. In contrast to the previous year's project where the goal might have been to simply "get it to work," meaning that students could design a drill-powered vehicle that would function at the run-off and then break shortly afterward, this year's project challenged students to attempt to design a trike that would function well beyond the end of the semester, which added a level of complexity to the design process. Aron says you had to actually care about the project. Joey agrees.

Sam and Joey agree that one of the least valuable aspects of the project was not being able to work handson with the client. This resulted in them feeling unable to gather enough client information in order to design a compatible trike. Sam's team only had one video conference meeting with their client (versus a face-to-face meeting), which he feels was inadequate. He suggests that more emphasis be placed on how crucial it is to gather as much client information as possible during the initial client meeting because the students didn't know that they wouldn't have this opportunity as the project progressed.

Another challenge mentioned by Aron, who was his team's project manager, was assessing his team members' technical abilities and keeping everybody motivated and on-task. He found that he couldn't just rely on what his team members said they could and would do. It was also challenging for him to find ways to engage his team members that he perceived as being less-skilled so they felt like they were contributing. The conversation then shifted to Sam and Aron discussing the idea of implementing a method to evaluate other people's skill sets prior to the formation of teams, similar to the skill surveys used in Senior Design. This could help ensure a more balanced distribution of skills across teams. Although it's natural to want to work with friends, it might not result in the most effective team dynamic. Joey suggests that more instruction be given on how to choose teams because teams for this course had been chosen hastily. 
Related to skills, the next question posed to the students is to describe the technical and non-technical skills they gained from the project. Joey mentions fabrication and learning how long it takes to fabricate components. Sam also mentions gaining fabrication skills and learning the names of new tools, which made him feel more confident talking with people in industry. He also says he gained an understanding of how difficult and time-consuming it actually is to fabricate a component and suggests that more instruction be provided regarding different machining processes. Aron feels that it would have made more sense to take Manufacturing prior to Component Design because in Manufacturing you learn about different machining processes and how to design for manufacturing.

Related to non-technical skills, both Aron and Sam (also a project manager) mention learning time management and group management skills. Aron says he experienced a great deal of motivation issues such as team members not following through on deadlines, and he felt like he lacked the power to enforce deadlines. He also learned that he was more successful in motivating his team if he could get them excited about the design process rather than just being focused on meeting course deadlines. Sam experienced difficulty getting everybody to meet on a weekly basis and also had difficulty enforcing his team members' follow-through on tasks.

Technical writing was another non-technical skill strengthened. Sam mentions having taken a science writing course in the past but that he only learned technical writing this semester. He states that technical writing is different than science writing. All three students express frustrations with their team members' technical writing abilities. Aron and Sam also express difficulty knowing how to critique team members' work in a "nurturing" rather than a "demeaning" manner.

The conversation returns to challenges encountered on the project, specifically the non-technical skills of communicating ideas to teammates. Joey, who identifies himself as the team's technical writer, had trouble communicating the drive-train system and the chassis design to the rest of his team members, who he perceived to be less technically-inclined. Sam suggests having a workshop that covers the job description for each team role and that provides some examples and guidelines for students to succeed in each role. Aron thinks it would also be helpful to have had more instruction on nomenclature of tools and even basic concepts like the difference between metric and standard units to help facilitate technical communication among team members

Next the students are asked to describe how the project impacted their excitement for Component Design. Joey says that initially he wasn't excited about the project because he couldn't "play with it" like the drillpowered vehicle project. His feelings of engagement increased at the end when he felt like he was accomplishing something for someone else. Sam agrees that his team had a slow start initially but that interest increased near the end, especially after the bike was painted and ready to be assembled. He explains that his team was uncertain about the project being successful and hence didn't put forth a lot of effort until the end when they felt that the project was going to turn out well. Aron and Joey agree with this.

As an impromptu question, the students are asked if they found the project context, which was different than drill-powered vehicles, to be interesting. Joey says the context might have been even more interesting and engaging because it provided him an opportunity to understand what it takes to build something for a client and not just to earn a grade. Sam agrees and says it was different to focus on building something to make someone else proud instead of building something to make himself proud. 
Aron agrees and adds that he felt that a lot of people initially perceived the project to be mechanically simple so they tried to add complexity, which had to be eliminated from the design later. Joey and Sam agree. The conversation then turns to the team mentors. All three students indicate that their mentors could have been more helpful by providing more substantial insight during the initial design phase.

Lastly the students are asked if they had anything else to say. Sam says that he realizes that some of what they were "complaining about" was actually good to learn prior to Senior Design and if they had been "babied too much" they wouldn't have learned. Aron again stressed how important it is to focus on design revisions in the early stages of the project.

\section{SUMMARY OF FOCUS GROUP $02-2012$}

There were two students who participated in this focus group: Jeff and Henry.

The first question is for students to describe what they found most valuable about the course. Jeff says that he liked the way the original homework problems gave him a wider variety of examples of how to set up and analyze problems. Henry describes the course as the most tangible course he's ever had. He was able to look at concepts like fatigue and relate them to everyday experience. It was also the most realistic experience he's had in terms of team dynamics and working with a client. These factors increased his confidence as an engineer.

Next the students are asked to describe what they found least valuable about the course. Both students agree that they found it to be ineffective to have in-class workshops everyday, especially when they are due that same period. Also, having five students on a workshop team is ineffective because not everybody participates.

The second question is for students to describe how their interest in Component Design changed over the course of the semester. Jeff says that although he's known he wants to be here in engineering, he's had trouble figuring out where he fits in. This was the first class that made him feel more comfortable because he was able to design, select components, and be hands-on in the design lab. He believes it will be easier to finish his degree now. Henry didn't know what to expect from this course and was surprised to learn and now appreciates how much thought goes into components like bushings, bearings, and fasteners. Although he found the course content to be less dense than other engineering courses, he found it interesting to see formulas actually be applied to real life. He was surprised that the course is only three credits and says he got more out of it than he expected.

The next question is for the students to describe what they felt was special or unique about the course. Henry describes the focus on communication throughout the course. He learned how crucial communication skills are and how much team members must coordinate. He feels that communication is not taught in engineering but is an important part of the profession and also feels like he understands what to expect in a professional job context now. Jeff agrees that he feels like students experienced a great deal of growth in terms of learning how to communicate specific ideas and tasks to each other and that working together will be easier in the future because of this course. 
Next, students are asked to describe the most and least valuable aspects of the project. Jeff describes the reward of having "real clients and real smiles" as the best part. Even though his team's trike was not as compatible with their client, as soon as he saw all of the kids riding the trikes he felt good about the project. Henry says he felt empowered by doing something that was worth more than a grade. Knowing that he was building a trike for his client motivated him to stay up late the last few days before the expo. His team's trike also didn't work as expected and he realized that you can "pour your heart into working on something and still not achieve exactly what you want."

Jeff mentions one of his team members who said he'd "never thought of doing a project for someone else" and feels that many of his peers may not have realized how motivating it is to volunteer and to take their engineering skills into the real world to improve the community. Henry mentions Engineers Without Borders as one opportunity but says this project was different because it was mandatory. He feels like civil engineering students are more involved in these types of projects, maybe because they study civil engineering because they want to help people. He perceives mechanical engineers as being motivated by "building cool stuff and making money," so this was probably an eye-opening experience for many of the students by changing the way they think about what is possible and what can be achieved through engineering.

The students are then asked to describe what they found to be least valuable about the project. Jeff, who was a technical director, enjoyed working hands-on in the design lab but felt disappointed at times that he couldn't be involved with all aspects of the project. He also thinks that some teams had a good experience while others didn't. There was always one person dropping the ball while the others picked up the slack. The second student was a project manager and found it challenging to trust team members to get their job done without micromanaging. He also recommends that it be made more clear to the students what they should actually be learning during the project. On his team some people did computer-aided engineering, some people did mostly writing, some people worked in the machine shop, so he was concerned that not everybody learned the same thing.

Both students also indicate that access to tools outside the design lab could be improved. Many teams (including their own) had access to tools, expertise, and facilities outside of the design lab, and they indicate that they thought it would have been difficult for all of the teams' trikes to be fabricated without this outside help.

Then the students are asked to describe any technical or non-technical skills they gained from the project. Henry mentions technical writing, which he was surprised to learn in a course like Component Design. He also mentions gaining a tangible understanding of how to weld. Additionally, he describes that he learned how to be more resourceful and creative and didn't envision himself sewing or using glitter spray.

Working under a budget constraint was also a new skill gained that will be important in the real world. He was also struck by how much community support was shown toward the project.

Jeff mentions a couple project elements he feels will help him on his first job, like technical writing and keeping a record of machining and fabrication tasks. He also mentions learning how to be resourceful, for example by asking people in the community to donate supplies for the project. Henry then mentions the challenge of keeping track of things like receipts. It would have been nice to have heard the importance of record keeping emphasized more, but he recognizes this as a good real world experience. 
Next the students are asked how the project impacted their excitement for Component Design. Jeff exclaims that it's what he "wants to do and that it was a lot of fun." He did have some difficulty performing well on the exams and also knowing how to study for them. He says he is more motivated to become a design engineer but that he also had to step back and consider what that meant. He described an element of it as "encountering a problem and not freaking out but going through all of the steps, even if not all of them are known." Henry says that it was all an exciting and positive experience for him. He's excited for both his degree and also now has an appreciation for Component Design. He thinks there is a difference between being familiar with the material and knowing how to implement it. Jeff agrees that implementation is the most exciting part.

Henry remarks that even though Dana warned them that things always take longer than expected, that they had to experience for themselves and that it's helped him appreciate how much thought goes into the design of everyday objects, and that this makes him excited for design.

Jeff brings up the idea of implementation again and states that his prior courses didn't prepare him to move from an idea of a product to the actual product. There was a lot of learning regarding what happens in between. Henry remarks that watching videos helped. Jeff says it can revitalize a classroom and keep students engaged when they understand why they are learning something.

The two students are then asked if there is any additional feedback they'd like to provide. Henry reiterates that Component Design was a very valuable course on so many levels, and he'll remember it when he reflects on his mechanical engineering experience. He found it very rewarding to work with his team and to have the project featured in the newspaper and realize that people care about the projects like this. He feels it was interesting and impressive to see other students' designs, especially ones that he had maybe thought of but didn't know how to approach. He says that although the students view each other differently, they were united by the common goal of trying to improve somebody's life and by trying to make a difference in society. It connected him on a personal level with people he didn't know previously. It felt much different than a "textbook" class.

Jeff comments that this is the second assistive technology project he's completed at this university. He feels these projects get the school involved with the community and also involved with people that aren't typically easy to interact with. He feels that the course was successful at integrating all of the concepts into a final product and wishes more of his classes like Statics and Dynamics would follow this model. He believes that if the courses were more integrated the students would feel less stressed.

Henry agrees that it's "all engineering" and would increase the students' motivation to see how it's all related. Jeff concludes by commenting that a focus of the project was communication but that the professors aren't always communicating. 


\section{SUMMARY OF FOCUS GROUP $03-2012$}

There were four students who participated in this focus group: Mitch, Steve, Jen, and Ryan.

The students are first asked to describe the aspects of the course that were most valuable. Mitch describes the hands-on building, which he doesn't feel is taught elsewhere in the curricula other than First-Year Projects and Senior Design. He thinks it rare to find an engineer and can build something from beginning to end. Steve agrees that learning how to apply the concepts learned in class was valuable. Jen mentions the project first and says that, especially from working with the design lab supervisor, Jerry, she gained a more realistic sense of what is possible to fabricate. She describes the difficulty of having an idea in her head about what she wants to build but not knowing how long it is going to take. About the class, she describes fatigue failure being a really important concept learned. Mitch also mentions that the course provided the opportunity for students to be creative, which will teach them much more than just writing down equations.

The students are then prompted to describe the least valuable aspects of the course. Jen thinks that springs, bearings, and gears were covered too quickly, and the students weren't given any design problems involving these components, so she didn't learn it very well. Mitch thinks the class could have more potential. He appreciated the use of hands-on props and videos but believes these topics would be better taught in a more active manner, like analyzing a real automobile. He also mentions the large amount of printed course material as being wasteful and not useful. Jen agrees that everything can be retrieved online. Ryan mentions that there was hardly any mention of sustainability in the course, which Mitch agrees is surprising. Steve cannot think of a least valuable course element.

The next question posed to the students is to describe how their interest in Component Design changed over the course of the semester. Steve says his interest didn't change because he was interested in the material to start. When prompted to elaborate, he describes the real world videos and also the project. Mitch agrees and states that at the beginning of the semester he was interested because he felt he'd finally understand what they'd be doing with their careers. He felt intimidated at the beginning of the semester but his confidence increased as he began to understand how little components fit together in one design. Jen was initially worried that this would be another "Statics" course. She became a lot more interested when she realized the course covered real-world material like actual stress distributions and failure of parts and that it included a project. Mitch agrees and says he liked how the course went over how to identify loading scenarios in the real world and that when he was working on the project he could see these scenarios actually taking place, which served to increase his confidence as an engineering student.

Ryan describes his confidence being increased by learning the process of design. He also thinks more feedback on their designs could have been given by the professor or by the senior mentors. It would have been helpful to get some guidance on how to simplify a design, what can realistically be fabricated in the design lab, more instruction in the design lab, and more guidance on where to find materials. The three other students agree. Jen states that it was very helpful to have Jerry look over their design before they finalized it. 
Next the students were asked to describe what they found special or unique about the course. Steve says "Dana", and Mitch and Jen agree. Steve describes her as having a presence in the classroom that other professors don't. She shows excitement and is involved with the students rather than just her own research. Mitch then mentions seeing the entire design process served to remind him of why we started engineering. Jen describes that Dana used the TAs effectively by involving them in the helping her teach the class and with the oral exams. Steve agrees and feels that Dana and the TAs were committed "as a team" to helping the students. Mitch agrees.

The students are then asked to describe the most valuable aspect of the project. Ryan mentions that it finally allowed the students to be creative. Steve mentions having the opportunity to work with a real world client. Mitch agrees. Jen says that having the real world client made the project "mean something" because it had the potential to improve somebody's life. Mitch commented on the value of such a multifaceted the project with many different roles to fill.

Next the students are asked about the least valuable aspects of the project. Jen mentions having to perform a stress analysis on different parts of the trike too early in the project for it to be effective. Steve and Mitch agree. The designs weren't finalized at this point, so the students didn't see the point in the assignment. Ryan expressed quite a bit of frustration with the whole analysis process. He feels that they are taught to simplify real world components to "look like" book problems, which makes the analysis incomplete and inaccurate. He also states that his team didn't performing testing of their bike early on because they didn't see the value in doing so. Mitch then mentions it would have been helpful to have workshops about what is expected from each project role. Jen who was communications director agrees and feels she did not have adequate feedback on how to prepare meetings agendas and meeting minutes. Ryan perceived the meeting minutes and agenda as busy work.

Ryan mentions that it would be very helpful if, like Senior Design, the students had to fill out a skills form to help balance the students' skills across the teams and also so people don't just end up working with their friends. Steve agrees and thinks it would have been better if Dana and the TAs worked together to assign the teams. Ryan agrees and describes the team formation process as being extremely rushed. Jen and Steve agree, and Jen says this was also true of the project role selection process. Her team just happened to be lucky because there was one team member with both machining and industry experience. Overall the students agree that the skills should be distributed more equitably across teams, especially because many students haven't had prior machining or fabrication experience.

The students are then asked to describe any technical or non-technical skills they gained from the project. Mitch mentions working with teammates. Steve agrees and also mentions scheduling as a skill he gained. Jen mentions machining skills and learning how to generate a properly-dimensioned drawing that can be read by a machinist. Ryan mentions computer-aided engineering as a skill he improved greatly. He does think that the students should have been taught how to create a properly formatted drawing. Mitch says he has a much better understanding of how long it takes to create a real product from a design. He also learned more about scheduling and time management.

Next the students are asked how the project impacted their excitement for Component Design. Jen and Steve say that without the project Component Design would have been just another "boring class." Jen thinks the project made Component Design more interesting and relevant. Steve thinks it allowed them apply course concepts to the real world. Mitch says he can't even imagine what the course would be like 
without the project. Ryan and Steve agree. Jen says that when she thinks back to the class she'll think of the project, not the coursework. The three other students agree. Jen continues talking about how this was a very good experience prior to Senior Design. Steve and Ryan agree.

The students are asked an impromptu question about how it influenced their design to have young clients. Mitch thinks that his team considered his client's cerebral palsy more than his age in terms of their factor of safety. Steve agrees. Ryan says that because the clients were smaller in stature they weren't worried about dealing with huge stresses. Jen says that safety was a priority for her team, and Steve and Mitch agree. Jen also feels like it was more meaningful to give the project to a client versus handing it over to industry. It made all of the long hours worth it in the end. Mitch and Steve agree. Steve feels that having a younger client provided them with a new perspective by exposing them to a unique set of needs they might not otherwise experience in industry. Ryan feels the project was like "giving a gift" instead of doing something for someone "above" him. Steve agrees and states that the altruistic aspect of the project motivated him to finish the project. Mitch adds that it allowed them to be more creative than they could have been with an adult who probably would have wanted a standard bike.

The students are then asked if they have any other final statements. Ryan thinks they need to be taught the proper design process, and Steve agrees. Ryan elaborates on elements he feels weren't adequately covered such as more instruction about the machines, access to resources, and guidelines on how to design such as fitting form to function and considering the true lifecycle of a product. He says he asked if his client had siblings because his siblings might interact with the trike and hence should be considered in the design. He feels this is an example of more "holistic" design that's not taught in textbooks. Mitch comments that the course and the project felt separate and could have been integrated better. Ryan returns to the concept of holistic design and stresses that design shouldn't be taught linearly but instead focus on lifecycle analysis and sustainability. He mentions that the idea of recyclability wasn't even mentioned in the class.

Jen describes liking the creative aspect of the course. Unlike the rest of the curriculum, which she feels focuses on getting the right answer on a test and thinking inside the box, this course was a truly good learning experience because it challenged them to take everything into account, like their clients' siblings. She suggests that the project always be taught with real life clients even though it's difficult to find them and to deal with them. Mitch comments that other courses could "learn" from this course. As juniors, he feels like they should have had some real-world experience already, especially with some of the concepts like recyclability that Ryan mentioned. Steve agrees and feels like the hands-on aspect of the course is what differentiates it from other courses. He feels there are a lot of improvements to be made, especially like the recycling and sustainability components, but feels overall that he will always remember this course.

Ryan concludes by stressing the importance of letting students be creative as way to help them learn. He feels that creativity is a very important engineering skill that can't be taught and thinks it had been stressed even more during the semester. He concludes by saying "you can't teach creativity, you can only allow for creativity." 